MARCELO JUN IKEDA

DETERMINAÇÃO DE ÍNDICES DE AJUSTE NO CONTROLE DE SISTEMA DE CONDICIONAMENTO DE AR DO TIPO “TETO FRIO" 
MARCELO JUN IKEDA

\title{
DETERMINAÇÃO DE ÍNDICES DE AJUSTE NO CONTROLE DE SISTEMA DE CONDICIONAMENTO DE AR DO TIPO “TETO FRIO”
}

\author{
Dissertação apresentada à Escola \\ Politécnica da Universidade de São \\ Paulo para a obtenção de Título de \\ Mestre em Engenharia.
}


MARCELO JUN IKEDA

\title{
DETERMINAÇÃO DE ÍNDICES DE AJUSTE NO CONTROLE DE SISTEMA DE CONDICIONAMENTO DE AR DO TIPO “TETO FRIO”
}

\author{
Dissertação apresentada à Escola \\ Politécnica da Universidade de São \\ Paulo para a obtenção de Título de \\ Mestre em Engenharia. \\ Área de Concentração: \\ Engenharia Civil \\ Orientadora:
}

Profa. Dra. Brenda Chaves Coelho Leite 
Este exemplar foi revisado e alterado em relação à versão original, sob responsabilidade única do autor e com a anuência de seu orientador.

São Paulo, de junho de 2008.

Assinatura do autor:

Assinatura da orientadora:

FICHA CATALOGRÁFICA

Ikeda, Marcelo Jun

Determinação de índices de ajuste no controle de sistema de condicionamento de ar do tipo "teto frio" / M. J. Ikeda. - São Paulo, 2008.

$190 \mathrm{p}$.

Dissertação (Mestrado) - Escola Politécnica da Universidade de São Paulo. Departamento de Engenharia de Construção Civil.

1. Ar condicionado. 2. Ar condicionado (Eficiência).

3.Conforto térmico das construções. 4. Radiação térmica I. Universidade de São Paulo. Escola Politécnica. Departamento de Engenharia de Construção Civil II. t. 


\section{DEDICATÓRIA}

A Cristina, minha noiva, com amor, admiração e gratidão por sua compreensão, carinho, presença e grande apoio ao longo do período de elaboração deste trabalho.

A Deus e a minha família, pelo apoio, dedicação, paciência, amor e presença em todos os momentos difíceis destes anos de preparativo do mestrado. 


\section{AGRADECIMENTOS}

À minha orientadora, $\operatorname{Prof}^{\mathrm{a}} \operatorname{Dr}^{\mathrm{a}}$ Brenda Chaves Coelho Leite, que nos anos de convivência, muito me ensinou, contribuindo para meu crescimento científico e intelectual.

À Fundação de Amparo à Pesquisa do Estado de São Paulo - FAPESP - pela concessão do apoio financeiro para a realização desta pesquisa (Processo $\mathrm{N}^{\circ}$ 06/59334-1).

Ao meu amigo e estudante de iniciação científica Matias Nicolas Rubio e à mestranda Renata Maria Marè, pelo grande auxílio na fase de coleta de dados e, ao primeiro, também pelo inestimável auxílio na fase de geração de modelos na representação gráfica.

Ao meu amigo e mestrando Fabio Kenji Motezuki, pelo auxílio e sempre disposição na escolha e uso da ferramenta de representação gráfica.

Ao Prof. Dr. Marcos Aurélio Marques Noronha, pela especial atenção e apoio durante o processo de definição e orientação, me apoiando na pesquisa principalmente na fase de representação gráfica.

A minha família, Dona Eliana, Sr. Yoshio, minhas irmãs Silvia e Márcia e seus

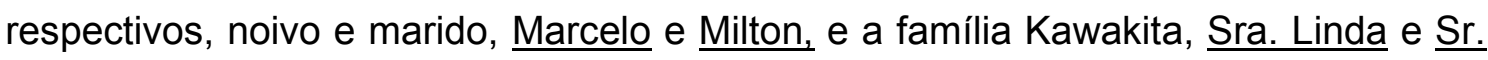
Hideo pela especial ajuda e compreensão nos momentos difíceis de elaboração desta dissertação.

Aos meus amigos do Laboratório de Ensino de CAD (LABCAD) do Departamento de Construção Civil da EPUSP, especialmente Rodrigo, Viviane e Thais, pelo coleguismo, colaboração e auxílio na orientação desta pesquisa. 
"O pessimista queixa-se do vento, o otimista espera que ele mude e o realista ajusta as velas" (Willian George Ward) 
O presente trabalho é um estudo para a determinação de índices de ajuste em medidas efetuadas por sensores de temperatura do ar utilizadas em algoritmos de controle do sistema de automação do sistema de condicionamento de ar do tipo "Teto Frio". É um trabalho experimental baseado na coleta de dados de diversas variáveis ambientais em um laboratório que utiliza este tipo de sistema. Esse laboratório possui um sistema de climatização misto composto por circuitos de água gelada que percorre serpentinas instaladas em placas metálicas de forro, para troca de calor por radiação (retirada de calor sensível) e circuitos de ar, com distribuição de ar pelo teto, para troca de calor por convecção (retirada de calor latente). Seu funcionamento é controlado por um sistema de automação (hardware e software) específico. Este estudo pretende determinar índices de ajuste que, introduzidos nos algoritmos de controle do sistema de automação, corrijam as leituras de temperatura do ar realizadas no ambiente por sensores do sistema posicionados em locais que, embora esteticamente sejam os mais adequados, funcionalmente, não o são. Os resultados, concluídos através de método estatístico e recursos de representação gráfica, promoverão além do melhor entendimento das condições térmicas do ambiente oferecidas pelo sistema de "teto frio", a otimização da operação do sistema, isto é, a melhoria do conforto para os ocupantes e a conservação de energia.

Palavras-chave: Ar Condicionado. Teto Frio. Índice de Ajuste. Resfriamento Radiante. Propriedades Radiativas. 
The present work is a study to determine adjustment indexes in measurements made by air temperature sensors used in control algorithms of automation system applied to "Cooling Ceiling" air conditioning system. It is an experimental work based on data collection of several environmental variables at a laboratory which uses this kind of system. This laboratory owns a mixed air conditioning system compounded by chilled water circuits which pass through coils installed on metal ceiling tiles, for heat exchange by radiation (sensitive heat withdrawal), and air circuits with distribution by ceiling, for heat exchange by convection (latent heat withdrawal). Its functioning is controlled by a specific automation system (hardware and software). This study intends to determine adjustment indexes which, added in system control algorithms correct the air temperature readings accomplished in the environment by system sensors located in places that, although aesthetically are more suited, functionally are not. The results, concluded through statistic methods, and graphic representation researches, will promote beyond better understanding of thermal conditions of environment offered by this cooling ceiling system, optimization of system operation, that are a better comfort for the occupants and the energy saving.

Keywords: Air Conditioning. Cooling Ceiling. Adjustment Indexes. Radiant Cooling, Radiative Properties. 


\section{LISTA DE ILUSTRAÇÕES}

Figura 1 - Ambiente Experimental - Vista pelo fundo da sala ............................40

Figura 2 - Ambiente Experimental - Vista pela frente da sala .............................41

Figura 3 - Esquema dos circuitos hidráulicos: primário e secundário* ...................42

Figura 4 - Central de Água Gelada (CAG) - Circuito hidráulico primário ..................43

Figura 5 - Tanques de Expansão (TE) e Tanques de Inércia Metálico (TQ) ............43

Figura 6 - Circuitos hidráulicos primário e secundário - Ramais de água gelada que atendem ao Fan Coil (seta vermelha) e às placas de forro (setas amarelas)

(a)

Figura 7 - Circuito hidráulico primário - Trocador de calor a placas......................45

Figura 8 - Esquema interno de transferência de calor do trocador de calor a placas *

Figura 9 - Circuito hidráulico secundário - Placas de Forro Metálicas com

Serpentinas ............................................................................ 46

Figura 10 - Circuito hidráulico secundário - Bomba de Água Gelada (BAG) .........47

Figura 11 - Circuito hidráulico secundário - Tanque de expansão" (TE) .................47

Figura 12 - Circuitos de Água Gelada * .................................................... 47

Figura 13 - Fan Coil e dutos de distribuição e retorno de ar.................................49

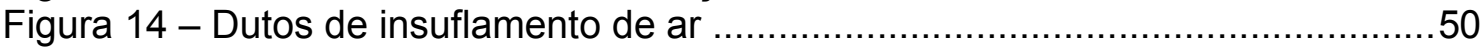

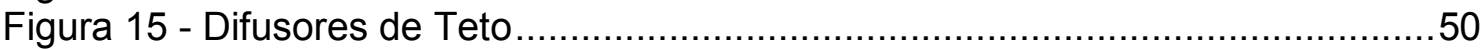

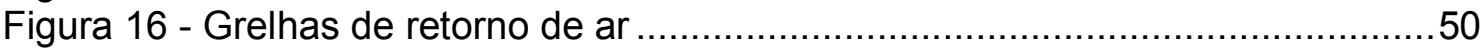

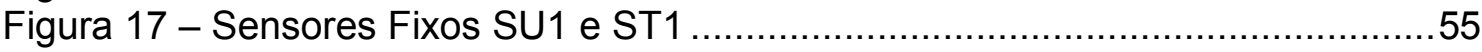

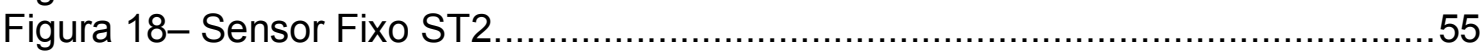

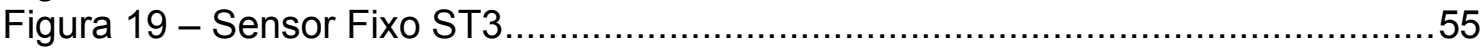

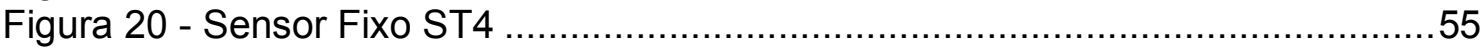

Figura 21 - Sensor de Ponto de Orvalho no teto da sala ......................................55

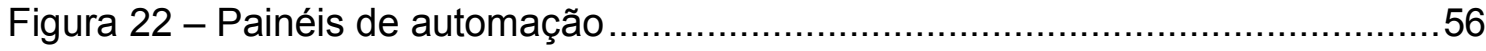

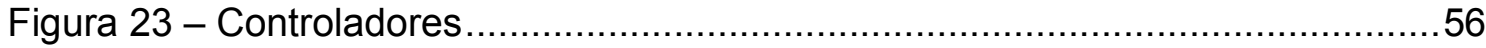

Figura 24 - Atuadores de válvulas de controle de vazão de água das serpentinas das placas radiantes ..................................................................... 57

Figura 25 - Esquema de um loop básico de um sistema de controle ......................58

Figura 26 - Esquema de loop de controle de temperatura do ambiente ..................59

Figura 27 - Posicionamento dos sensores fixos nas paredes..................................69

Figura 28 - Posicionamento dos sensores fixos nas paredes e no teto* .................71

Figura 29 - Pontos de medições móveis (1 a 16 e T) - Vista Planta Baixa * ............73

Figura 30 - Pontos de medições móveis - Vista em Corte ....................................74

Figura 31 - Disposição da haste com sensores e aquisição.................................78

Figura 32 - Haste metálica......................................................................... 78

Figura 33 - Interligação dos dataloggers (Desenho do Auto CAD) .........................78

Figura 34 - Sensores de temperatura e velocidade do ar ..................................... 80

Figura 35 - Sensores de temperatura de Globo, assimetria de radiação e umidade

relativa do ar ............................................................................... 80

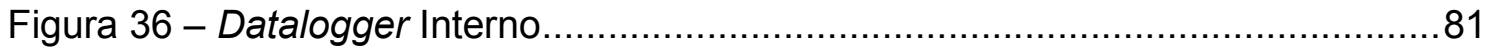

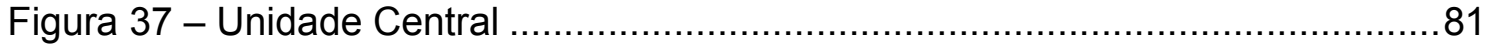

Figura 38 - Computador de Medição ............................................................ 81

Figura 39 - Computador de Supervisão Predial ................................................. 81 
Figura 40 - Ambiente de medição - com ocupação ...............................................81

Figura 41 - Ambiente de medição - com ocupação …....................................... 82

Figura 42 - Pontos de Medições Setoriais * ........................................................96

Figura 43 - Representação gráfica, da temperatura do ar na superfície, no nível

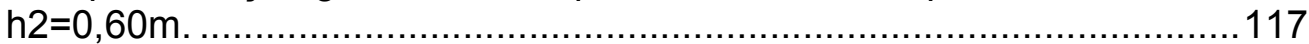

Figura 44 - Regiões de delimitação (Quadrantes) ...........................................122

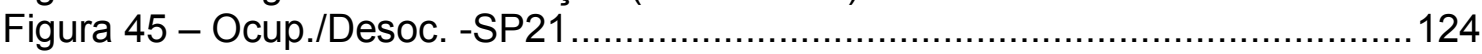

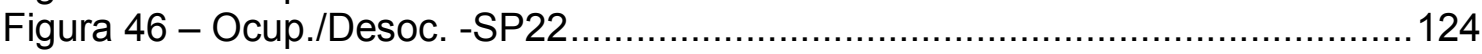

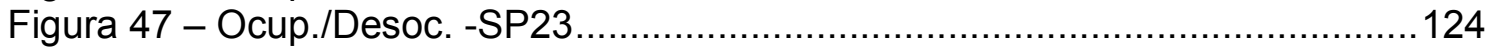

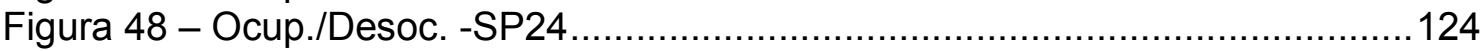

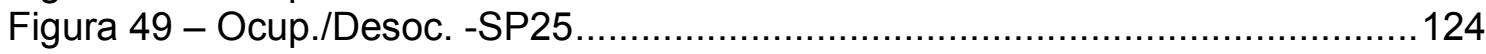

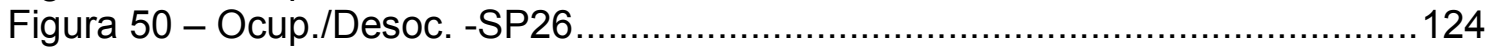

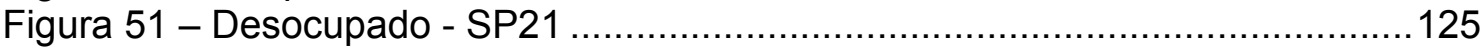

Figura 52 - Desocupado. -SP22 …................................................................ 125

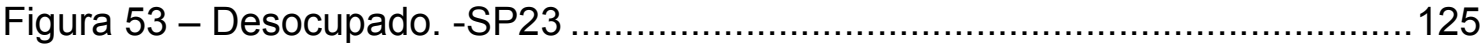

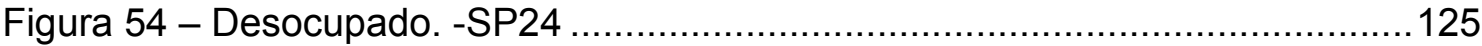

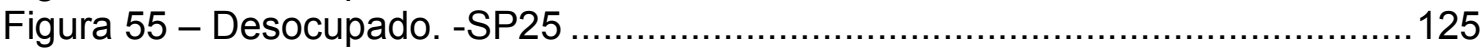

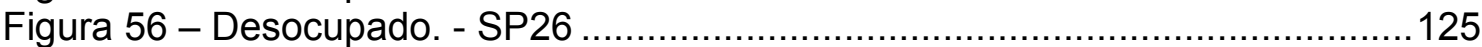

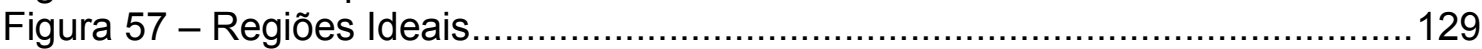

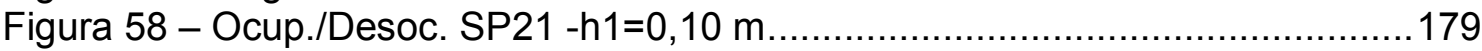

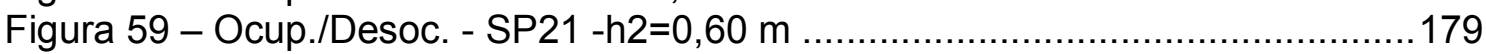

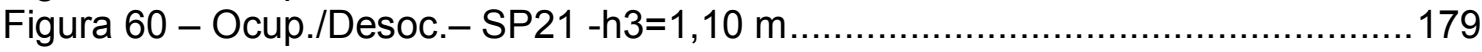

Figura 61 - Ocup./Desoc.- SP21 -h4=1,70 m....................................... 179

Figura 62 - Ocup./Desoc.- SP21 -h5=2,00 m.............................................. 179

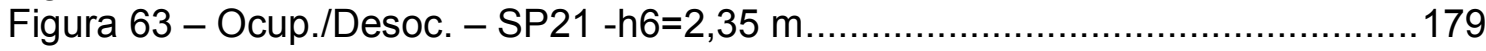

Figura 64 - Ocup./Desoc. - SP22 -h1=0,10 m..........................................180

Figura 65 - Ocup./Desoc. - SP22 -h2=0,60 m............................................ 180

Figura 66 - Ocup./Desoc.- SP22 -h3=1,10 m...........................................180

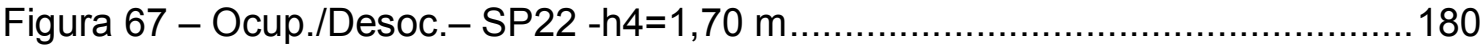

Figura 68 - Ocup./Desoc.- SP22 -h5=2,00 m.................................................180

Figura 69 - Ocup./Desoc. - SP22 -h6=2,35 m............................................. 180

Figura 70 - Ocup./Desoc.- SP23 -h1=0,10 m.............................................. 181

Figura 71 - Ocup./Desoc.- SP23 -h2=0,60 m.......................................... 181

Figura 72 - Ocup./Desoc. - SP23 -h3=1,10 m......................................... 181

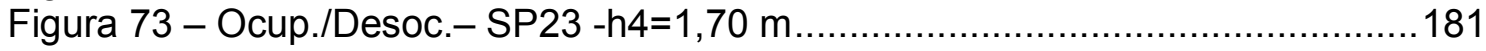

Figura 74 - Ocup./Desoc. - SP23 -h5=2,00 m................................................. 181

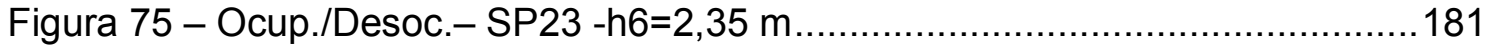

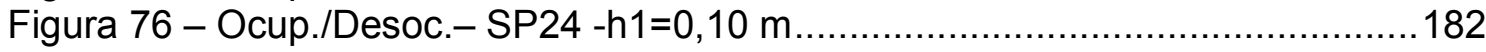

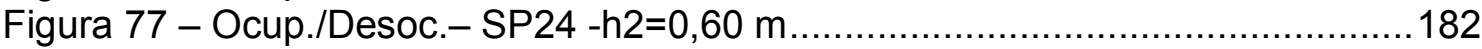

Figura 78 - Ocup./Desoc.- SP24 -h3=1,10 m................................................ 182

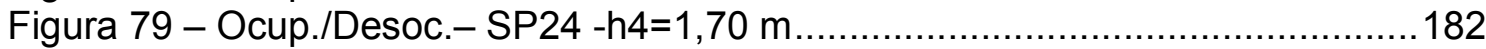

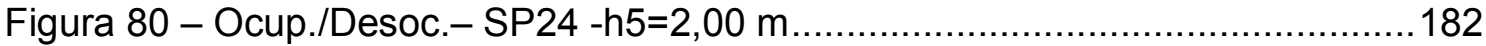

Figura 81 - Ocup./Desoc.- SP24 -h6=2,35 m............................................... 182

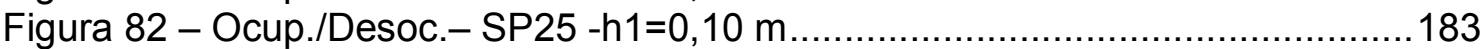

Figura 83 - Ocup./Desoc.- SP25 -h2=0,60 m.......................................... 183

Figura 84 - Ocup./Desoc.- SP25 -h3=1,10 m.............................................. 183

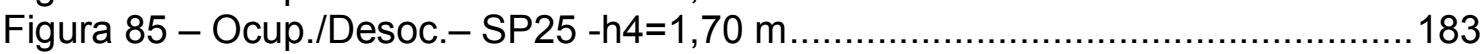

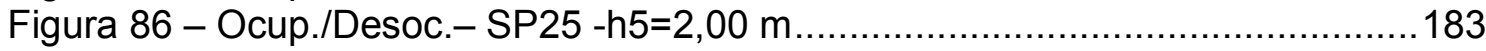

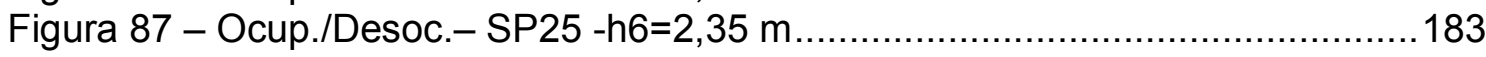

Figura 88 - Ocup./Desoc. - SP26 $-\mathrm{h} 1=0,10$ m......................................... 184 
Figura 89 - Ocup./Desoc.- SP26 -h2=0,60 m............................................... 184

Figura 90 - Ocup./Desoc.- SP26 -h3=1,10 m........................................... 184

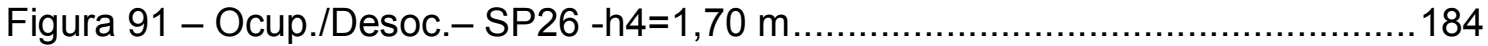

Figura 92 - Ocup./Desoc.- SP26 -h5=2,00 m............................................ 184

Figura 93 - Ocup./Desoc.- SP26 -h6=2,35 m.............................................. 184

Figura 94 - Ocup./Desoc.- SP21 .............................................................. 185

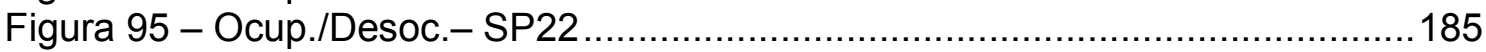

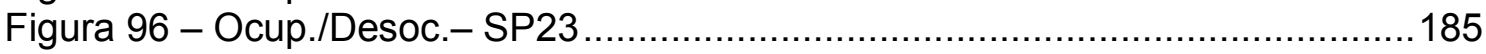

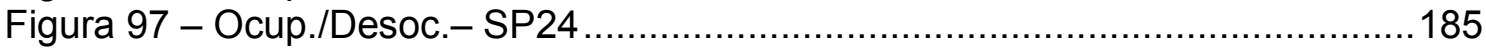

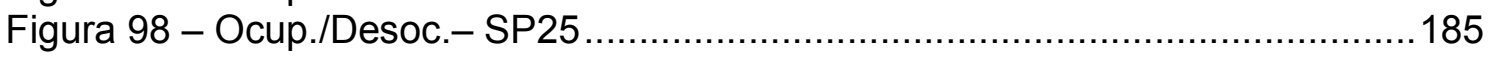

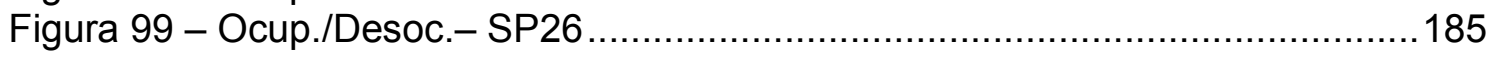

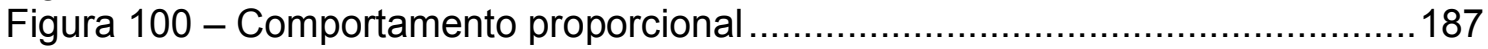

Figura 101 - Comportamento Integral ....................................................... 188

Figura 102 - Comportamento Diferencial..................................................... 189

Figura 103 - Comportamento PID ............................................................ 190

\section{LISTA DE QUADROS}

Quadro 1 - Especificação dos Sensores Fixos....................................................... 54

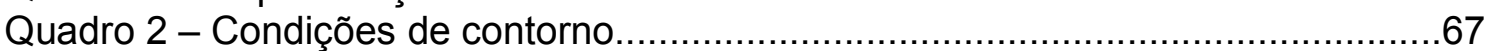

Quadro 3 - Especificação dos Sensores Móveis...........................................79

Quadro 4 - Especificação dos Dataloggers, Unidade Central e Computador............79

Quadro 5 - Relatório de Medição............................................................... 84

Quadro 6 - Desvio padrão das alturas nos 6 setpoints de temperatura................117 


\section{LISTA DE GRÁFICOS}

Gráfico 1 - Temperatura do sensor móvel para SP21 e h1=0,10 m .....................93

Gráfico 2 - MSM e MSF versus setpoints - h2 = 0,60 m - Ocup./Desoc...............106

Gráfico 3 - Índices de Ajuste versus setpoints - h2 = 0,60 m - Ocup./Desoc.......106

Gráfico 4 - MSM e MSF versus setpoints - h2 = 0,60 m - "Desocupado" .............107

Gráfico 5 - Índices de Ajuste versus setpoints - h2 = 0,60 m - "Desocupado". ....107

Gráfico 6 - Índices de Ajuste versus setpoints (h2=0,60m) - União de Pontos......108

Gráfico 7 - Índices de Ajuste versus setpoints (h2=0,60m) - Regressão Linear ....109

Gráfico 8 - Índices de Ajuste versus setpoints (h2=0,60m) - Polinômio de Grau 3109

Gráfico 9 - Temperatura média do ar dos 16 pontos de medição e 6 alturas -

Ocup./Desoc.

Gráfico 10 - Temperatura média do ar dos 16 pontos de medição e 6 alturas Ocup./Desoc.

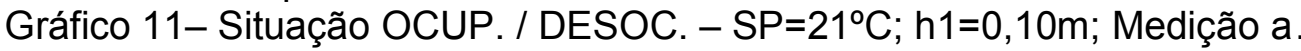

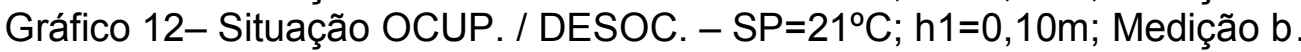

Gráfico 13- Situação OCUP. / DESOC. - SP $=21^{\circ} \mathrm{C}$; $\mathrm{h} 1=0,10 \mathrm{~m}$; Medição c

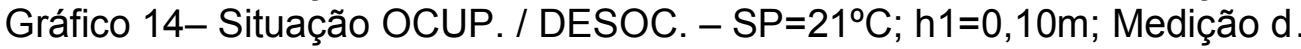

Gráfico 15- Situação OCUP. / DESOC. - SP $=21^{\circ} \mathrm{C}$; $\mathrm{h} 1=0,10 \mathrm{~m}$; Medição e

Gráfico 16- Situação OCUP. / DESOC. - SP $=21^{\circ} \mathrm{C}$; $\mathrm{h} 1=0,10 \mathrm{~m}$; Resumo das Medições

Gráfico 17- Situação OCUP. / DESOC. $-\mathrm{SP}=21^{\circ} \mathrm{C}$; h2=0,60m; Medição a ...........143

Gráfico 18- Situação OCUP. / DESOC. - SP $=21^{\circ} \mathrm{C}$; h2=0,60m; Medição a ........... 143

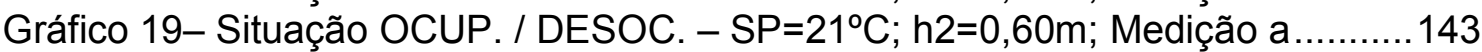

Gráfico 20- Situação OCUP. / DESOC. - SP $=21^{\circ} \mathrm{C}$; h2=0,60m; Medição d ............144

Gráfico 21- Situação OCUP. / DESOC. $-\mathrm{SP}=21^{\circ} \mathrm{C}$; h2=0,60m; Medição e ............144

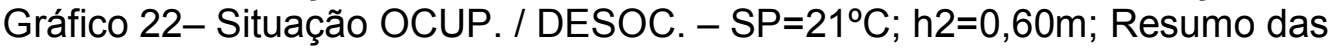

Medições

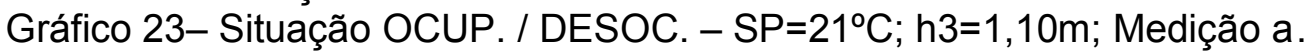

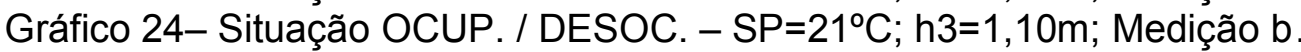

Gráfico 25- Situação OCUP. / DESOC. - SP=21 ${ }^{\circ} \mathrm{C}$; h3=1,10m; Medição c

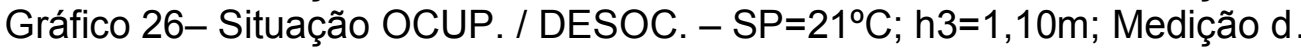

Gráfico 27- Situação OCUP. / DESOC. - SP $=21^{\circ} \mathrm{C}$; $\mathrm{h} 3=1,10 \mathrm{~m}$; Medição e

Gráfico 28- Situação OCUP. / DESOC. - SP $=21^{\circ} \mathrm{C}$; $\mathrm{h} 3=1,10 \mathrm{~m}$; Resumo das Medições

Gráfico 29- Situação OCUP. / DESOC. - SP $=21^{\circ} \mathrm{C}$; h4=1,70m; Medição a ............147

Gráfico 30- Situação OCUP. / DESOC. - SP $=21^{\circ} \mathrm{C}$; h4=1,70m; Medição b.......... 147

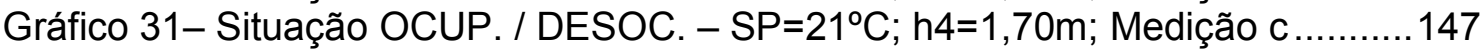

Gráfico 32- Situação OCUP. / DESOC. $-\mathrm{SP}=21^{\circ} \mathrm{C} ; \mathrm{h} 4=1,70 \mathrm{~m}$; Medição d ............148

Gráfico 33- Situação OCUP. / DESOC. $-\mathrm{SP}=21^{\circ} \mathrm{C}$; $\mathrm{h} 4=1,70 \mathrm{~m}$; Medição e ............148

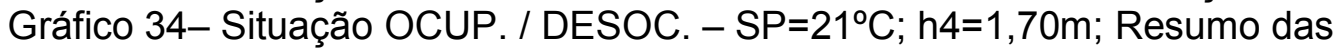

Medições

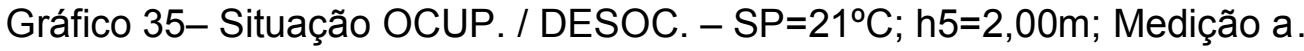

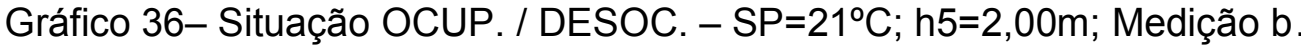

Gráfico 37- Situação OCUP. / DESOC. - SP=21 ${ }^{\circ} \mathrm{C}$; h5=2,00m; Medição c .

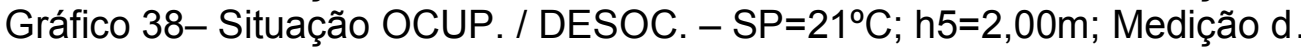

Gráfico 39- Situação OCUP. / DESOC. - SP $=21^{\circ} \mathrm{C}$; h5=2,00m; Medição e

Gráfico 40- Situação OCUP. / DESOC. $-\mathrm{SP}=21^{\circ} \mathrm{C}$; h5 $=2,00 \mathrm{~m}$; Resumo das Medições 
Gráfico 41- Situação OCUP. / DESOC. $-\mathrm{SP}=21^{\circ} \mathrm{C}$; h6=2,35m; Medição a ...........151

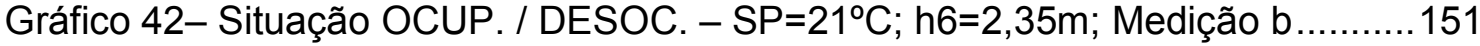

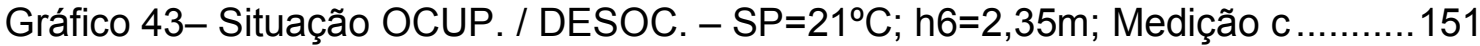

Gráfico 44- Situação OCUP. / DESOC. $-\mathrm{SP}=21^{\circ} \mathrm{C}$; h6=2,35m; Medição d...........152

Gráfico 45- Situação OCUP. / DESOC. - SP $=21^{\circ} \mathrm{C}$; h6=2,35m; Medição e ............ 152

Gráfico 46- Situação OCUP. / DESOC. $-\mathrm{SP}=21^{\circ} \mathrm{C}$; h6=2,35m; Resumo das Medições

Gráfico 47 - MSM e MSF nas 6 alturas de medição; Ocup./Desoc. - SP21 .......... 155

Gráfico 48 - MSM e MSF nas 6 alturas de medição ; Ocup./Desoc. - SP22 .......... 155

Gráfico 49 - MSM e MSF nas 6 alturas de medição; Ocup./Desoc. - SP23........... 155

Gráfico 50 - MSM e MSF nas 6 alturas de medição; Ocup./Desoc. - SP24 ...........155

Gráfico 51 - MSM e MSF nas 6 alturas de medição; Ocup./Desoc. - SP25...........155

Gráfico 52 - MSM e MSF nas 6 alturas de medição; Ocup./Desoc. - SP26...........155

Gráfico 53 - MSM e MSF nas 6 alturas de medição; Desocupado - SP21 ............157

Gráfico 54 - MSM e MSF nas 6 alturas de medição; Desocupado - SP22 ............157

Gráfico 55 - MSM e MSF nas 6 alturas de medição; Desocupado. - SP23 ...........157

Gráfico 56 - MSM e MSF nas 6 alturas de medição; Desocupado. - SP24 ...........157

Gráfico 57 - MSM e MSF nas 6 alturas de medição; Desocupado - SP25 ............157

Gráfico 58 - MSM e MSF nas 6 alturas de medição; Desocupado - SP26 ............157

Gráfico 59 - MSM nos 16 pontos de medição - SP21 - Ocup./Desoc.....................159

Gráfico 60 - MSM nos 16 pontos de medição - SP22 - Ocup./Desoc. ...................160

Gráfico 61 - MSM nos 16 pontos de medição - SP23 - Ocup./Desoc....................161

Gráfico 62 - MSM nos 16 pontos de medição - SP24 - Ocup./Desoc. ..................162

Gráfico 63 - MSM nos 16 pontos de medição - SP25 - Ocup./Desoc. ...................163

Gráfico 64 - MSM nos 16 pontos de medição - SP26 -“Ocup./Desoc.” ...................164

Gráfico 65 - MSM nos 16 pontos de medição - SP21 -"Desocupado" ...................165

Gráfico 66 - MSM nos 16 pontos de medição - SP22 -“Desocupado.” ..................166

Gráfico 67 - MSM nos 16 pontos de medição - SP23 -“Desocupado." ..................167

Gráfico 68 - MSM nos 16 pontos de medição - SP24 - Desocupado.....................168

Gráfico 69 - MSM nos 16 pontos de medição - SP25 - "Desocupado" ...................169

Gráfico 70 - MSM nos 16 pontos de medição - SP26 - "Desocupado". ................170

\section{LISTA DE TABELAS}

Tabela 1 - Dados para SP21, altura h1=0,1m, Medição "a" ..................................87

Tabela 2 - Classes de Freqüências de Temperaturas - Sensor Móvel .....................89

Tabela 3 - Temperaturas Médias dos Sensores Móveis e Fixos ............................93

Tabela 4 - Análise das curvas MSF e MSM - Situação: "Ocupado / Desocupado" 103

Tabela 5 - Análise das curvas MSF e MSM - Situação: "Desocupado" ................104

Tabela 6 - Índices de ajuste de temperatura para h2=0,60m - Ocup./Desoc.. ...... 106

Tabela 7 - Índices de ajuste de temperatura para h2=0,60m - "Desocupado." ..... 107

Tabela 8 - Comparativo dos Índices de Ajuste para as 2 situações de medição....108

Tabela 9 - Comportamento dos Índices de Ajuste ............................................110

Tabela 10 - Temperaturas do Ambiente nos níveis de conforto 0,1 e $1,1 \mathrm{~m} \ldots \ldots \ldots .119$

Tabela 11 - Dados de assimetria de radiação por setpoint de temperatura ...........120 
Tabela 12 - "Temperaturas Ideais" para as duas situações de medição .................122

Tabela 13 - Tabela de decisão - Situação: Ocup./Desoc......................................123

Tabela 14 - Tabela de decisão - Situação: "Desocupado" ....................................123

Tabela 15 - "Tabela Resumo e 6 setpoints de temperatura ...............................128

Tabela 16 - Situação OCUP. / DESOC. - SP=21 ${ }^{\circ} \mathrm{C}$; $\mathrm{h} 1=0,10 \mathrm{~m}$; Medição a ..........141

Tabela 17 - Situação OCUP. / DESOC. $-\mathrm{SP}=21^{\circ} \mathrm{C}$; $\mathrm{h} 1=0,10 \mathrm{~m}$; Medição b ..........141

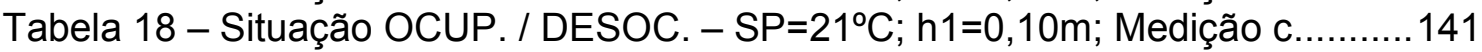

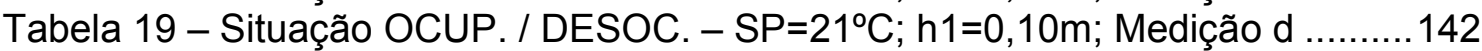

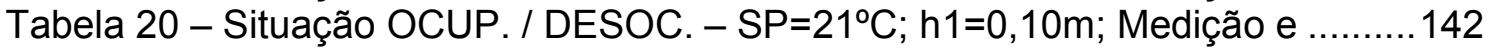

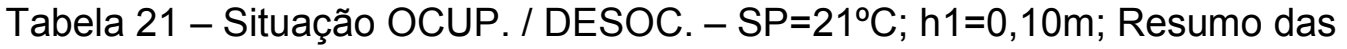

Medições ............................................................................. 142

Tabela 22 - Situação OCUP. / DESOC. $-\mathrm{SP}=21^{\circ} \mathrm{C} ; \mathrm{h} 2=0,60 \mathrm{~m}$; Medição a ..........143

Tabela 23 - Situação OCUP. / DESOC. $-\mathrm{SP}=21^{\circ} \mathrm{C}$; $\mathrm{h} 2=0,60 \mathrm{~m}$; Medição b ..........143

Tabela 24 - Situação OCUP. / DESOC. $-\mathrm{SP}=21^{\circ} \mathrm{C}$; h2=0,60m; Medição c............143

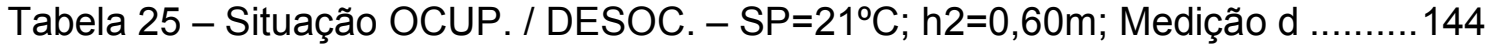

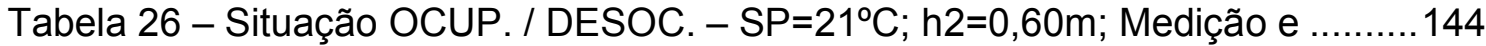

Tabela 27 - Situação OCUP. / DESOC. - SP $=21^{\circ} \mathrm{C}$; h2=0,60m; Resumo das Medições ............................................................................... 144

Tabela 28 - Situação OCUP. / DESOC. $-\mathrm{SP}=21^{\circ} \mathrm{C}$; h3=1,10m; Medição a ..........145

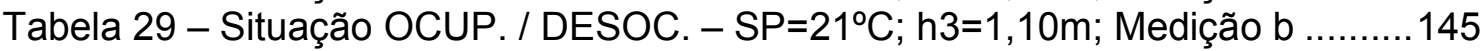

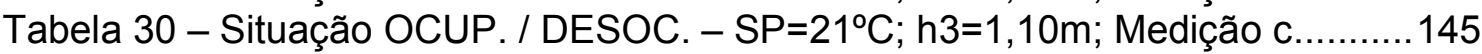

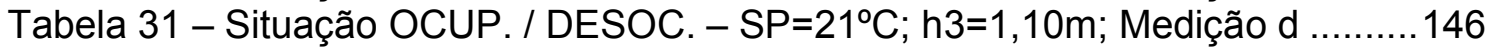

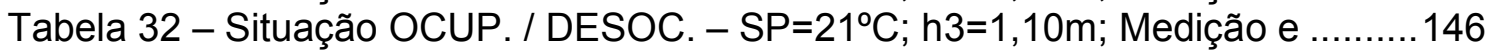

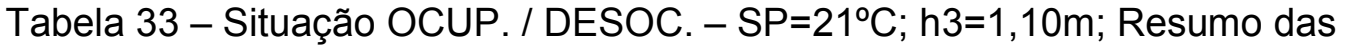

Medições ...............................................................................146

Tabela 34 - Situação OCUP. / DESOC. $-\mathrm{SP}=21^{\circ} \mathrm{C}$; $\mathrm{h} 4=1,70 \mathrm{~m}$; Medição a ..........147

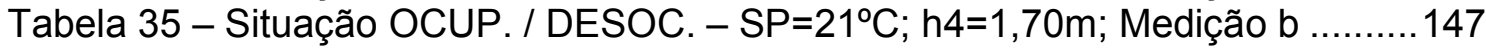

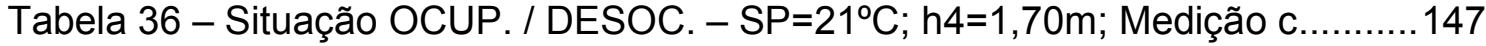

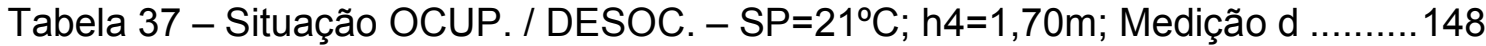

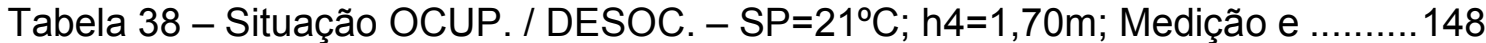

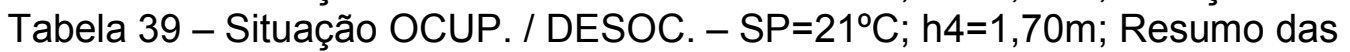

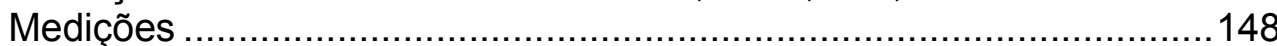

Tabela 40 - Situação OCUP. / DESOC. $-\mathrm{SP}=21^{\circ} \mathrm{C} ; \mathrm{h} 5=2,00 \mathrm{~m}$; Medição a ..........149

Tabela 41 - Situação OCUP. / DESOC. $-\mathrm{SP}=21^{\circ} \mathrm{C}$; h5=2,00m; Medição b .......... 149

Tabela 42 - Situação OCUP. / DESOC. $-\mathrm{SP}=21^{\circ} \mathrm{C}$; h5=2,00m; Medição c........... 149

Tabela 43 - Situação OCUP. / DESOC. $-\mathrm{SP}=21^{\circ} \mathrm{C}$; h5=2,00m; Medição d .......... 150

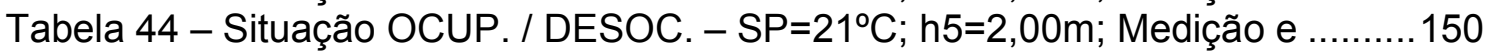

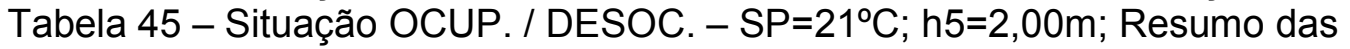

Medições ................................................................................150

Tabela 46 - Situação OCUP. / DESOC. - SP $=21^{\circ} \mathrm{C}$; h6=2,35m; Medição a .......... 151

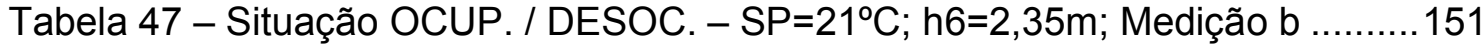

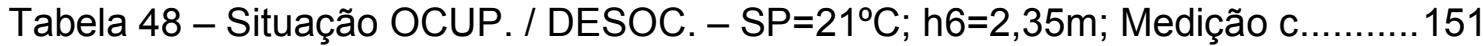

Tabela 49 - Situação OCUP. / DESOC. $-\mathrm{SP}=21^{\circ} \mathrm{C}$; h6=2,35m; Medição d ..........152

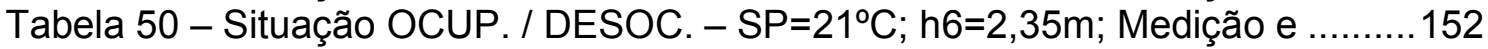

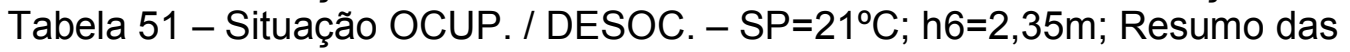
Medições

Tabela 52 - Índices de Ajuste- Ocup./Desoc. - SP21 ....................................... 154

Tabela 53 - Índices de Ajuste - Ocup./Desoc. - SP22 ....................................... 154

Tabela 54 - Índices de Ajuste - Ocup./Desoc. - SP23 ................................... 154

Tabela 55 - Índices de Ajuste - Ocup./Desoc. - SP24 
Tabela 56 - Índices de Ajuste - Ocup./Desoc. - SP25 ........................................154

Tabela 57 - Índices de Ajuste - Ocup./Desoc. - SP26 …..................................154

Tabela 58 - Índices de Ajuste- Desocupado - SP21 ......................................156

Tabela 59 - Índices de Ajuste - Desocupado. - SP22 ………….....................156

Tabela 60 - Índices de Ajuste - Desocupado - SP23 ….................................156

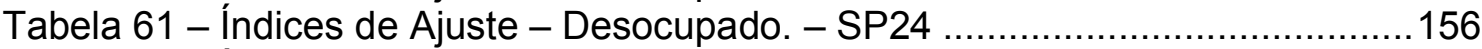

Tabela 62 - Índices de Ajuste - Desocupado - SP25 …................................156

Tabela 63 - Índices de Ajuste - Desocupado - SP26 …..................................156

Tabela 64 - Dados de MSM e MSF nas 16 posições e 6 alturas -SP21 Ocup./Desoc.

Tabela 65 - Dados de MSM e MSF nas 16 posições e 6 alturas - SP22 Ocup./Desoc.

Tabela 66 - Dados de MSM e MSF nas 16 posições e 6 alturas - SP23 Ocup./Desoc.

Tabela 67 - Dados de MSM e MSF nas 16 posições e 6 alturas - SP24 Ocup./Desoc.

Tabela 68 - Dados de MSM e MSF nas 16 posições e 6 alturas - SP25 :Ocup./Desoc.

Tabela 69 - Dados de MSM e MSF nas 16 posições e 6 alturas - SP26 Ocup./Desoc.....

Tabela 70 - Dados de MSM e MSF nas 16 posições e 6 alturas - SP21 -: Desocupado.

Tabela 71 - Dados de MSM e MSF nas 16 posições e 6 alturas - SP22 Desocupado.

Tabela 72 - Dados de MSM e MSF nas 16 posições e 6 alturas - SP23 -

Desocupado

Tabela 73 - Dados de MSM e MSF nas 16 posições e 6 alturas - SP24 Desocupado.

Tabela 74 - Dados de MSM e MSF nas 16 posições e 6 alturas - SP25 Desocupado.

Tabela 75 - Dados de MSM e MSF nas 16 posições e 6 alturas - SP26 Desocupado.

Tabela 76 - Resumo dos dados de temperatura do ar - Ocup./Desoc. ..................172

Tabela 77 - Temperaturas do ar nas alturas de conforto - Ocup./Desoc...............173

Tabela 78 - Resumo dos dados de temperatura do ar - Desocupação ...................175

Tabela 79 - Temperaturas do ar nas alturas de conforto - Desocupado ................176 


\section{LISTA DE ABREVIATURAS E SIGLAS}

ISO

- International Organization for Standardization

ASHRAE

- American Society of Heating Refrigeration and Air conditioning

Engineers Inc.

\section{LISTA DE SÍMBOLOS}

\section{Variáveis}

A

$A_{\text {eff }}$

$\mathrm{D}$

$\mathrm{H}$

I

MSM

MSF

$\mathrm{R}$

$\mathrm{SP}$

$T$

$t_{a}$

$t_{0}$

$\overline{t_{r}}$

$V_{a}$

UR

$\left(\Delta t_{p r}\right)$

$\Delta \mathrm{T}$

$\Delta \mathrm{M}$

$\varepsilon$

$\sigma$
- Área da superfície do corpo negro $\left[\mathrm{m}^{2}\right]$

- Área de radiação efetiva do corpo revestido $\left[\mathrm{m}^{2}\right]$;

- Diâmetro do globo [m]

- Altura [m]

- Intensidade de radiação $\left[\mathrm{Wm}^{-2}\right]$;

- Média de temperatura do sensor móvel $\left[{ }^{\circ} \mathrm{C}\right]$

- Média de temperatura do sensor fixo $\left[{ }^{\circ} \mathrm{C}\right]$

- Calor transferido por radiação $\left[\mathrm{W} / \mathrm{m}^{2}\right]$

- Setpoint de temperatura $\left[{ }^{\circ} \mathrm{C}\right]$

- Temperatura do corpo negro [K];

- Temperatura do ar $\left[{ }^{\circ} \mathrm{C}\right]$

- Temperatura operativa $\left[{ }^{\circ} \mathrm{C}\right]$

- Temperatura radiante média $\left[{ }^{\circ} \mathrm{C}\right]$

- Velocidade média do ar [m/s]

- Umidade relativa (\%)

\section{Letras gregas}

- Assimetria de temperatura radiante $\left[{ }^{\circ} \mathrm{C}\right]$

- Índice de ajuste $\left[{ }^{\circ} \mathrm{C}\right]$

- Máxima diferença de valores de temperatura entre as curvas das variáveis MSM e MSF nas 6 alturas de medição [ $\left.{ }^{\circ} \mathrm{C}\right]$

- Emissividade [adimensional]

- Constante de Stefan-Boltzmann $\left[\mathrm{Wm}^{-2} \mathrm{~K}^{-4}\right]$ 


\section{SUMÁRIO}

RESUMO

8

ABSTRACT

9

LISTA DE ILUSTRACÕES

10

LISTA DE QUADROS

12

LISTA DE GRÁFICOS

13

LISTA DE TABELAS

14

SUMÁRIO

18

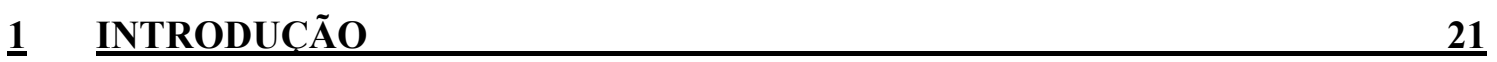

$\begin{array}{llr}1.1 & \text { OBJETIVOS } & 27\end{array}$

1.1.1. OBJETIVO GERAL 27

1.1.2. OBJETIVOS ESPECÍFICOS 28

1.2 DESENVOLVIMENTO DO TRABALHO 28

1.3 REVISÃO DA LITERATURA

$\underline{2} \quad \underline{\text { DESCRIĊÃO DO OBJETO DE ESTUDO }}$

2.1 AMBIENTE EXPERIMENTAL

2.2 SISTEMA DE CONDICIONAMENTO DE AR

2.2.1. CIRCUITO DE ÁGUA 42

A. Circuito Primário: $\quad 42$ 
B. Circuito Secundário: $\quad 46$

2.2.2. CIRCUITO DE AR 49

2.3 SISTEMA DE AUTOMAÇÃO E CONTROLE

2.3.1. HARDWARE

2.3.2. SOFTWARE

2.3.3. ROTINAS DE CONTROLE 60

A. Rotinas de Controle do Suprimento de Água Gelada 60

B. Rotinas de controle do suprimento de ar frio $\quad 62$

C. Rotina de controle de umidade $\quad 64$

$\underline{3}$ MÉTODO DE TRABALHO

3.1 ATIVIDADE 1 - DEFINIÇÃO DAS CONDIÇÕES DE CONTORNO PARA ELABORAÇão DO $\begin{array}{ll}\text { EXPERIMENTO } & \mathbf{6 7}\end{array}$

3.1.1. VARIÁVEIS A SEREM MEDIDAS

3.1.2. DEFINIÇÃO DOS PONTOS DE MEDIÇÃO 69

A. Pontos de medições fixos $\quad 69$

B. Pontos de medições móveis $\quad 72$

3.1.3. DEFINIÇÃO DOS PERÍODOS DE MEDIÇÕES

3.2 ATIVIDADE 2 - ESCOLHA DOS EQUIPAMENTOS NECESSÁRIOS A MEDIÇÕES E AQUISIÇÃo DE DADOS

3.3 ATIVIDADE 3 - TESTES PRELIMINARES PARA VERIFICAÇÃO DO MÉTODO DE TRABALHO

3.4 ATIVIDADE 4 - COLETA DE DADOS NO LABORATÓRIO 84

3.5 ATIVIDADE 5 - TRATAMENTO DOS DADOS 86

3.6 ATIVIDADE 6 - TÉCNICAS E PROCESSOS UTILIZADOS PARA A REALIZAÇÃO DOS
OBJETIVOS ESPECÍ́FICOS No 2 E 3

3.6.1. OBJETIVO ESPECÍFICO N ${ }^{\circ}$ 2: PERFIL DE ESTRATIFICAÇÃO DAS TEMPERATURAS 95

3.6.2. OBJETIVO ESPECÍFICO N 3: REPRESENTAÇÃO GRÁFICA DAS CONDIÇÕES TÉRMICAS 97

4 RESULTADO DAS MEDICÕES E ANÁLISE QUANTITATIVA DAS CONDICÕES TÉRMICAS DO AMBIENTE

4.1 RESULTADOS E ANÁLISES DA ATIVIDADE 5

4.1.1. PRIMEIRA PARTE: ÍNDICES DE AJUSTE POR ALTURA DE MEDIÇÃO 100

4.1.2. SEGUNDA PARTE: ÍNDICES DE AJUSTE POR SETPOINT DE TEMPERATURA

4.1.3. TERCEIRA PARTE: ÍNDICES DE AJUSTE NA ALTURA DE CONFORTO 105

A. Resultados dos Índices de Ajuste 106

B. Análise de comportamento dos Índices de Ajuste 108

4.2 RESULTADOS E ANÁLISES DA ATIVIDADE 6

4.2.1. CARACTERIZAÇÃO DO AMBIENTE EXPERIMENTAL COM RELAÇÃO AO PERFIL DE ESTRATIFICAÇÃO DE TEMPERATURA DO AR 111

A. Resultados das temperaturas do ar nas 16 posições e 6 alturas de medição 112

B. Análises das características térmicas do ambiente 114

4.2.2. DETERMINAÇÃO DO "LOCAL IDEAL" 121

A. Resultados das Condições Térmicas do "Local Ideal" na altura h2=0,60 m 124

B. Análise dos "Locais Ideais" na altura h2=0,60 m 126

$\underline{5}$ CONCLUSÕES E CONSIDERACÕES FINAIS 127 
APÊNDICE A - Tabelas e gráficos de dados da variável temperatura do ar por setpoint (SP) e altura (h) - Situação: Ocup./Desoc. - Setpoint $21^{\circ} \mathrm{C}$; h1 =0,10 m

APÊNDICE B - Tabelas e gráficos dos índices de ajuste sob 6 condições térmicas (setpoints); Situação de medição Ocupado/Desocupado e Desocupado

APÊNDICE C - Tabelas e gráficos dos dados da variável temperatura do ar nos 16 pontos de medição em relação às 6 altura $(\mathrm{h})$ )

APÊNDICE D - Resumo dos dados de temperatura do ar na situação de medição com Ambientes "Ocupado / Desocupado"

APÊNDICE E - Gráficos das condições térmicas do ambiente experimental da situação de medição Ocup./Desoc

ANEXO A - Explicação sobre Modos de controle Proporcional (P), Integral (I) e Derivativo (D) e suas combinações 


\section{INTRODUÇÃO}

Os projetos de sistemas de climatização de ambientes têm a função principal de compensar os incrementos de cargas térmicas oriundos de pessoas, de equipamentos, de radiação solar e trocas de calor com as paredes e ar externo. Estes sistemas preocupam-se principalmente com a retirada de calor sensível, originado principalmente de pessoas e equipamentos, mas também com a retirada de calor latente, originado de pessoas. Dessa forma, busca-se garantir a manutenção das condições de temperatura, umidade e velocidade do ar dentro dos limites de conforto para as pessoas em ambientes fechados.

Segundo Niu (1995), os sistemas de condicionamento de ar modernos podem ser classificados basicamente em duas categorias: sistemas convectivos e, sistemas radiantes.

No sistema convectivo, que corresponde ao sistema tradicional de climatização de ambientes, a compensação de calor sensível e latente pode ser realizada mediante o fornecimento de uma vazão de ar a uma temperatura inferior à do local. Para isso, existem duas estratégias que podem ser empregadas: um sistema com volume de ar constante (VAC) e sistema de volume de ar variável (VAV).

A segunda categoria, caracterizada por uma combinação dos sistemas radiantes e convectivos utiliza duas estratégias de compensação de calor. $O$ calor latente e uma parte do calor sensível são retirados através dos tradicionais sistemas de insuflamento de ar resfriado, tais como: as unidades de climatização através de Fan Coils, com volume de ar constante ou variável. Concomitantemente, a maior parte do calor sensível é retirado através de elementos estruturais. Em alguns casos, em alguns países onde o clima é muito severo, estes elementos estruturais também podem ser usados para o aquecimento do ambiente. No mercado, este sistema de condicionamento de ar é conhecido como sistema de "teto frio" (Cooling Ceiling System ou Cooled Ceiling System) ou sistema de painéis de resfriamento radiante (Radiant Cooling Panel System).

As instalações com o sistema do tipo "teto frio" são mais comuns em países nórdicos (Noruega, Suécia, Finlândia, Dinamarca e Islândia) e na Europa Central (principalmente Suiça e Alemanha), devido principalmente às exigências de conforto 
térmico e acústico. Estes requisitos referem-se principalmente à necessidade de se ter baixos índices de turbulência do ar na zona de ocupação resultando em baixos níveis de velocidades de ar. Outra característica importante deste tipo de sistema e muito valorizada nestes países é o seu grau de eficiência energética, isto é, comparativamente aos demais sistemas tradicionais de condicionamento de ar, o sistema do tipo "teto frio" aparece como uma opção com baixo consumo de energia (Imanari et al,1999; Miriel et al, 2002; Sodec, 1999; Stetiu, 1999; Novoselac, 2002; Mumma, 2002).

O sucesso de seu uso pode ser comprovado através de pesquisas de avaliação de satisfação do usuário com o sistema, como o estudo feito por Sodec (1999), onde se comprovou que a instalação conseguiu atender a vários requisitos de conforto, tais como:

- Baixo gradiente de temperatura;

- Baixa velocidade do ar;

- Baixo nível sonoro (manutenção do nível de pressão sonora permissível).

O funcionamento do sistema de "teto frio" baseia-se principalmente em dois tipos de trocas térmicas: ele remove a carga térmica das fontes de calor diretamente através da radiação e indiretamente através da convecção (NOVOSELAC, 2002). Existem no mercado diferentes tipos de "teto frio", tais como, viga fria (chilled beams), lajes frias (cooling slabs), grelhas frias (cooling grids), mas os mais utilizados são as placas metálicas de forro (painéis radiantes) acoplados aos tubos metálicos (serpentinas), instalados no teto, que usam a água gelada como líquido refrigerante. No interior destas serpentinas, a água gelada remove o calor do ar em contato com os painéis radiantes. E externamente, pelo princípio da troca térmica por radiação, a temperatura do ar do ambiente ao redor das placas metálicas de forro e serpentinas é diminuída até um nível controlado de forma que se consiga obter uma climatização agradável do ambiente.

Normalmente, no mercado, a construção de cada painel radiante é feita utilizando-se uma placa de alumínio acoplada diretamente a um conjunto de serpentinas de cobre, de forma que fiquem presas à superfície do painel. A 
construção destas estruturas pode ser feita de diferentes maneiras, porém, geralmente o seu uso é no teto, através de placas radiantes apoiadas no sentido horizontal. Por isso, a denominação de sistema de climatização do tipo "teto frio".

Segundo Mumma (2002), para a maioria das aplicações, o fluxo de calor na superfície do painel é de aproximadamente $30 \mathrm{Btu} / \mathrm{h} \cdot \mathrm{ft}^{2}\left(95 \mathrm{~W} / \mathrm{m}^{2}\right)$ para aplicações de teto embutido. Além das características dos materiais utilizados na construção das placas, que influenciam diretamente na eficácia das trocas térmicas, 0 distanciamento das serpentinas, por onde percorre a água gelada, e a qualidade do contato térmico das serpentinas ao painel definem o efeito radiante no processo de troca térmica do ar com o ambiente.

Por meio deste sistema, o calor sensível é removido do ambiente através da combinação de trocas de calor por convecção e radiação. Na maioria das aplicações, observa-se que os dois mecanismos de trocas térmicas possuem uma importância praticamente equivalente e baseiam-se no diferencial de temperatura média da placa e na temperatura do ar do ambiente. Com relação à troca térmica, o processo funciona da seguinte maneira: O fluxo de energia emitido pela placa radiante é baseado na equação eq. (1) de Stefan-Boltzmann, conforme mostrado abaixo:

A potência emitida $(P(T))$ por um corpo negro é regido pela seguinte fórmula:

$$
\mathrm{P}(\mathrm{T})=\sigma \mathrm{AT}^{4}
$$

Onde: $\quad \boldsymbol{\sigma}=5,67 \times 10^{-8} \mathrm{Wm}^{-2} \mathrm{~K}^{-4}$ é a constante de Stefan-Boltzmann;
A: área da superfície do corpo negro $\left[\mathrm{m}^{2}\right] \mathrm{e}$
T: $\quad$ temperatura do corpo negro $[\mathrm{K}]$

Para uma troca térmica entre duas superfícies, a potência resultante é dada pela eq. (2):

$$
\mathrm{P}_{1-2}=\frac{1}{\frac{1}{\varepsilon_{1}}+\frac{1}{\varepsilon_{2}}-1} \sigma \mathrm{A}\left(\mathrm{T}_{1}^{4}-\mathrm{T}_{2}^{4}\right)
$$

Onde: I: intensidade de radiação $\left[\mathrm{Wm}^{-2}\right]$;

$\varepsilon$ : emissividade, um fator numérico adimensional compreendido entre 0 e 1, e que depende da constituição do corpo emissor ( 0 para o refletor perfeito e 1 para o corpo negro). 

A: área da placa radiante $\left[\mathrm{m}^{2}\right] \mathrm{e}$
T: $\quad$ temperaturas das superfícies $[\mathrm{K}]$

Considerando em uma das superfícies um corpo negro, resulta na eq. (3):

$$
\mathrm{P}=\varepsilon \sigma \mathrm{A}\left(\mathrm{T}_{1}^{4}-\mathrm{T}_{2}^{4}\right)
$$

De acordo com esta equação de Stefan-Boltzmann que quantifica a emissão de energia de radiação proveniente de qualquer corpo físico, pode-se observar que o sistema de placas radiantes possui um alto efeito radiante.

Segundo Brunk (1993), o painel de resfriamento, feito de alumínio com as tubulações integradas de água, atinge uma temperatura média de superfície de aproximadamente $17,4{ }^{\circ} \mathrm{C}$ com uma temperatura de água de $16{ }^{\circ} \mathrm{C}$. A temperatura média da superfície, alcançada pelos painéis radiantes que estão conectados às tubulações de cobre é quase $3 \mathrm{~K}$ maior que temperatura da água utilizada. Assim, para obter a mesma capacidade de resfriamento, a temperatura de água deve ser diminuída de aproximadamente $3 \mathrm{~K}$.

Adicionalmente às propriedades radiantes do "teto frio", o resfriamento do ambiente também conta com unidades convectivas de resfriamento por meio da introdução de ar resfriado em difusores instalados no teto, originado de algum sistema de condicionamento de ar com expansão direta ou indireta.

Essa introdução de "ar resfriado" tem a função de compensar o calor latente existente no ambiente, uma vez que os ocupantes são geradores deste tipo de calor. Além desta função, o ar resfriado contribui para o condicionamento de ar, trocando calor por convecção e garante a taxa mínima de renovação de ar. Comparativamente, segundo levantamentos de trabalhos experimentais feitos por Novoselac e Srebric (2002), para uma determinada carga de resfriamento total em seu ambiente de estudo, 60 \% desta carga foi removida pelo sistema de teto frio, quando esta tinha uma temperatura de placa radiante de $18^{\circ} \mathrm{C}$. O restante, $40 \%$, foi removido por outro sistema com ventilação por deslocamento.

No caso de uma composição híbrida de resfriamento, composta pelos circuitos de ar e água, o seu funcionamento é controlado por um sistema de automação específico. Este sistema controla o sistema de condicionamento de ar de forma que o nível de resfriamento por radiação seja determinado indiretamente pela 
temperatura do ar medido no local e pela temperatura do ponto de orvalho. Como segurança, existe um controle de temperatura da água de alimentação das placas para evitar o efeito indesejável da condensação.

O fenômeno da condensação do vapor de água pode acontecer quando a temperatura da água que percorre as serpentinas das placas é diminuída a um nível que faz com que a temperatura do ar ao redor da superfície das placas e serpentinas fique abaixo da temperatura do ponto de orvalho. Assim, quando a temperatura do ar ficar abaixo da temperatura de ponto de orvalho, existe a probabilidade de haver condensação do vapor de água. Uma alternativa para se evitar este problema é desumidificar o ar, principalmente em locais de alta umidade relativa. No caso desta pesquisa, para o controle da taxa de umidade do ar foram utilizadas resistências de aquecimento controladas pelo sistema de automação em conjunto com o sistema de condicionamento de ar.

Devido ao risco deste fenômeno, os sistemas de resfriamento radiantes requerem estratégias de controle bem ajustadas para manterem os níveis de umidade e temperatura do ar em uma margem bem tolerável.

Com relação ao controle de temperatura do ar no ambiente, observa-se, na prática, que os sistemas de climatização podem ter uma diminuição de sua eficiência em função da deficiência de leitura de seu medidor. Tradicionalmente, o valor da temperatura de referência utilizado para a comparação com o setpoint de temperatura do ar do ambiente é obtido por meio de leituras de sensores localizados no duto de retorno do ar ou no próprio ambiente. No caso dos sensores de temperatura que ficam no ambiente, normalmente, estes são posicionados em locais não muito adequados por questões essencialmente estéticas, isto é, eles podem ser encontrados em locais muito altos ou muito baixos em relação à altura de conforto, atrás da porta ou perto de algum equipamento dissipador de calor.

Dessa forma, o posicionamento inadequado destes sensores de temperatura do ar pode implicar em medidas errôneas que, interpretadas pelo sistema de controle fazem com que o sistema de condicionamento do ar opere inadequadamente. Apenas como exemplo, supõe-se que seja configurado o setpoint de temperatura do ar de uma sala em $22^{\circ} \mathrm{C}$ e tem-se um sensor de temperatura de ar posicionado na parede, a dois metros do piso, medindo $25^{\circ} \mathrm{C}$. Verificado que a temperatura mais representativa do ambiente era $23^{\circ} \mathrm{C}$ no centro da sala, à altura de $0,60 \mathrm{~m}$, altura de referência para conforto (ISO 7730, 1994), observa-se uma diferença de $2^{\circ} \mathrm{C}$ entre a 
temperatura medida junto à parede e a temperatura no centro da sala. Nestes casos, certamente, o equipamento de condicionamento de ar irá ignorar esta diferença e considerará em seu algoritmo de controle, erroneamente os $25^{\circ} \mathrm{C}$ como a temperatura de referência. Assim, o equipamento de ar condicionado, por meio de seu algoritmo de controle, promoverá a diminuição de $3^{\circ} \mathrm{C}$ ao invés de apenas $1^{\circ} \mathrm{C}$. Essa diferença resulta em uma diminuição da eficiência do sistema de condicionamento de ar e, inclusive, pode provocar sensação de desconforto no ocupante, além de exigir mais do equipamento, gastando-se mais energia do que o necessário.

Portanto, para resolver este problema, esta pesquisa visa encontrar a temperatura mais representativa do ambiente, que corresponde a um valor de média de temperatura na altura de conforto e denominada nesta pesquisa de "temperatura ideal". Esta "temperatura ideal" servirá para determinar a posição ou região que melhor represente as condições do ambiente na altura de conforto, chamado de "local ideal" ou "região ideal", local este que teoricamente poderia ser posicionado o sensor de temperatura. Entretanto, tendo-se em vista que nem sempre é possível posicionar estes sensores em um "local ideal", esta pesquisa de campo visa determinar valores de correções nas medidas de temperatura do ar efetuadas pelos sensores do sistema de controle. Estas correções são traduzidas em índices a serem incrementados nos algoritmos de controle do sistema de automação. Em outras palavras, este ajuste resolve indiretamente o problema da má estimativa de temperatura do ambiente, em decorrência do mau posicionamento do sensor. Isto faz com que o sistema opere baseado em um valor mais coerente com as condições térmicas do ambiente. Como resultado, esta solução pode proporcionar uma melhor condição de conforto térmico e gasto de energia elétrica otimizado. 


\subsection{OBJETIVOS}

Tendo-se em vista o problema com medições inadequadas de temperatura do ar do ambiente, em decorrência do mau posicionamento dos sensores no local, esta pesquisa propõe solucionar este problema, através de um estudo experimental. Neste estudo, pretende-se determinar índices de ajuste aplicáveis aos valores de temperatura do ar, lidos pelos sensores do ambiente, e que possam ser incrementados nos algoritmos de controle da operação do sistema de condicionamento de ar do tipo "teto frio". Os índices de ajuste serão determinados considerando medições feitas por sensores localizados em posições fixas no ambiente, em comparação com resultados de medições da variável "temperatura do ar", realizadas no ambiente. Durante o trabalho será possível se verificar a influência do posicionando dos sensores de temperatura instalados no ambiente em relação ao desempenho do sistema de condicionamento de ar.

\subsubsection{OBJETIVO GERAL}

Um dos grandes objetivos de se implantar um sistema de condicionamento de ar em uma edificação é proporcionar aos seus ocupantes o maior conforto térmico possível, de uma forma saudável e preferencialmente com baixo consumo de energia. Dessa forma, esta pesquisa visa melhorar a eficiência do sistema de condicionamento de ar de uma sala experimental, através de um método inovador, adequando a leitura da temperatura de ar de referência, usada pelo sistema de automação e controle, com um índice de ajuste nas medidas. Isto permite com que o sistema de condicionamento de ar responda com mais eficiência em termos de consumo de energia e de conforto ao usuário da sala. 


\subsubsection{OBJETIVOS ESPECÍFICOS}

Esta pesquisa tem os seguintes objetivos específicos:

1. Solucionar o problema da má estimativa da temperatura do ar de referência para o funcionamento do sistema, devido ao posicionamento inadequado dos sensores de temperatura do ar no ambiente, com a determinação dos índices de ajuste em medidas efetuadas pelos sensores de temperatura do ar;

2. Caracterizar o perfil de estratificação da temperatura do ar do ambiente experimental, comparando-a com a norma ISO 7726 (1998), que determina os critérios para se considerar um ambiente homogêneo;

3. Representar graficamente o comportamento das variáveis temperatura e velocidade do ar, nas diferentes condições térmicas impostas pelas condições de contorno. Além disso, identificar graficamente os locais que apresentam a temperatura mais representativa do ambiente, na altura de conforto ("locais ideais"), de forma a permitir o mapeamento das possíveis condições térmicas resultantes no ambiente.

\subsection{DESENVOLVIMENTO DO TRABALHO}

A apresentação deste trabalho segue a ordem da seqüência de realização da pesquisa. Inicialmente, no capítulo 1, é apresentada uma revisão da bibliografia específica do tema, incluindo alguns comentários a respeito das principais características do sistema de condicionamento de ar.

No capítulo 2, é feita uma descrição detalhada dos aspectos básicos que compõem o objeto de estudo desta pesquisa, que são: "Ambiente Experimental", "Sistema de Condicionamento de ar" e "Sistema de Automação e Controle".

O capítulo 3 é dedicado à descrição das diferentes atividades que compõem o método de trabalho desta pesquisa. Estas atividades seguem a seqüência cronológica do desenvolvimento do trabalho. No total são 6 atividades. 
Neste capítulo são descritas as condições de contorno, as variáveis estudadas, os equipamentos e procedimentos para coleta de dados e o processo de tratamento destes dados para se determinar os índices de ajuste. Adicionalmente, são apresentadas as técnicas, processos e ferramentas utilizadas para a caracterização do ambiente térmico tais como o perfil de estratificação e nível de homogeneidade do ar, assim como o mapeamento das condições térmicas do ambiente,

O capítulo seguinte, capítulo 4, apresenta os resultados das medições e as análises quantitativas das condições térmicas do ambiente. Basicamente ele é dividido em dois sub-capítulos: O primeiro apresenta os resultados e análises relativos à atividade 5 e o segundo relativos à atividade 6 .

Para este primeiro sub-capítulo existem três partes: A primeira parte apenas mostra os resultados dos índices de ajuste por altura de medição através de tabelas e gráficos. A segunda parte mostra os índices de ajuste obtidos nas condições de temperatura ensaiadas. E a última parte mostra os resultados dos índices, em específico, na altura de conforto, de forma a analisar o seu comportamento com as mudanças de setpoints de temperatura para algumas situações de ocupação da sala.

Para o segundo sub-capítulo são apresentados resultados e análises de dois objetivos específicos apresentados na pesquisa. Ela é dividida em duas partes: A primeira faz uma caracterização do ambiente experimental com relação ao perfil de distribuição de temperatura do ar no ambiente e a segunda mostra os resultados gráficos do comportamento das variáveis temperatura e velocidade do ar, nas diferentes condições térmicas impostas pelas condições de contorno.

O capítulo 5 trata das conclusões dos resultados obtidos no capitulo 4 e comenta sobre $\mathrm{o}$ atendimento aos objetivos propostos.

Por último, os capítulos 6 e 7 apresentam, respectivamente, as referências que auxiliaram na realização desta pesquisa. 


\subsection{REVISÃO DA LITERATURA}

Para se fazer uma análise quantitativa das condições térmicas geradas pelo sistema de condicionamento de ar do tipo "teto frio", foco desta pesquisa, algumas considerações sobre os efeitos da radiação sobre o conforto térmico, assim como algumas normas e resultados de estudos relacionados a este assunto foram utilizadas como referência nesta pesquisa, tais como: as principais variáveis de conforto, o efeito da radiação no conforto, o desconforto térmico local, os efeitos da assimetria de radiação e o teto quente.

Segundo Fanger (1972), existem diversos fatores que podem influenciar diretamente as condições de conforto térmico, tais como, nível de atividade, vestimenta e variações das variáveis ambientais (temperatura operativa ${ }^{1}$, temperatura radiante média, umidade e velocidade relativa do ar), denominados primários. Outros fatores, chamados de secundários, também podem influenciar no conforto, porém, em menor escala, tais como: constituição física, sexo, ciclo menstrual, diferenças étnicas, ritmo circadiano, tipo de alimentação, idade, cor e ruído,

Segundo a ASHRAE (2005), existem alguns parâmetros de conforto que servem como referência para as avaliações de conforto, e que dependem das características bioclimáticas da região. Por exemplo, para climas mais quentes da América do Norte, $25^{\circ} \mathrm{C}$ é considerado uma temperatura ótima, podendo variar entre $23^{\circ} \mathrm{C}$ e $27^{\circ} \mathrm{C}$, para uma velocidade média de $0,5 \mathrm{~m} / \mathrm{s}$ e umidade relativa entre $30 \%$ e $70 \%$. Entretanto, usualmente, para uma pessoa trajando roupa apropriada, as condições de conforto térmico adequadas podem ser obtidas com uma temperatura operacional $\left(20^{\circ} \mathrm{C}\right.$ a $\left.26^{\circ} \mathrm{C}\right)$; temperatura de ponto de orvalho de 2 a $17^{\circ} \mathrm{C}$ e velocidade média do ar (até $0,25 \mathrm{~m} / \mathrm{s}$ ) (Stoecker, 1985).

A temperatura operativa pode ser calculada por meio da média aritmética da temperatura de bulbo seco e da temperatura radiante média, desde que este seja menor que $50^{\circ} \mathrm{C}$ e a velocidade do ar seja menor que $0,4 \mathrm{~m} / \mathrm{s}$. Para ambientes condicionados, a temperatura operativa pode ser calculada utilizando-se da eq.(4):

$$
t_{o}=\alpha t_{a}+(1-\alpha) \bar{t}_{r}
$$

\footnotetext{
${ }^{1}$ Temperatura operativa é a temperatura uniforme de um invólucro negro imaginário, na qual uma pessoa trocaria a mesma quantidade de calor por radiação e convecção, do que se estivesse num ambiente real não uniforme. (ASHRAE, 2005)
} 


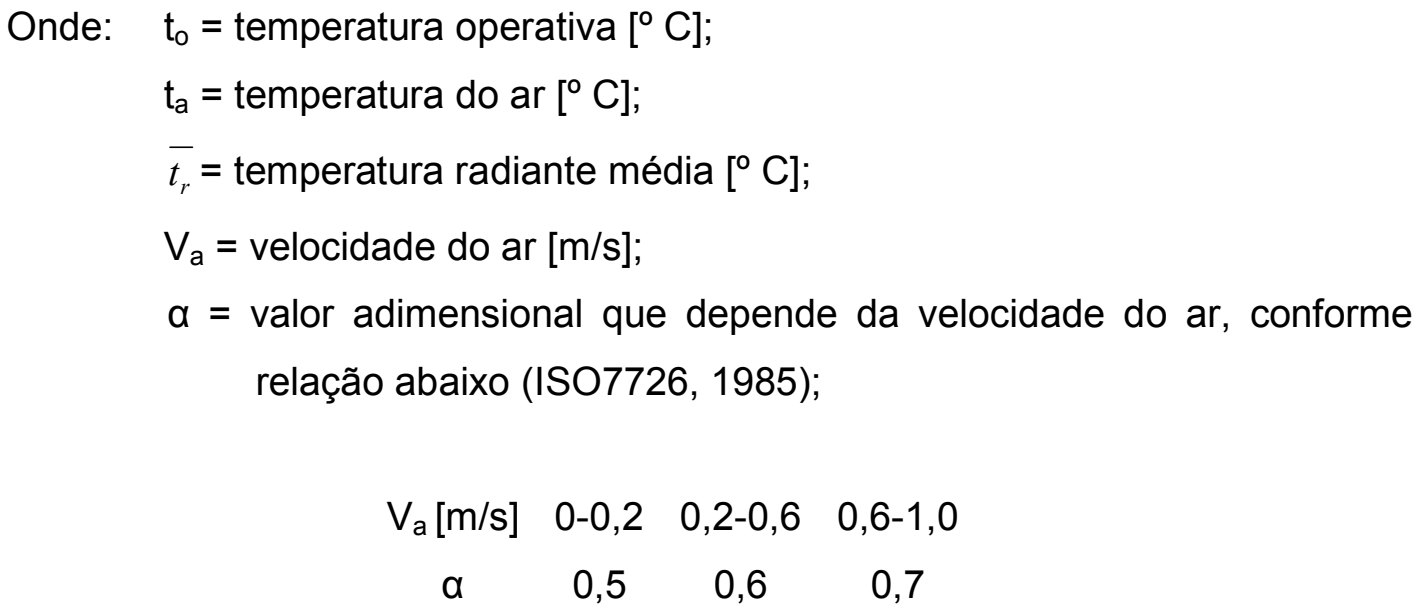

A temperatura da superfície para a qual o corpo irradia é comumente denominada de temperatura radiante média. De acordo com Fanger (1970), a temperatura radiante média em relação a uma pessoa em uma dada postura e vestimenta posicionada em um ponto da sala é definida como a temperatura uniforme de um meio imaginário com o qual o corpo troca a mesma quantidade de calor por radiação que com o meio real. Esta temperatura tem uma considerável influência na perda de calor do homem e conseqüentemente no estado de conforto do indivíduo. Seu calculo é importante na análise térmica de um ambiente. Nos ambientes moderados, isto é, "onde as condições ambientais se aproximam dos padrões adotados pela ISO7730 (ISO7726, 1985), a temperatura radiante média é muito próxima da temperatura do ar ambiente, o que não ocorre quando as paredes externas, janelas e paredes internas são afetadas pela radiação solar (insolação).

De acordo com a ASHRAE (2005), a temperatura radiante média pode ser calculada pela medição das temperaturas das superfícies e os correspondentes fatores angulares entre a pessoa e as superfícies. Ela também pode ser determinada pela temperatura radiante média em seis direções opostas, ponderadas de acordo com os fatores de área projetadas para uma pessoa. Para o seu cálculo, o instrumento mais utilizado é o termômetro de globo preto (Bedford e Warmer, 1935; Vernon, 1932). Este termômetro consiste de uma esfera oca com geralmente $15 \mathrm{~cm}$ de diâmetro, revestido por uma tinta preta com um termopar ou um bulbo de termômetro em seu centro. A temperatura estimada pelo globo em equilíbrio resulta do balanço dentre o calor ganho e perdido por radiação e convecção. A temperatura radiante é calculada pela eq. (5): 


$$
\overline{t_{r}}=\left[\left(t_{g}+273\right)^{4}+\frac{1,10 \times 10^{8} V_{a}^{0,6}}{\varepsilon D^{0,4}}\left(t_{g}-t_{a}\right)\right]^{1 / 4}-273
$$

Onde: $\mathrm{t}_{\mathrm{r}}=$ temperatura radiante média $\left[{ }^{\circ} \mathrm{C}\right]$;

$\mathrm{t}_{\mathrm{g}}=$ temperatura de globo $\left[{ }^{\circ} \mathrm{C}\right]$;

$\mathrm{V}_{\mathrm{a}}=$ velocidade do $\operatorname{ar}[\mathrm{m} / \mathrm{s}] ;$

$\mathrm{t}_{\mathrm{a}}=$ temperatura do $\operatorname{ar}\left[{ }^{\circ} \mathrm{C}\right]$;

$\mathrm{D}=$ diâmetro do globo $[\mathrm{m}]$;

$\varepsilon=$ emissividade $(0,95$ para corpo negro $)$

A temperatura radiante média é definida em relação ao corpo humano. Para uma pessoa sedentária, o globo representa uma boa aproximação. O globo negro também superestima a influência da radiação por ondas-curtas (por exemplo, a radiação solar) (ASHRAE, 2005).

O efeito da radiação em certas situações pode influenciar muito as condições de conforto térmico humano. Teoricamente, a transferência de calor por radiação se dá como resultado do deslocamento de fótons de uma superfície para outra, podendo ser um corpo, uma parede ou qualquer emissor de radiação (Por exemplo: equipamentos ou sol), Ao atingir uma superfície esses fótons podem ser absorvidos, refletidos ou transmitidos.

Assim, além da influência da radiação externa no ambiente decorrente de alguma fonte de radiação, e estimada através do cálculo da temperatura radiante média, o conforto térmico depende de fatores inerentes a forma como o corpo humano troca calor com o meio externo. Em outras palavras, uma pessoa, que realiza um trabalho leve em um ambiente condicionado, elimina calor gerado internamente pelo corpo, principalmente por convecção (por meio do ar ambiente) e por radiação (por meio das superfícies circundantes a uma temperatura menor que a da superfície do corpo). Segundo Stoecker (1985), cada um desses mecanismos é responsável por $30 \%$ do calor total eliminado. Os restantes $40 \%$ são eliminados pela respiração e transpiração. Essas porcentagens podem variar em função das condições ambientais ou do nível de atividade.

De acordo com Fanger (1972), a troca de calor por radiação acontece entre o corpo humano e sua superfície ao redor, assim como entre dois objetos físicos 
quaisquer. A perda de calor por radiação de uma superfície externa do corpo revestido pode ser expresso pela expressão da Lei de Stefan-Boltzmann, eq. (6):

$$
R=A_{e f f} \varepsilon \sigma\left[\left(t_{c l}+273\right)^{4}-\left(t_{m r t}+273\right)^{4}\right]
$$

Onde: $\quad \mathrm{R}=$ resistência térmica ou perda de calor radiativa pela pele [kcal/hr] $A_{\text {eff }}=$ área de radiação efetiva do corpo revestido $\left[\mathrm{m}^{2}\right]$; $\varepsilon=$ emitância da superfície mais externa do corpo revestido; $\boldsymbol{\sigma}=4,96 \times 10^{-8} \mathrm{kcal} / \mathrm{m}^{2} \mathrm{hr}^{\circ} \mathrm{K}^{4}$ é a constante de Stefan-Boltzmann; $t_{c l}=$ temperatura da superfície do corpo revestido $\left[{ }^{\circ} \mathrm{C}\right]$ $t_{\mathrm{mrt}}=$ temperatura radiante média $\left[{ }^{\circ} \mathrm{C}\right]$

Nem todas as partes do corpo irradiam para o meio; algumas irradiam para outras partes do corpo. A área do corpo efetiva para a radiação é, portanto, menor que sua área superficial, em geral $70 \%$ desta.

As emissividades da pele e da vestimenta são muito próximas da do corpo negro, podendo, para todos os efeitos práticos, serem iguais a 1,0. Como a emitância da pela humana é próxima de 1.0 e a maioria dos tipos de vestimentas têm emitância aproximadamente de 0,95, um valor médio de 0,97 é normalmente utilizado. As emitâncias da pele e da vestimenta independem da cor para baixas radiações de temperatura. Por outro lado, segundo Fanger (1972), se uma pessoa é irradiada com radiação de ondas-curtas (por exemplo, de radiação originada do sol ou de alguma fonte de alta temperatura radiante), o total de transferência de calor por radiação ainda pode ser calculado com a eq. (5). Para este caso, o cálculo de $t_{\text {rmt }}$ deve levar em consideração informações sobre a reflectância da pele e da vestimenta, que para radiação de ondas-curtas é altamente dependente das cores. Por exemplo: para uma pessoa recebendo radiação solar, a temperatura radiante média será muito maior se este estiver vestido de preto do que se ele estivesse vestido de branco, e a temperatura radiante média será maior em relação a uma pessoa com a pele escura em relação a uma pessoa de pele clara.

Para radiação normal de ondas longas (baixa temperatura), a absortância é igual à emitância que para a pele e todos as texturas normais é perto da unidade. 
Em alguns casos, pode ser previsto que a temperatura radiante média é muito próxima da temperatura do ar. Isso pode ser verificado através das equações de conforto de Fanger ou pelos gráficos do Voto Médio Estimado ( $P M V=0)$ (Fanger, 1970).

Com relação às condições de aceitabilidade do ambiente térmico, este deve atender a certas condições de aspectos ambientais, como temperatura operativa, velocidade do ar e umidade do ar e aspectos pessoais, tais como nível de atividade e vestimenta. Caso contrário pode existir desconforto térmico.

De acordo com a ASHRAE Standard 55 (2004), o limite recomendado para desconforto térmico geral é baseado em um critério de $10 \%$ de insatisfeitos. A insatisfação térmica também pode ser causada por aquecimento ou resfriamento indesejável em uma parte específica do corpo (desconforto térmico local). Para esta situação, esta norma recomenda um limite de desconforto térmico baseado em um critério de insatisfação de $5 \%$ a $15 \%$. Alguns aspectos ambientais decorrentes de alguma alteração na uniformidade no ambiente podem ocasionar o desconforto local, tais como a diferença vertical de temperatura do ar; as correntes de ar (draught rate - DR, expresso em porcentagem de insatisfeitos); temperatura do piso e assimetria de temperatura radiante.

A diferença vertical de temperatura do ar, em uma ambiente fechado, geralmente aumenta do piso ao teto. Esta diferença de temperatura pode ser verificada pelo perfil de estratificação da temperatura e ser expressa por um desconforto térmico localizado principalmente nos níveis dos pés $(0,1 \mathrm{~m})$ e da cabeça $(1,10 \mathrm{~m})$, caso o gradiente de temperatura seja maior que $3^{\circ} \mathrm{C}$, para pessoas em atividade leve, vestindo roupa com isolamento de 0,5 clo a 0,7 clo (ASHRAE Standard 55, 2004).

A corrente de ar (Draft Rate - DR) corresponde a um resfriamento localizado indesejável do corpo causado pela movimentação do ar. A sensação de corrente de ar depende da velocidade do ar, da temperatura do ar, da intensidade de turbulência, da atividade e da vestimenta das pessoas. A sensibilidade à corrente de ar é maior em partes do corpo descobertas, especialmente na região da cabeça, pescoço e ombros e na região dos pés, tornozelos e pernas. Os limites de taxa de corrente de ar indicados pela ASHRAE Standard 55 (2004) < 20\%.

Quanto à temperatura da superfície de piso, os ocupantes de ambientes fechados podem se sentir desconfortáveis devido ao contato com as superfícies do 
piso que estiverem muito quentes ou muito frios. A temperatura do piso depende principalmente do tipo de material de revestimento do piso. Os limites de temperatura de piso indicados pela ASHRAE Standard 55 (2004) são: $19^{\circ} \mathrm{C}$ a $29^{\circ} \mathrm{C}$.

A assimetria de temperatura radiante em espaços pode ser originada de superfícies e equipamentos frios ou quentes ou devido à radiação solar direta. Esta assimetria de radiação pode causar desconforto térmico local e reduzir a aceitabilidade térmica do espaço. As orientações e recomendações com respeito à assimetria de temperatura radiante podem ser observadas pelas normas ISO 7730 (1994) e ASHRAE Standard 55 (2004) e estes foram baseadas nos estudos relatados por Fanger et al. De acordo com a ASHRAE Standard 55 (2004), os limites para se evitar o desconforto local decorrente da assimetria da temperatura radiante, para indivíduos nas condições de atividade especificadas anteriormente, medidos à altura de 0,60 m (para pessoas sentadas) ou a 1,10 $\mathrm{m}$ (para pessoas em pé), são:

- Para teto quente: assimetria $<5^{\circ} \mathrm{C}$;

- Para teto frio: assimetria $<14^{\circ} \mathrm{C}$;

- Para parede quente: assimetria $<23^{\circ} \mathrm{C}$;

- Para parece fria: assimetria $<10^{\circ} \mathrm{C}$;

O sistema de painéis radiantes é aplicado tanto para o aquecimento quanto para o resfriamento de ambientes. Inicialmente a sua aplicação era destinada ao aquecimento de ambientes por meio de painéis radiantes quentes em climas frios, denominados de "teto quente" quando utilizados no teto e de "paredes quentes" quando utilizados na parede. Este aquecimento pode ser feito por meio de aquecimento de água ou por placas radiantes com circuitos elétricos.

A sua função inicial era conseguir aquecer o ambiente sem aquecer o ar, pelo princípio da radiação. Este sistema de aquecimento era utilizado principalmente em locais onde se tinha dificuldade de aquecer o ar ou com pouco isolamento térmico. Portanto, conseguia-se certo nível de conforto térmico, sem aquecer o ar, por meio da radiação. A medida desta radiação proporcionada às pessoas normalmente é feita pela temperatura de globo. Assim, os controles dos painéis radiantes para aquecimento normalmente são feitos por termômetros de globo colocados estrategicamente em certos locais no ambiente.

Com respeito ao conforto térmico, um dos grandes problemas dos painéis radiantes de aquecimento é o problema da assimetria de radiação. De acordo com a 
ASHRAE Standard 55 (2004), as pessoas são mais sensíveis à radiação assimétrica causada pelo teto quente do que àqueles por superfícies verticais frias ou quentes, isto é, aquece-se bastante a cabeça e não se aquece os pés. Portanto devido a este desconforto, os painéis radiantes para aquecimento não são muito difundidos.

Posteriormente, foram desenvolvidos sistemas de placas radiantes para resfriamento do ambiente, onde a água gelada percorre o interior de serpentinas acopladas a estes painéis e o conjunto resfria o ambiente também pelo princípio da radiação. Teoricamente, em um ambiente onde não se consiga resfriar o ar, seria possível conseguir conforto térmico só com perda de calor por radiação ou por troca radiante. Entretanto, o efeito do resfriamento é potencializado pela convecção natural. Isto faz com que o ar frio desça por gravidade e também resfrie o ar por convecção. Este efeito praticamente não acontece com o teto quente, pois o ar quente fica estagnado próximo ao teto e não desce. Portanto, para o teto quente praticamente não se consegue aquecer $o$ ar nas partes próximas ao piso, principalmente se a altura for muito alta.

No caso dos painéis radiantes para resfriamento, não existe tanta assimetria de radiação e quando existe esta assimetria de certa forma, é benéfica ao condicionamento de ar, pois ela provoca uma situação desejada, isto é, cabeça mais fria e pés mais quentes. Esta situação acontece pelo efeito da convecção decorrente da movimentação do ar frio do teto para o piso gerando um resfriamento indireto do ar do ambiente. A corrente de ar resultante desta movimentação não chega a causar desconforto local devido ao baixo gradiente de temperatura. Este fenômeno é muito semelhante nas demais alturas, de forma que se verifica um baixo perfil de estratificação de temperatura resultando em uma grande homogeneidade de temperatura do ar no ambiente.

Para esta análise, existem especificações e métodos contidos na norma de padrões de conforto e padrões de stress que subdividem os ambientes em dois tipos: O primeiro, do tipo $\mathrm{C}$, refere-se às medições executadas em ambientes moderados, próximos do conforto. O segundo, do tipo $S$, refere-se às medições executadas em ambientes sujeitos a estresse térmico. As medições de conforto térmico do tipo $\mathrm{C}$ e as medições de stress térmico do tipo $\mathrm{S}$ podem ser classificadas de duas formas: Ambientes homogêneos são aqueles onde as variações nos valores das variáveis físicas no espaço ao redor da pessoa são inferiores a $5 \%$, isto é, o a relação do desvio padrão pela média de temperatura do ar deve ser menor que $5 \%$ 
(DP/Media < 5 \%). Em outras palavras, um ambiente pode ser considerado "homogêneo", do ponto de vista bioclimático, se em um dado momento suas variáveis físicas ao redor da pessoa possam ser consideradas praticamente constantes. Ambientes heterogêneos são aqueles onde as variações nos valores das variáveis físicas no espaço ao redor da pessoa são superiores a $5 \%$.

O sistema de condicionamento de ar do tipo "teto frio" ainda é pouco estudado no Brasil e seu emprego ainda é pouco expressivo, quando seu uso poderia ser mais difundido devido ao fato de apresentar características muito positivas de conforto térmico (SODEC, 1999). Já em outros países, principalmente em países nórdicos e na Europa Central, como, por exemplo, na Alemanha, existem várias estudos sobre este tipo de sistema, principalmente relacionados ao conforto térmico, qualidade do ar e eficiência energética.

Com relação ao Conforto Térmico, são listados alguns estudos:

Loveday et al (2002) realizou pesquisas experimentais sobre conforto térmico com voluntários em uma sala com condicionamento de ar do tipo "teto frio" e ventilação por deslocamento (displacement ventilation). Foi mostrado que o modelo de conforto térmico de Fanger, de acordo com o ISO 7730 (1994), pode ser usado sem modificações para as previsões de conforto térmico de trabalhadores com atividades sedentárias em escritórios equipados com tais sistemas.

Matsuki et al (1999), através de um trabalho experimental, apresentou uma relação entre a temperatura operativa e a sensação térmica de sujeitos exposto a um sistema de condicionamento de ar tradicional à baixa temperatura e a um sistema de resfriamento com painéis radiantes. Sua análise sugeriu um sistema híbrido combinando os dois sistemas mencionados integrados com um sistema de armazenamento de gelo. Ele constatou que a velocidade do ar do sistema "teto frio" é menor que a do sistema tradicional, e o intervalo de temperatura operativa ${ }^{1}$ de $26,6^{\circ} \mathrm{C}$ a $26,9^{\circ} \mathrm{C}$ no sistema "teto frio" pode produzir um conforto equivalente ao do sistema tradicional somente a ar no intervalo de temperatura de $25,7^{\circ} \mathrm{C}$ a $26,9{ }^{\circ} \mathrm{C}$. Constatou também que a temperatura radiante média (MRT) no mês de agosto no Japão, local do experimento, foi $1,6{ }^{\circ} \mathrm{C}$ menor que a temperatura ambiente no sistema de resfriamento radiante, enquanto que, no sistema convencional, o MRT foi $1,6^{\circ} \mathrm{C}$ maior que a temperatura ambiente.

Assim, verificou que o efeito do resfriamento radiante com painéis radiantes em relação ao sistema tradicional foi de aproximadamente $3,2^{\circ} \mathrm{C}$. Também verificou que 
mesmo no mês de junho, mês de verão, com clima tipicamente quente e úmido, este sistema foi bastante satisfatório, porque conseguiu manter o nível de umidade relativa do ar em um nível baixo, diminuindo-se o risco de condensação.

Com relação à Qualidade do ar, algumas pesquisas interessantes foram desenvolvidas nesta área como a de Niu (1994), onde foram feitas análises de conforto térmico e o efeito da distribuição de contaminantes. Para isso, foi feito um modelamento computacional de um espaço através de simulação de dinâmica térmica e emprego de técnicas de CFD (Computactional Fluid Dynamics) com três opções de sistema de condicionamento de ar: um sistema de ventilação por deslocamento convencional; um sistema de "teto frio" com ventilação por deslocamento e um sistema de "teto frio" com fornecimento de ar frio pelo teto. Os resultados da simulação numérica indicaram que o "teto frio" diminui o gradiente de temperatura enquanto que manteve uma eficiência de ventilação principalmente a uma carga próxima de $50 \mathrm{~W} / \mathrm{m}^{2}$ de área de andar. Por meio da análise dos vetores das velocidades do ar e dos padrões de distribuição de poluentes, foi constatado que o efeito do fornecimento de ar frio pelo teto a baixa velocidade juntamente com o sistema de placas frias foram muito eficazes na recirculação e retirada de poluentes dentro do ambiente. Constatou-se também que a combinação deste sistema com o sistema de ventilação por deslocamento permite um melhor desempenho em termos de conforto térmico e eficiência de ventilação com uma carga térmica interna de $50 \mathrm{~W} / \mathrm{m}^{2}$. Constatou-se também que as eficiências de conforto térmico e ventilação do "teto frio" foram quase equivalentes àquelas da ventilação por deslocamento quando se tinha uma carga térmica interna de $25 \mathrm{~W} / \mathrm{m}^{2}$.

Behne (1999) fez um estudo sobre qualidade do ar e gradiente vertical de temperatura do ar, e sugeriu uma combinação do sistema de "teto frio" com sistema de ventilação mista para redução dos níveis de poluentes, tais como o $\mathrm{CO}_{2}$, Compostos Orgânicos Voláteis (VOCs) e odores. Seus resultados mostraram que quando uma porção da carga de resfriamento é removida e substituída por um novo fornecimento de ar, existe um aumento da qualidade do ar na zona "Ocupada".

Entretanto, alguns pesquisadores como Imanari et al (1999), Miriel et al (2002), Sodec (1999), Stetiu (1999) e Niu et al (1995) fizeram estudos principalmente enfocando vantagens relacionadas à sua viabilidade econômica.

Imanari et al (1999) investigou várias características do sistema de painéis de teto radiante e suas aplicações práticas para edifícios de escritórios. Foi feita uma 
comparação entre o sistema de "teto frio" com o sistema de condicionamento de ar tradicional em termos de conforto térmico e consumo de energia. Os resultados de seus estudos mostraram que o primeiro sistema é capaz de criar um gradiente vertical de temperatura do ar menor e um ambiente mais confortável do que o sistema convencional. Ele constatou que ao utilizar o sistema do tipo "teto frio" em um dos três andares do edifício simulado, o consumo de energia foi reduzido de $10 \%$.

Miriel et al (2002) desenvolveu um modelo para simulação com o programa TRNSYS, utilizando como base um estudo experimental com resultados de desempenho, conforto térmico e consumo de energia. Ele observou que além das qualidades fundamentais do sistema de painéis no teto com água gelada, como o conforto acústico e térmico, a técnica permitiu uma redução de $10 \%$ no consumo de energia.

Sodec (1999), em seu estudo comparativo dos sistemas VAV e "teto frio", comparou vários parâmetros para a determinação de sua influência no custo e constatou que o sistema de "teto frio" incorreu em um custo menor de energia e uma exigência menor de espaço em relação ao sistema VAV, principalmente em uma variação de carga específica de 45 a $55 \mathrm{~W} / \mathrm{m}^{2}$.

Já Stetiu (1999), em seu estudo para estimar o potencial de economia de energia e potências de pico em edifícios comerciais nos EUA, mostrou que, empregando-se o sistema de "teto frio" ao invés do sistema tradicional somente a ar, houve uma economia média de $30 \%$ no consumo de energia e $27 \%$ na demanda de potência de pico devido ao condicionamento do espaço. 


\section{DESCRIÇÃO DO OBJETO DE ESTUDO}

Para a boa compreensão do experimento faz-se necessário descrever três aspectos básicos que compõem o objeto de estudo desta pesquisa, que são: "Ambiente Experimental", "Sistema de Condicionamento de ar" e "Sistema de Automação e Controle".

\subsection{AMBIENTE EXPERIMENTAL}

O ambiente experimental é o Laboratório para Ensino de CAD do Departamento de Engenharia da Construção Civil da Escola Politécnica da USP (Figs. 1 e 2). Trata-se de uma sala de aula para alunos de graduação em Engenharia, atendendo a cerca de 800 alunos por ano. $O$ ambiente possui geometria retangular com uma área de piso de aproximadamente $180 \mathrm{~m}^{2}$. O pé direito da sala mede $2,75 \mathrm{~m}$. As paredes são de alvenaria e divisórias, e o acesso é feito por duas portas de vidro de $10 \mathrm{~mm}$ de espessura. As janelas são de vidros simples, localizam-se na face oposta à das portas e perfazem um total $25 \mathrm{~m}^{2}$ de área envidraçada. $O$ teto da sala é composto por placas metálicas de alumínio de $0,78 \mathrm{~m}^{2}(0,625 \mathrm{~m} \times 1,25 \mathrm{~m})$ cada uma. O forro e a laje de teto delimitam um espaço (Plenum) de $40 \mathrm{~cm}$ de altura. Nesse forro existem 36 pontos de iluminação com 2 lâmpadas fluorescentes de 32 W cada uma, 6 grelhas de retorno nas laterais da sala e 15 difusores de ar distribuídos no teto. Além disso, este forro possui um projetor localizado quase no centro da sala que é direcionado a um telão localizado na face da porta, a meia distância das duas portas. Este telão se encontra na posição central de dois quadros brancos, e possui quatro pontos de iluminação de $32 \mathrm{~W}$ em sua parte superior.

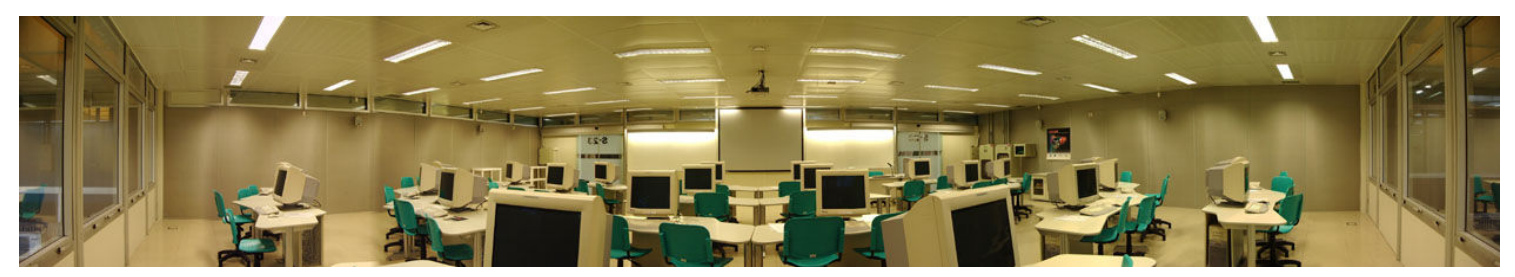

Figura 1 - Ambiente Experimental - Vista pelo fundo da sala 


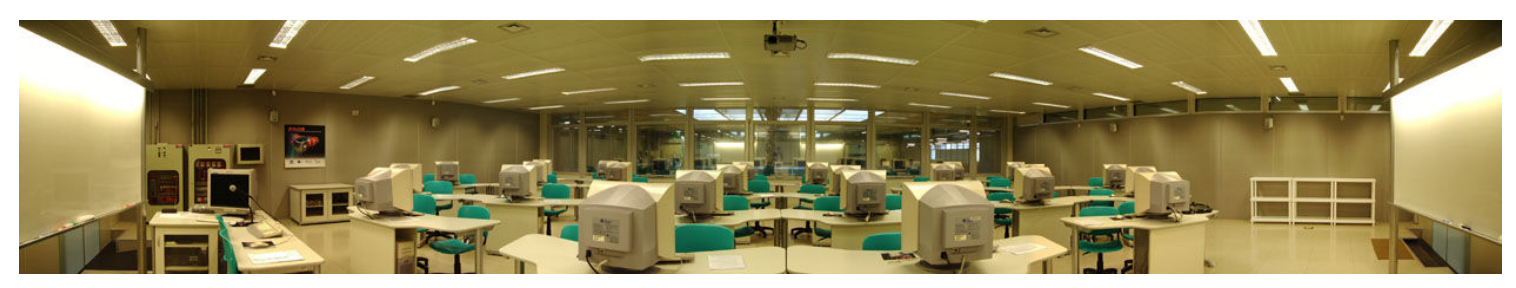

Figura 2 - Ambiente Experimental - Vista pela frente da sala

Dentro do ambiente existem 25 mesas, 50 cadeiras e 26 computadores, sendo que cada estação de trabalho de alunos possui um computador e duas cadeiras, com exceção da mesa do professor que possui dois computadores.

A sala possui um sistema de condicionamento de ar do tipo expansão indireta, com sistema de controles automatizados, que mantém o resfriamento do ambiente através de placas metálicas resfriadas com suprimento de água gelada e insuflamento de ar frio pelo teto. Este sistema será descrito com mais detalhes a seguir.

\subsection{SISTEMA DE CONDICIONAMENTO DE AR}

O sistema de condicionamento de ar instalado no ambiente experimental é formado por um sistema misto composto por dois tipos de circuitos: circuitos de água e circuitos de ar. Os dois circuitos representam duas estratégias de resfriamento de ar diferentes. A primeira é representada pelo sistema de climatização do tipo "teto frio", cujo funcionamento necessita da água gelada como meio de transferência de calor dentro de seus elementos estruturais. A segunda estratégia é representada pelo sistema convencional de resfriamento de ar com Fan Coil. Ambos os circuitos serão descritos com mais detalhes nos itens seguintes. 


\subsubsection{CIRCUITO DE ÁGUA}

No circuito de água, esta é utilizada como meio de transferência de calor, e seu emprego depende de uma planta de circulação de água gelada composta de dois circuitos hidráulicos, cada um contendo equipamentos específicos, conforme ilustra a Fig. 3:

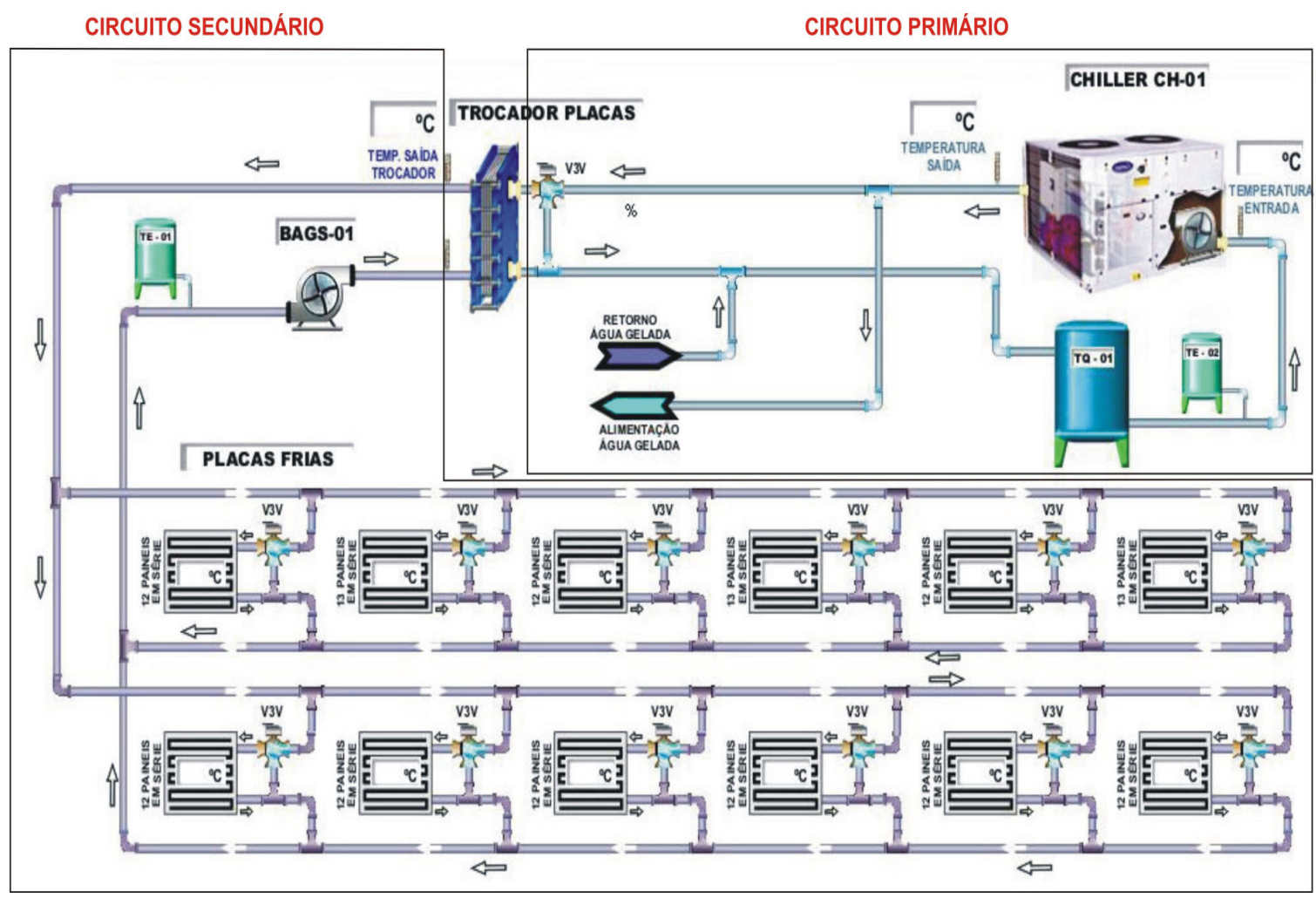

Figura 3 - Esquema dos circuitos hidráulicos: primário e secundário*

* Fonte: Ilustração retirada da Tela de Interface do Aplicativo ComfortView

\section{A. Circuito Primário:}

É composto por uma Central de Água Gelada (CAG), por um trocador de calor a placas e por 2 Fan Coils, sendo um de 4 TR de capacidade nominal de resfriamento para a sala objeto de estudo e outro de 7,5 TR, para a climatização de outro laboratório, que não faz parte desta pesquisa. 
A CAG, representada pela Fig. 4, é composta por um resfriador de liquido (chiller), com compressores do tipo centrífugo e condensadores resfriados a ar, com capacidade nominal de resfriamento de $18 \mathrm{TR}$, e sistema de partida soft-starter. No circuito primário há também dois tipos de tanques (Fig. 5), o primeiro denominado de "tanque de inércia metálico" (TQ), com capacidade de 1500 litros, cuja função é diminuir a temperatura da água que entra no chiller, por meio da mistura da água que retorna da válvula de 3 vias do trocador de calor e da água que retorna do Fan Coil. O segundo tipo, com duas unidades, denominado de "tanque de expansão" (TE), com capacidade de 135 litros, tem a função de compensar as perdas de água na linha decorrentes de vazamentos ou expurgo de água.

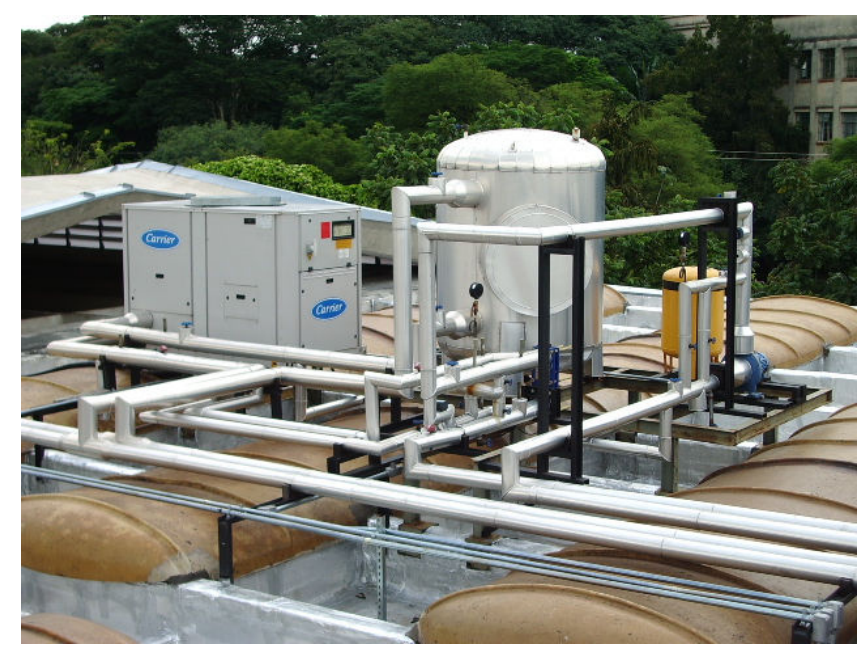

Figura 4 - Central de Água Gelada (CAG) - Circuito hidráulico primário

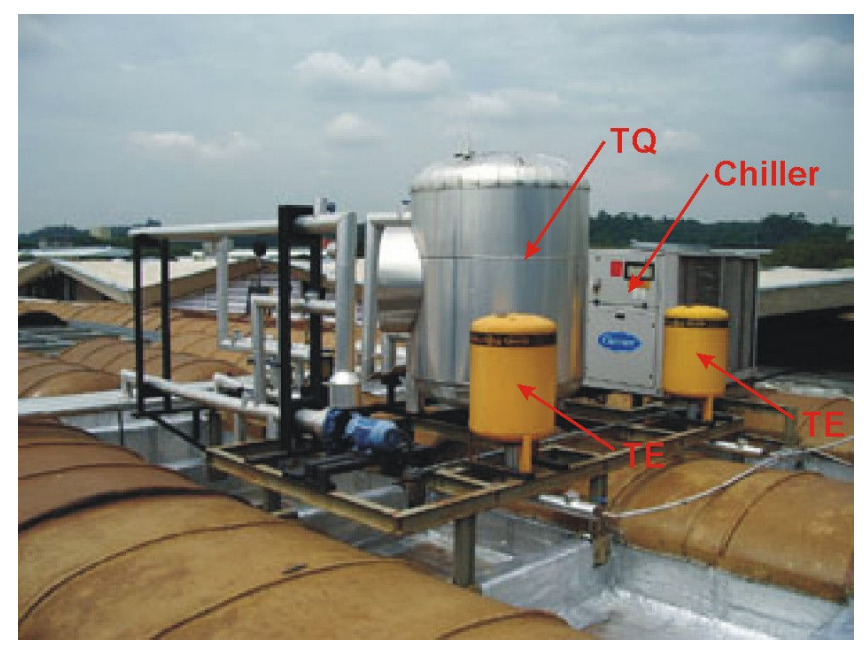

Figura 5 - Tanques de Expansão (TE) e Tanques de Inércia Metálico (TQ) 
O chiller fornece água gelada diretamente para os 2 Fan Coils, citados anteriormente, e para um trocador de calor a placas, em regime de vazão de água variável, regulada por uma válvula de 3 vias. A temperatura da água do circuito secundário é diminuída de acordo com a modulação desta válvula que se localiza na entrada do trocador de calor, do lado do circuito primário, mandando mais ou menos água proveniente do chiller de acordo com a exigência de temperatura da água no circuito secundário. A Fig. 6 mostra os ramais de água gelada, fornecidos pelo chiller e que atendem ao circuito primário do Fan Coil e ao circuito secundário das placas de forro.

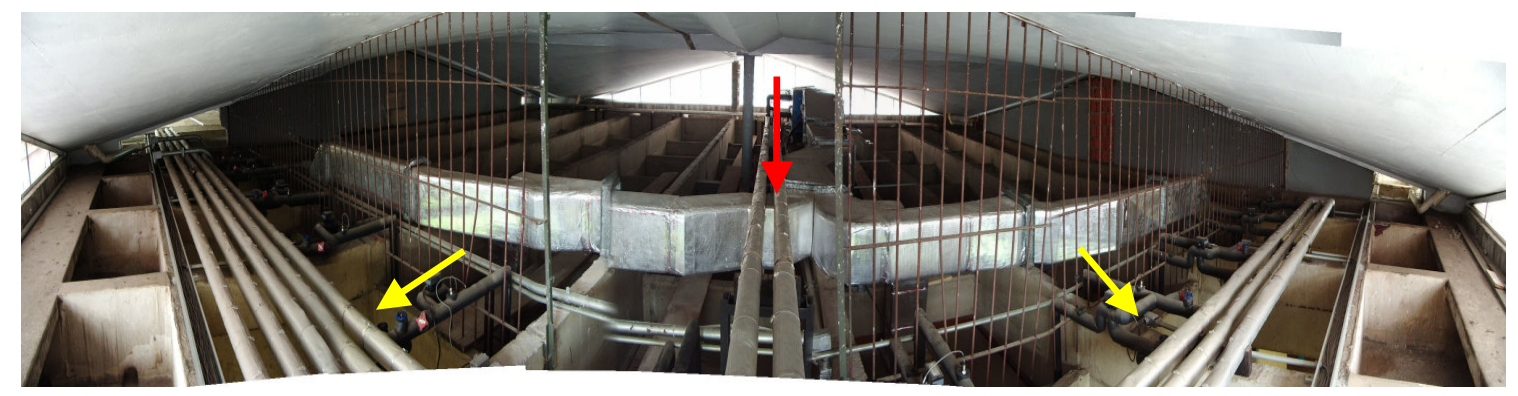

Figura 6 - Circuitos hidráulicos primário e secundário - Ramais de água gelada que atendem ao Fan Coil (seta vermelha) e às placas de forro (setas amarelas)

A existência dos dois circuitos hidráulicos e do trocador de calor a placas devese ao fato de que cada circuito trabalha de forma mais eficiente em uma dada temperatura e vazão. No circuito hidráulico primário, a água gelada proveniente do chiller se mantém a uma temperatura de aproximadamente 6 a $7^{\circ} \mathrm{C}$ e atende tanto os 2 Fan coils quanto ao trocador de calor a placas. A vazão de água gelada que entra no trocador de calor a placas é de até $1,6 \mathrm{~m}^{3} / \mathrm{h}$ e as temperaturas de entrada e saída de água, respectivamente, em torno de $6,0^{\circ} \mathrm{C}$ e de $11,5^{\circ} \mathrm{C}$. Por outro lado, no circuito secundário, a água entra no trocador de calor a uma temperatura de cerca de 16 a $18^{\circ} \mathrm{C}$, com uma vazão de até $4,5 \mathrm{~m}^{3} / \mathrm{h}$ e sai com 14 a $16^{\circ} \mathrm{C}$ aproximadamente.

Por uma questão estrutural de composição dos circuitos de placas radiantes existentes e para evitar os efeitos da condensação, verificou-se que a temperatura da água que circula por entre as suas serpentinas é de aproximadamente $8 \mathrm{~K}$ maior que a temperatura da água que é fornecida aos Fan coils. Para isso, o trocador de calor a placas foi inserido entre os dois circuitos de forma que o circuito de placas 
radiantes não receba a água gelada diretamente do chiller, pois o mesmo fornece água a uma temperatura tal que poderia provocar a condensação nas serpentinas das placas.

O trocador de calor a placas, representado pela Fig. 7, é construído com placas planas lisas ou com alguma forma de ondulações e representa um elemento de interligação do circuito primário com o secundário. Sua função é de diminuir a temperatura da água do circuito hidráulico secundário através de um mecanismo de troca de calor por contato indireto, isto é, os fluidos do circuito primário e secundário permanecem separados e o calor é transferido continuamente através de uma parede, pela qual se realiza a troca térmica (Fig. 8). O tipo de transferência de calor é do tipo direto, onde há um fluxo contínuo de calor do fluido quente ao frio através de uma parede que os separa. Não há mistura entre eles, pois cada corrente permanece em passagens separadas.
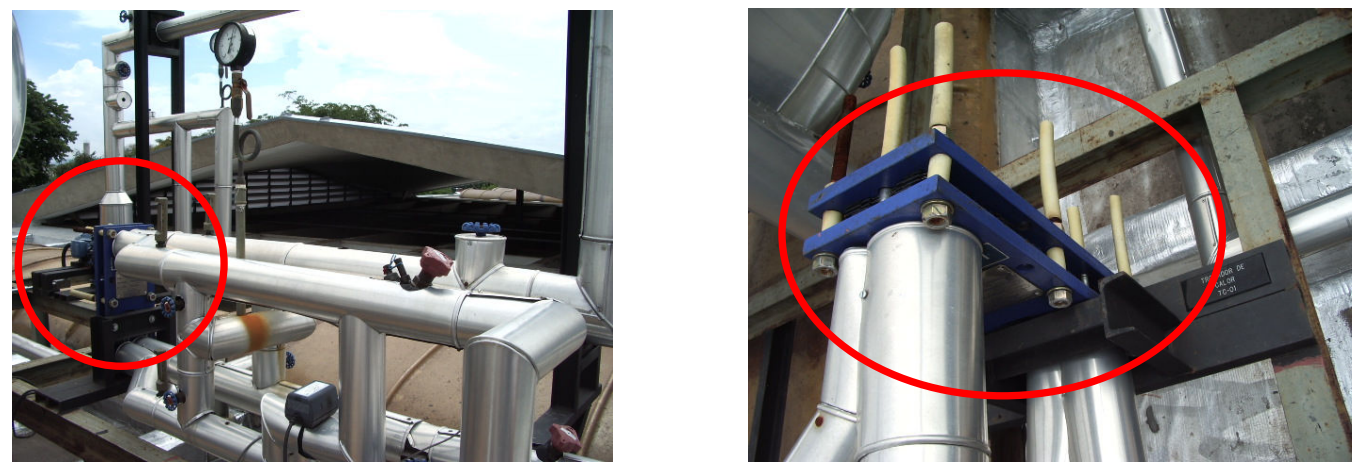

Figura 7 - Circuito hidráulico primário - Trocador de calor a placas

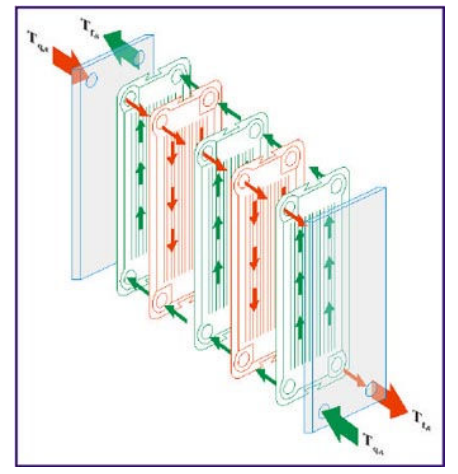

Figura 8 - Esquema interno de transferência de calor do trocador de calor a placas *

* Fonte: TROCADORES DE CALOR. Apresenta descrição de trocadores de calor a placas.

Disponível em: <http://www.ucs.br/ccet/demc/craltafi/TrocadoresdeCalor.pdf>. Acesso em: 13 ago.2007. 
Tanto a CAG quanto o trocador de calor a placas estão localizados na cobertura do edifício, a aproximadamente $8 \mathrm{~m}$ de distância da cobertura do laboratório, enquanto que o Fan Coil que atende o ambiente experimental está localizado exatamente em cima do laboratório, no espaço entre o forro e a cobertura.

\section{B. Circuito Secundário:}

É composto pelo circuito fechado de placas radiantes, por uma Bomba de Água Gelada (BAG), de 3,0 HP de potência e por um "tanque de expansão" (TE) com capacidade igual à do circuito hidráulico primário.

A Fig. 9 mostra um circuito de placas de forro metálicas (placas radiantes) com as serpentinas acopladas e interligadas.

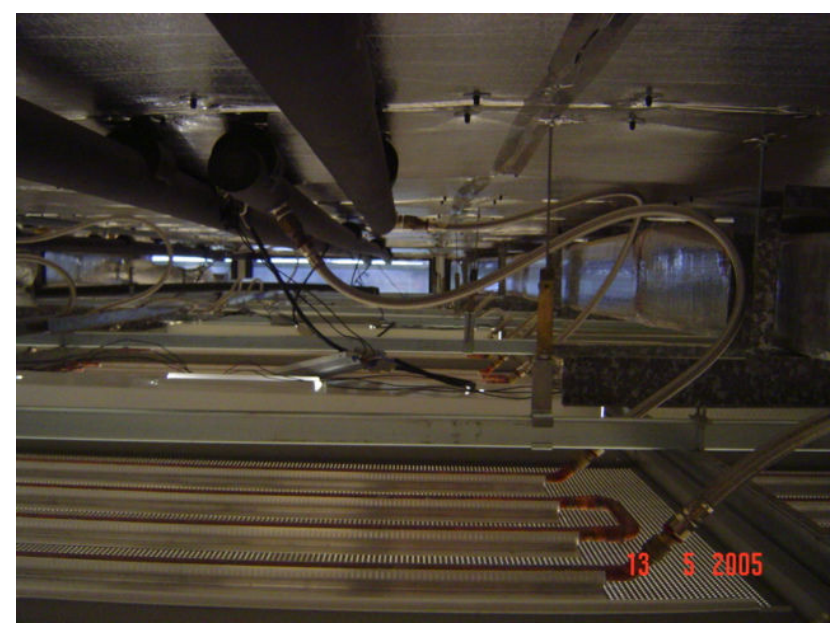

Figura 9 - Circuito hidráulico secundário - Placas de Forro Metálicas com Serpentinas

Conforme mostrado a Fig. 3, o circuito das Placas Radiantes é composto por um conjunto de 12 circuitos fechados, esquematizados na Fig. 12, sendo que cada circuito, por sua vez, é formado por um conjunto de 12 ou 13 painéis radiantes agrupados em conjuntos de 6 placas ligadas em série ligadas em série, por onde é feita a circulação de água gelada. Esta água que circula pelas serpentinas acopladas aos painéis radiantes do circuito secundário é impulsionada pela Bomba de Água Gelada (BAG), ilustrada pela Fig. 10, e resfriada pelo trocador de calor a 
placas que, por sua vez, recebe água gelada do chiller. A compensação de água na linha, pela perda decorrente de expurgo de água ou por qualquer outro motivo, é feita pelo "tanque de expansão" (TE), conforme ilustra a Fig. 11.

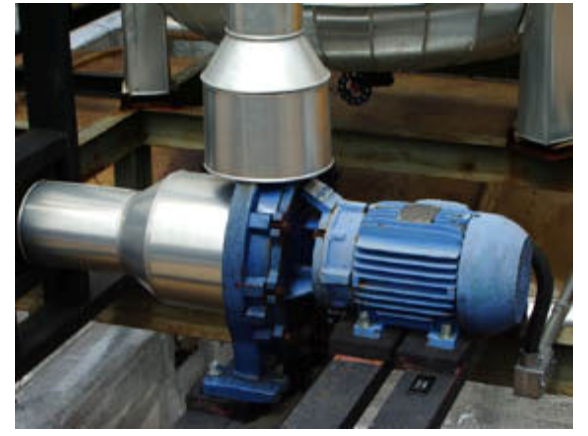

Figura 10 - Circuito hidráulico secundário Bomba de Água Gelada (BAG)

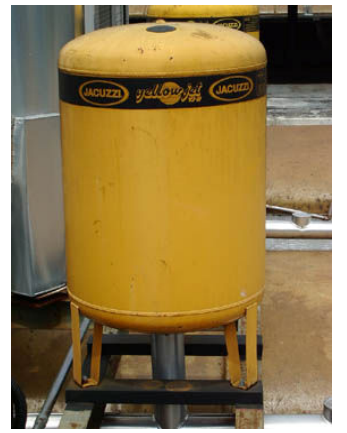

Figura 11 - Circuito hidráulico secundário Tanque de expansão" (TE)

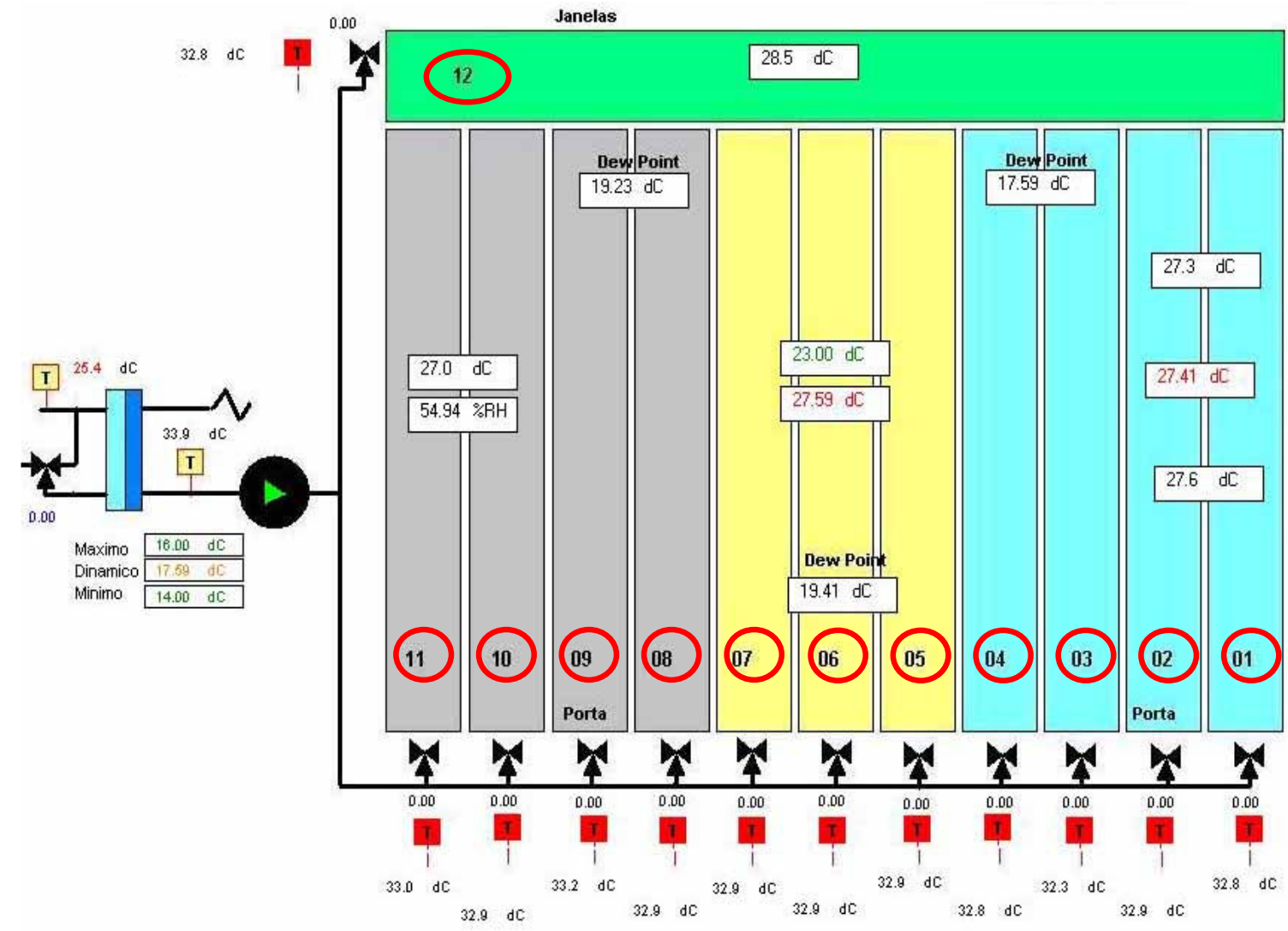

Figura 12 - Circuitos de Água Gelada *

* Fonte: Ilustração retirada da Tela de Interface do Aplicativo ComfortView 
Cada circuito, que atende a um conjunto de 12 placas de forro metálico ativadas por serpentinas de cobre é controlado por uma válvula motorizada que mantém a vazão de água gelada de acordo com a necessidade de retirada de uma quantidade de carga térmica originada principalmente das fontes abaixo do teto. Adicionalmente, os circuitos foram agrupados em conjuntos, formando quatro zonas térmicas com a finalidade de melhorar o controle e o desempenho do sistema de condicionamento de ar em função de possíveis variações de carga térmica dentro do ambiente. Estas zonas térmicas possuem controles de vazão de água independentes, ou seja, o ambiente é dividido em 4 zonas térmicas, como se fossem constituídos de 4 blocos "independentes" com as respectivas cargas térmicas. Duas zonas térmicas estão localizadas nas laterais da sala e são constituídas de quatro circuitos cada uma; uma zona térmica localizada no centro do ambiente compreende três circuitos e uma zona térmica localizada na porção em frente às janelas, apenas um circuito.

As duas zonas térmicas, localizadas nas faces laterais da sala, formadas pelo conjunto de circuitos numerados de 1 a 4 e, esquematicamente pintada de cor azul, e pelo conjunto de circuitos de 8 a 11, pintada de cor cinza, são atendidas, cada uma, por 4 válvulas. Estas válvulas são acionadas por atuadores que modulam de acordo com um sistema de controle que faz a comparação do valor da medição de temperatura do ar medida em cada zona térmica com o setpoint de temperatura do ar, previamente estabelecido. De forma análoga, a zona térmica central, formada pelo conjunto de circuitos 5, 6 e 7 é atendida por 3 válvulas que desempenham a mesma função descrita acima e é controlada em função da média das temperaturas do ar medidas pelos sensores das demais zonas. Por último, a zona térmica localizada na porção em frente às janelas, possui apenas o circuito 12 e é atendido por uma única válvula.

Em cada uma das 4 zonas térmicas existem cerca de 6 mesas e 12 cadeiras. Portanto, cada zona térmica recebe, em média, a carga térmica de 6 computadores e 12 pessoas, quando ocupados os lugares, além da iluminação localizada no teto. A exceção fica com a zona térmica próxima à janela, que além de possuir também as 6 mesas com 6 computadores e 12 cadeiras, pode sofrer alguma influência da radiação térmica externa, sendo, por isso, atendida por um circuito de placas radiantes dedicado, ao longo de toda a extensão da fachada posterior com janelas.

Por exemplo, se o sistema de controle verificar através das medições de temperatura efetuadas por seus sensores que certa zona térmica está com carga 
térmica alta, e necessita ser resfriada para manter as condições estipuladas de setpoint de temperatura, este tentará suprir esta necessidade com uma carga de resfriamento equivalente, através da abertura proporcional das válvulas de água fria nos circuitos de painéis radiantes localizados nesta zona. Não se deve esquecer que como o ambiente é amplo e sem baias ou divisórias, existe uma interação constante da carga térmica e da umidade entre estas zonas térmicas, o que faz com que as zonas vizinhas sejam influenciadas por qualquer alteração que por ventura venha a existir em qualquer ponto da sala.

\subsubsection{CIRCUITO DE AR}

Para evitar os efeitos da condensação, uma vez que no ambiente da sala existe calor latente, há introdução de ar resfriado e desumidificado, que também contribui tanto para o condicionamento do ar, trocando calor por convecção, quanto para a qualidade do ar, com a renovação. O resfriamento do ar é feito por meio de um Fan Coil dimensionado para o equivalente calor latente, ilustrado na Fig. 13. Este ar frio é distribuído através de uma rede de dutos e difusores de teto (Respectivamente, Figs. 14 e 15) em 15 pontos uniformemente distribuídos no teto. O equipamento Fan Coil possui as capacidades nominais: serpentina de 4 TR e ventilador de $3000 \mathrm{~m}^{3} / \mathrm{h}$. O sistema fornece ao ambiente vazão de ar variável com controle de temperatura e umidade.

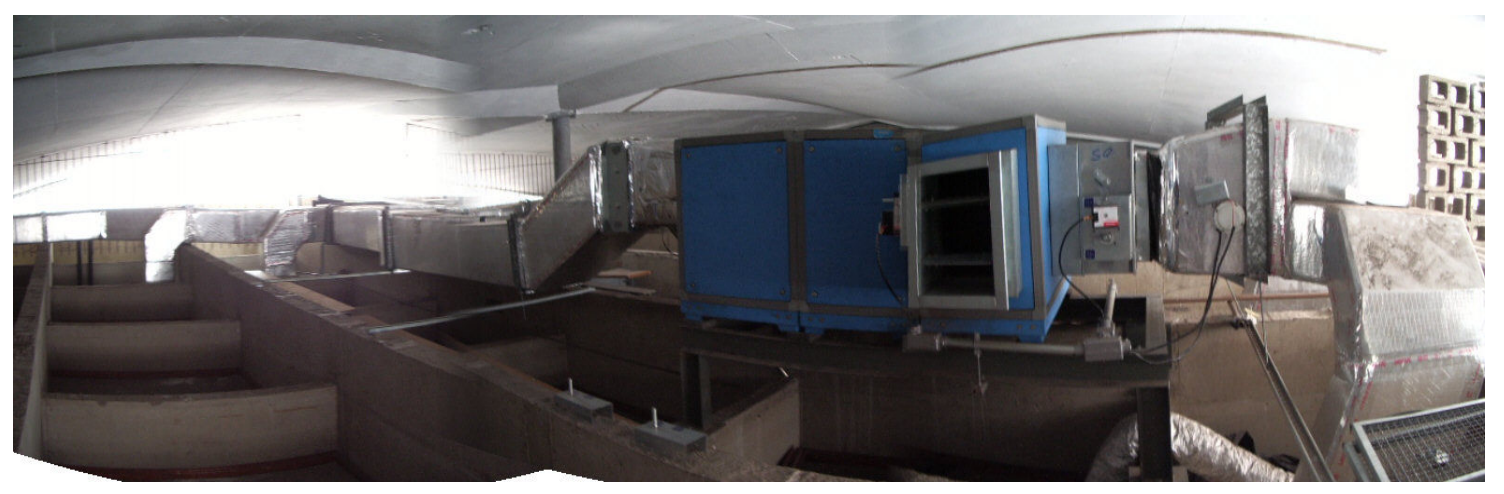

Figura 13 - Fan Coil e dutos de distribuição e retorno de ar 


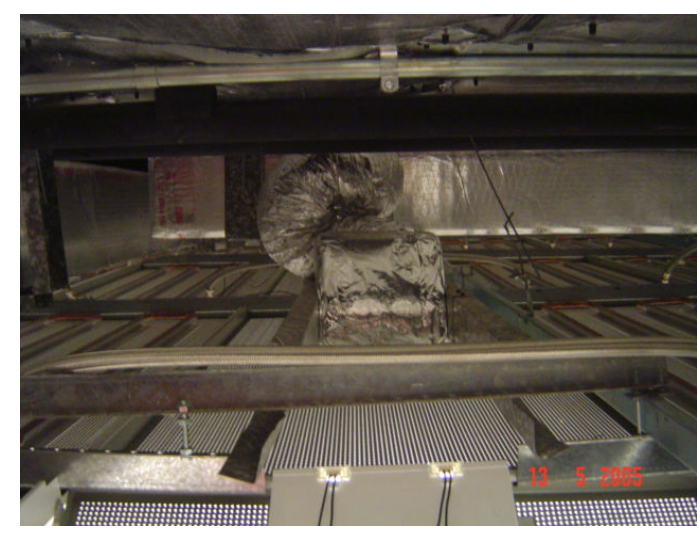

Figura 14 - Dutos de insuflamento de ar

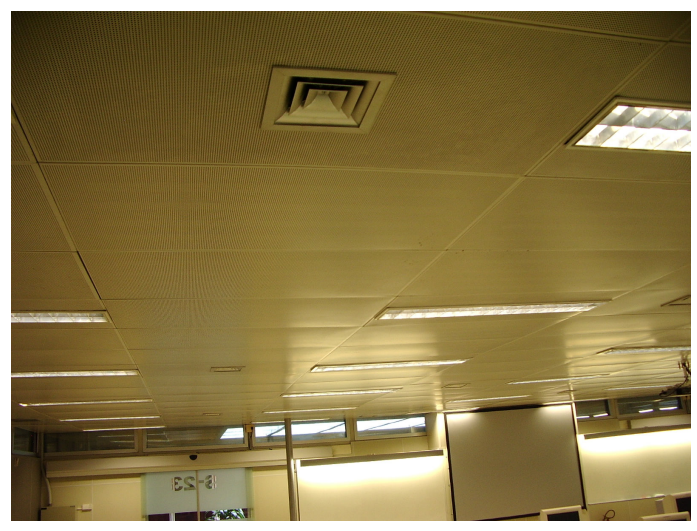

Figura 15 - Difusores de Teto

A extração do volume de ar do ambiente ocorre através de 6 grelhas de retorno localizadas nas placas de forro laterais do ambiente experimental (Fig. 16), e igual volume de ar tratado é introduzida no ambiente, através de difusores (Figs. 14 e 15), para manter o ciclo em operação. $\mathrm{O}$ ar insuflado é geralmente uma mistura de ar "usado" (retorno) e resfriado com ar "novo" tomado ao exterior, garantido a renovação permanente do ar ambiente. Esta renovação atua duplamente: uma parte dos poluentes é retirada do ambiente com a parcela do ar expurgado; simultaneamente, a concentração dos poluentes remanescentes é diluída pela introdução de ar novo.
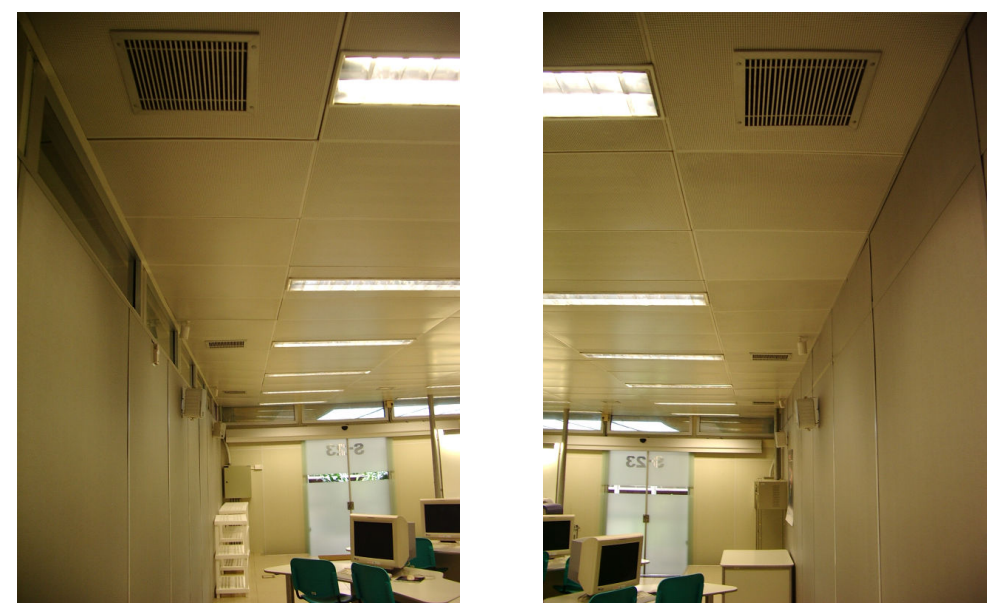

Figura 16 - Grelhas de retorno de ar 


\subsection{SISTEMA DE AUTOMAÇÃO E CONTROLE}

Antes de descrever o sistema de automação e controle do objeto de estudo desta pesquisa, faz-se necessária uma breve explicação conceitual sobre esse aspecto.

O sistema de automação e controle envolve alguns processos e componentes que normalmente são utilizados, tais como, elementos sensores, elementos atuadores, sistemas de controle, sistemas de supervisão e aquisição de dados e outros métodos que utilizem os recursos da eletrônica, da mecânica e da informática. Entretanto, seu uso tem sido bastante difundido no processo de "automatização" de edificações devido à necessidade e demanda de sistemas e equipamentos mais eficientes e econômicos. O sistema de climatização de ambientes, principalmente em áreas grandes, onde requerem Centrais de Água Gelada (CAG), emprega-se bastante o sistema de automação e controle em seu processo de funcionamento. Seu uso pode ser observado também em controles automáticos de iluminação, controle de acesso e controle de qualidade do ar em ambientes que necessitem total controle da temperatura, umidade e qualidade do ar, tais como laboratórios ou salas de cirurgia em hospitais.

Conceitualmente, um sistema de controle é um dispositivo, ou um grupo deles, que gerencia o comportamento de um ou mais equipamentos, sendo que alguns dispositivos ou sistemas podem ou não ser controláveis. Ele pode ser uma interconexão de componentes conectados ou relacionados, de tal maneira, a comandar, controlar ou ajustar a si mesmo ou outro sistema. Em outras palavras, são aqueles que unem o resultado da leitura dos elementos sensores com a ação dos elementos atuadores. Eles recebem as informações enviadas pelos sensores para saber qual é a atual posição do processo, enviam esta informação para o processador que executa uma lógica pré-definida e, só então, gera uma resposta para os atuadores, de modo que a situação atual se iguale ou se aproxime da situação desejada.

Para desenvolver sistemas de controle, são utilizados dispositivos como microcontroladores, CLP's e microprocessadores, entre outros. Estes dispositivos possuem em comum: portas de entradas e saídas (I/O), que servem para realizar a comunicação com os dispositivos periféricos (sensores e atuadores). Estas portas de 
I/O também podem ser destinadas a realizar a comunicação com outros sistemas, a fim de fornecer dados de leitura dos sensores ou até receber instruções externas para os atuadores. Além destes dispositivos, os sistemas de controle se baseiam na modelagem matemática de diversas naturezas, analisando o seu comportamento dinâmico, e usando a teoria de controle para calcular os parâmetros de um controlador que faça o sistema evoluir da forma desejada.

Quanto ao sistema de automação, este inclui fazer um processo manual se tornar um processo automático. A automação acontece realmente quando toda uma linha de produção ou um processo funciona do começo ao fim sem a intervenção humana, agindo apenas pelo controle das próprias máquinas e controladores. Este funcionamento pode ser feito através de programação horária de ligamento e desligamento, assim como todo o controle de temperatura e umidade do ambiente pode ser automático e dependente de parâmetros pré-determinados de temperatura do ar.

No caso desta pesquisa, o sistema de automação e controle aplicado às instalações de ar condicionado da sala experimental possui vários objetivos, tais como: regular o sistema de condicionamento de ar para se obter conforto no ambiente; evitar efeitos nocivos aos ocupantes e fazer com que os equipamentos de ar condicionado operem de forma eficiente.

Basicamente, para manter as condições desejadas de conforto, as variáveis ambientais a serem controladas direta ou indiretamente são: a temperatura, a umidade, a velocidade do ar e a concentração de dióxido de carbono, que influencia na qualidade do ar.

Resumidamente, para se fazer o monitoramento e controle destas variáveis, 0 sistema de controle de condicionamento de ar é constituído basicamente de três partes essenciais:

- Os elementos de campo: Responsáveis pelas medições das variáveis ambientais. São compostos por sensores ou transdutores de temperatura do ar ambiente, sensor de temperatura do ar para dutos, sensor de umidade relativa do ar, sensor de ponto de orvalho, sensor de concentração de dióxido de carbono, termostatos e relés monitores de corrente. 
- O sistema de aquisição de dados: Representado pelos controladores. É responsável por coletar os dados de medições dos sensores através de suas entradas analógicas e digitais e armazená-los em sua memória de massa. Além disso, os controladores, quando bem configurados, também fazem o tratamento destas informações e comandam atuadores de válvulas e dampers, de forma a gerar um conjunto de "ações" necessárias para manter as condições ambientais conforme determinado pelo setpoint. Esses controladores podem funcionar automaticamente de modo "Stand-Alone", isto é, independentemente do sistema de supervisão. Isso é feito através de programas contendo rotinas de controle, com setpoints pré-estabelecidos de temperatura, umidade, vazão e concentração de dióxido de carbono. No caso deste ambiente experimental, os controladores funcionam em "Stand-Alone", porém, trabalham em conjunto com o sistema de supervisão predial que se encontra em uma sala vizinha ao laboratório.

- O sistema supervisório: Representa um elemento adicional e essencial para a avaliação de eficiência do sistema de automação e controle. Ele faz o monitoramento dos dados recebidos pelos controladores e permite mudanças de configurações de setpoints, quando o painel de automação está configurado para acesso remoto, na chave local/remota. É representado pelo aplicativo ComfortView.

Estas três partes essenciais do sistema de automação e controle utilizado na pesquisa também podem ser classificadas basicamente em hardware e software.

\subsubsection{HARDWARE}

Quanto ao hardware, um sistema de controle eletrônico aplicado ao sistema de ar condicionado é composto basicamente por: sensores, controladores e atuadores, complementados por dispositivos (painéis) indicativos de valores, dispositivos de interface (computadores) e elementos de controle final (válvulas, dampers, acessórios, inversores de freqüência, etc.). 
O funcionamento do sistema de controle depende das características de cada uma das partes; entretanto, as três primeiras são mais significativas para o estudo desse sistema, sendo, por isso, abordadas nesta pesquisa.

- Elemento Sensor: É o dispositivo responsável pela leitura de valores das variáveis e fornecimento de informações (sinais) referentes às mudanças de condições ao controlador; isto é, as condições de operação do sistema de ar condicionado variam de acordo com alterações de valores das variáveis intrínsecas do sistema bem como, com as referentes aos ambientes interno e externo. Estes transdutores ou sensores convertem uma forma de energia em outra transformando as informações ambientais em dados mensuráveis. O sinal de saída de um sensor eletrônico é geralmente muito baixo, sendo necessária sua amplificação. Para isto, são usados amplificadores que, na maioria dos casos, utilizam circuitos em ponte para condicionar um sinal (ampliação e linearização) para que este fique adequado para transmissão e uso do controlador. Os sensores podem ser de posição, de temperatura, de nível, de pressão, dentre outros. Eles enviam para o processador a atual situação do processo para que este possa tomar as medidas necessárias. No quadro 1 é apresentada a especificação técnica dos principais sensores do sistema, aqui denominados "fixos", utilizados na pesquisa, conforme Figs. 17 a 21.

Quadro 1 - Especificação dos Sensores Fixos

\begin{tabular}{|c|c|c|c|c|}
\hline Sensores Fixos & Tipo & $\begin{array}{c}\text { Faixa de } \\
\text { Medição }\end{array}$ & Incerteza & Unidades \\
\hline $\begin{array}{c}\text { Temperatura de bulbo } \\
\text { seco no ambiente } \\
\text { (ST1, ST2, ST3 e ST4) }\end{array}$ & $\begin{array}{c}\text { Termo-resistor, } \\
\text { Com barreira } \\
\text { radiante }\end{array}$ & 0 a $90^{\circ} \mathrm{C}$ & $0,1^{\circ} \mathrm{C}$ & 4 \\
\hline Umidade Relativa (SU) & Tipo capacitivo & 5 a $98 \%$ & $2 \%$ & 1 \\
\hline $\begin{array}{c}\text { Sensor de temperatura } \\
\text { do ponto de orvalho do ar } \\
\text { de retorno }\end{array}$ & Termoresistor & 0 a 90 & $0,1^{\circ} \mathrm{C}$ & 3 \\
\hline $\begin{array}{c}\text { Sensor de concentração } \\
\text { de Dióxido de carbono }\end{array}$ & Não fornecido & Não fornecido & Não fornecido & 1 \\
\hline $\begin{array}{c}\text { Sensores de temperatura } \\
\text { do ar para dutos }\end{array}$ & Termoresistor & 0 a 90 & $0,1^{\circ} \mathrm{C}$ & 2 \\
\hline
\end{tabular}




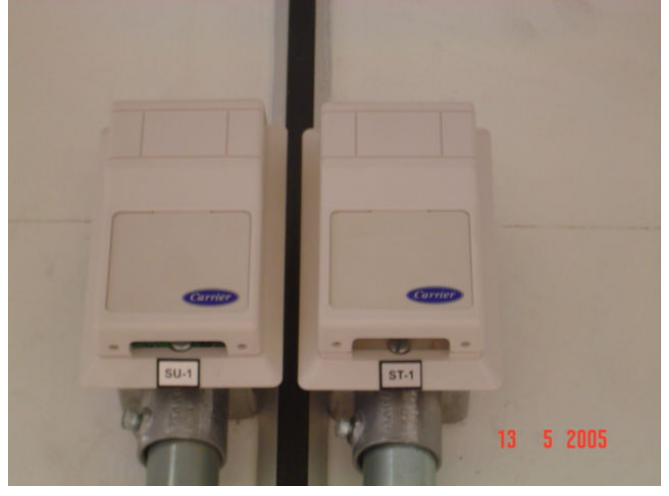

Figura 17 - Sensores Fixos SU1 e ST1

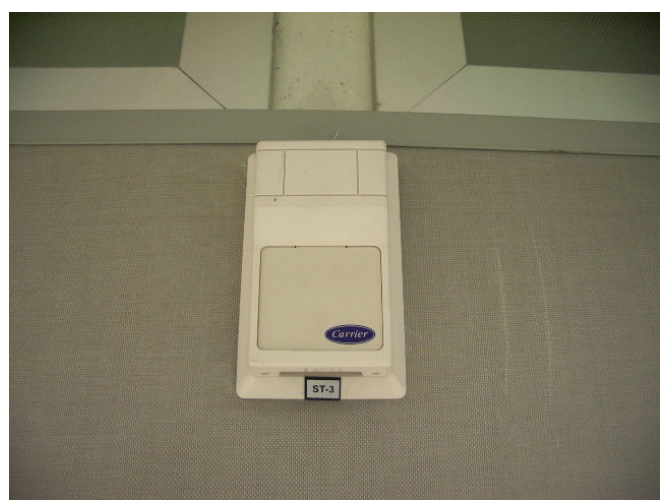

Figura 19 - Sensor Fixo ST3

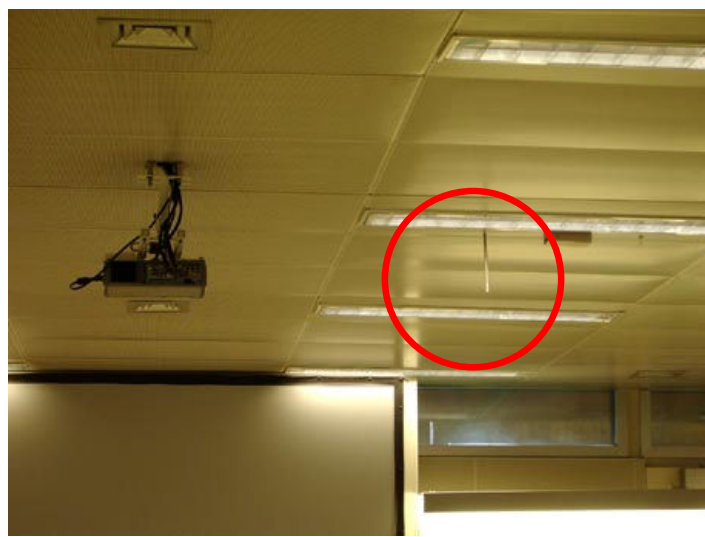

Figura 21 - Sensor de Ponto de Orvalho no teto da sala

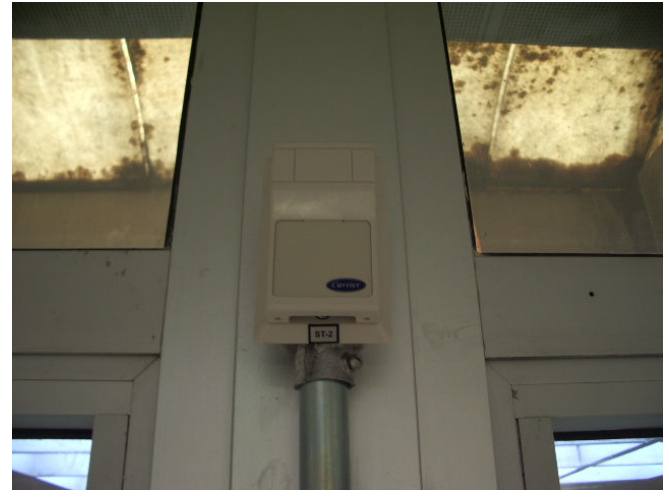

Figura 18- Sensor Fixo ST2

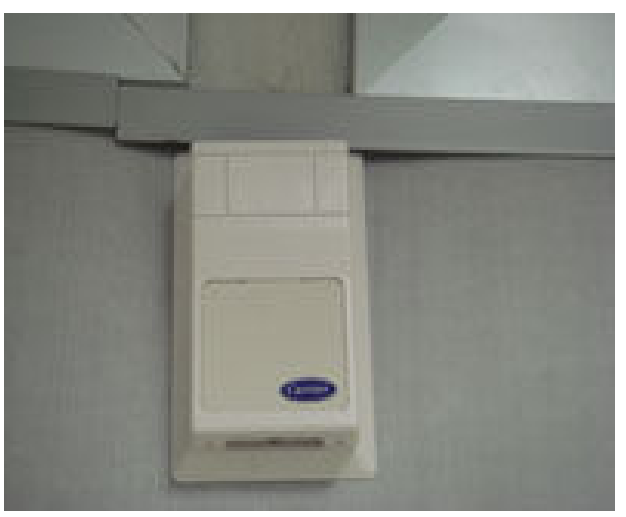

Figura 20 - Sensor Fixo ST4 
- Controlador: Representa o "cérebro" do sistema de automação. Ele coleta os dados de medições provindos dos sensores, através de suas entradas analógicas e/ou digitais e os armazena em suas memórias de massa, fazendo o processo de aquisição de dados. Além disso, o controlador eletrônico geralmente recebe o sinal do amplificador, mas pode receber o sinal diretamente do sensor, amplificá-lo e/ou condicioná-lo de forma que podem processar essas informações por meio da comparação com seus setpoints préestabelecidos e tomar as decisões cabíveis quando necessárias. Assim, ele pode emitir sinais de controle em suas portas de saída, tais como, comandar atuadores de válvulas ou dampers. Ele pode funcionar Stand-Alone, isto é, consegue tomar decisões automaticamente através de uma pré-programação de suas atividades elaboradas em um programa contendo rotinas de controle. Da mesma forma, podem ser configuradas para trabalhar conforme uma configuração horária de funcionamento. As Figs. 22 e 23 mostram respectivamente o painel de automação e os controladores.

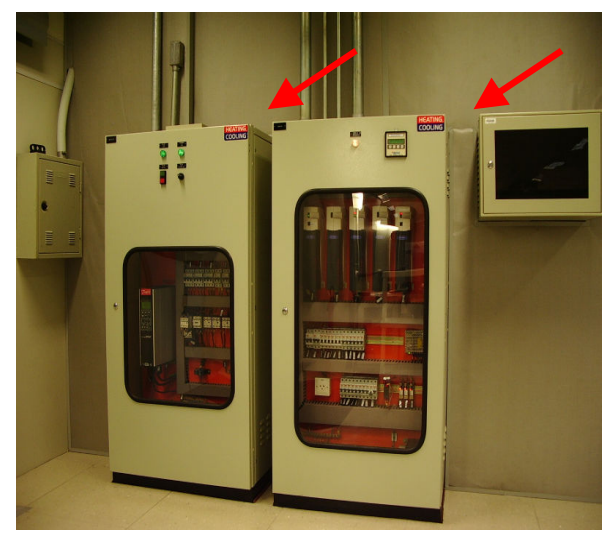

Figura 22 - Painéis de automação

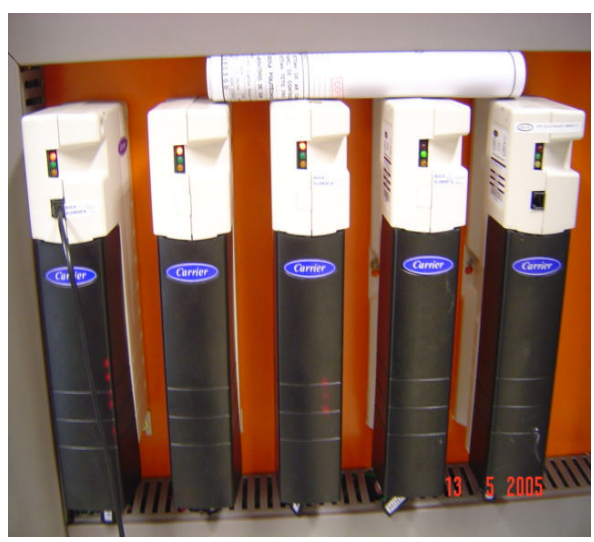

Figura 23 - Controladores

- Atuadores: Elementos atuadores são aqueles que produzem movimento, atendendo a comandos que podem ser manuais ou automáticos. Como exemplo, pode-se citar atuadores de movimento induzido por cilindros pneumáticos (pneumática) ou cilindros hidráulicos (Hidráulica) e motores (dispositivos rotativos com acionamento de diversas naturezas). Atuadores, relés e transdutores são dispositivos que usam os sinais de saída dos controladores (tensão, corrente ou contatos de relés) para realizar uma função 
física nos elementos finais de controle (por exemplo, a partida de um ventilador e a modulação de uma válvula). Os atuadores podem ser divididos em dispositivos que promovem ações de duas posições e de modulações. Os dispositivos de duas posições, como relés, partidas de motores e válvulas solenóides têm somente dois estados discretos (por exemplo, ligado/desligado, aberto/fechado) e fazem a interface dos controladores e os elementos finais de controle. Os atuadores de modulação utilizam o sinal do controlador para ajustar os elementos finais de controle. Por exemplo, uma válvula modulada controla a quantidade de água gelada que entra na serpentina de tal forma que o suprimento de ar frio seja apenas o suficiente para igualar a temperatura do ar a um "setpoint" de temperatura desejada. Os atuadores de modulação mais comuns aceitam um sinal de tensão variando de 0 a 10 Vcc ou 2 a 10 Vcc ou um sinal de corrente de 4 a $20 \mathrm{~mA}$. Outra forma de atuador requer um sinal intermitente (pulsante) para desenvolver as funções de modulação. No caso desta pesquisa, foram utilizados atuadores com controle de tensão de 0 a 10 Vcc, ilustrado na Fig. 24.
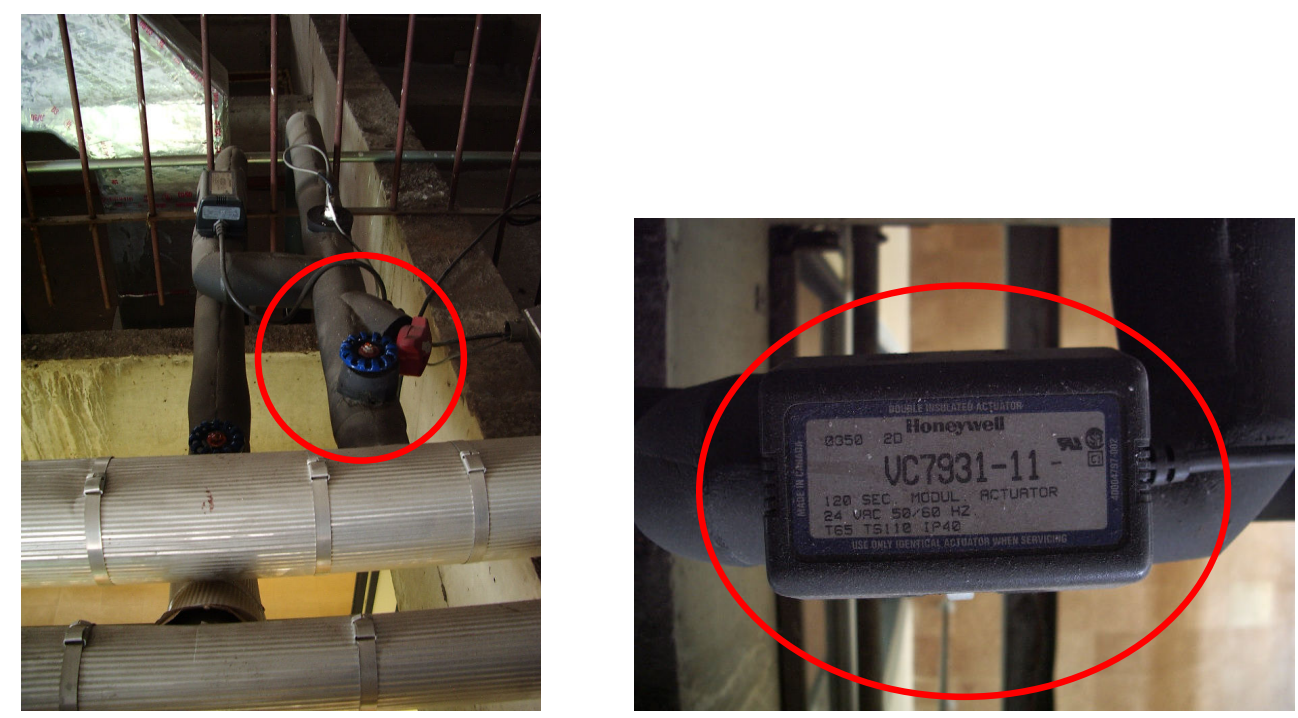

Figura 24 - Atuadores de válvulas de controle de vazão de água das serpentinas das placas radiantes 


\subsubsection{SOFTWARE}

Quanto ao software, residente nos controladores, este representa a "inteligência" do sistema de automação e controle. Sua função é de monitorar e fazer o controle automático dos dispositivos que influenciam as variáveis ambientais, como por exemplo, atuadores de válvulas e dampers e inversores de freqüência. Esta "inteligência" é baseada em uma programação com rotinas de controle, configurados de forma a manterem as condições de conforto térmico estabelecidas.

De forma mais detalhada, no caso deste laboratório, um sistema de controle consiste do seguinte procedimento: um elemento sensor que, ao identificar o valor de uma determinada variável, em tempo real, emite um sinal elétrico ("input") a um controlador que o processa, comparando-o com um parâmetro pré-determinado com as condições desejadas ("setpoint"); este produz um sinal de saída ("output") que é enviado a um elemento atuador para que seja realizada a operação necessária. Todo este processo é denominado de "Loop" de controle e pode ser esquematizado conforme a Fig. 25.

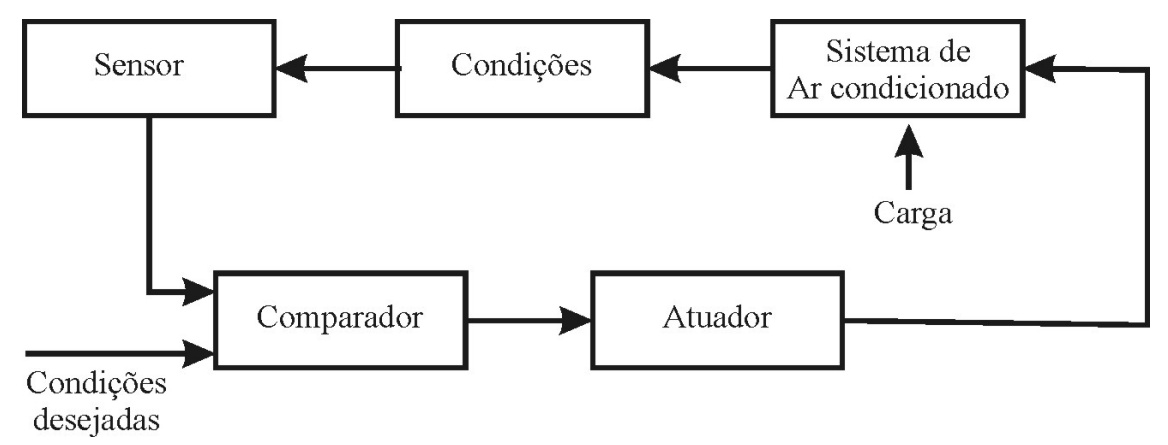

Figura 25 - Esquema de um loop básico de um sistema de controle * Fonte: Stoecker; Jones (1985)

Os sinais utilizados no sistema de controle são de natureza analógica ou digital e são manipulados com diferentes modos de controle, para que sejam atingidos os propósitos de controle de temperatura e umidade do ambiente. No caso da parte hidráulica do sistema, estes controles, por sua vez, dependem do controle de abertura e fechamento de 12 válvulas motorizadas que enviam água gelada às serpentinas das placas radiantes e de 1 válvula motorizada que envia água gelada às serpentinas do Fan Coil. 
No sistema de controle desta pesquisa, foram utilizados, os Controles dos tipos: Proporcional $(\mathrm{P})$, Proporcional - Integral $(\mathrm{PI})$ e Proporcional - Integral - Derivativo (PID). Para um melhor entendimento desses modos de controle, no ANEXO A é apresentada uma descrição sucinta de cada modo de controle.

De forma esquemática, a Fig. 26 apresenta o Loop de Controle de temperatura do ar do laboratório. Um elemento sensor, ao identificar o valor da variável temperatura, emite um sinal elétrico ("input") a um controlador que processa a informação, comparando-a com um parâmetro pré-determinado ou condição desejada ("setpoint"); este produz um sinal de saída ("output") que é enviado a um elemento atuador para que seja realizada a operação necessária.

Portanto, o Software deve trabalhar de forma integrada com todos os dispositivos (Hardware), constituindo o sistema de automação e controle da sala, promovendo o resfriamento do ambiente através de um sistema eficiente de condicionamento de ar. Porém, para se atingir este objetivo, os controladores devem possuir em sua memória alguns algoritmos que correspondem à programação lógica de funcionamento do sistema de automação e controle. Estes algoritmos estão organizados em diferentes Rotinas de Controle, tendo cada uma delas uma função específica, como será mostrado a seguir.

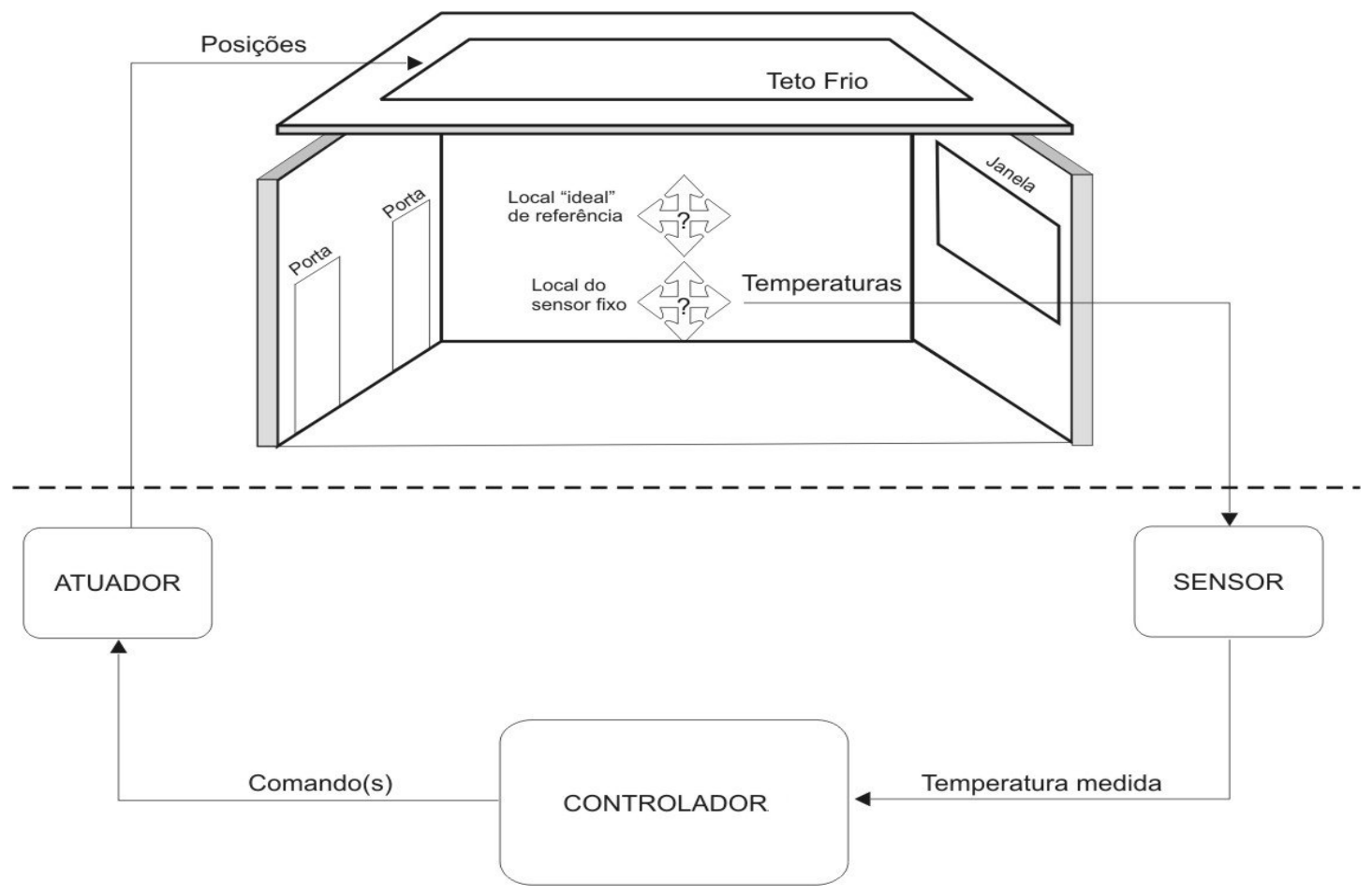

Figura 26 - Esquema de loop de controle de temperatura do ambiente 


\subsubsection{ROTINAS DE CONTROLE}

Especificamente para este estudo de caso, para o resfriamento do ambiente, o sistema de controle utiliza basicamente três tipos de rotinas de controle: A) o primeiro tipo, que se refere às rotinas para controle do circuito hidráulico, no que tange ao suprimento de água gelada das placas de forro; B) o segundo tipo, que é responsável pelo suprimento de ar resfriado; C) o terceiro tipo, que se encarrega de fazer o controle da umidade relativa do ar.

\section{A. Rotinas de Controle do Suprimento de Água Gelada}

O resfriamento do ambiente acontece principalmente através do sistema de circuitos hidráulicos das placas radiantes e seu funcionamento é regido por meio dos seguintes controles:

- Controle da válvula e temperatura do trocador de placas (do lado do chiller): O controle de temperatura da água no circuito secundário é determinado pela temperatura e vazão de água gelada proveniente do chiller e que chega até o trocador de calor a placas. Como a temperatura da água que sai do chiller é pré-estabelecida, o controle de temperatura da água do circuito secundário é função direta da vazão de água gelada que entra no trocador a placas pelo circuito primário. Para isso, existe uma rotina baseada no algoritmo Adaptive (PID) que controla a modulação de uma válvula de três vias, localizada na entrada do trocador a placas (do lado do chiller). Esta rotina controla a abertura / fechamento da válvula para manter uma determinada temperatura da água na saída do trocador de calor (que alimenta os circuitos das placas de forro). Essa temperatura da água na saída do trocador a placas é determinada em função de um setpoint dinâmico, que corresponde ao menor valor instantâneo das 3 temperaturas de ponto de orvalho do ar de retorno lido pelos três sensores instalados no sistema. Assim, a modulação da válvula de 3 vias é função das temperaturas de ponto de orvalho do ambiente. $O$ algoritmo controla 
o percentual de abertura da válvula baseado no cálculo efetuado com os valores lidos e a ação é liberada pelo status de uma bomba secundária localizada na linha hidráulica secundária. Se a bomba não estiver ligada, a válvula do trocador permanece fechada.

\section{- Controle da vazão de água gelada nas serpentinas do "teto frio": Para o} controle da vazão de água gelada nas serpentinas das placas radiantes, há um Loop de controle para cada válvula de cada circuito de placas radiantes. A modulação das válvulas depende da comparação da temperatura do ar medida pelo sensor fixo no ambiente, individualmente para cada região que compreende um conjunto de circuitos de água gelada, e do setpoint de temperatura do ar estabelecido para o ambiente. Existe ainda outro controle, chamado de "controle de segurança" que determina o fechamento das válvulas por completo. Ele depende da temperatura de ponto de orvalho do ar de retorno. Essas rotinas são descritas mais detalhadamente a seguir.

- Rotina de controle de abertura das válvulas dos circuitos de água gelada dos painéis radiantes: $O$ controle de abertura das válvulas funciona independentemente para cada zona térmica, isto é, para cada zona térmica, que agrupa um conjunto de circuitos, os algoritmos de controle denominados de Adaptive (PID) monitoram a média das temperaturas do ar da sala, coletadas pelos sensores fixos especificados para cada zona, e os compara com o setpoint de temperatura do ar da sala. Com estes valores, o algoritmo gera um valor de percentual de abertura das válvulas referentes aos circuitos desta zona térmica. A liberação do funcionamento do algoritmo é feita pelo ponto de controle LMSTxx, onde xx representa o número do sensor de temperatura da água de retorno de cada circuito. As temperaturas médias do ar em cada zona térmica podem ser obtidas de acordo com o seguinte critério: Para a zona térmica, composta pelos circuitos 1, 2, 3 e 4 das placas do teto, a média das temperaturas do ar da sala é obtida pela média aritmética das temperaturas coletadas pelos sensores fixos ST3 e ST4. Para os circuitos 5, 6 e 7, a média da temperatura da sala é dada pela média aritmética das temperaturas coletadas pelos sensores ST1, ST2, ST3 e 
ST4. Nos circuitos 8, 9, 10 e 11, a temperatura média da sala é a própria temperatura coletada pelo sensor ST1. E por último, no circuito 12 das placas do teto (circuito da janela) a temperatura média é o valor de temperatura coletado pelo sensor ST2. A abertura da válvula ocorrerá no instante em que a temperatura média da sala, obtida por meio destes critérios for maior que o setpoint de temperatura. Caso a temperatura média da sala for menor, a válvula é fechada através do modo de controle PID.

- Rotina de bloqueio das válvulas dos circuitos das placas do teto: Como medida de segurança para evitar o efeito indesejado da condensação do ar, existe o fechamento forçado das válvulas dos circuitos das placas do teto. Este bloqueio é feito pela comparação da temperatura da água de retorno do circuito com a temperatura de ponto de orvalho da respectiva zona térmica. Quando a temperatura da placa estiver abaixo ou igual ao valor da temperatura do ponto de orvalho, o ponto de bloqueio é acionado e o algoritmo de controle da válvula comanda o percentual da mesma a $0 \%$, fechando-a totalmente.

\section{B. Rotinas de controle do suprimento de ar frio}

O suprimento de ar resfriado no ambiente depende basicamente de 3 fatores: ela depende da temperatura pré-estabelecida para a saída do chiller, para alimentação das serpentinas do Fan Coil; da vazão de água que atende as serpentinas do Fan Coil e também depende da vazão de ar impulsionada pelo seu ventilador.

Este último fator é conseqüência tanto das condições de operação do ventilador, que tem sua rotação controlada por um variador de freqüência (controle de vazão de ar) quanto pela modulação de dampers (de ar externo, retorno e mistura). A modulação de dampers é importante para que sejam mantidas adequadas às pressões nos dutos e nos espaços como também a qualidade do ar, no que diz respeito à taxa de renovação. 
As duas rotinas responsáveis pelo controle da vazão de água gelada nas serpentinas do Fan Coil e pelo controle da vazão de ar frio estão descritas abaixo:

- Rotina de controle da válvula de água gelada das serpentinas do Fan Coil: O algoritmo Adaptative (PID) controla a vazão de água gelada que alimenta as serpentinas do Fan Coil através da modulação de uma válvula de três vias, em função de um diferencial de temperatura entre o setpoint de temperatura do ar e a temperatura do ar do ambiente. Esta última é estimada pela medição da temperatura do ar no duto de retorno do Fan Coil. Quando a temperatura do ar de retorno for maior que o setpoint de temperatura, e o status do Fan Coil estiver ativo, o algoritmo mandará "abrir" a válvula através de seu controle PID, Caso contrário, a válvula se manterá fechada.

- Rotina de controle da vazão de ar do Fan Coil: A vazão de ar do Fan Coil depende da velocidade de rotação do ventilador que, por sua vez, depende da freqüência determinada pelo variador de freqüência. O programa de controle do variador de freqüência se baseia na leitura da vazão de ar do Fan Coil e no setpoint dinâmico SPTVAZAO determinado por um algoritmo de controle Adptative (PID). Este setpoint dinâmico de vazão de ar corresponde a um percentual do setpoint de vazão máxima acrescido do valor do setpoint de vazão mínima, sendo os valores máximos (3000 m3/h) e mínimos $(2000$ m3/h) prédefinidos. Por outro lado, este algoritmo considera que este percentual é função de um diferencial de temperatura entre o setpoint de temperatura do ar e a média aritmética das 4 temperaturas da sala medidas pelos quatro sensores fixos de temperatura.

O controle da vazão de ar do Fan Coil e o controle de temperatura do ambiente são feitos em duas rotinas independentes, como Loops de controle Mestre / Escravo. Nesse contexto, com a variação da temperatura do ar no ambiente, tem-se uma variação correspondente no setpoint dinâmico de vazão de ar, aumentando ou diminuindo o suprimento de ar frio no ambiente. 


\section{Rotina de controle de umidade}

O Loop de controle da umidade permite acionar uma resistência elétrica de aquecimento proporcional para gerar uma carga térmica adicional. Esse acionamento provoca um aumento na temperatura do ar a ser resfriado, forçando uma maior abertura da válvula de água gelada, provocando a desumidificação do ar.

De forma mais detalhada, a umidade do ar no ambiente é controlada pelo percentual de acionamento do variador de potência da resistência, determinado pelo algoritmo HUMID01, que varia de zero a 100\%, conforme a variação da umidade ambiente em relação ao seu setpoint SETPT03. O algoritmo é ativado caso seja habilitado pelo ponto de controle acionado por um programa chamado VRFQ que verifica qual a freqüência do variador do ventilador do Fan Coil. Este programa permite o aquecimento somente com um valor de freqüência de rotação do ventilador superior à freqüência mínima admitida. 


\section{MÉTODO DE TRABALHO}

O método utilizado para a determinação dos índices de ajuste em medidas efetuadas pelos sensores de temperatura do ar se baseia em um conjunto de procedimentos de avaliação de ambientes térmicos em regime permanente, adaptados para esta pesquisa, que foi em regime transiente. Os procedimentos e técnicas adotados seguem as recomendações das normas ISO 7726 (1998) e ASHRAE 55 (2004), como também alguns utilizados por Leite (2003), que propõem procedimentos de avaliação em regime permanente. Esses procedimentos atendem, num primeiro momento, às necessidades deste estudo experimental porque, durante as medições, o sistema permaneceu estável, promovendo condições térmicas no ambiente com variações insignificantes. Para o caso específico desta pesquisa, a temperatura do ar, que é medida através de sensores de temperatura nas paredes da sala, influencia diretamente o funcionamento do sistema de condicionamento de ar. Esta medição, por sua vez, pode sofrer as mais diversas influencias, como por exemplo, a quantidade de pessoas existentes no recinto, a carga térmica gerada pelos equipamentos, a temperatura e umidade do ar externo e a radiação solar.

Para comparar a eficiência da medição de temperatura do ambiente coletada pelos sensores na parede, procurou-se outra referência de temperatura na sala de forma que todo o ambiente foi termicamente mapeado.

As medições foram realizada no período de transição Outono-Inverno (entre os dias 14 e 21 de junho de 2007) sob seis condições térmicas internas diferentes (setpoints), tendo essas atividades sido realizadas com ou sem pessoas no ambiente, identificadas nas tabelas de resultados, como "ambiente ocupado/ desocupado" e "ambiente desocupado".

Posteriormente, no período de transição Primavera-Verão (entre os dias 13 de novembro e 3 de dezembro de 2007) a experiência foi repetida. Entretanto, como as condições de ocupação (pouca gente freqüentando o laboratório) não correspondiam às das medições anteriores; por isso, os resultados não foram analisados, uma vez que a comparação não seria adequada.

Ao final, o objetivo foi avaliar o comportamento dos índices de ajuste nas seis condições térmicas, de forma a se verificar a existência de um único valor ou um 
gráfico de tendência de ajuste para todos os setpoints de temperatura, o qual poderia ser adicionado no algoritmo de controle.

Para a coleta de dados foram designadas seis atividades que foram necessárias para se atingir os objetivos específicos estipulados na programação da pesquisa. As atividades são as seguintes:

A atividade 1 se refere ao estabelecimento das condições de contorno; a definição das variáveis a serem medidas e à definição dos pontos e períodos de medições para o experimento.

A atividade 2 trata da escolha dos equipamentos necessários à pesquisa, bem como da descrição dos processos de aquisição dos dados de medição in loco.

A atividade 3 explica como foi o processo de validação do método através de testes preliminares e a sua importância quanto à definição de detalhes e solução de problemas no processo de medição e atendimento aos objetivos.

A atividade 4 descreve o processo de coleta de dados no laboratório, isto é, quais foram os procedimentos de medição; como foi feito o planejamento e acompanhamento das condições de coleta. Por fim, explica como as informações das variáveis eram transmitidas entre os equipamentos de aquisição de dados.

O passo seguinte trata de procedimentos de apuração e apresentação dos dados, conforme o que se segue:

$\mathrm{Na}$ atividade 5 é explicado como foi feito o tratamento dos dados para se encontrar a temperatura mais representativa do ambiente ou "temperatura ideal". Por meio desta temperatura foi possível se determinar os índices de ajuste por setpoint e por altura e assim atingir o objetivo específico 1. Esta "temperatura ideal" também servirá para determinar a posição ou região que melhor represente as condições do ambiente na altura de conforto, chamado de "local ideal".

Por último, a atividade 6 é uma atividade complementar que foi adicionada à pesquisa para informar sobre quais foram as técnicas e processos utilizados para se realizar os objetivos específicos 2 e 3 . São apresentadas as informações sobre como os dados foram processados, as variáveis que foram analisadas e como os resultados serão apresentados. 


\subsection{ATIVIDADE 1 - DEFINIÇÃO DAS CONDIÇÕES DE CONTORNO PARA ELABORAÇÃO DO EXPERIMENTO}

As condições de contorno foram determinadas tendo-se em vista as características desta pesquisa, que analisa quantitativamente as condições térmicas de um ambiente atendido por um sistema misto de condicionamento de ar.

O método adotado se fundamentou em indicações das principais normas de conforto térmico: ISO 7730 (1994), ASHRAE Standard 55 (2004) e procedimentos da ISSO 7726 (1998). Estas normas recomendam que, para uma avaliação mais adequada do comportamento térmico do ambiente, as medições das principais variáveis ambientais sejam efetuadas sob certas condições de temperatura operativa, velocidade e umidade relativa do ar, dentro da zona de conforto proposta por elas. Neste trabalho, a temperatura operativa foi substituída pela temperatura do ar pela proximidade de valores, já constatada em pesquisas anteriores (LEITE, 2003), realizadas em ambientes similares ao desta pesquisa.

Da mesma forma, foram levadas em conta as características do ambiente de ocupação e a atividade do ocupante, já que são informações importantes para a determinação do "local ideal". Como os ocupantes da sala de aula se encontravam, a maior parte do tempo, sentadas e o tipo de atividade desenvolvida podia ser considerada como leve ou sedentária, as condições de contorno sugeridas pela ISO 7730 (1994), que trata das exigências recomendadas para conforto térmico foram semelhantes às utilizadas em ambientes de escritório devido a sua semelhança nestes aspectos. O quadro 2 representa os dados sugeridos por esta norma:

Quadro 2 - Condições de Contorno

\begin{tabular}{|c|c|}
\hline Temperatura do $\operatorname{ar}\left(\mathrm{t}_{\mathrm{a}}\right)\left[{ }^{\circ} \mathrm{C}\right]$ & $21,22,23,24,25$ e $26{ }^{\circ} \mathrm{C} ;$ \\
\hline Velocidade média do $\operatorname{ar}\left(\mathrm{V}_{\mathrm{a}}\right)[\mathrm{m} / \mathrm{s}]$ & $0,10<\mathrm{V}_{\mathrm{a}}<0,30 \mathrm{~m} / \mathrm{s}$ \\
\hline Umidade relativa do $\operatorname{ar}(\mathrm{UR}) \%$ & Aproximadamente $50 \%$. \\
\hline
\end{tabular}




\subsubsection{VARIÁVEIS A SEREM MEDIDAS}

Nesta pesquisa, foram feitas medições de duas variáveis ambientais de acordo com as normas da ASHRAE 55 (2004) e ISO 7726 (1998).

- Temperatura do ar $\left(\mathrm{t}_{\mathrm{a}}\right)$;

- Velocidade do ar $\left(\mathrm{V}_{\mathrm{a}}\right)$.

Todas as principais análises desta pesquisa serão enfocadas na variável temperatura, que deve atender aos propósitos das atividades 3, 4 e 5. Embora dados da velocidade do ar e umidade relativa do ar também foram coletadas para se verificar o atendimento às condições de contorno.

Adicionalmente outras variáveis foram coletadas para auxiliar nas análises dos dados das medições dos sensores móveis, tais como sensores de temperatura e umidade relativa do ar externo. E internamente, foram coletados valores de assimetria de radiação e temperatura de globo, cuja função, respectivamente, foi verificar a interferência da radiação solar no ambiente e a influência da convecção decorrente da temperatura das paredes, pisos e teto.

Paralelamente, outras variáveis foram medidas através de sensores de uso exclusivo do sistema de automação e controle, fixos no ambiente, tais como: umidade relativa do ar, concentração de dióxido de carbono e temperatura de ponto de orvalho. E externamente, alguns sensores fixos coletaram informações das seguintes variáveis: valores de temperatura da água que entra e sai do Chiller, temperatura de água de saída do trocador de calor a placas, temperatura de água gelada de retorno das serpentinas do Fan Coil e temperatura de água gelada de retorno das placas radiantes. 


\subsubsection{DEFINIÇÃO DOS PONTOS DE MEDIÇÃO}

Os pontos para a realização de medições foram divididos em pontos fixos e móveis. No caso especifico da variável temperatura, os pontos de medições fixos são os locais onde estão instalados os sensores de temperatura do sistema de automação e controle; os pontos de medição móveis são locais distribuídos ao longo do ambiente, previamente marcados, onde foram instalados os sensores dedicados às medições de temperatura e velocidade do ar para o mapeamento térmico do ambiente.

\section{A. Pontos de medições fixos}

Para controlar o sistema de condicionamento de ar em estudo, através do controle de suprimento de água gelada, ar resfriado e umidade, o sistema de automação e controle possui alguns sensores localizados em posições estrategicamente fixas dentro do ambiente ou em alguma tubulação de água ou duto de ar.

No sistema de automação e controle desta sala, o controle do suprimento de água gelada e de suprimento de ar resfriado depende principalmente dos valores de temperatura do ar coletados no ambiente através de quatro sensores fixos de temperatura denominados de ST1, ST2, ST3 e ST4. Eles estão posicionados na parede em quatro pontos distintos, a dois metros do piso, destacados na Fig. 27:

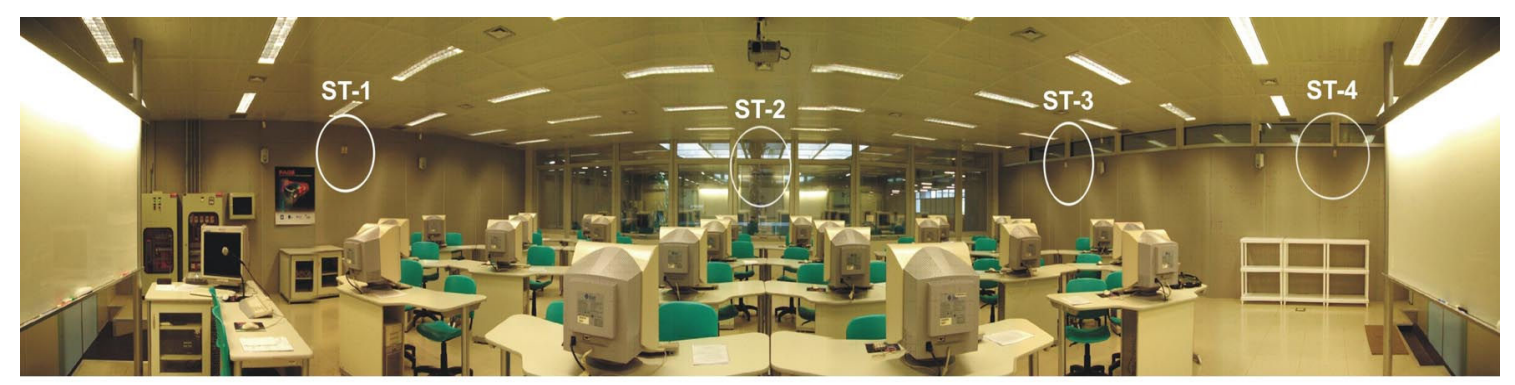

Figura 27 - Posicionamento dos sensores fixos nas paredes 
Pela Fig. 27, é possível se observar que existem três pontos nas paredes laterais da sala, onde se encontram os sensores ST1, ST3 e ST4 e um ponto na janela, onde está o sensor ST2. Em uma das paredes estão posicionados dois sensores de temperatura (ST3 e ST4), ao contrário da parede oposta e a da janela, que têm, respectivamente, apenas um sensor de temperatura. Esta parede com dois sensores necessita de um sensor de temperatura adicional porque existe uma grande circulação temporária de pessoas que atravessam uma porta de acesso automática localizada nesta região, próxima ao sensor ST4. No momento da abertura da porta ocorre uma considerável troca térmica do meio externo com o interno, interferindo no processo de homogeneidade do ambiente. Este fato acontece com mais freqüência no período que antecede o começo da aula, com a entrada dos alunos. Essa mesma parede também possui uma porta, porém, como ela se encontra fechada a maior parte do tempo, não houve a necessidade de um sensor de temperatura do ar adicional.

Além dos sensores de temperatura, existem outros sensores posicionados em locais fixos no ambiente, dentro ou fora da sala, sendo de uso exclusivo do sistema de automação e de condicionamento de ar. Entretanto, como será dada mais ênfase aos dados coletados pelos sensores fixos de temperatura do ar, dado o enfoque desta pesquisa, os demais sensores fixos serão apresentados a seguir sem muito detalhamento e também citados no capítulo referente às "Rotinas de Controle".

Por exemplo, para o controle de abertura das válvulas que fazem o Suprimento de Água Gelada para os 12 circuitos fechados de placas radiantes, explicado detalhadamente no capítulo "Rotinas de Controle", o algoritmo do sistema de controle apenas necessita dos valores obtidos pelos sensores fixos ST1, ST2, ST3 e ST4. Por outro lado, para o bloqueio destas válvulas, o sistema de controle necessita dos dados de temperatura de ponto de orvalho de cada zona térmica. Devido a esta necessidade, existem três sensores de ponto de orvalho; dois deles estão inseridos no duto de retorno de ar localizados acima do forro nas laterais da sala, ambos em lados opostos; e um deles, localizado de forma aparente no forro, próximo à região central do teto da sala, conforme mostra a Fig. 28 abaixo. 


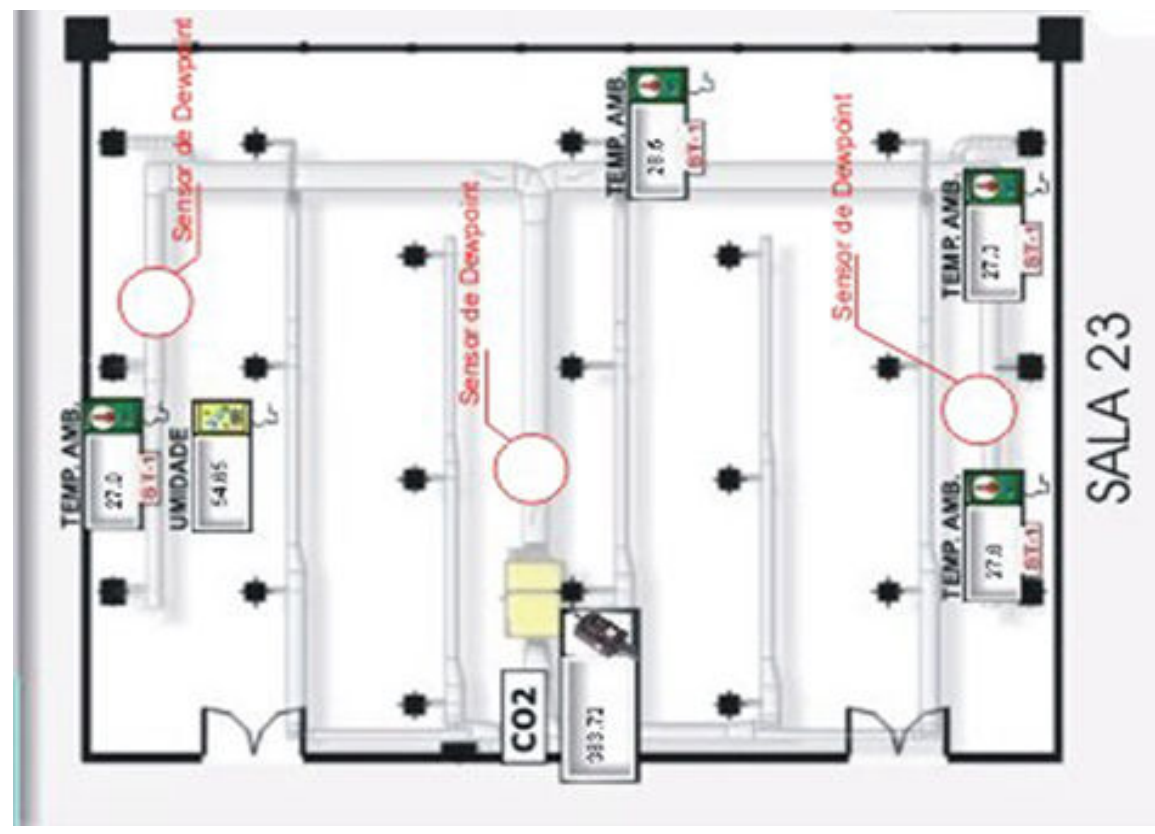

Figura 28 - Posicionamento dos sensores fixos nas paredes e no teto* * Fonte: Ilustração retirada da Tela de Interface do Aplicativo ComfortView.

Internamente, existem mais dois tipos de sensores: o primeiro é o sensor de umidade relativa do ar que está localizado em uma das paredes ao lado do sensor ST1. O segundo é um sensor de concentração de dióxido de carbono que está posicionado no teto, no centro da sala e é utilizado para controlar as taxas de trocas de ar com o meio externo, mantendo-se assim, esta concentração em um nível aceitável.

Externamente, existem outros sensores fixos usados no sistema de automação, como por exemplo, os sensores utilizados na monitoração e controle de temperatura da água do circuito hidráulico primário. O chiller possui sensores de monitoramento de temperatura e de pressão de água posicionado em sua entrada e saída, e internamente, sensores de proteção, para evitar o congelamento das serpentinas. A unidade de condicionamento de ar Fan Coil possui, internamente, sensores de temperatura da água de saída e sensores de temperatura do ar de suprimento e de retorno. No trocador de calor a placas, existem sensores de temperatura de água em sua saída, que correspondem à temperatura de água que atendem às placas radiantes. 


\section{B. Pontos de medições móveis}

Para a determinação do "local ideal", da "temperatura ideal", e para a caracterização e análise do ambiente térmico, um grande número de sensores móveis de temperatura e de velocidade do ar foi posicionado dentro do ambiente experimental.

Como a pesquisa foi realizada em regime transiente, as medições das variáveis ambientais foram feitas de forma simultânea e contínua. A quantidade mínima necessária de sensores de temperatura e velocidade e suas posições e períodos de medição, somente foi possível através de uma avaliação preliminar dos procedimentos de medição e estudo do ambiente experimental.

A análise preliminar permitiu concluir que seriam necessários 16 pontos de medição interna e 1 ponto de medição externa. No plano horizontal, seriam necessários 16 pontos de medições de temperatura e velocidade do ar, distribuídos uniformemente em toda a sala, sendo que cada ponto foi numerado de "1" a "16" (Fig. 29). Além desses, foi determinado um ponto de medição no lado de fora da sala, porém dentro da edificação, onde foram posicionados 1 sensor de temperatura do ar e 1 sensor de umidade relativa do ar, a uma altura de $4 \mathrm{~m}$ do piso, para medição das variáveis externas. Embora não fosse primordialmente necessário a esta pesquisa, além desses pontos, foi determinado mais um ponto extra para um confortímetro instalado em um Tripé (Ponto T), localizado na região central da sala. O confortímetro é constituído de 1 sensor de umidade relativa do ar, 1 sensor de assimetria de radiação e 1 sensor de temperatura de globo, para avaliar as condições de conforto.

No total, foram utilizadas as seguintes quantidades de sensores móveis: 96 sensores de temperatura; 96 anemômetros; 1 sensor de assimetria de radiação; 1 sensor de temperatura de globo; 1 sensor de umidade relativa do ar interno; 1 sensor de umidade relativa externa e 1 sensor de temperatura do ar externo, totalizando 197 sensores. 


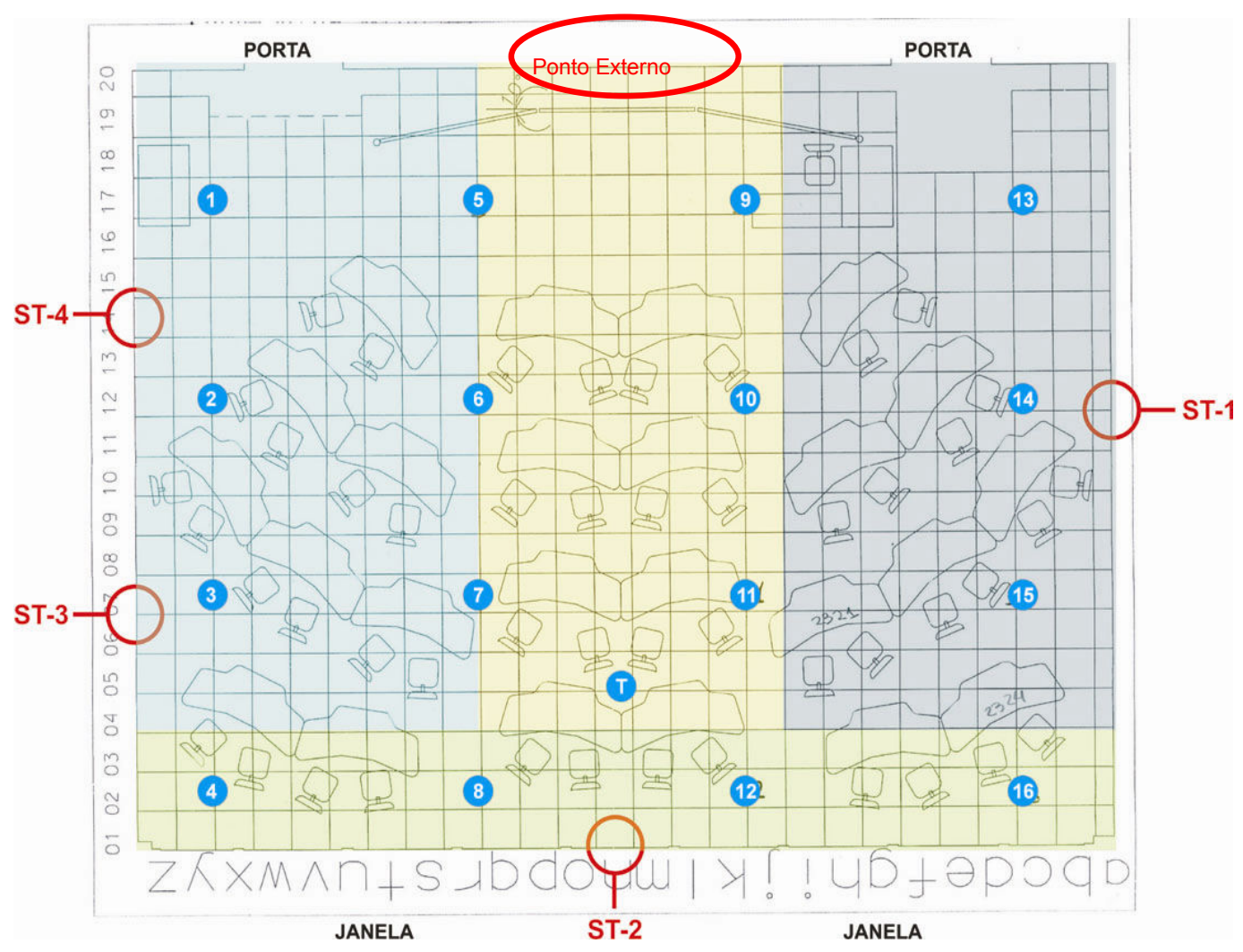

Figura 29 - Pontos de medições móveis (1 a 16 e T) - Vista Planta Baixa *

A disposição e quantidade de sensores se devem, essencialmente, a dois motivos:

Primeiramente, como um dos objetivos da pesquisa é determinar o "local ideal" e a "temperatura mais representativa", torna-se essencial fazer o mapeamento das condições térmicas da sala. Para isso, é necessário ter o maior número possível de dados colhidos simultaneamente para se encontrar resultados mais precisos. Sendo assim, como mostra a Fig. 29, os sensores móveis de temperatura do ar (Pontos 1 a 16) foram posicionados dentro de cada região, mantendo-se uma distância regular de um sensor ao outro de 4,20 m (representados pelas letras "a" à "z") na direção X dos eixos cartesianos e 3,00 m (representados pela numeração "1" à "20"), na direção Y. Dessa forma, em cada uma das 4 regiões, diferenciadas pelas cores, foram posicionados pelo menos 3 pontos de medições em cada uma das regiões, permitindo se medir a temperatura média em cada um deles.

Em segundo lugar, a disposição dos sensores no plano horizontal foi necessária para se determinar as "zonas de influência" no ambiente térmico, e no plano vertical, 
para se verificar o perfil de estratificação do ar (Fig. 30). As "zonas de influência" foram determinadas em função tanto de fatores externos, como por exemplo, incidência de radiação solar, quanto internos, como, por exemplo, a densidade ocupacional e layout de mobiliário que influenciam na distribuição de carga térmica. O espaço foi dividido em 3 zonas de influência, denominadas de Zonas de Ocupação, Zonas de Circulação e Zona Periférica. Essa distribuição horizontal permitiu avaliar a homogeneidade da temperatura do ar no ambiente. Este tópico é abordado com mais detalhes na atividade 5, onde foram feitas análises das condições térmicas do ambiente.

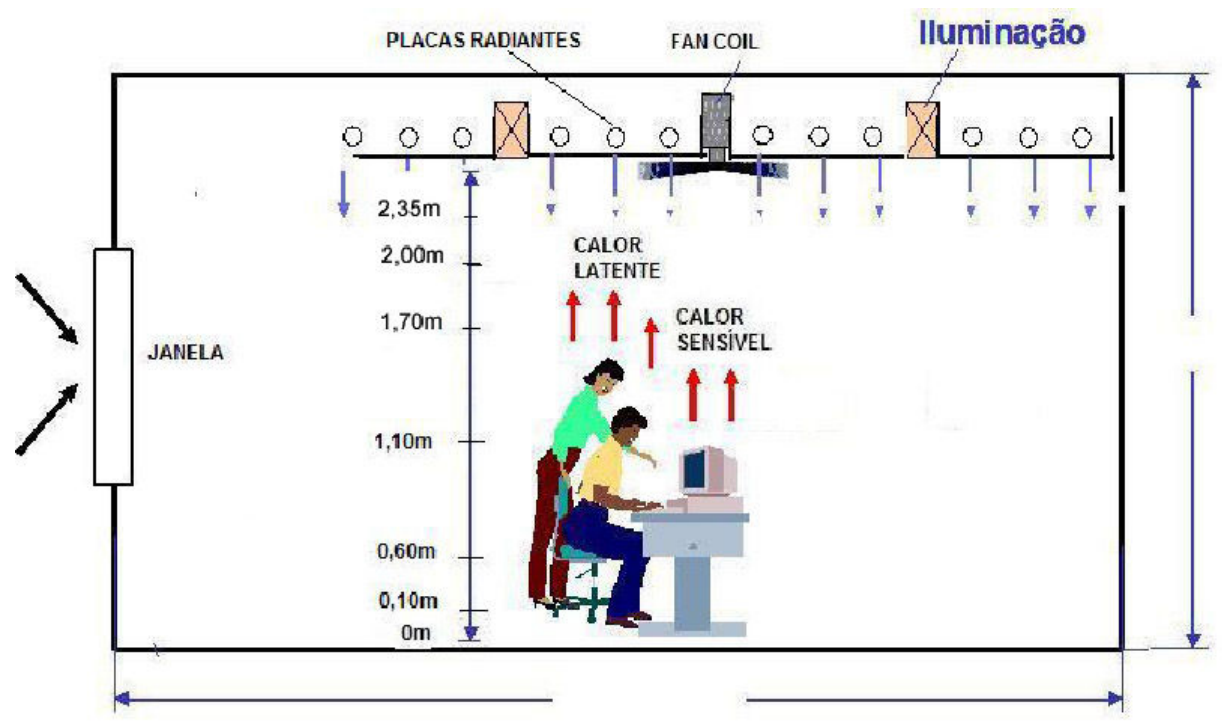

Figura 30 - Pontos de medições móveis - Vista em Corte

Com relação aos pontos de medição no plano vertical, em cada posição, a temperatura do ar interno foi medida em seis níveis: 0,$10 ; 0,60 ; 1,10 ; 1,70 ; 2,00$ e 2,35 m, sendo, a 0,10 m (nível do tornozelo); 0,60 m (nível do tronco); 1,10 m (nível da cabeça), recomendados pela ISO 7730 (1994) para conforto de pessoas sentadas e 0,10; 1,10 e 1,70 m, para pessoas em pé. Os demais níveis superiores (2,00 e 2,35 m), juntamente com os níveis inferiores, serviram para ajudar na análise do perfil de estratificação da temperatura do ar.

Com relação à variável velocidade do ar, os sensores foram posicionados nas mesmas 16 posições e 6 alturas de medição dos sensores de temperatura, de forma a permitir a caracterização do perfil da variável velocidade do ar interno, ao longo de todo o ambiente. Apesar desses sensores permitirem coletar grandezas escalares 
da velocidade, dadas as suas características construtivas, esses resultados são muito importantes para caracterizar o ambiente dentro das condições de contorno.

Quanto à variável umidade relativa do ar, esta foi medida internamente na posição "T", localizada a 0,60 m do piso, conforme recomenda a ISO 7730 (1994), também para caracterizar o ambiente dentro das condições de contorno. Externamente, outro sensor de umidade relativa do ar foi posicionado ao lado do sensor de temperatura do ar, para coletar dados que permitam avaliar a influência do meio externo no ambiente quando acontecem aberturas da porta.

\subsubsection{DEFINIÇÃO DOS PERÍODOS DE MEDIÇÕES}

As medições com os sensores móveis foram feitas atendendo às recomendações da ISO 7726 (1998). Segundo seus padrões de conforto, o laboratório utilizado como ambiente experimental tem um comportamento muito parecido com a de um ambiente de escritório, onde o tipo de atividade exercida pelos seus ocupantes é do tipo sedentário, com esforço moderado. Portanto, os dois ambientes podem ser considerados, do ponto de vista de padrão de ocupação e de atividade, muito semelhantes. Para este tipo de ambiente, adotando-se as condições de contorno usadas nesta pesquisa, a referida norma o classifica como um ambiente que se situa próximo à região de conforto. $E$, para esta classificação, a ASHRAE Standard 55 (2004) sugere que, para se proceder à avaliação do ambiente térmico, o período mínimo de medições de temperatura do ar seja de 3 minutos, com pelo menos 18 intervalos igualmente espaçados no tempo; e para as medições de velocidade do ar, 3 minutos. Portanto, as recomendações mínimas da norma foram atendidas, de forma que as medições das variáveis temperatura e velocidade do ar, assim como de todas as outras variáveis, foram feitas simultaneamente, em todas as posições determinadas.

É importante ressaltar que o período geral de medição por dia, que corresponde à soma do período de ocupação com o período de desocupação, foi de, pelo menos, 5 horas, resultando em um mínimo de 60 períodos de cinco minutos, igualmente espaçados no tempo, a menos de um dia, quando o período de ocupação durou cerca de 2 horas, quando houve apenas atividade de "monitoria". 
As medições foram realizadas em dias úteis da semana, das $11 \mathrm{~h} 00 \mathrm{~min}$ às $13 \mathrm{~h} 00 \mathrm{~min}$ (monitoria), das $13 \mathrm{~h} 00 \mathrm{~min}$ às $15 \mathrm{~h} 00 \mathrm{~min}$ (primeiro turno de aula), das $15 \mathrm{~h} 00 \mathrm{~min}$ às 17h00min (segundo turno de aula) e das 17h00min às 20h00min (sala desocupada e fechada). Nestes intervalos, todos os eventos, como por exemplo, aberturas de portas, foram devidamente registradas em relatórios de eventos.

As medições com ocupação começaram, em geral, 30 minutos após o início da aula. A única exceção foi durante a monitoria, que teve a medição no início do período de ocupação.

O sistema de aquisição de dados os organiza em intervalos iguais de cinco minutos. Cada um desses intervalos corresponde à média dos valores "instantâneos" referentes ao respectivo período. Adicionalmente, são calculados os respectivos desvios padrões de todas as variáveis dos sensores móveis para cada um desses intervalos.

Em relação ao tempo de resposta, testes preliminares permitiram verificar que o sistema de aquisição de dados demora cerca de $25 \mathrm{~ms}$ de varredura por sensor, já que o tempo total de varredura em todos os 197 sensores móveis é de cerca de 5 segundos.

Quanto aos dados, estes foram coletados de forma simultânea e sem interrupção. Simultaneamente, porque foram realizadas em uma situação nas reais condições de uso, isto é, em regime transiente, portanto, passíveis de mudanças de valores em pequenos intervalos de tempo. E, sem interrupção, porque um ambiente nestas condições pode estar sujeito às variações de temperatura que podem ocorrer principalmente devido à influência externa, como por exemplo, no evento de abertura de porta. A coleta ininterrupta de dados também se justificou pela possibilidade de se verificar o comportamento da temperatura em decorrência de qualquer evento que tenha existido durante o período de medição, como, por exemplo, o deslocamento de pessoas para uma determinada região dentro da sala ou a abertura da porta para entrada ou saída de alunos.

Paralelamente, neste mesmo período, foram coletados os dados de medição de variáveis ambientais por meio de sensores fixos, e as informações foram armazenadas em um banco de dados existente em um computador que foi utilizado na pesquisa para confrontar os dados e encontrar o índice de ajuste. 


\subsection{ATIVIDADE 2 - ESCOLHA DOS EQUIPAMENTOS NECESSÁRIOS A MEDIÇÕES E AQUISIÇÃO DE DADOS}

Para o cálculo do índice de ajuste foram necessárias informações provindas de duas fontes diferentes de sensores: Sensores fixos e sensores móveis. Para cada uma, a forma de aquisição de dados foi distinta.

No caso dos sensores fixos, as medições de temperatura são coletadas pelos controladores e armazenadas em um computador periodicamente, por meio de um software de supervisão predial da empresa Carrier chamado ComfortView, que monitora e controla remotamente as principais variáveis ambientais.

Por outro lado, as informações dos sensores móveis são transmitidas através de dataloggers instalados na base de uma haste metálica, centralizadas em um computador denominado de "unidade central" e armazenadas em um computador centralizador destas informações.

Para cada um dos 17 pontos de medição internos existe uma haste metálica (Figs. 31 e 32) ou um tripé para apoio dos sensores, distribuídos do seguinte modo: 16 hastes, contendo anemômetros e sensores de temperatura do ar, de forma que, tanto um como o outro ficam posicionados juntos nos 6 diferentes níveis, e mais um tripé adicional que apóia, no mesmo nível, um confortímetro constituído pelos seguintes sensores: 1 sensor de umidade interna do ar, 1 sensor de assimetria de radiação e 1 termômetro de globo. Os dados foram coletados por 17 módulos de aquisição (dataloggers), instalados na base de cada haste, conforme ilustra a Fig. 32. A única exceção é o Tripé, onde o datalogger fica situado no mesmo nível dos sensores, a 0,60 $\mathrm{m}$ do piso.

Os 17 dataloggers são interligados a uma Unidade Central, que corresponde a um microcomputador dedicado, através de protocolo de comunicação RS-485, que centraliza todas as informações de medições dos sensores móveis. Esta disposição de interligação dos dataloggers pode ser observada na Fig. 33. 


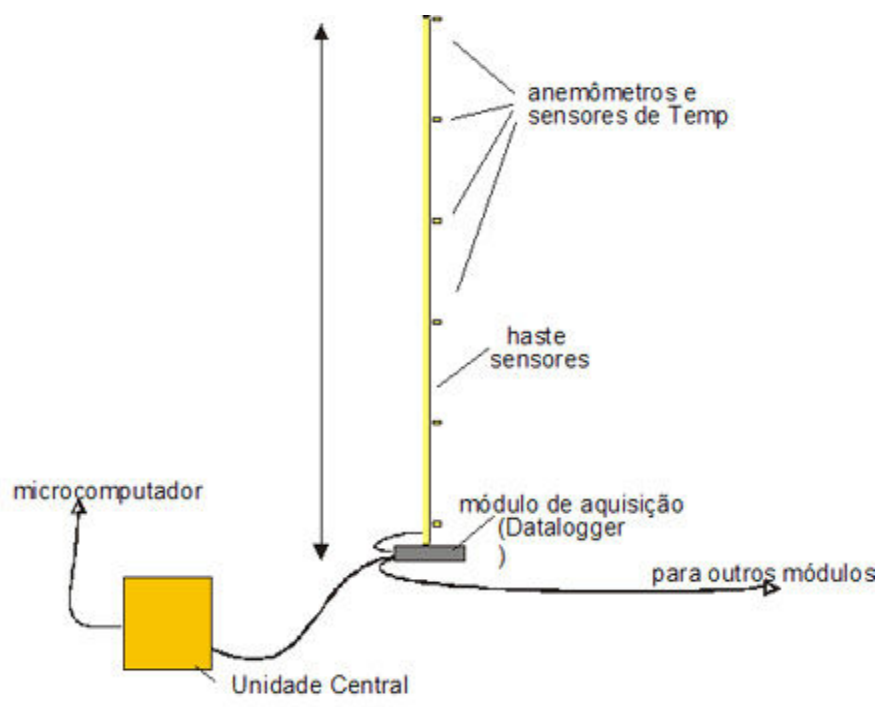

Figura 31 - Disposição da haste com sensores e aquisição

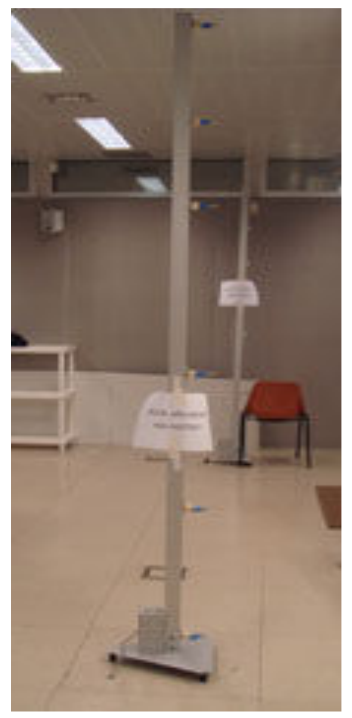

Figura 32 - Haste metálica

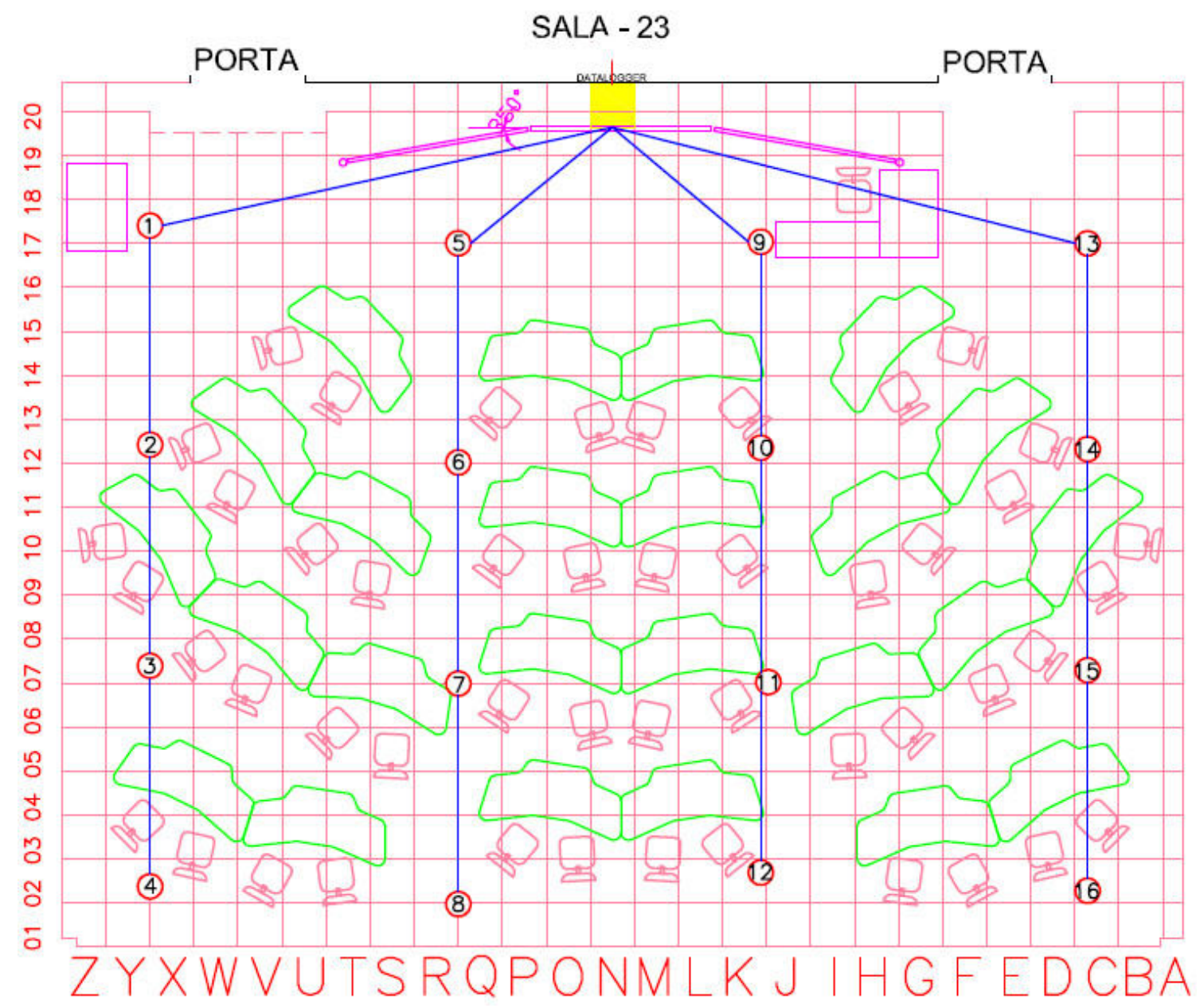

Figura 33 - Interligação dos dataloggers (Desenho do Auto CAD) 
Os dados numéricos dos sensores móveis que chegam a esta unidade central são transferidos a um equipamento denominado "Computador de Medição". Paralelamente, as medições dos sensores fixos são coletadas e armazenadas em um outro equipamento chamado de "Computador de Supervisão Predial", cuja principal função é controlar o sistema de supervisão predial desta sala. Por meio deste computador é possível configurar os controladores do sistema de automação e controle de forma a regular as condições térmicas do ambiente.

Para viabilizar a realização das medições, tornou-se necessária a aquisição do conjunto de equipamentos relacionados nos quadros 3 e 4 .

Quadro 3 - Especificação dos Sensores Móveis

\begin{tabular}{|c|c|c|c|c|}
\hline Sensores Móveis & Tipo & $\begin{array}{c}\text { Faixa de } \\
\text { Medição }\end{array}$ & Incerteza & Unidades \\
\hline $\begin{array}{c}\text { Temperatura de bulbo } \\
\text { seco do ar interno e } \\
\text { externo }\end{array}$ & Termoresistor. & 0 a $90^{\circ} \mathrm{C}$ & $0,1^{\circ} \mathrm{C}$ & 97 \\
\hline Velocidade do Ar & $\begin{array}{c}\text { Termo-anemômetro, baixo } \\
\text { aquecimento, omnidirecional. }\end{array}$ & 0 a $3 \mathrm{~m} / \mathrm{s}$ & $3 \%$ & 96 \\
\hline $\begin{array}{c}\text { Umidade Relativa do ar } \\
\text { interno e externo }\end{array}$ & Tipo capacitivo & 5 a $98 \%$ & $2 \%$ & 2 \\
\hline Assimetria de Radiação & Sensor fluximétrico, $50 \times 50 \mathrm{~mm}$. & $2 \%$ & 1 \\
\hline Temperatura de Globo & $\begin{array}{c}\text { Esfera metálica, segundo norma } \\
\text { ISO } 7726 .\end{array}$ & 0 a $90^{\circ} \mathrm{C}$ & $0,1^{\circ} \mathrm{C}$ & 1 \\
\hline
\end{tabular}

Quadro 4 - Especificação dos Dataloggers, Unidade Central e Computador

\begin{tabular}{|c|c|c|}
\hline Equipamento & Detalhe & Unidades \\
\hline $\begin{array}{l}\text { Módulo de aquisição } \\
\text { interno (datalogger) }\end{array}$ & $\begin{array}{c}\text { Microprocessado, } 12 \text { bits, } 16 \text { entradas analógicas, } 16 \\
\text { E/S digitais, transmissão RS485. }\end{array}$ & 17 \\
\hline $\begin{array}{l}\text { Módulo de aquisição } \\
\text { externo (datalogger) }\end{array}$ & $\begin{array}{c}\text { Microprocessado, } 12 \text { bits, } 8 \text { entradas analógicas, } 8 \\
\text { E/S digitais, transmissão RS485. }\end{array}$ & 1 \\
\hline Unidade Central & Unidade de alimentação e conversão RS485-RS232 & 1 \\
\hline $\begin{array}{l}\text { Computador de } \\
\text { Medição }\end{array}$ & $\begin{array}{c}\text { Computador DELL: Pentium 4, com monitor LCD, } \\
\text { teclado e mouse ótico. }\end{array}$ & 1 \\
\hline
\end{tabular}


A justificativa para a aquisição de 96 sensores de temperatura e velocidade do ar foi o fato da pesquisa ter sido feita em regime transiente, de forma que foi necessário que as medições tivessem sido feitas simultaneamente em todos os pontos e alturas, caso contrário, as análises dos dados numéricos poderiam ter ficado comprometidas. Através destas medições da temperatura do ar foi possível se determinar os índices de ajuste que se propõe esta pesquisa.

A velocidade do ar teve que ser medida simultaneamente com a temperatura nos mesmos pontos, para permitir um mapeamento do fluxo do ar (escoamento) no ambiente, nas diversas condições de vazão de ar. Além disso, depois de determinada a "temperatura ideal" e seus índices de ajuste, e posteriormente o "local ideal", foram avaliadas as condições de conforto térmico naquela região, representadas pelas temperaturas operativas, complementando-se com as medições das variáveis: temperatura de globo, umidade e assimetria de radiação.

Os equipamentos adquiridos por meio da Bolsa de Auxílio Individual à Pesquisa da FAPESP (Processo No 06/59334-1) serviram, num primeiro momento, para a esta pesquisa. Entretanto, eles capacitarão os laboratórios para outros trabalhos de pesquisa na mesma linha. Esses laboratórios, adequadamente instrumentados, certamente serão a base para trabalhos científicos de ponta, dada à atualidade da tecnologia aplicada e a possibilidade de exploração de temas na área de sistemas de climatização que ainda não foram explorados e que representam problemas ainda sem solução.

Alguns desses equipamentos podem ser visualizados nas figuras 34 à 38 . A única exceção é a Fig. 39, que mostra o Computador de Supervisão Predial, previamente adquirido.

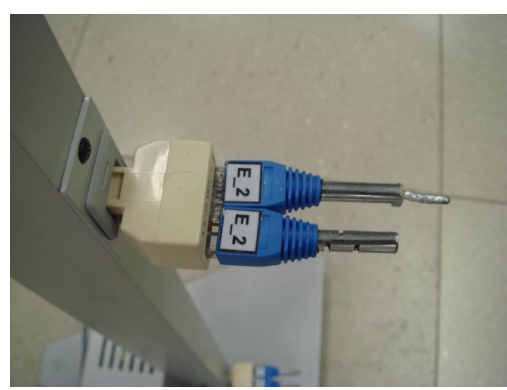

Figura 34 - Sensores de temperatura e velocidade do ar

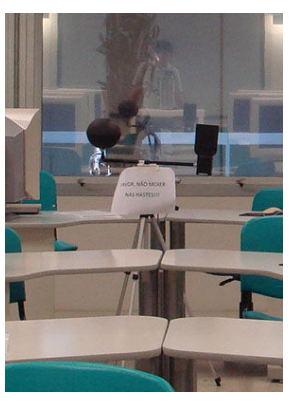

Figura 35 - Sensores de temperatura de Globo, assimetria de radiação e umidade relativa do ar 


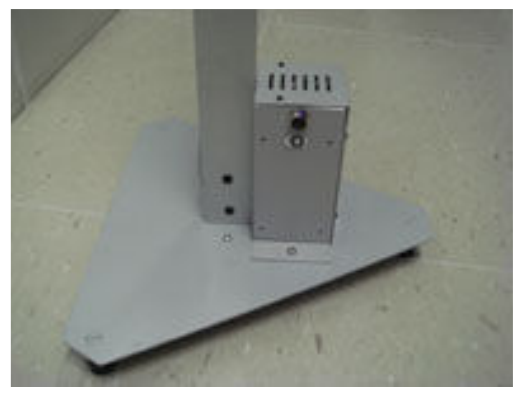

Figura 36 - Datalogger Interno

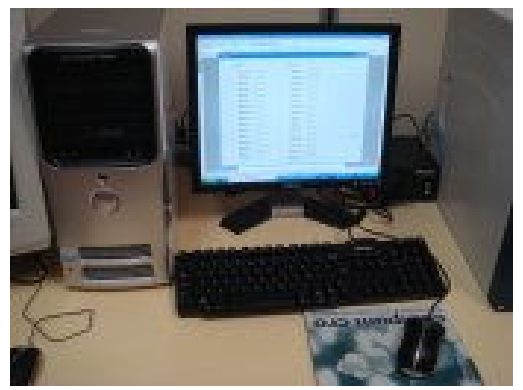

Figura 38 - Computador de Medição

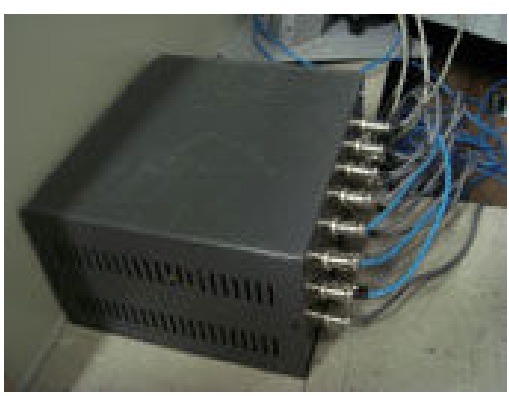

Figura 37 - Unidade Central

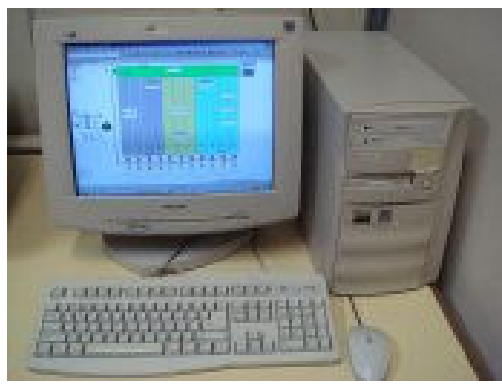

Figura 39 - Computador de Supervisão Predial

A Figura 40 mostra como ficou a disposição dos sensores móveis dentro da sala, com a ocupação de alunos. Nota-se que, embora em grande quantidade, eles foram confeccionados de forma a ficarem o mais discretamente possível.

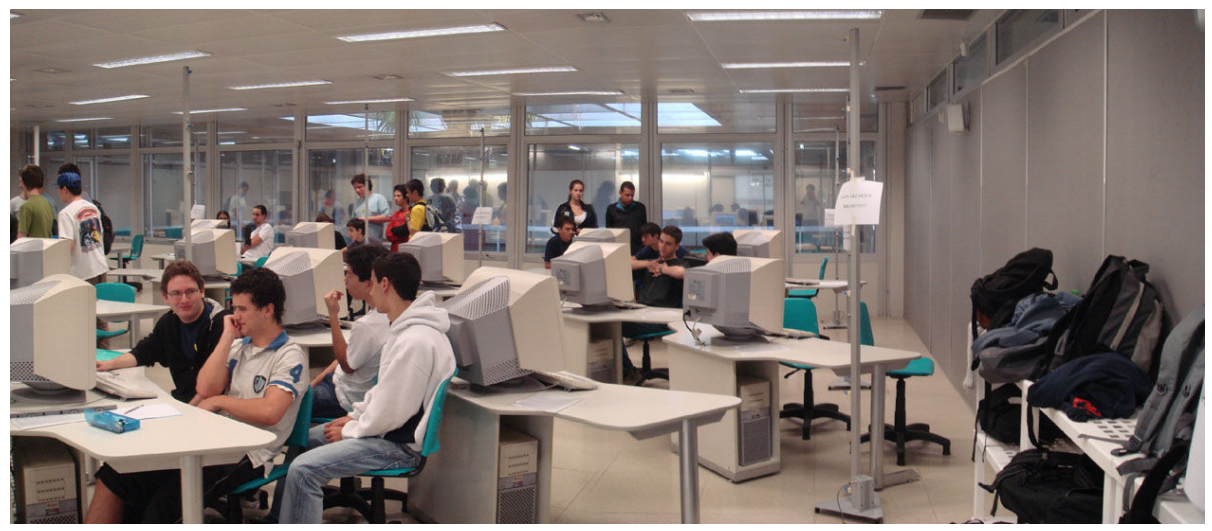

Figura 40 - Ambiente de medição - com ocupação 


\subsection{ATIVIDADE 3 - TESTES PRELIMINARES PARA VERIFICAÇÃO DO MÉTODO DE TRABALHO}

Para se validar o método do trabalho, isto é, para se atingir o objetivo desta pesquisa foi muito importante se fazer testes preliminares de coleta de dados de temperaturas e velocidades antes de realizar as medidas definitivas.

Os testes preliminares foram realizados entre o período de abril e setembro de 2006 no mesmo ambiente experimental desta pesquisa. Eles foram feitos com a sala "Ocupada" utilizando-se um suporte metálico que comporta um datalogger, um computador para receber as informações do datalogger e um monitor em sua base e 6 conjuntos de sensores de temperatura e velocidade do ar dispostos em 6 níveis de medições $(0,10 ; 0,60 ; 1,10 ; 1,70 ; 2,00$ e 2,35 m), conforme pode ser visualizado na Fig. 41:

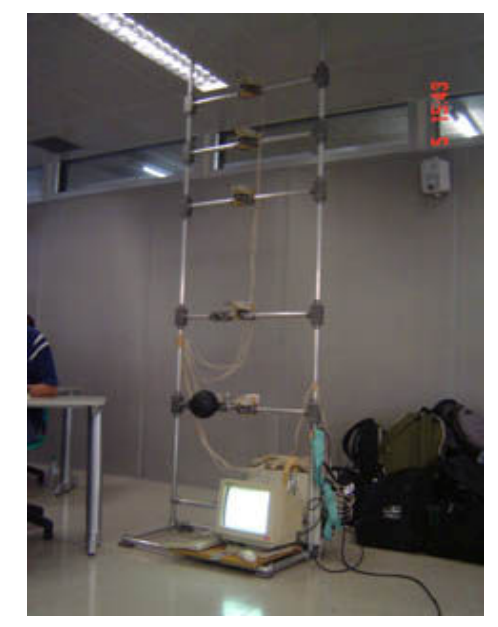

Figura 41 - Ambiente de medição - com ocupação

Primeiramente, por meio destes testes preliminares com a sala "Ocupada" foi possível sentir a real necessidade de se fazer as medições das variáveis ambientais de forma simultânea e com o máximo número de pontos possíveis. Isto porque, durante as medições, devido à existência sazonal de pessoas se movimentando e da abertura das portas automáticas, as medições variavam muito de um instante para outro. Assim, quando acontecia de se mudar o equipamento de posição, as temperaturas no ponto de medição anterior já haviam mudado. Portanto, essa não é uma forma muito confiável de se coletar os dados. 
Outro aspecto constatado foi a demora no fechamento da porta automática quando esta se encontrava no modo automático. Nos dias em que a temperatura externa em relação à interna era mais fria, notou-se, pelas medições próximas à porta que a temperatura interna da sala pode ser muito influenciada pela mudança na temperatura nestas regiões. Sendo assim, para os testes definitivos, optou-se que as portas permanecessem totalmente fechadas. As portas eram abertas, na maioria das vezes, no início e no fim das aulas ou monitorias. Isto diminuía a interferência do meio externo.

Para estes testes preliminares foi considerado um único setpoint de temperatura, $23^{\circ} \mathrm{C}$, pois o propósito foi coletar os dados, analisar as dificuldades de medição e propor soluções de melhoria na forma como seriam coletados os dados. Paralelamente, o método de tratamento dos dados foi sendo elaborado e posto à prova com os dados coletados, a fim de se afinar a forma de tratamento e ferramentas para se atingir aos objetivos específicos.

Adicionalmente, através destes testes preliminares foram definidos os 16 pontos de medição no plano horizontal e os 6 níveis de medição no plano vertical. Também foram verificadas diversas dificuldades com o uso do mancebo, como por exemplo: dificuldade de locomoção; possibilidade de danos ao equipamento; transtorno aos ocupantes e ao pesquisador; e a demora nas medições, pois se definia um período de 2 minutos para a estabilização dos sensores todas as vezes que o equipamento era mudado de posição.

Portanto, concluiu-se que nos 16 pontos escolhidos para medição deveriam existir suportes mais leves para o transporte, mais finos para não atrapalhar a visão dos alunos e preferencialmente fixos, com o datalogger na base da haste e um elemento centralizador de todas as informações, que, posteriormente, se tornou a "Unidade Central".

A forma de aquisição dos dados com que foi feita nos testes preliminares também foi importante para se verificar o quanto era necessário se ter um sistema versátil, prático e de fácil configuração para receber os dados. No teste preliminar os dados foram coletados diretamente em um datalogger e repassados a um computador ao seu lado, mas isso seria inviável nas medições definitivas, devido à quantidade de sensores; portanto, isso permitiu a criação de uma outra solução de recepção de dados através de uma "Unidade Central" e transferência a um único computador. 


\subsection{ATIVIDADE 4 - COLETA DE DADOS NO LABORATÓRIO}

A coleta de dados ocorreu no período de transição Outono-Inverno (entre os dias 14 e 21 de junho de 2007) e compreendeu 6 dias de medições, que correspondem, respectivamente, às seis condições térmicas impostas pelas condições de contorno.

Como não era conveniente mudar a temperatura durante as medições, devido à demora no tempo de estabilização do sistema de condicionamento de ar ao novo setpoint, estipulou-se que, para cada dia seria mantido um valor de referência de temperatura.

Como não era conveniente mudar a temperatura durante as medições, devido à demora no tempo de estabilização do sistema de condicionamento de ar ao novo setpoint, estipulou-se que, para cada dia seria mantido um valor de referência de temperatura. Quanto ao processo de coleta de dados, após escolher o dia da medição, os equipamentos eram montados na sala, um dia antes da medição, e testes eram feitos para se verificar qualquer tipo de anomalia com os dados e equipamentos. Caso algum equipamento, tal como sensores ou dataloggers apresentassem algum problema, esta informação era documentada em um "relatório de medição", tal como o apresentado no Quadro 5. Este relatório também era utilizado no dia da medição e continha informações sobre a quantidade de equipamentos ligados; o número de pessoas dentro da sala; o setpoint de temperatura estipulado para o dia; como estavam as condições ambientais externas, isto é, se estava chovendo, se estava frio, etc.

Quadro 5 - Relatório de Medição

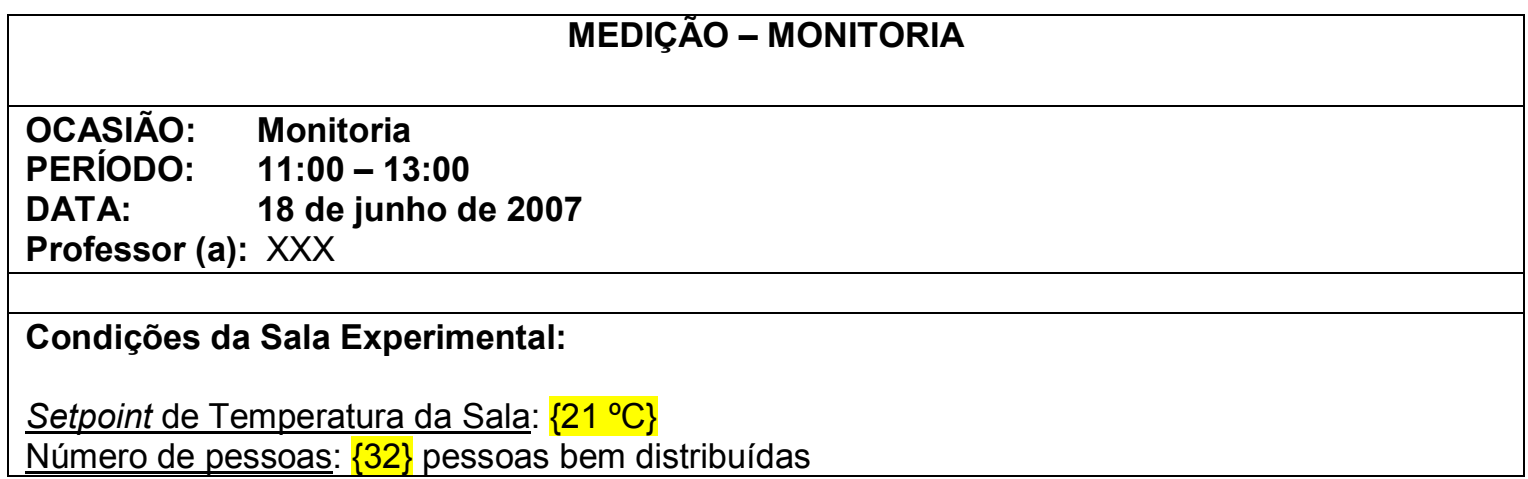




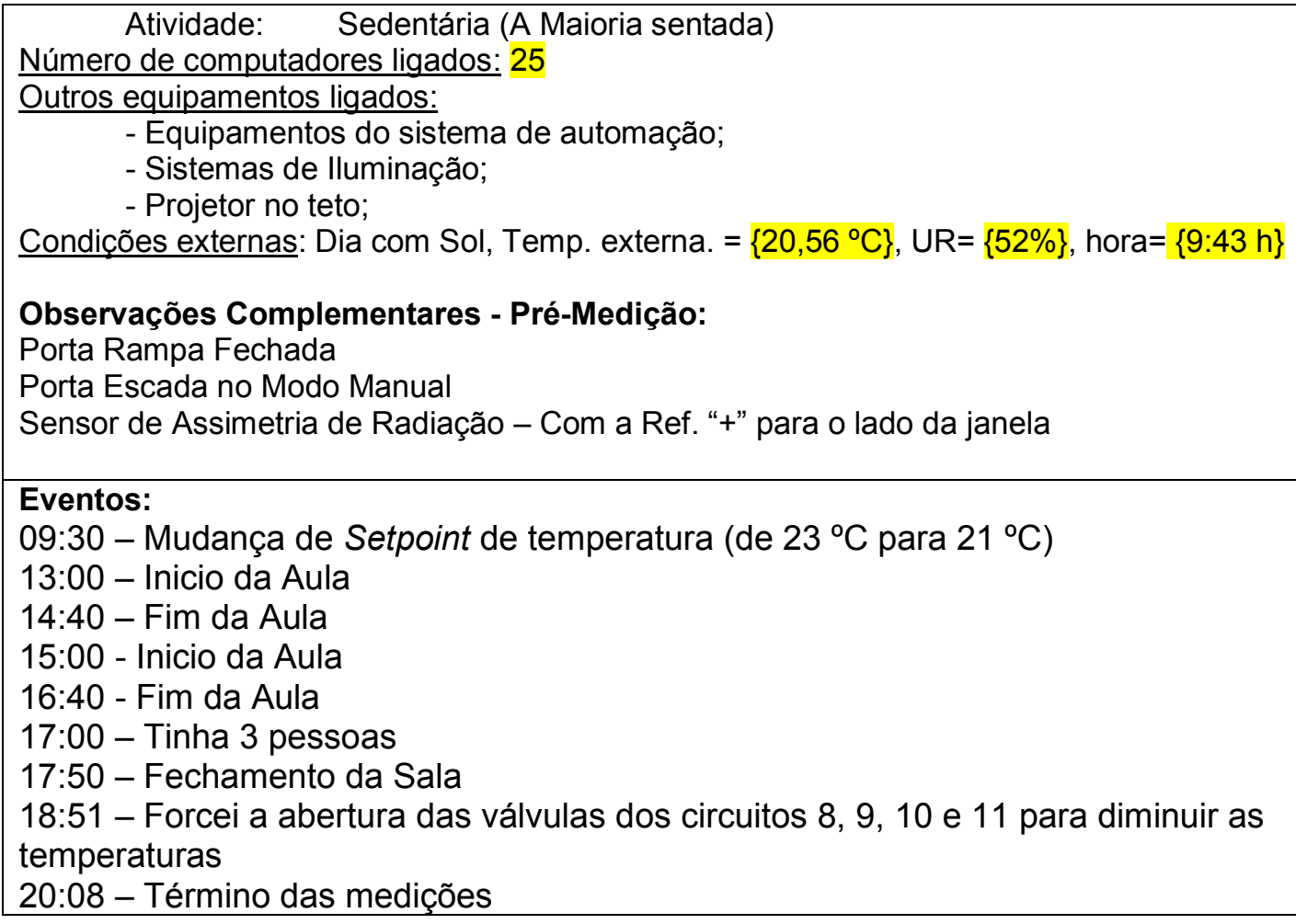

O setpoint de temperatura da sala era ajustado pelo Sistema de supervisão com pelo menos, duas horas de antecedência de qualquer medição para permitir que sistema de condicionamento de ar pudesse atingir tal setpoint. Foi verificado experimentalmente que o mesmo demorava pelo menos 20 minutos para se atingir a temperatura desejada.

A medição do dia começava sempre com 20 minutos de antecedência para que os equipamentos se estabilizassem. A aquisição dos dados foi feita a cada 25 ms, com médias calculadas e gravadas, a cada 5 segundos, em arquivo de texto (txt). Esta transferência de dados foi feita por meio de um aplicativo chamado "Aquis", que armazena as informações das medições provindas da "Unidade Central" no "computador de medição".

Este aplicativo, a cada 5 minutos calcula a média aritmética de todos os valores instantâneos de 5 segundos. Estes valores foram armazenados em um arquivo com formato de texto específico, previamente configurado, semelhantemente a um dataset para tratamento gráfico e determinação do "local ideal". 


\subsection{ATIVIDADE 5 - TRATAMENTO DOS DADOS}

O índice de ajuste foi calculado através de Método Estatístico, onde foram comparadas as medições internas de temperatura do ar, efetuadas pelos sensores localizados em posições fixas, em relação às medições de temperatura do ar efetuadas em posições ou regiões chamadas de móveis.

Através da análise da variável temperatura nas 16 posições móveis e 6 níveis correspondentes, totalizando 96 pontos de medição, foi possível se determinar a temperatura mais representativa do ambiente no nível de ocupação, aqui denominada de "temperatura ideal" e, por conseguinte, o local ou região onde esta temperatura se encontra dentro do ambiente medido, chamado de "local ideal". A determinação desta temperatura foi feita por meio de critérios de classes de freqüência.

Como explicado no capítulo sobre "Coleta de Dados" e "Períodos de Medição", os dados numéricos agrupados em períodos de 5 minutos correspondem à média dos valores instantâneos desta variável neste intervalo de tempo. Dentro deste conjunto de intervalos de 5 minutos, foram escolhidos como amostras representativas, os cinco "melhores intervalos" de tempo chamados de medições "a", "b", "c", "d" e "e". Os cinco "melhores intervalos" foram aqueles que apresentaram as melhores características de estabilidade de temperatura, isto é, que apresentaram o menor desvio padrão. A seleção destes intervalos foi realizada do seguinte modo: para cada setpoint de temperatura e altura de medição, foram considerados todos os intervalos de 5 minutos compreendidos dentro do período geral de medição com o ambiente "Ocupado" e "Desocupado", e dentro deste período foram escolhidos os cinco intervalos que apresentaram os menores desvios padrões.

Este critério de seleção de intervalos foi muito útil porque todas as medições foram realizadas em regime transitório, portanto estavam sujeitas às flutuações da temperatura pelos mais diferentes motivos, de forma que existiram períodos com muitas flutuações como também, períodos de estabilização da temperatura, chegando-se em certos instantes, próximas ao regime permanente. Como as principais normas internacionais utilizadas nesta pesquisa são baseadas no regime permanente, nada mais conveniente que escolher intervalos de tempo em que o perfil de comportamento da temperatura se assemelhe a esta situação. Portanto, 
este critério foi adotado para selecionar os períodos mais adequados, onde a temperatura do ar do ambiente se encontrava mais estabilizada e próxima do regime permanente.

Resumidamente, para cada dia de medição de temperatura do ar com os sensores móveis, foi estabelecido um setpoint (SP) fixo de temperatura, por exemplo, setpoint igual a $21^{\circ} \mathrm{C}\left(\mathrm{SP}=21^{\circ} \mathrm{C}\right.$ ou SP21). Neste dia foram escolhidas 5 medições ("a", "b", "c", "d" e "e") de temperatura do ar. Estes resultados foram apresentados em planilhas eletrônicas diferentes por setpoint e diferenciadas nas 6 alturas (h) de medição (h1=0,10m; h2=0,60m; h3=1,10m; h4=1,70m; h5=2,00m e h6=2,35m).

Após a escolha do intervalo de medição, os dados de temperatura do ar medidos através dos sensores fixos e sensores móveis foram tabulados, de forma semelhante à Tabela 1. Os comentários abaixo se baseiam nesses dados.

Tabela 1 - Dados para SP21, altura h1=0,1m, Medição "a"

\begin{tabular}{|c|c|c|c|c|c|c|c|c|c|c|}
\hline & \multicolumn{5}{|c|}{ Sensores Móveis } & \multicolumn{5}{|c|}{ Sensores Fixos } \\
\hline Medição & tempo & posiçāo & temp 'C & MTSM & Critério & ST1 & ST2 & ST3 & ST4 & MAST \\
\hline & $19 h 08 m$ & 1 & 20,9 & 21,1 & $\mathrm{D}$ & 22,1 & 21 & 21,2 & 21,3 & 21,4 \\
\hline & & 2 & 20,4 & 21,1 & $\mathrm{C}$ & 22,1 & 21,0 & 21,2 & 21,3 & 21,4 \\
\hline & & 3 & 20,9 & 21,1 & D & 22,1 & 21,0 & 21,2 & 21,3 & 21,4 \\
\hline & & 4 & 20,8 & 21,1 & D & 22,1 & 21,0 & 21,2 & 21,3 & 21,4 \\
\hline & & 5 & 20,9 & 21,1 & D & 22,1 & 21,0 & 21,2 & 21,3 & 21,4 \\
\hline Temperatura & & 6 & 20,7 & 21,1 & $\mathrm{D}$ & 22,1 & 21,0 & 21,2 & 21,3 & 21,4 \\
\hline SP21 & & 7 & 20,8 & 21,1 & D & 22,1 & 21,0 & 21,2 & 21,3 & 21,4 \\
\hline h1 & & 8 & 21,1 & 21,1 & $\mathrm{E}$ & 22,1 & 21,0 & 21,2 & 21,3 & 21,4 \\
\hline $\mathbf{a}$ & & 9 & 21,2 & 21,1 & E & 22,1 & 21,0 & 21,2 & 21,3 & 21,4 \\
\hline & & 10 & 21,3 & 21,1 & $E$ & 22,1 & 21,0 & 21,2 & 21,3 & 21,4 \\
\hline & & 11 & 21,2 & 21,1 & $E$ & 22,1 & 21,0 & 21,2 & 21,3 & 21,4 \\
\hline & & 12 & 20,9 & 21,1 & $\mathrm{D}$ & 22,1 & 21,0 & 21,2 & 21,3 & 21,4 \\
\hline & & 13 & 21,6 & 21,1 & $\mathrm{~F}$ & 22,1 & 21,0 & 21,2 & 21,3 & 21,4 \\
\hline & & 14 & 22,2 & 21,1 & G & 22,1 & 21,0 & 21,2 & 21,3 & 21,4 \\
\hline & & 15 & 21,7 & 21,1 & $F$ & 22,1 & 21,0 & 21,2 & 21,3 & 21,4 \\
\hline & & 16 & 21,1 & 21,1 & E & 22,1 & 21,0 & 21,2 & 21,3 & 21,4 \\
\hline
\end{tabular}

A tabela 1 é dividida basicamente em três partes: a primeira coluna da esquerda apresenta os dados da medição, como o setpoint de $21^{\circ} \mathrm{C}$ (SP21), a altura de medição $h 1=0,10 \mathrm{~m}$ (h1) e a indicação de qual o intervalo de medição foi selecionado; no caso foi a medição "a". A segunda parte, representada pelas colunas dos Sensores Móveis, mostra o intervalo o intervalo de tempo de medição 
que foi selecionado; as 16 posições no plano horizontal da sala; sua temperatura média correspondente a um intervalo de 5 minutos; a média de temperatura dos sensores móveis (MSM) nas 16 posições e a designação de intervalo dentro de um critério de classes de freqüências que será explicado posteriormente. Quanto à terceira parte desta tabela, no lado direito da tabela, constam os dados dos sensores fixos de temperatura e sua média, calculada pela média aritmética das 4 temperaturas do ar colhidas pelos sensores (ST1, ST2, ST3 e ST4) para este mesmo intervalo de tempo, conforme é feito pelas rotinas de controle do sistema de automação e controle.

Para o cálculo do MSM, a simples média aritmética dos 16 pontos de medição não era a mais indicada porque ela poderia incorporar a erros decorrentes de valores de temperatura que estivessem distantes da média geral. $O$ ideal seria que os valores de temperatura medidos estivessem próximos ao valor do setpoint de temperatura ou dentro de um intervalo de temperatura "tolerável". Entretanto, as medições estavam sujeitas a diversos eventos que poderiam interferir na qualidade das medições. Por exemplo, os sensores estavam sujeitos às interferências da própria movimentação das pessoas no recinto e eventos como aberturas de portas, possibilitando troca de calor com o meio externo. A possibilidade de haver alguma temperatura mais discrepante da média era considerável, haja vista que a temperatura do ar em todos os pontos da sala era relativamente estável quando não estava sujeita a estas situações. Além do mais, os erros poderiam ser agravados por algum problema momentâneo e de incidência rara, como por exemplo, mau contato do sensor na haste, ou erro de transmissão de natureza desconhecida, como interferências diversas ou problemas internos do datalogger. Para minimizar este tipo de "erro", adotou-se o critério de classes de freqüência para o cálculo das médias de temperaturas dos sensores móveis (MSM), incorporando certos limites nos valores de temperatura e retirando os valores mais discrepantes que possivelmente não eram interessantes para a medição.

"A distribuição de freqüências em classes é apropriada para apresentar dados quantitativos contínuos ou discretos com um número elevado de possíveis valores" (MEDRONHO, 2003, p.231). Os dados das temperaturas são divididos em intervalos ou faixas de valores denominadas classes. Uma classe é uma linha da distribuição de freqüências. Em outras palavras, as classes de freqüência de temperatura representam subintervalos de temperatura, isto é, um intervalo 
considerado de temperatura subdividido em pequenos intervalos iguais de temperatura.

Cada classe de freqüência é delimitada por um valor mínimo e máximo, denominadas de limite inferior da classe (linf) e o limite superior da classe (Isup). A média aritmética destes dois limites para cada classe é representada pela variável mi e este intervalo de temperatura é identificado por um conjunto de letras, variando de "A" a "I", denominadas de Critério, conforme ilustrado na Tabela de Classes de Freqüências (Tabela 2).

Tabela 2 - Classes de Freqüências de Temperaturas - Sensor Móvel

\begin{tabular}{|c|c|c|c|c|}
\hline$I_{\text {inf }}$ & $I_{\text {sup }}$ & Critério & Freq. & mi \\
\hline 19,0 & 19,5 & A & 0,0 & 19,3 \\
\hline 19,5 & 20,0 & B & 0,0 & 19,8 \\
\hline 20,0 & 20,5 & C & 1,0 & 20,3 \\
\hline 20,5 & 21,0 & D & 7,0 & 20,8 \\
\hline 21,0 & 21,5 & E & 5,0 & 21,3 \\
\hline 21,5 & 22,0 & F & 2,0 & 21,8 \\
\hline 22,0 & 22,5 & G & 1,0 & 22,3 \\
\hline 22,5 & 23,0 & H & 0,0 & 22,8 \\
\hline 23,0 & 23,5 & I & 0,0 & 23,3 \\
& & Total & 16,0 & \multicolumn{2}{|c}{} \\
& & \multicolumn{3}{|l}{}
\end{tabular}

A variável ni indica a freqüência (absoluta) de ocorrência, isto é, indica a quantidade de valores de temperaturas que se enquadram em cada classe. A soma de todas as observações ou freqüências de ocorrências de temperatura é representada pela variável $\boldsymbol{n}$. No caso da tabela $2, \mathrm{n}=16$.

De acordo com a Literatura, o número ideal de classes ou intervalos de uma tabela não é definido. Este número depende, muitas vezes, mais do bom senso do pesquisador que de regras rígidas pré-estabelecidas. A escolha dos intervalos é arbitrária. A familiaridade do pesquisador com os dados é que lhe indicará quantas e quais classes (intervalos) devem ser usadas. Entretanto, observa-se que, com um número pequeno de classes, algumas informações são perdidas, e com um número grande de classes, o objetivo de resumir os dados fica prejudicado.

"Se houver muitos intervalos, o resumo não constituirá grande melhoria com relação aos dados brutos. Se houver muito poucos, um grande volume de informações se perderá. Embora não seja necessário, os intervalos são 
freqüentemente construídos de modo que todos tenham larguras iguais, o que facilita as comparações entre as classes". (PAGANO, 2004, p.10).

Milone (2004) apresenta os seguintes critérios (eq. (7) a (10)) para a determinação do número de intervalos, denotado por $\boldsymbol{k}$ : $\mathrm{O}$ número de classes de distribuição de freqüência $(k)$ é um número inteiro que pode ser determinados por estas quatro fórmulas abaixo:

$$
\begin{array}{ll}
\text { 1. Raiz quadrada: } & k=\sqrt{ } n \\
\text { 2. Log (Sturges): } & k=1+3,3 \log n \\
\text { 3. In (Milone): } & k=-1+2^{*} \ln (n) \\
\text { 4. } k=1+10^{d} \text { AT } &
\end{array}
$$

Onde $\boldsymbol{A T}$ é a amplitude total dos dados e $\boldsymbol{d}$ é o número de decimais de seus elementos. Como $\boldsymbol{k}$ é o número de classes, o resultado obtido por cada um dos critérios deve ser o número inteiro mais próximo ao obtido.

Dentre todas estas regras citadas na literatura, duas têm sido universalmente adotadas, que são eq. (8) de Sturges e a eq. (9) de Milone. Para simplificar, suponha-se que a eq. (8) represente a Regra 1 e eq. (9), a Regra 2.

Ambas são equivalentes para $n \leq 80$. Entretanto, para $n>80$, a Regra 2 fornece valores que crescem rapidamente enquanto a Regra 2 cresce menos. Desse modo, a Regra 1, proposta por Sturges tem sido preferida.

No caso desta pesquisa, aplicando-se a Regra 1, para $n=16$, tem-se: que $\mathrm{k}=4.97$ o que resulta em $\mathrm{k}=5$ classes. Entretanto, para esta pesquisa, adotou-se: $\mathrm{k}=9$ classes de freqüência. O número maior de classes se deve ao fato de que, no sistema de "teto frio", o gradiente de temperatura é baixo, conforme é confirmado por Sodec (1999) e demonstrado através de testes preliminares. Este aumento do número de classes de freqüência diminui a perda de informações.

A fase posterior a determinação do número de classes da distribuição de freqüências, segundo Milone (2004), foi determinar a amplitude de cada classe, representada por $\boldsymbol{h}$. Matematicamente, a amplitude de classe é definida pela eq. (11):

$$
h=\frac{A T}{k}
$$


Assim, todas as classes terão a mesma amplitude, o que permitirá a construção de gráficos e cálculo de medidas descritivas.

Para o exemplo acima citado, na Tabela 2, foi utilizado o setpoint de temperatura $\left(\mathrm{SP}=21^{\circ} \mathrm{C}\right)$ e uma amplitude total de dados (AT) de $4,5^{\circ} \mathrm{C}$.

Para $\mathrm{k}=9$ e $\mathrm{AT}=4,5$, resulta em uma amplitude de $0,5^{\circ} \mathrm{C}$.

Portanto, entre a temperatura máxima $23,50{ }^{\circ} \mathrm{C}$ e a temperatura mínima $19,50^{\circ} \mathrm{C}$ existem 9 classes de freqüências de temperatura divididas em intervalos de $0,5^{\circ} \mathrm{C}$.

O valor de $4,5^{\circ} \mathrm{C}$ para a amplitude total dos dados justifica-se pelo fato do ambiente experimental, em alguns momentos, estar sujeito a situações de perturbações da temperatura do ar, conforme mencionado anteriormente. Esta amplitude total, conforme constatado em testes preliminares, possivelmente englobaria a maioria dos valores de temperaturas medidos. Os valores que estivessem fora destes limites, não seriam descartados, mas seriam incluídos nas classes extremas da tabela; isto é, na classe onde se situam as temperaturas máximas ou mínimas da Tabela de Distribuição de Classes de Freqüência.

Idealmente, nota-se que cada um dos valores observados deve pertencer a uma e somente uma classe. É usual que o limite inferior da primeira classe seja igual ao menor valor observado e que o maior valor pertença à última classe. Quando o limite superior da última classe coincidir com o maior valor observado é mais apropriado fechar este intervalo, contando o elemento nesta classe, do que abrir uma nova classe contendo apenas uma freqüência absoluta. Por outro lado, se o maior valor observado for inferior ao limite superior da classe, não há problemas, pois se fixa todas as classes com a mesma amplitude.

Entretanto, devido à grande quantidade de valores que foram coletados através das medições, tornou-se mais viável fixar os limites máximos e mínimos de temperatura "toleráveis" para cada setpoint de temperatura do ar, obedecendo à amplitude calculada pela eq. (11). Dessa forma, os valores de temperatura que estavam fora dos limites mínimos e máximos foram automaticamente desconsiderados.

Resumidamente, para cada setpoint de temperatura, existem 9 classes de freqüência com amplitude de $0,5^{\circ} \mathrm{C}$, sendo que, os limites de temperatura foram atendidos pelas seguintes regras, demonstradas pelas eq.(12) e eq. (13): 


$$
\begin{aligned}
\text { Temperatura máxima } & =\text { setpoint }+2,5^{\circ} \mathrm{C} \\
\text { Temperatura máxima } & =\text { setpoint }-2,0^{\circ} \mathrm{C}
\end{aligned}
$$

Estabelecido os parâmetros básicos para a construção da Tabela de Classe de Distribuição de Freqüência, o processo seguinte refere-se à composição de seu conteúdo que pode ser realizados através de equacionamento matemático, conforme é apresentado abaixo.

A média de temperatura dos sensores móveis, que para efeito de cálculo, também está representada pela variável $\bar{x}$ é calculada através da somatória do produto de mi por ni dividido pelo número total de freqüência de ocorrência (n). Matematicamente, têm-se as eq. (14) e (15) abaixo:

$$
\begin{gathered}
\bar{x}=\frac{\sum_{i=1}^{c} m_{i} \cdot n_{i}}{n} \\
m_{i}=\frac{\left(l_{\text {inf } i}+l_{\sup _{i}}\right)}{2}
\end{gathered}
$$

Onde:

c: Número total de classes

$\boldsymbol{i} \quad \quad$ Número da classe, variando de $\boldsymbol{i}=1$ até $\boldsymbol{c}$

ni: $\quad$ Freqüência de ocorrência

linf $_{i}=$ Limite inferior da classe $\mathrm{i}$

Isup $_{i}=$ Limite superior da classe $\mathrm{i}$

Como resultado, para cada medição será gerado um gráfico, exemplificado pelo gráfico 1, que mostra o comportamento da temperatura do ar medido nas 16 posições, para uma determinada altura e setpoint de temperatura do ar. Adicionalmente, o gráfico faz uma comparação desta temperatura com os dados medidos pelos 4 sensores fixos de temperatura, isoladamente e também com o seu valor médio. 
Gráfico 1 - Temperatura do sensor móvel para SP21 e h1=0,10 m

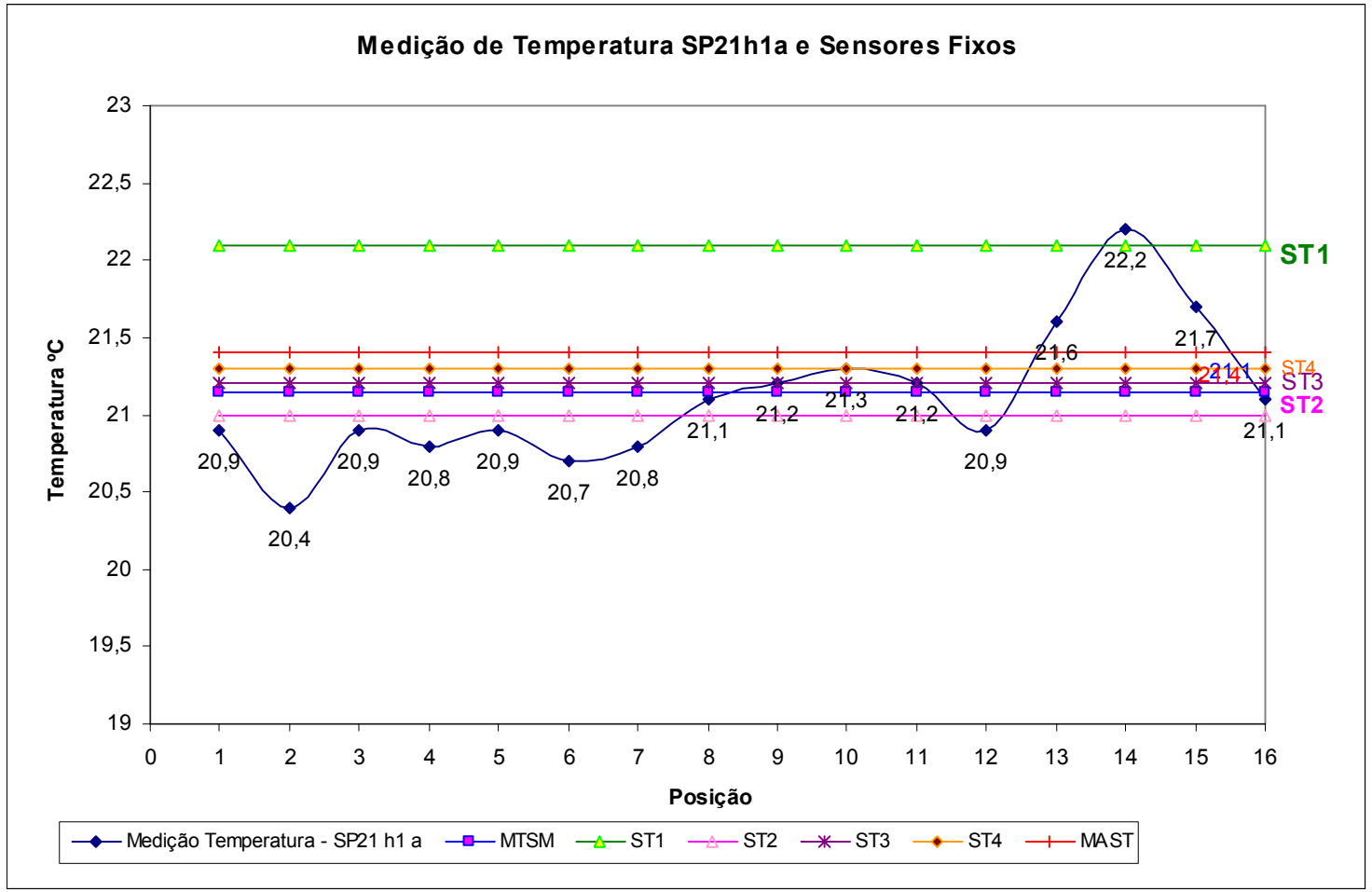

O mesmo processo é feito com as demais medições ("b", "c", "d" e "e"), de forma que, os 5 valores médios das temperaturas dos sensores móveis e seus correspondentes valores médios dos sensores fixos são apresentados em uma tabela resumo, conforme exemplificado na Tabela 3.

Tabela 3 - Temperaturas Médias dos Sensores Móveis e Fixos

\begin{tabular}{|c|c|c|c|c|c|c|c|c|c|}
\hline \multirow{3}{*}{ Medição } & \multicolumn{4}{|c|}{ Sensores Móveis } & \multicolumn{5}{|c|}{ Sensores Fixos } \\
\hline & medidas & MTSM & $\Delta \mathrm{T}$ & Critério & ST1 & ST2 & ST3 & ST 4 & MAST \\
\hline & Medição a & 21,1 & & $E$ & 22,1 & 21,0 & 21,2 & 21,3 & 21,4 \\
\hline \multirow{5}{*}{$\begin{array}{c}\mathrm{SP}=21^{\circ} \mathrm{C} \\
\mathrm{h} 1=0,10 \mathrm{~m}\end{array}$} & Mediçãob & 21,2 & & $E$ & 22,1 & 21,0 & 21,2 & 21,4 & 21,4 \\
\hline & Medição c & 21,2 & & $E$ & 22,1 & 21,0 & 21,2 & 21,3 & 21,4 \\
\hline & Mediçãod & 21,2 & & $\mathrm{E}$ & 22,2 & 21,0 & 21,2 & 21,3 & 21,4 \\
\hline & Mediçãoe & 21,2 & & $E$ & 22,1 & 21,0 & 21,1 & 21,3 & 21,4 \\
\hline & SP21h1 & 21.3 & -0.1 & & 22.1 & 21,0 & 21,2 & 21,3 & 21.4 \\
\hline
\end{tabular}

A média geral de temperatura do sensor móvel (MSM) para esta altura e setpoint de temperatura (SP21h1), é obtida matematicamente aplicando-se o mesmo critério de classes de freqüências de temperaturas, explicado anteriormente. A 
média de temperatura do sensor fixo (MSF) ainda é obtida através da média aritmética das 5 temperaturas obtidas nas cinco medições.

A partir destes dados resumidos de temperaturas é possível se determinar o índice de ajuste de temperatura, que corresponde à diferença da média de temperatura do sensor móvel (MSM), com a média de temperatura do sensor fixo (MSF), conforme a eq. (16).

$$
\Delta T=M S M-M S F
$$

Resumidamente, para cada setpoint é obtida uma temperatura do ar representativa do ambiente para cada uma das alturas, que corresponderá à "Media de Temperatura do Sensor Móvel” (MSM). Ao mesmo tempo, existirá uma temperatura média dos 4 sensores fixos, que será calculada por meio de média aritmética simples, de forma semelhante à feita no algoritmo de controle do sistema de automação da sala.

Portanto, como resultados serão apresentados planilhas e gráficos contendo todos os valores de médias de temperaturas dos sensores móveis (MSM), os valores de médias de temperaturas dos sensores fixos (MSF) e seus respectivos índices de ajuste por altura e setpoints.

Por último, embora, se tenha determinado todos os índices de ajuste em todas as alturas, a altura de referência na qual o sistema de automação do sistema de condicionamento de ar deve atender e servir de referência é a altura de ocupação ou de conforto; isto é, o nível "h2=0,60 m", que corresponde ao nível do tronco do ocupante na sua atividade predominante, conforme a eq. (17).

$$
\Delta T_{h 2=0,60 m}=M S M-M S F
$$

Como resultado final, no capítulo intitulado "Resultados da Pesquisa", serão apresentados tabelas e gráficos com as variações das temperaturas MSM e MSF e os índices de ajustes neste nível $\left(\Delta T_{h 2=0,60 m}\right)$ considerando as seis condições de temperaturas. A partir destes gráficos são feitas algumas análises sobre 0 comportamento destas variáveis em relação às mudanças de setpoint e em relação a cada uma das situações de medições desta pesquisa. 


\subsection{ATIVIDADE 6 - TÉCNICAS E PROCESSOS UTILIZADOS PARA A REALIZAÇÃO DOS OBJETIVOS ESPECÍFICOS Nº 2 E 3}

Esta atividade se refere aos procedimentos necessários para se caracterizar o perfil de estratificação do ar quanto à homogeneidade, assunto do objeto específico $N^{0}$ 2. Do mesmo modo são apresentadas as técnicas utilizadas para o mapeamento das condições térmicas do ambiente, assunto do objetivo específico $N^{\circ} 3$

\subsubsection{OBJETIVO ESPECÍFICO N 2: PERFIL DE ESTRATIFICAÇÃO DAS TEMPERATURAS}

O perfil de estratificação do ar é um aspecto muito importante na avaliação de satisfação do indivíduo, assim como, a corrente de ar e a assimetria de temperatura radiante. Suas influências podem ser maiores em situações onde existam condições térmicas distintas no espaço; mesmo assim, estes aspectos normalmente não são levados muito em conta em avaliações da satisfação do usuário. (LEITE, 2003).

Uma das causas do desconforto local pode ser a diferença vertical de temperatura do ar ou estratificação da temperatura, que corresponde a uma alteração da uniformidade do ambiente. No caso do sistema de "teto frio", utilizado em um ambiente fechado, a temperatura do ar tende a aumentar do teto para o piso devido ao efeito da radiação emitida pelas placas de forro metálicas. Em contrapartida, a carga térmica originada de equipamentos e pessoas tende a forçar o ar quente a subir, de forma a diminuir o gradiente de temperatura.

Diante do exposto, com esta atividade pretende-se caracterizar o perfil de estratificação da temperatura do ar do ambiente experimental, comparando-o com a norma ISO 7726 (1985), que determina os critérios para considerar um ambiente homogêneo. Este estudo avalia as principais variáveis ambientais em diferentes posições da sala de acordo com as recomendações da ISO 7730 (1994) para a avaliação de conforto térmico. 
Adicionalmente, foi feita uma avaliação da influência da assimetria de radiação no desconforto térmico local. As orientações e recomendações com respeito a assimetria de temperatura radiante podem ser observadas pelas normas ISO 7730 (19994) e ASHRAE Standard 55 (2004).

O primeiro procedimento feito foi determinar como eram os locais onde estavam posicionados os 96 sensores de temperatura e velocidade. Embora a análise do perfil de estratificação do ar seja feita na direção vertical foi importante destacar em qual local do ambiente no plano horizontal, deveriam ser colhidos os dados para estas análises. Por este motivo, a sala foi dividida em zonas de demarcação de ambientes funcionais, isto é, as zonas de influência, conforme mostra a Fig. 42.

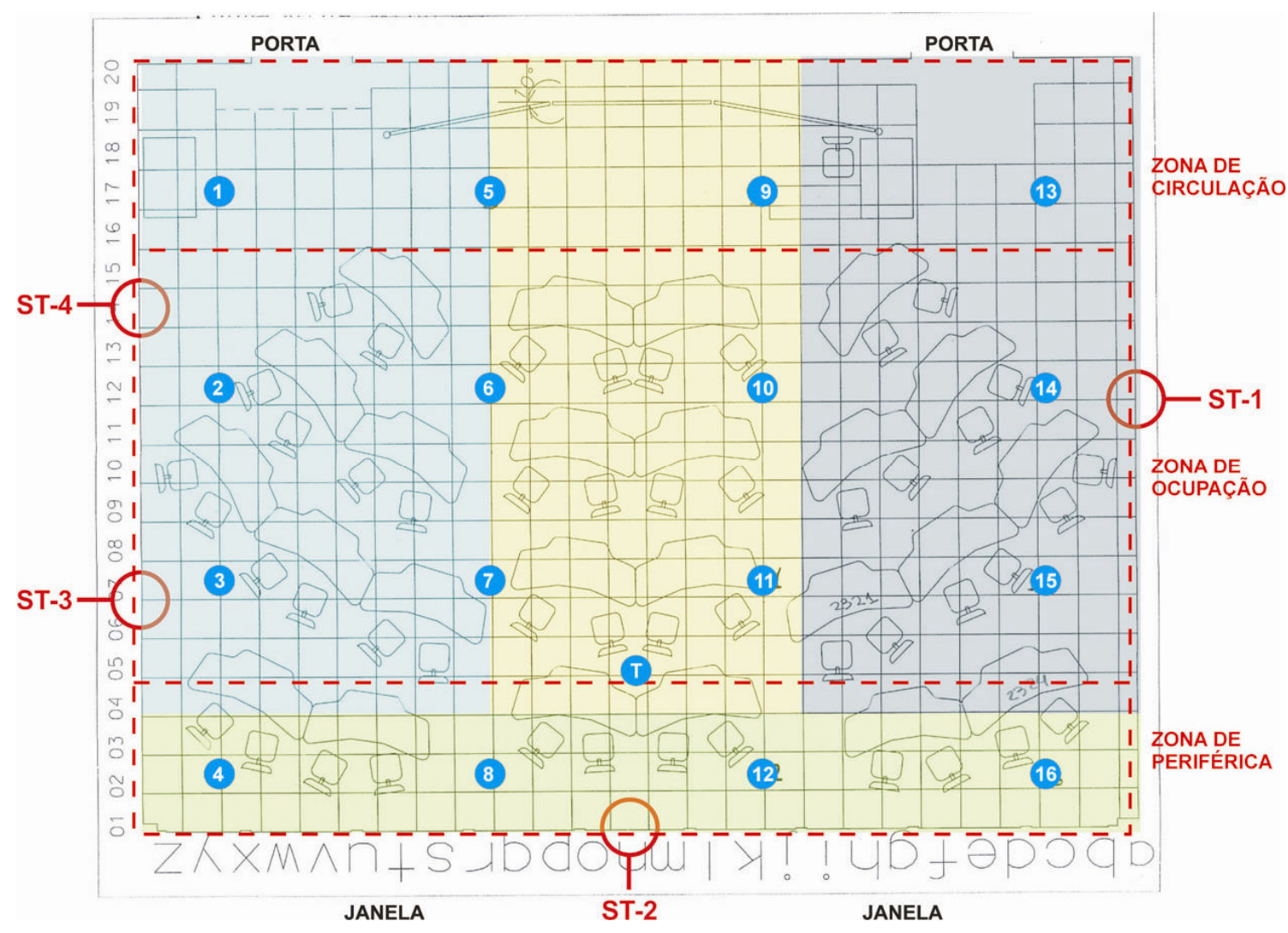

Figura 42 - Pontos de Medições Setoriais *

Estas zonas compreendem três locais previamente determinados em planta, com características diferentes de ocupação, compreendendo a sala inteira, ou seja, zonas de ocupação (próximos às estações de trabalho - Pontos 2, 3, 6, 7, 10, 11, 14 
e 15); zona periférica (próximo às janelas e, portanto com risco maior de sofrer influências da radiação solar - Pontos 4, 8, 12 e 16) e zona de circulação (espaço entre os mobiliários e a lousa usado para circulação de pessoas - Pontos 1, 5, 9 e 13).

No capítulo intitulado Resultados da ATIVIDADE 6 serão mostrados os resultados das análises dos seguintes itens:

- Característica de homogeneidade do ambiente;

- Diferença na temperatura do ar, no sentido vertical e perfil de estratificação;

- Comportamento da temperatura nas diferentes zonas.

\subsubsection{OBJETIVO ESPECÍFICO № 3: REPRESENTAÇÃO GRÁFICA DAS CONDIÇÕES TÉRMICAS}

O objetivo específico $N^{0} 3$ é fazer uma representação gráfica (modelo) do ambiente térmico, obtido com o auxílio de um aplicativo computacional que utiliza métodos numéricos e algoritmos do Computational Fluid Dynamics (CFD). Através desta ferramenta busca-se determinar e representar graficamente o "Local ou Região Ideal", onde a temperatura do ar é a mais representativa do ambiente.

Adicionalmente, deve ser apresentado um mapeamento das características térmicas e de velocidade do ar no ambiente experimental. Em outras palavras, objetiva-se neste item visualizar o comportamento da temperatura e da velocidade do ar nos 96 pontos de medição.

No caso desta pesquisa foi utilizado o software Paraview versão 2.6, da empresa Kitware Inc para visualização de dados em 2 e 3 dimensões. O método empregado discretiza o domínio espacial em pequenas células para formar uma malha ou grade de volume e então aplica um algoritmo adequado para resolver as equações de movimento.

Para a visualização das características térmicas, os valores de médias de temperaturas dos sensores móveis (MSM) das seis condições de setpoint de 
temperatura foram inseridos neste software através de um dataset com formatação específica.

Os resultados estão apresentados no capitulo referente aos "Resultados da Atividade 6", onde constam gráficos de todos os setpoints de temperatura em relação às alturas de medição, de forma que, no final, é apresentada a representação gráfica da posição do "local ou região ideal”. 


\section{RESULTADO DAS MEDIÇÕES E ANÁLISE QUANTITATIVA DAS CONDIÇÕES TÉRMICAS DO AMBIENTE}

\subsection{RESULTADOS E ANÁLISES DA ATIVIDADE 5}

Neste capítulo são apresentados os resultados das medições efetuadas pelos sensores fixos e móveis no período de transição Outono-Inverno sob seis condições térmicas internas diferentes (setpoints). Estas medições aconteceram em períodos com ou sem pessoas no ambiente, identificadas nas tabelas de resultados, como "ambiente ocupado/ desocupado" e "ambiente desocupado". na situação de "Desocupado", a única carga existente é a carga sensível dos equipamentos da sala que se mantiveram ligados durante toda a medição. $E$ na situação "Ocupado/Desocupado" é acrescido a carga térmica das pessoas no ambiente.

Os resultados são apresentados em três partes, de acordo com os passos, descritos anteriormente, para a determinação dos índices de ajuste.

A primeira parte apresenta, através de tabelas e gráficos,,os dados de medição dos 5 intervalos de medição ("a", "b", "c", "d' e "e") selecionados para cada uma das 6 alturas ( $\mathrm{h} 1, \mathrm{~h} 2, \mathrm{~h} 3, \mathrm{~h} 4, \mathrm{~h} 5$ e h6), considerando as 6 condições de setpoints de temperaturas $\left(21^{\circ} \mathrm{C}\right.$ a $\left.26^{\circ} \mathrm{C}\right)$. Adicionalmente são apresentados os índices de ajuste por altura de medição., conforme cálculo demonstrado no capítulo destinado ao tratamento dos dados.

A segunda parte apresenta as tabelas e gráficos dos índices de ajuste obtidos nas seis condições de temperatura. Os resultados são ordenados de acordo com o setpoint de temperatura.

Por ultimo, na terceira parte, é feita uma análise mais específica na altura de conforto, destacando o comportamento dos valores de MSM, de MSF e dos índices de ajuste. 


\subsubsection{PRIMEIRA PARTE: ÍNDICES DE AJUSTE POR ALTURA DE MEDIÇÃO}

Esta seção apresenta de forma mais detalhada como estão organizados os dados numéricos das medições efetuadas pelos sensores móveis, sensores fixos e os respectivos índices de ajuste por altura de medição. Para cada condição térmica (setpoint) foram considerados os cinco melhores intervalos, isto é, àqueles que apresentaram o menor desvio padrão. Paralelamente são correlacionados os dados de medição dos quatro sensores fixos coletados pelo sistema de automação no mesmo intervalo de tempo selecionado.

A título de demonstração, o APÊNDICE A, apresenta os resultados obtidos com base no Setpoint $21{ }^{\circ} \mathrm{C}$; nas 6 alturas de medição; Situação Ocupado/Desocupado. Observa-se que para cada altura de medição existem 5 tabelas representadas pelos intervalos selecionados. Com base nestas tabelas são gerados gráficos contendo informações, tais como, temperatura do ar nos 16 pontos de medição; média de temperatura dos sensores móveis (MSM); temperaturas dos 4 sensores fixos para o mesmo intervalo de tempo; "média de temperatura do sensor fixo" (MSF) e alguns gráficos dos índices de ajuste por altura de medição nas condições de contorno. Adicionalmente, são apresentadas as tabelas com os intervalos de classes de freqüência utilizadas para o cálculo da média de temperatura dos sensores móveis (MSM).

\subsubsection{SEGUNDA PARTE: ÍNDICES DE AJUSTE POR SETPOINT DE TEMPERATURA}

Esta seção resume as informações tratadas no item anterior, onde são apresentados os índices de ajuste por setpoint de temperatura. Os resultados das duas situações de medições encontram-se no APÊNDICE B.

Com base nos dados deste APÊNDICE, algumas análises foram realizadas considerando as duas situações de medição: "ambiente ocupado/ desocupado" e "ambiente desocupado".

A primeira análise é um comparativo dos gráficos gerados de MSM e MSF, analisadas individualmente. Para esta análise buscou-se comparar as semelhanças entre as curvas geradas por estas variáveis comparando os índices de ajustes calculados em cada altura. Primeiramente foi verificado qual foi a máxima 
diferença de valores de temperatura entre as curvas das variáveis MSM e MSF entre as 6 alturas de medição $(\Delta M)$, que é dado pela eq. (18).

$$
\Delta \mathrm{M}=\mathrm{MTSM}_{\max }-\mathrm{MAST}_{\max }
$$

Para fins de comparação, entre as curvas de MSM e MSF, dada a pequena variação dos índices de ajuste verificado experimentalmente durante as medições para este sistema de teto frio, a variação de $\Delta \mathrm{M}$ em módulo obedeceu este critério:

\begin{tabular}{|c|c|}
\hline pequena & $0 \leq \Delta \mathrm{M} \leq 0,5^{\circ} \mathrm{C}$ \\
\hline média & $0,5<\Delta \mathrm{M} \leq 1,0^{\circ} \mathrm{C}$ \\
\hline grande & $\Delta \mathrm{M}>1,0^{\circ} \mathrm{C}$ \\
\hline
\end{tabular}

A segunda análise refere-se à semelhança das curvas de MSF e MSM. Esta avaliação refere-se a um estudo quantitativo, onde é feito uma avaliação do grau de semelhança de ambos os gráficos por meio de uma avaliação do "desempenho" individual de cada índice de ajuste com relação aos demais índices de ajuste das outras alturas, envolvidas na análise. Assim, o critério de avaliação adotado foi o cálculo dos Índices $Z$ de cada resultado analítico.

Este índice reflete o desvio de cada variável a partir de sua média, normalizado pelo seu desvio padrão, isto é, levando-se em conta a dispersão dos resultados, como se fossem unidades fracionárias de desvios padrões. Trata-se de um dos critérios de aceitação de resultados e avaliação de desempenho adotado pela norma ABNT ISO/IEC Guia 43-1:1999. Sua equação provém da eq. (19) e (20):

$$
Z_{i}=\frac{x_{i}-\bar{x}}{D P}
$$

Onde: Zi é o índice $Z$ para i-ésima índice de ajuste;

$x_{i}$ é o resultado do índice de ajuste na altura $i$;

$\bar{x}$ é o índice de ajuste médio e;

$\left(x_{i}-\bar{x}\right)$ corresponde ao erro

$$
D P=\sqrt{\frac{1}{n-1} \sum_{k=1}^{n}\left(x_{k}-\bar{x}\right)}
$$


Onde: $\boldsymbol{D P}$ é o desvio padrão;

$\bar{x}$ é a média da amostra;

n é o tamanho da amostra

Com os resultados obtidos de $\mathrm{Zi}$, o seguinte critério foi adotado para avaliação do desempenho de cada temperatura, de forma a concluir se o "desempenho" foi satisfatório ou não.

\section{Condições de desempenho:}

$$
\begin{array}{ll}
|\mathrm{Zi}|<2 & \rightarrow \text { desempenho satisfatório } \\
2<|\mathrm{Zi}|<3 & \rightarrow \text { desempenho questionável } \\
|\mathrm{Zi}|>3 & \rightarrow \text { desempenho insatisfatório }
\end{array}
$$

Para criar um índice $Z$ de referência para comparar se os índices $Z$ de cada um dos índices de ajuste por altura estavam dentro de condições satisfatórias, foi preciso, primeiro, definir qual seria um de erro máximo admissível.

Um valor bem razoável seria considerar um erro de até $5 \%$ em relação à média dos valores. Considerando esta margem de erro, para um desempenho razoável, isto é, $\mid Z \mathrm{Z} /<2$, ter-se-ia um desvio padrão da ordem de $2,5 \%$, que é bastante razoável para este tipo de sistema de condicionamento de ar, haja vista que os índices de ajuste são bem pequenos.

Entretanto, admitiu-se para esta análise um índice z de referência (Zref) com valor: $/ Z$ ref $/=1,5$, e assim obter $\mathrm{DP}=3,3 \%$.

Assim, foram contadas quantas vezes o módulo do índice $Z$ ( $Z i$ ) de todas as alturas foi maior que $o$ índice $Z$ de referencia e foi estipulado o seguinte critério:

Se a quantidade de alturas que tiveram $/ Z i />1,5$ for igual a 6 , isto é, em todas as alturas o índice $Z$ individual estiver dentro do desejado, conclui-se que as curvas de MSF e MSM são "muito semelhantes";

Se esta quantidade for igual a 5 , as curvas são "semelhantes". Caso contrário, as curvas são consideradas "diferentes". Os resultados são apresentados na tabela 4. 
Tabela 4 - Análise das curvas MSF e MSM - Situação: "Ocupado / Desocupado" 
Tabela 5 - Análise das curvas MSF e MSM - Situação: "Desocupado" 


\subsubsection{TERCEIRA PARTE: ÍNDICES DE AJUSTE NA ALTURA DE CONFORTO}

De acordo com a norma ASHRAE Standard 55 (2004), das 6 alturas tomadas como referência: 0,$10 ; 0,60 ; 1,10 ; 1,70 ; 2,00$ e 2,35 m, a temperatura operativa mais recomendável para representar as condições do ambiente onde o ocupante se encontra para a condição de uma pessoa sentada a maior parte do tempo, está na altura $0,60 \mathrm{~m}$, denominada de altura de conforto. Portanto, esta é a altura de referência para conforto térmico na sala, onde foi determinada a "Temperatura Ideal". No caso das Tabelas 6 e 7, que são apresentadas em seguida, a "temperatura ideal" corresponde ao valor da temperatura média dos sensores móveis (MSM) na altura de conforto, obtida por meio de critérios de classes de freqüências anteriormente explicados e demonstrados para cada um dos setpoints. Através desta "temperatura ideal" são feitos os cálculos dos índices de ajuste que correspondem ao propósito desta pesquisa.

Adicionalmente, também é analisado o comportamento destes índices na altura de conforto, conforme a variação dos 6 setpoints estipulados. Por este motivo, busca-se responder as seguintes perguntas: Qual é o padrão de comportamento do índice de ajuste para cada situação de medição? Ele varia conforme a variação de setpoint? Existe uma relação da ocupação da sala com o seu valor?

Para responder a estas questões, são apresentados resultados e análises das variações dos valores de MSF e MSM e, conseqüentemente, dos índices de ajuste para as 6 condições térmicas consideradas. 


\section{A. Resultados dos Índices de Ajuste}

Tabela 6 - Índices de ajuste de temperatura para h2=0,60m - Ocup./Desoc..

\begin{tabular}{|c|c|c|c|c|c|c|c|c|c|}
\hline & \multicolumn{2}{|c|}{ Sensores Móveis } & \multicolumn{5}{|c|}{ Sensores Fixos } & índice & \multirow[b]{2}{*}{ SetPoint $\left({ }^{-} C\right)$} \\
\hline \multirow{7}{*}{$\begin{array}{c}\text { Índices de } \\
\text { Ajuste de } \\
\text { Temperatur } \\
a\end{array}$} & alturas $(\mathrm{m})$ & MTSH ['C] & ST1 & ST2 & ST3 & ST4 & MAST $\left[{ }^{\circ} \mathrm{C}\right]$ & $\Delta \mathrm{T}(=\mathrm{C})$ & \\
\hline & \multirow{6}{*}{$h 2=\mathbf{0 . 6 0}$} & 21,3 & 22,2 & 21,0 & 21,2 & 21,3 & 21,4 & $-0,1$ & 21,0 \\
\hline & & 21,8 & 22,4 & 21,7 & 22,0 & 22,0 & 22,0 & $-0,2$ & 22,0 \\
\hline & & 22,8 & 23,2 & 22,4 & 22,4 & 22,5 & 22,6 & 0,2 & 23,0 \\
\hline & & 23,7 & 24,0 & 23,8 & 23,5 & 23,0 & 23,6 & 0,1 & 24,0 \\
\hline & & 24,7 & 24,8 & 24,6 & 24,3 & 24,1 & 24,5 & 0,2 & 25,0 \\
\hline & & 25,3 & 25,3 & 25,2 & 24,5 & 24,5 & 24,9 & 0,4 & 26,0 \\
\hline
\end{tabular}

Gráfico 2 - MSM e MSF versus setpoints - h2 = 0,60 m - Ocup./Desoc..

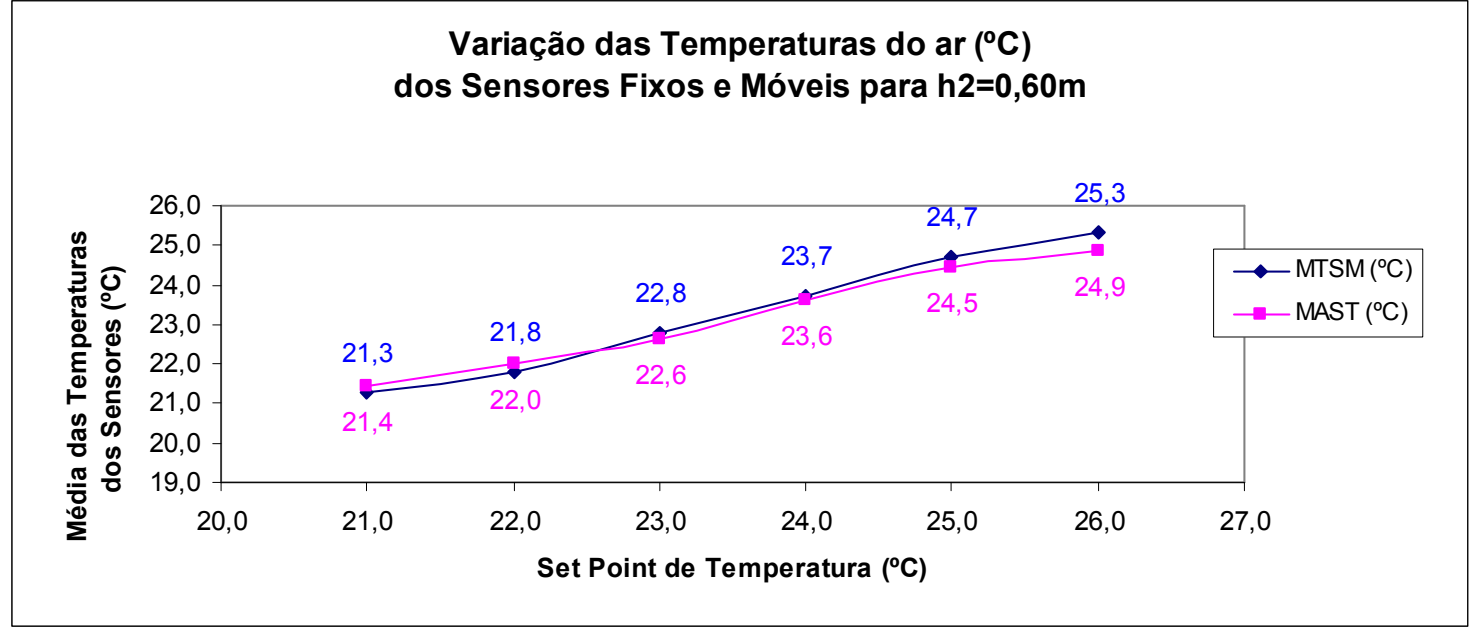

Gráfico 3 - Índices de Ajuste versus setpoints - h2 = 0,60 m - Ocup./Desoc..

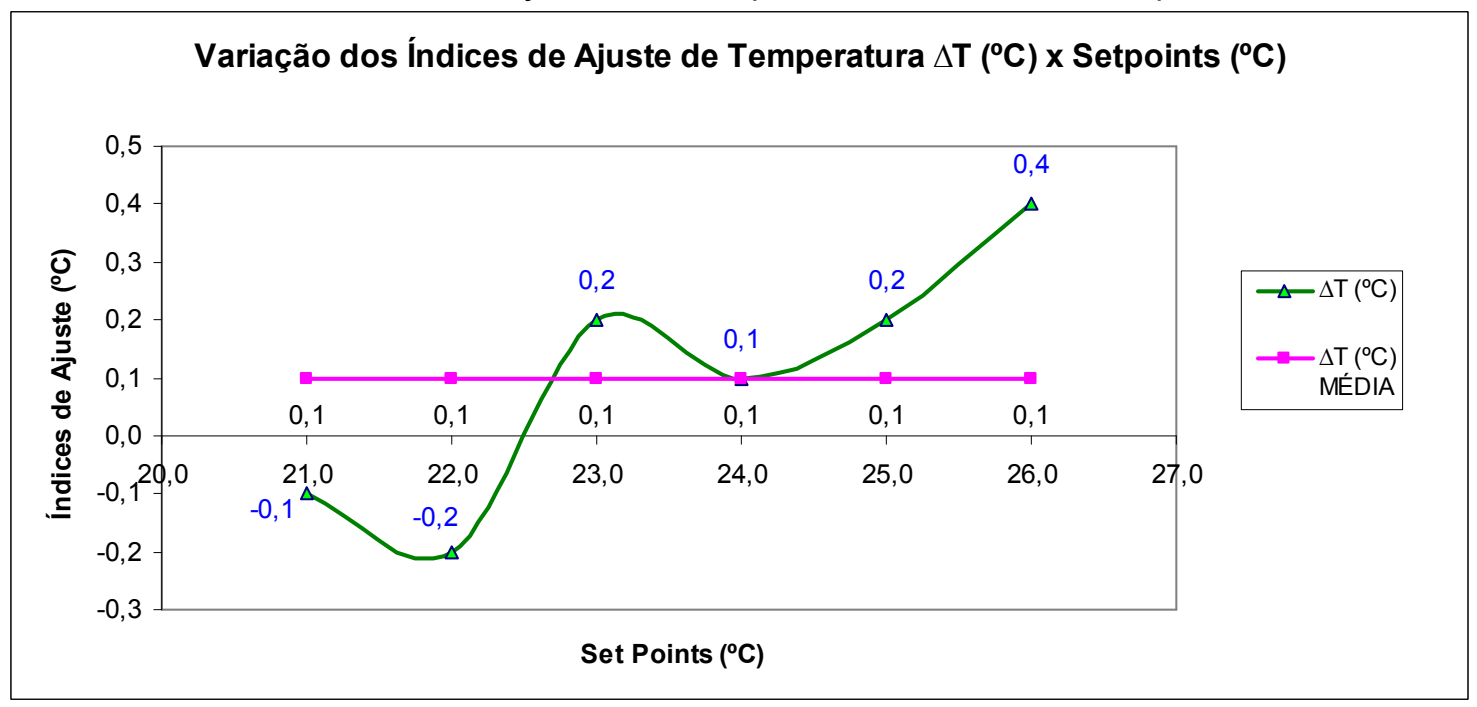


Tabela 7 - Índices de ajuste de temperatura para h2=0,60m - "Desocupado."

\begin{tabular}{|c|c|c|c|c|c|c|c|c|c|}
\hline & \multicolumn{2}{|c|}{ Sensores Móveis } & \multicolumn{5}{|c|}{ Sensores Fixos } & índice & \multirow[b]{2}{*}{ SetPoint ('C) } \\
\hline \multirow{7}{*}{$\begin{array}{l}\text { Indices de } \\
\text { Ajuste de } \\
\text { Temperatura }\end{array}$} & alturas (m) & MTSM ('C) & ST1 & ST2 & ST3 & ST4 & MAST ("C) & $\Delta \mathrm{T}(\mathrm{E}) \mathrm{C})$ & \\
\hline & \multirow{6}{*}{$h 2=\mathbf{0 . 6 0}$} & 21,3 & 22,2 & 21,0 & 21,2 & 21,3 & 21,4 & $-0,1$ & 21,0 \\
\hline & & 21,8 & 22,4 & 21,7 & 22,0 & 22,0 & 22,0 & $-0,2$ & 22,0 \\
\hline & & 22,8 & 23,2 & 22,5 & 22,3 & 22,5 & 22,6 & 0,2 & 23,0 \\
\hline & & 23,3 & 23,7 & 23,3 & 23,6 & 23,1 & 23,4 & $-0,1$ & 24,0 \\
\hline & & 23,9 & 24,3 & 23,8 & 23,7 & 23,7 & 23,9 & 0,0 & 25,0 \\
\hline & & 24,7 & 24,5 & 23,9 & 23,8 & 23,9 & 24,0 & 0,7 & 26,0 \\
\hline
\end{tabular}

Gráfico 4 - MSM e MSF versus setpoints - h2 = 0,60 m - "Desocupado"

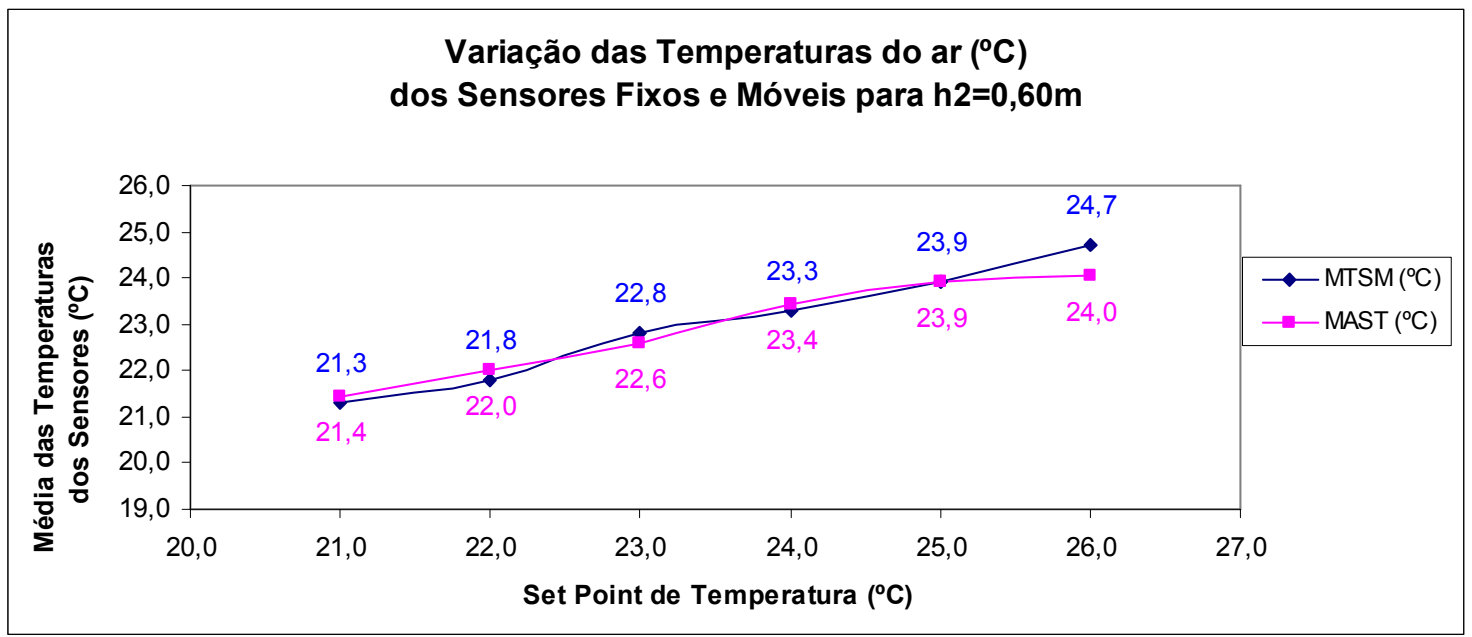

Gráfico 5 - Índices de Ajuste versus setpoints - h2 = 0,60 m - "Desocupado".

Variação dos Índices de Ajuste de Temperatura $\Delta \mathrm{T}\left({ }^{\circ} \mathrm{C}\right) \times$ Setpoints $\left({ }^{\circ} \mathrm{C}\right)$

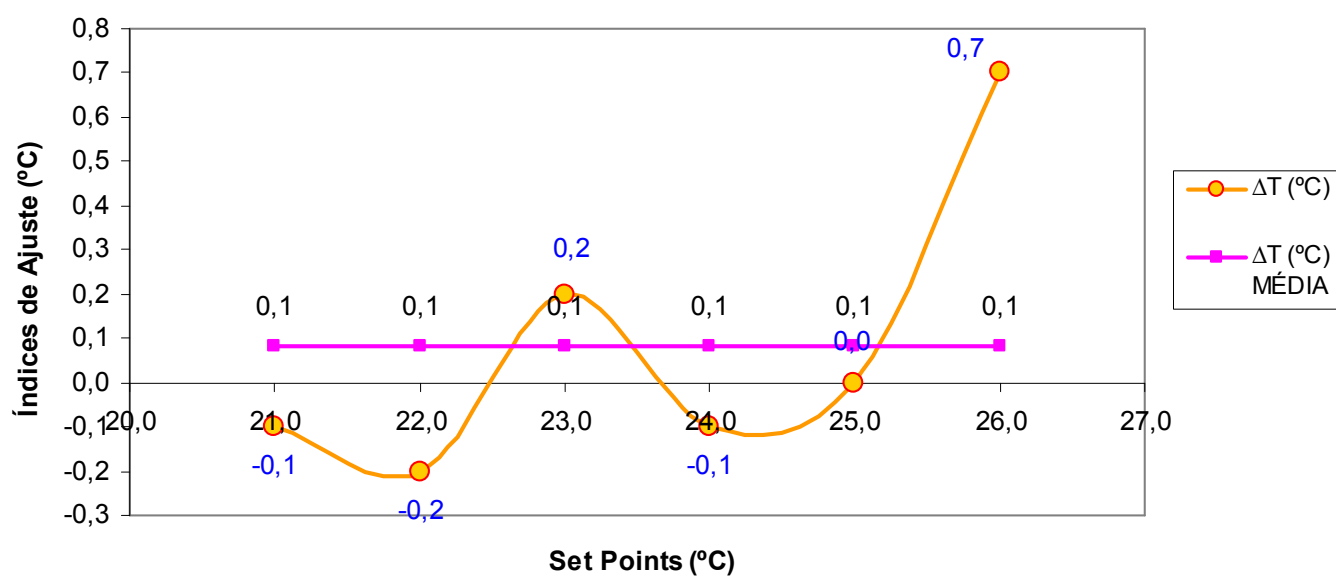




\section{B. Análise de comportamento dos Índices de Ajuste}

O comportamento das curvas dos índices de ajuste na altura de conforto (h2 $=0,60 \mathrm{~m}$ ) é analisado com base na tabela 8 e nos gráficos 6,7 e 8 . Os três gráficos representam as variações que este índice teve em função das 6 condições térmicas do experimento. O primeiro apresenta os pontos interligados, onde são destacadas características pontuais dos índices por setpoint; o segundo faz uma regressão linear entre os pontos indicando tendências gerais de comportamento, tais como, aumento, constância ou diminuição dos valores e por último, o terceiro faz uma aproximação polinomial de grau 3 , onde simula uma tendência de variação de valores de acordo com suas variações ao longo dos setpoints.

Tabela 8 - Comparativo dos Índices de Ajuste para as 2 situações de medição

\begin{tabular}{|c|c|c|}
\cline { 2 - 3 } \multicolumn{1}{c|}{} & \multicolumn{2}{c|}{ INDICES DE AJUSTE } \\
\hline $\begin{array}{c}\text { Setpoint } \\
{\left[{ }^{\circ} \mathrm{C}\right]}\end{array}$ & $\begin{array}{c}\text { Ambiente } \\
\text { "Desoc./Ocup." }\end{array}$ & $\begin{array}{c}\text { Ambiente } \\
\text { "Desocupado" }\end{array}$ \\
\hline 21 & -0.2 & -0.1 \\
\hline 22 & -0.2 & -0.2 \\
\hline 23 & 0.2 & 0.2 \\
\hline 24 & 0.1 & -0.1 \\
\hline 25 & 0.2 & 0 \\
\hline 26 & 0.4 & 0.7 \\
\hline \multirow{3}{*}{} & 0.1 & 0.1 \\
\cline { 2 - 3 } & \multicolumn{2}{|c|}{ MEDIA } \\
\cline { 2 - 3 } & \multicolumn{2}{c}{} \\
\cline { 2 - 3 }
\end{tabular}

Gráfico 6 - Índices de Ajuste versus setpoints (h2=0,60m) - União de Pontos.

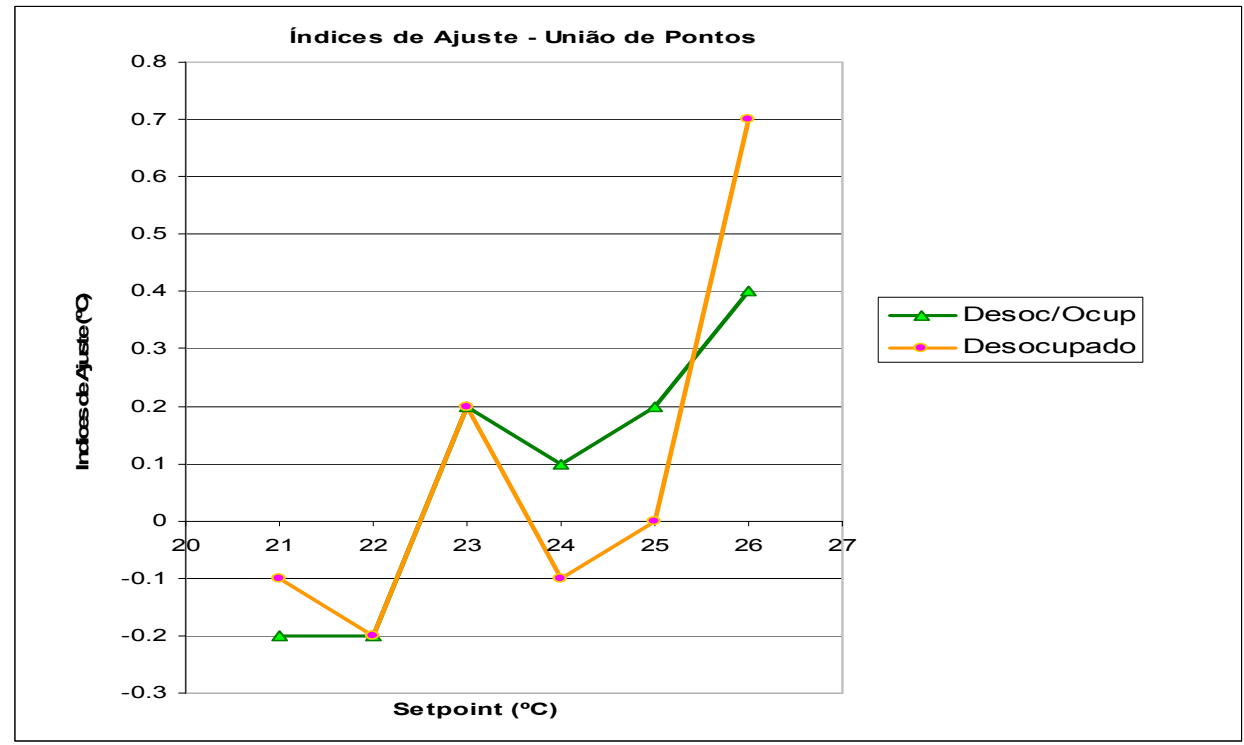


Gráfico 7 - Índices de Ajuste versus setpoints (h2=0,60m) - Regressão Linear

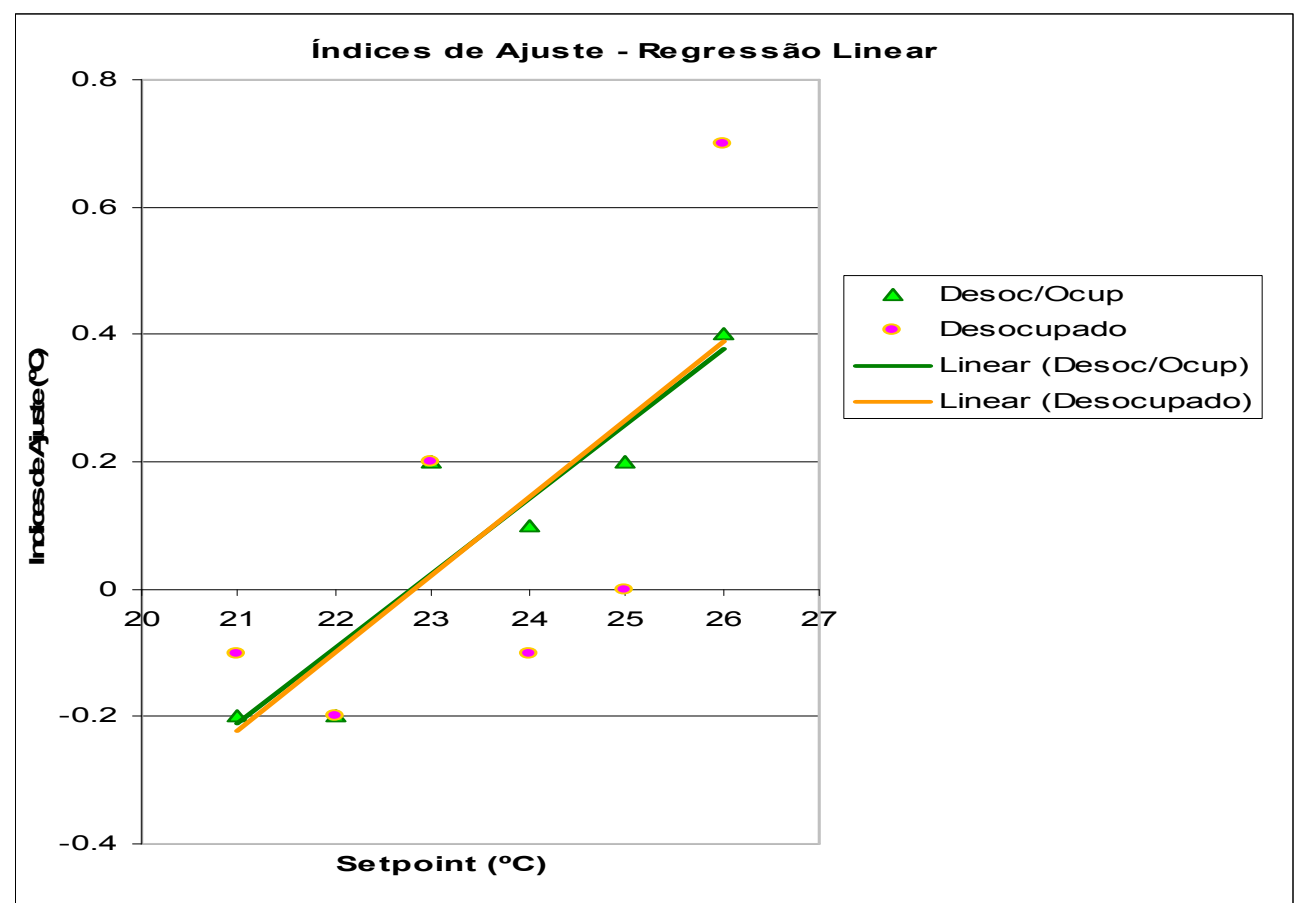

Gráfico 8 - Índices de Ajuste versus setpoints (h2=0,60m) - Polinômio de Grau 3

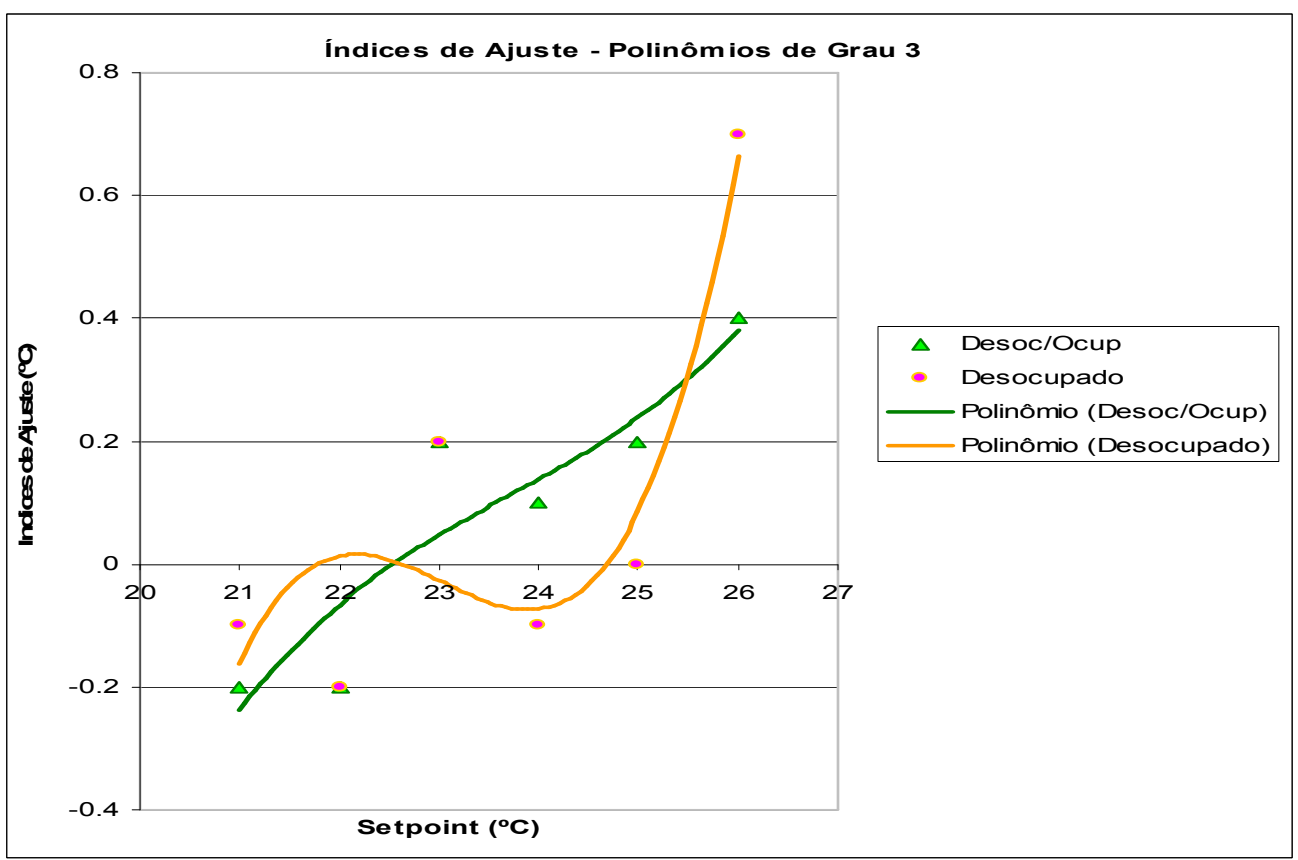

Pode-se observar que para cada uma das situações de medição, a variação dos valores de índices de ajuste é ligeiramente linear, com uma tendência crescente 
de valores com o aumento de temperatura. Para ambas as situações, os valores são muito próximos nos setpoints 21,22 e $23^{\circ} \mathrm{C}$ e ficam um pouco diferentes a partir do setpoint $24^{\circ} \mathrm{C}$. A semelhança de comportamento destes valores provavelmente seja em decorrência das medições em ambas as situações de medição para cada setpoint terem sido realizadas no mesmo dia, indicando uma forte influência da carga térmica mesmo após o período de desocupação. Esta semelhança é refletida na média aritmética destes valores que coincidentemente foram iguais a $0,1^{\circ} \mathrm{C}$.

Através da análise do gráfico 6 é possível se observar as variações de valores mínimos e máximos dos índices de ajuste $(\Delta T)$, sua máxima amplitude de valores e o sua característica de comportamento quanto à linearidade de suas curvas nas 6 condições térmicas. Estas informações estão resumidas na tabela 9.

Tabela 9 - Comportamento dos Índices de Ajuste

\begin{tabular}{|c|c|c|c|}
\hline MEDIÇÃO & $\begin{array}{c}\text { ÍNDICE DE } \\
\text { AJUSTE }(\Delta \mathrm{T})\end{array}$ & AMPLITUDE & $\begin{array}{c}\text { COMPORTAMENTO } \\
\text { DE } \Delta \mathrm{T}\end{array}$ \\
\hline Desoc/Ocup & $-0,2<\Delta \mathrm{T}<0,4$ & $0,6^{\circ} \mathrm{C}$ & $\sim$ Linear \\
\hline Desocupada & $-0,2<\Delta \mathrm{T}<0,7$ & $0,9{ }^{\circ} \mathrm{C}$ & $\sim$ Linear \\
\hline
\end{tabular}

Por meio das informações da tabela 9, nota-se que a máxima diferença de valor dos índices de ajuste (amplitude) nas duas situações de medição não passa de $1{ }^{\circ} \mathrm{C}$ e o comportamento destes índices, visível no gráfico 8 , apresentam características quase lineares, principalmente nos setpoints $21{ }^{\circ} \mathrm{C}$ a $25{ }^{\circ} \mathrm{C}$. A exceção foi a temperatura $26{ }^{\circ} \mathrm{C}$ (Situação "Desocupado") que apresentou uma inexplicável elevação em seu valor. 


\subsection{RESULTADOS E ANÁLISES DA ATIVIDADE 6}

A atividade 6 é dedicada aos objetivos específicos $N^{\circ} 2$ e 3 propostos no escopo inicial da pesquisa. Trata-se de estudos adicionais à proposta inicial, importantes para uma melhor compreensão das condições térmicas do ambiente. Visam, além de ampliar o conhecimento sobre os efeitos do sistema de climatização do tipo teto frio no ambiente, fomentar futuros estudos a serem desenvolvidos também com outros sistemas de climatização, haja vista a sua utilização geral como auxílio em análises das condições ambientais para estudo de conforto térmico.

Os resultados apresentados na atividade 6 se referem às condições de ensaio, tendo como referência os setpoints de temperatura de $21^{\circ} \mathrm{C}$ a $26^{\circ} \mathrm{C}$, medidos no período do ano considerado para as duas situações de medição: ambiente "Desocupado/Ocupado" e ambiente "Desocupado".

\subsubsection{CARACTERIZAÇÃO DO AMBIENTE EXPERIMENTAL COM RELAÇÃO AO PERFIL DE ESTRATIFICAÇÃO DE TEMPERATURA DO AR}

A compreensão das condições térmicas do ambiente é importantíssima para se avaliar se o sistema de condicionamento de ar está atendendo ao seu propósito primordial que é oferecer conforto térmico a seus ocupantes.

Para isso, este estudo pretende caracterizar o perfil de estratificação da temperatura do ar do ambiente experimental, comparando-o com as indicações da norma ISO 7726 (1998), que determina os critérios para se considerar um ambiente homogêneo. Os resultados obtidos através de análises estatísticas indicarão se o ambiente poderá ser considerado homogêneo ou não, mesmo que o experimento tenha sido realizado em regime transiente.

O propósito deste estudo não é fazer uma avaliação do conforto térmico dos ocupantes, pois, seriam necessárias outras ferramentas de avaliação subjetiva. Porém, sabe-se que o ambiente influencia direta ou indiretamente a sensação térmica das pessoas (FANGER, 1972). Por isso, este estudo é tão importante para se entender indiretamente qual é o efeito da variação de temperatura no humor das pessoas. Dessa forma, algumas recomendações de conforto térmico sugeridas por 
algumas normas internacionais como a ISO 7730 (1994) e ASHRAE Standard 55 (2004), são comentadas e analisadas neste estudo.

Um exemplo da importância do entendimento das condições térmicas do ambiente é a compreensão dos efeitos da temperatura e suas flutuações na percepção da sensação térmica humana. Segundo a norma ISO 7730 (1994), que determina os índices de satisfação térmica humana e que estabelece as condições de conforto térmico de um ambiente, um dos principais efeitos indesejáveis da estratificação de temperatura do ar, é a sensação de frio nos pés ou calor na cabeça, ou vice-versa. Conforme comentado anteriormente na revisão da literatura, esta norma comenta que se o gradiente de temperatura entre os pés e a cabeça for maior que $3^{\circ} \mathrm{C}$ pode ocorrer desconforto local, embora o corpo como um todo possa estar em situação de conforto. Segundo esta norma, para que este fato não ocorra, o gradiente de temperatura não deve ser maior que $3^{\circ} \mathrm{C}$, para pessoas em atividade leve, vestindo roupa com isolamento de 0,5 a 0,7 clo. Este limite de diferença de temperatura do ar na direção vertical, com o valor máximo de $3{ }^{\circ} \mathrm{C}$, também é recomendado pela norma ASHRAE STANDARD 55 (2004), que estabelece que para prevenir o desconforto localizado, a diferença de temperatura dentro da zona ocupada entre os níveis $0,10 \mathrm{~m}$ a $1,10 \mathrm{~m}$ não deve exceder $3^{\circ} \mathrm{C}$.

A seguir são apresentados alguns resultados das medições feitas pelos sensores móveis e fixos nos 16 pontos de medição e 6 alturas para os 6 setpoints de temperaturas estipulados. A partir destes resultados algumas análises serão apresentadas posteriormente.

\section{A. Resultados das temperaturas do ar nas 16 posições e 6 alturas de medição}

As informações contidas em tabelas e gráficos, que embasam os resultados da variável MSM coletada pelos sensores móveis nas 16 posições do plano horizontal e 6 alturas de medição nos 6 setpoints de temperatura se encontram no APÊNDICE C. Através destes gráficos, gerados a partir das tabelas 60 a 71, é possível se observar o comportamento das curvas das temperaturas de cada um dos 16 pontos de medição e assim verificar como a temperatura do ar é distribuída dentro do ambiente. Em todos estes gráficos, os pontos que determinam a temperatura em cada altura foram interligados de forma ligeiramente linear 
Adicionalmente, através das tabelas: 72 e 74, presentes no APÊNDICE D, são gerados os gráficos 9 e 10, presentes neste capítulo. Estes gráficos apresentam as curvas referentes aos médias de temperatura dos 16 pontos de medição nas 6 alturas sob 6 condições térmicas diferentes. Trata-se de uma visão geral das condições térmicas onde é possível se observar o comportamento da temperatura média do ar em cada uma das alturas de medição. A partir destes dados serão feitas considerações sobre o perfil de estratificação do ar e análises mais detalhadas nas alturas de conforto.

Gráfico 9 - Temperatura média do ar dos 16 pontos de medição e 6 alturas - Ocup./Desoc.

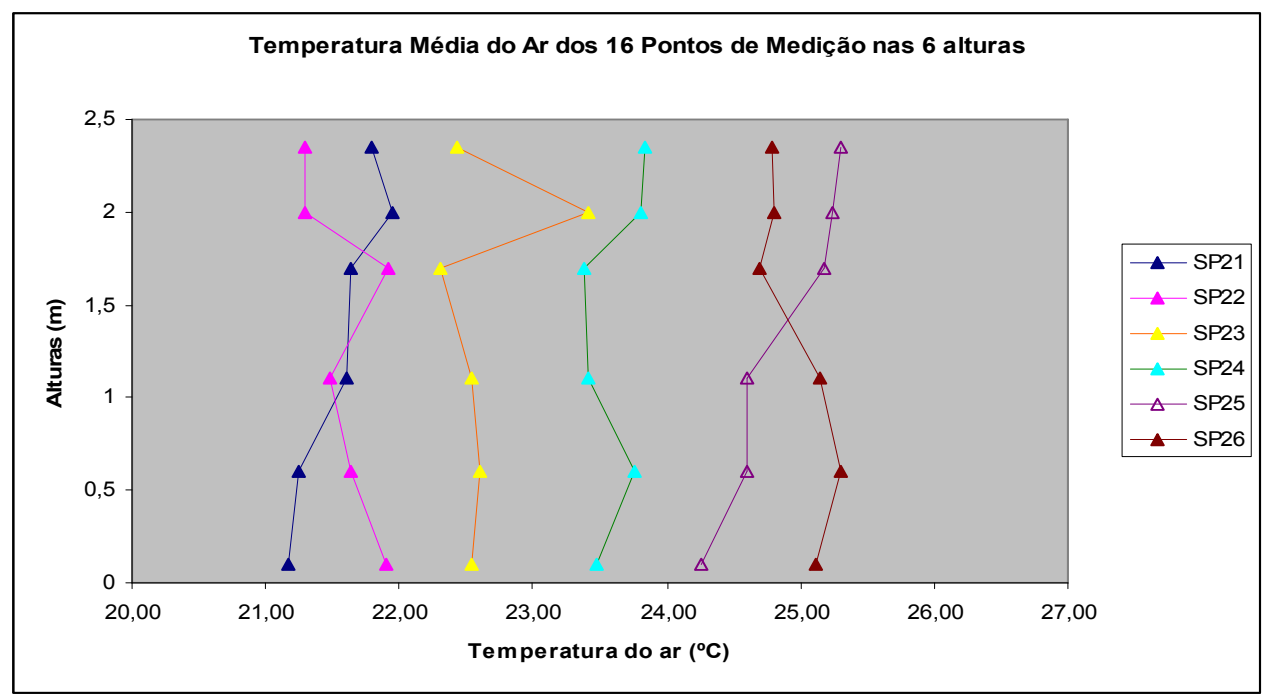

Gráfico 10 - Temperatura média do ar dos 16 pontos de medição e 6 alturas - Ocup./Desoc.

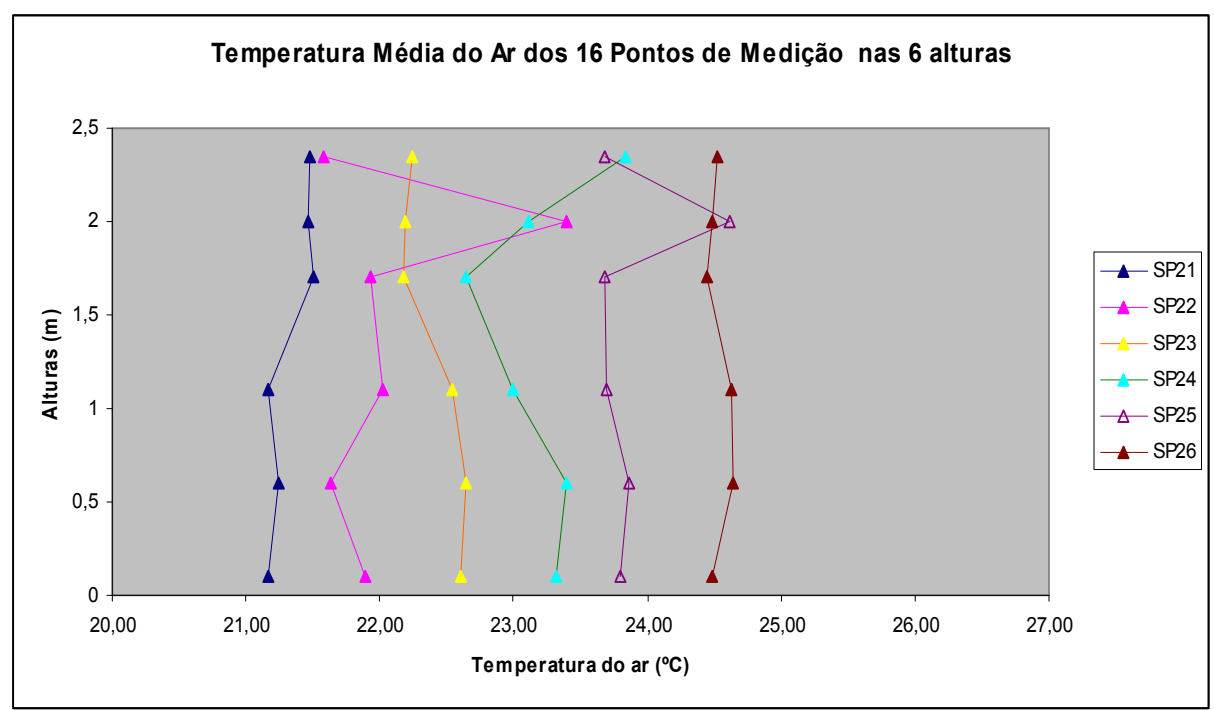




\section{B. Análises das características térmicas do ambiente}

As análises das condições térmicas foram feitas com base nos resultados apresentados nas tabelas 72 a 75 do APÊNDICE D e nos gráficos 9 e 10. Como auxílio a estas análises foram utilizados as seguintes normas e guias de referência:

ISO 7730 (1994): Ambientes térmicos moderados - Determinação dos índices $P M V$ e PPD e especificações das condições para conforto térmico. Esta norma propõe um método de determinação da sensação térmica e o grau de desconforto das pessoas expostas a ambientes térmicos moderados e especifica condições térmicas aceitáveis para o conforto.

ISO 7726 (1998): Ambientes térmicos - Instrumentos e métodos para medições das quantidades físicas. Esta norma especifica as características mínimas dos instrumentos de medição das variáveis físicas, assim como apresenta métodos de medição desses parâmetros.

ASHRAE Standard 55 (2004): Ambientes Térmicos - Condição para ocupação humana. Esta norma americana especifica condições ambientais aceitáveis para a perfeita saúde das pessoas sujeitas a pressões atmosféricas equivalentes a altitudes superiores a 3,00 m em ambientes internos projetados para a ocupação humana por períodos não inferiores há 15 minutos.

ASHRAE Fundamentals Handbook (2005) - cap. 8 Thermal Comfort: Guia normativo da sociedade Americana de aquecimento, refrigeração e ar condicionado. Apresenta os fundamentos de termoregulação humana e conforto em termos úteis aos engenheiros para a operação de sistemas e preparação de projetos e aplicações para o conforto dos ocupantes de edificações. Ela apresenta de maneira resumida todos os dizeres das normas ISO anteriormente referidas.

Tendo-se por base a Fig. 42, as zonas de influência são dividas em três locais previamente determinados em planta, abrangendo a sala inteira, com características diferentes de ocupação. Estas zonas compreendem: a zona de ocupação (próximos às estações de trabalho - Pontos $2,3,6,7,10,11,14$ e 15); zona periférica (próximo às janelas; teoricamente, com maior risco de sofrer influências da radiação solar - Pontos 4, 8, 12 e 16) e zona de circulação (espaço entre os mobiliários e a lousa usado para circulação de pessoas - Pontos 1, 5, 9 e 13).

Em cada uma das 16 posições, a variável temperatura foi medida nas mesmas alturas consideradas na atividade 5 : níveis 0,$10 ; 0,60 ; 1,10 ; 1,70 ; 2,00$ e 
2,35 m, sendo que alguns destes níveis são recomendados pelas normas internacionais.

A ISO 7730 (1994) recomenda os níveis $0,10 \mathrm{~m}$ (nível do tornozelo); 0,60 m (nível do abdômen); 1,10 m (nível da cabeça), para conforto de pessoas sentadas e 0,$10 ; 1,10$ e $1,70 \mathrm{~m}$, para pessoas em pé. Os demais níveis (superiores) foram utilizados para complementar a análise do perfil de estratificação da temperatura do ar, atendendo as especificações da norma ISO 7726 (1985) que estabelece os critérios para a caracterização de ambientes homogêneos.

Com base na observação das tabelas 72 a 75 do APÊNDICE D foram feitas as seguintes considerações sobre as condições térmicas do ambiente.

\section{Característica de homogeneidade do ambiente}

No caso desta pesquisa, o laboratório se enquadra no ambiente do tipo C, pois as medições foram executadas em ambientes moderados, próximos do conforto. Para este tipo de ambiente, a norma ISO 7726 (1998) caracteriza como ambiente homogêneo àquele que apresenta uma relação de desvio padrão das temperaturas médias pelos seus valores espaciais médios menores que $\pm 5 \%$ (DP/Media < $5 \%$ ).

Para esta análise foram utilizadas as tabelas 72 e 74, às quais geraram os gráficos 9 e 10, onde são apresentadas as temperaturas médias do ar das 16 posições por altura, seu desvio padrão e a relação do desvio padrão pela média. Verificou-se que os resultados atenderam as especificações da ISO 7726 (1998), porque a relação do desvio padrão das 6 temperaturas médias (correspondentes às 6 alturas de medição) e seus valores espaciais médios não excedeu $\pm 5 \%$ (DP/Media < 5 \%). Portanto, o ambiente pode ser considerado homogêneo.

O mesmo critério foi utilizado na análise das alturas mais importantes para 0 conforto térmico, alturas 0,$10 ; 0,60$ e 1,10 m. As informações são baseadas nas tabelas 73 e 75 do APÊNDICE D, onde constam os dados das temperaturas médias por setpoint de temperatura considerando as três zonas de influência e o ambiente como um todo. 
Nos níveis que compreendem a região entre o tornozelo (nível $0,10 \mathrm{~m}$ ) e o abdômen (nível 0,60 m), para pessoas sentadas (situação verificada durante as medições), observou-se que nos 16 pontos de medições do ambiente, em todas as zonas de influência, a temperatura do ar se manteve homogênea desde o nível dos pés até o nível do abdômen. Isto pode ser comprovado pela relação DP/Media em relação a estas duas alturas, onde se observa que a DP/Media $<5 \%$. Para o cálculo desta relação, inicialmente, é calculada a média das temperaturas das duas alturas (h1 e h2); depois, o desvio padrão destas duas temperaturas e por último a relação do desvio padrão dividido pela média

Com relação ao comportamento da temperatura nas diferentes zonas de influência, foram levadas em consideração as alturas de referência para conforto $(0,1 \mathrm{~m}$ e $0,6 \mathrm{~m})$.

Com Bse nas informações das tabelas 73 e 75 (APÊNDICE D), nota-se que as temperaturas nas 3 zonas são bastante uniformes, com predominância de homogeneidade nas zonas periféricas e zonas de ocupação, onde a relação de DV/Media foi menor. Observa-se também que a zona periférica, que fica próxima à janela, não sofre muita influência da radiação solar externa, pois apresentou uma boa homogeneidade em relação às duas outras zonas. O pior nível de homogeneidade aconteceu na zona de circulação, talvez em decorrência da abertura de portas durante as aulas, comprovando-se a influência do meio externo nas condições térmicas do ambiente.

Outro fato observado é que as temperaturas do ar medidas pelos sensores móveis principalmente na situação de medição "ocupado/desocupado" foram maiores nos pontos de medição que ficam abaixo dos circuitos de água gelada 8, 9, 10 e 11 (Pontos de medição 9 a 16). Um dos supostos motivos talvez seja o fato desta região ser mais quente em decorrência da existência dos equipamentos de automação e temperatura de ponto de orvalho na região abaixo destes circuitos normalmente ser maior que a temperatura de ponto de orvalho dos outros circuitos. Como resultado, as válvulas destes circuitos $(8,9,10$ e 11) ficam mais tempo fechadas (cor vermelha), que as dos outros favorecendo o aumento de temperatura nesta região. A Fig. 43 mostra o exato momento quando acontece este evento: 


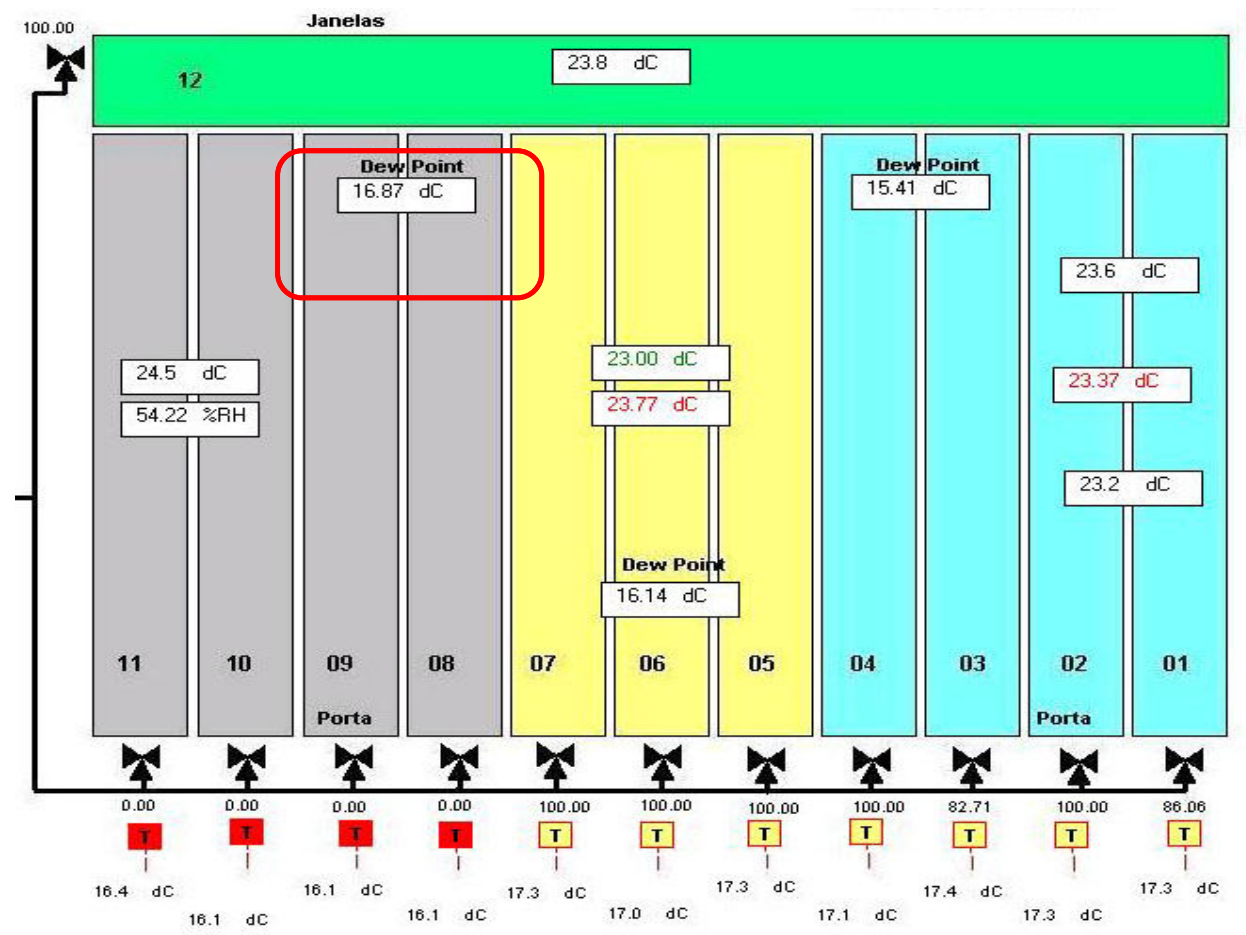

Figura 43 - Representação gráfica, da temperatura do ar na superfície, no nível h2=0,60m. Fonte: Ilustração retirada da Tela de Interface do Aplicativo ComfortView

\section{Diferença na temperatura do ar, no sentido vertical e perfil de estratificação}

Com base nas tabelas 72 e 74 (APÊNDICE D), observou-se que para cada uma das 6 condições térmicas, a variação das temperaturas médias do ar de cada um dos 6 níveis de medição, foi muito pequena, fato comprovado pelo baixo valor de desvio padrão em todas as alturas. Este comportamento foi verificado nas duas situações de medição, de forma que resumidamente, os maiores valores de desvios padrões das temperaturas para cada situação podem ser vistos no quadro 6 .

Quadro 6 - Desvio padrão das alturas nos 6 setpoints de temperatura

\begin{tabular}{|c|c|}
\hline Situação & Desvio Padrão da temperatura nas 6 alturas e 6 setpoints \\
\hline Ocup./Desoc. & $<0,43$ \\
\hline Desocupado & $<0,67$ \\
\hline
\end{tabular}


Com relação ao perfil de estratificação do ar, por meio dos gráficos 9 e 10, nota-se que, nas duas situações de medição, existe uma ligeira estratificação da temperatura, que se iniciou no nível $0,60 \mathrm{~m}$, com um pequeno aumento da temperatura. Nesta altura, estavam situados os principais dissipadores de calor como computadores e pessoas. As demais alturas apresentaram uma pequena variação na média, com exceção da altura $h 5=2,00 \mathrm{~m}$, onde houve um ligeiro aumento da temperatura em relação às demais alturas. Nas proximidades do teto, altura mais elevada $(\mathrm{h} 6=2,35 \mathrm{~m}$ ), na maioria dos casos, a temperatura do ar é levemente diminuída em relação a altura de 2,00 $\mathrm{m}$ talvez pela proximidade do teto frio. Entretanto, esta diferença é quase irrelevante e menor que $0,5^{\circ} \mathrm{C}$. Portanto, pode-se concluir que praticamente, o sistema de teto frio não provoca estratificação do ar no ambiente.

Entretanto, observou-se que existe uma pequena diferença entre os valores de temperatura média e o setpoint, isto é, pelas curvas apresentadas nos gráficos 9 e 10, verifica-se que as temperaturas médias calculadas para cada altura, em sua grande maioria, apresentaram valores mais baixos que os valores de setpoint de temperatura. Esse fenômeno aconteceu principalmente nos setpoints 22 a $26^{\circ} \mathrm{C}$.

\section{Desconforto térmico local causado por diferenças de temperatura}

A insatisfação térmica também pode ser causada por aquecimento ou resfriamento indesejável em uma parte específica do corpo (desconforto térmico local). Para esta situação, a norma ASHRAE Standard 55 (2004), recomenda um limite de desconforto térmico baseado em um critério de insatisfação de 5\% a 15\%. Um dos aspectos ambientais decorrentes de alguma alteração na uniformidade no ambiente que podem ocasionar o desconforto local pode ser a diferença vertical de temperatura do ar

A diferença vertical de temperatura do ar, em uma ambiente fechado, geralmente aumenta do piso ao teto. Esta diferença de temperatura pode ser verificada pelo perfil de estratificação da temperatura e ser expressa por um desconforto térmico localizado principalmente nos níveis dos pés $(0,1 \mathrm{~m})$ e da 
cabeça $(1,10 \mathrm{~m})$, caso o gradiente de temperatura seja maior que $3^{\circ} \mathrm{C}$, para pessoas em atividade leve, vestindo roupa com isolamento de 0,5 clo a 0,7 clo (ASHRAE Standard 55, 2004).

No caso desta pesquisa, as diferenças verticais de temperatura, entre os níveis $0,1 \mathrm{~m}$ e $1,1 \mathrm{~m}$, apresentaram valores inferiores a $3{ }^{\circ} \mathrm{C}$, conforme pode ser observado na tabela 10. Portanto, não houve a evidência de desconforto em relação ao gradiente de temperatura.

Tabela 10 - Temperaturas do Ambiente nos níveis de conforto 0,1 e 1,1 m

\begin{tabular}{|c|c|c|c|c|c|}
\hline \multirow{2}{*}{$\begin{array}{c} \\
\text { Setpoint } \\
{\left[{ }^{\circ} \mathrm{C}\right]}\end{array}$} & \multirow[b]{2}{*}{$\begin{array}{c}\text { altura } \\
{[\mathbf{m}]}\end{array}$} & \multicolumn{2}{|c|}{ "Desoc./Ocup." } & \multicolumn{2}{|c|}{ "Desocupado" } \\
\hline & & $\begin{array}{c}\text { Temp. Média do } \\
\text { Ar -16 Pontos } \\
{\left[{ }^{\circ} \mathrm{C}\right]}\end{array}$ & $\begin{array}{c}\text { Diferença de } \\
\text { temperatura } \\
{\left[{ }^{\circ} \mathrm{C}\right]}\end{array}$ & $\begin{array}{c}\text { Temp. Média do } \\
\text { Ar -16 Pontos } \\
{\left[{ }^{\circ} \mathrm{C}\right]}\end{array}$ & $\begin{array}{c}\text { Diferença de } \\
\text { temperatura } \\
{\left[{ }^{\circ} \mathrm{C}\right]}\end{array}$ \\
\hline \multirow{2}{*}{21} & 1.1 & 21.60 & \multirow{2}{*}{0.43} & 21.16 & \multirow{2}{*}{0.01} \\
\hline & 0.1 & 21.17 & & 21.17 & \\
\hline \multirow{2}{*}{22} & 1.1 & 21.49 & \multirow{2}{*}{0.41} & 22.02 & \multirow{2}{*}{0.13} \\
\hline & 0.1 & 21.90 & & 21.89 & \\
\hline \multirow{2}{*}{23} & 1.1 & 22.54 & \multirow{2}{*}{0.01} & 22.54 & \multirow{2}{*}{0.06} \\
\hline & 0.1 & 22.54 & & 22.61 & \\
\hline \multirow{2}{*}{24} & 1.1 & 23.42 & \multirow{2}{*}{0.06} & 22.99 & \multirow{2}{*}{0.33} \\
\hline & 0.1 & 23.48 & & 23.3 & \\
\hline \multirow{2}{*}{25} & 1.1 & 24.59 & \multirow{2}{*}{0.34} & 23.69 & \multirow{2}{*}{0.10} \\
\hline & 0.1 & 24.25 & & 23.79 & \\
\hline \multirow{2}{*}{26} & 1.1 & 25.15 & \multirow{2}{*}{0.03} & 24.63 & \multirow{2}{*}{0.15} \\
\hline & 0.1 & 25.12 & & 24.48 & \\
\hline
\end{tabular}

\section{Desconforto térmico local causado por assimetria de temperatura radiante}

O efeito do desconforto térmico local por assimetria de temperatura radiante ou assimetria de radiação no ambiente experimental, caso exista, pode ser decorrentes das superfícies das paredes, pisos, teto, computadores, lâmpadas, equipamentos de automação ou devido à radiação solar direta provinda da janela da sala.

Para esta análise, as orientações e recomendações com respeito a assimetria de radiação podem ser observadas pelas normas ISO 7730 (1994) e ASHRAE 
Standard 55 (2004) e estes foram baseadas nos estudos relatados por Fanger et al. De acordo com a ASHRAE Standard 55 (2004), os limites máximos para se evitar o desconforto local decorrente da assimetria da temperatura radiante, para indivíduos nas condições de atividade leve e sedentária, medidos à altura de 0,60 m (para pessoas sentadas) ou à $1,10 \mathrm{~m}$ (para pessoas em pé), no caso do teto frio, é $14^{\circ} \mathrm{C}$.

Os dados da Tabela 11 referem-se às informações de assimetria de radiação coletadas à altura de $0,60 \mathrm{~m}$. Os dados mostram que praticamente não existe problema de desconforto térmico local por assimetria de radiação na sala experimental, pois os valores são menores que os limites determinados pela ASHRE Standard 55 (2004).

Tabela 11 - Dados de assimetria de radiação por setpoint de temperatur
\begin{tabular}{|c|c|}
\hline Setpoint $\left[{ }^{\circ} \mathrm{C}\right]$ & Variação de Assimetria de radiação \\
\hline 21 & $-0,06<\left(\Delta t_{p r}\right)<0,07$ \\
\hline 22 & $0<\left(\Delta t_{p r}\right)<0,03$ \\
\hline 23 & $-0,03<\left(\Delta t_{p r}\right)<0,03$ \\
\hline 24 & $-0,04<\left(\Delta t_{p r}\right)<0,04$ \\
\hline 25 & $-0,03<\left(\Delta t_{p r}\right)<0,03$ \\
\hline 26 & $-0,04<\left(\Delta t_{p r}\right)<0,01$ \\
\hline
\end{tabular}




\subsubsection{DETERMINAÇÃO DO “LOCAL IDEAL”}

Este capitulo apresenta os resultados referentes ao objetivo especifico $\mathrm{N}^{\circ} 3$ através da representação gráfica (modelo) das condições térmicas dos 96 pontos de medição, obtidos com o auxílio de um aplicativo computacional denominado Paraview que utiliza métodos numéricos e algoritmos do Computational Fluid Dynamics (CFD). Através deste aplicativo foi possível se obter a representação gráfica das condições térmicas do laboratório no período de medição e o "Local Ideal", onde a temperatura média do ar é a mais representativa do ambiente e no qual seria interessante se posicionar um sensor de temperatura para coleta da temperatura de referência.

Primeiramente, o primeiro procedimento foi modelar o ambiente experimental de acordo com a geometria da sala. Isto foi possível com a inserção das informações de temperatura coletadas pelos sensores em cada uma das 16 posições no plano horizontal e 6 pontos de medição no plano vertical, o que gerou uma representação pontual das diferentes temperaturas em cada um dos 96 pontos de medição.

Posteriormente, por meio de um processo computacional de interpolação dos dados de temperatura dos 96 pontos de medição foi possível gerar uma representação gráfica das condições térmicas do ambiente. A interpolação utilizada pelo aplicativo foi do tipo linear, isto é, entre o intervalo de cada ponto, foram determinadas automaticamente gradientes de temperaturas variando de forma linear. Este tipo de interpolação foi adequado a este estudo porque a variação da temperatura não sofre mudanças bruscas e não existiam fatores que poderiam modificar significativamente o perfil das temperaturas entre um ponto e outro, pois o ambiente foi considerado homogêneo, conforme conclusão do estudo sobre a caracterização do ambiente térmico. O resultado da interpolação destes pontos gera uma superfície em 3 dimensões na qual é possível a visualização das condições térmicas em qualquer ponto ou região da sala.

A título de exemplo, os resultados das vistas aéreas dos planos horizontais nas 6 alturas das condições térmicas para situação de medição com o ambiente "Ocupado./Desocupado" e "Desocupado" podem ser visualizados no APÊNDICE E. 
Posteriormente, para se determinar o "Local Ideal", devem-se verificar quais são os locais com maior ocorrência da "temperatura ideal" que corresponde ao valor da variável temperatura média do sensor móvel (MSM).. A tabela 12 resume todas as "Temperaturas Ideais" por setpoint nas duas situações de medições.

Tabela 12 - "Temperaturas Ideais" para as duas situações de medição

\begin{tabular}{|c|c|c|c|c|c|c|c|}
\cline { 3 - 8 } \multicolumn{2}{c|}{} & \multicolumn{6}{|c|}{ Setpoints de Temperatura $\left[{ }^{\circ} \mathbf{C}\right]$} \\
\cline { 3 - 8 } \multicolumn{2}{c|}{} & $\mathbf{2 1}$ & $\mathbf{2 2}$ & $\mathbf{2 3}$ & $\mathbf{2 4}$ & $\mathbf{2 5}$ & $\mathbf{2 6}$ \\
\hline $\begin{array}{c}\text { Temperaturas } \\
\text { Ideais }\left[{ }^{\circ} \mathrm{C}\right]\end{array}$ & OCUP./DESOC. & 21,3 & 21,8 & 22,8 & 23,7 & 24,7 & 25,3 \\
\cline { 2 - 8 } & DESOC & 21,3 & 21,8 & 22,8 & 23,3 & 23,9 & 24,7 \\
\hline
\end{tabular}

Em cada um destes gráficos, o software Paraview representa a "temperatura ideal" como sendo uma "linha" de cor branca. As regiões de ocorrência da "temperatura ideal" representam indicações de que estes locais podem ser os locais procurados. Entretanto, devido à constatação da diversidade de locais onde esta temperatura poderia estar, foi convencionado nesta pesquisa que os 16 pontos que constituem o plano horizontal na altura h2=0,60 m fossem divididos em 9 quadrantes de dimensões iguais, conforme a Fig. 44. Portanto, as análises serão feitas com base nestes quadrantes ou regiões.

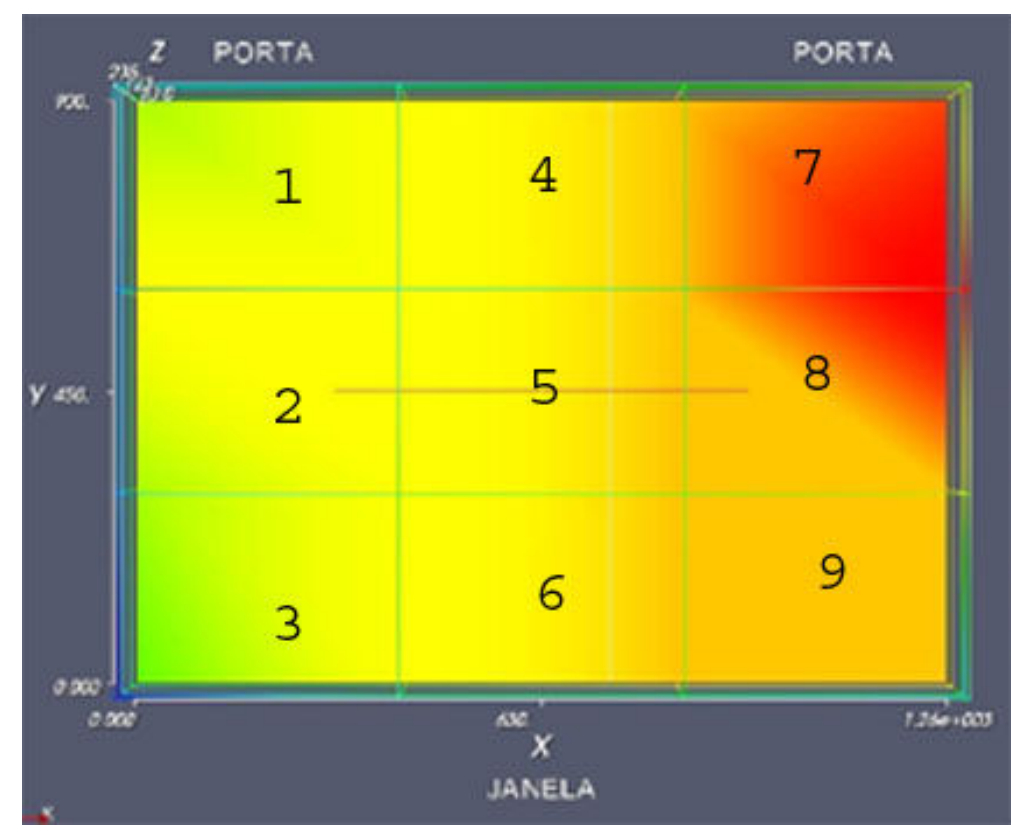

Figura 44 - Regiões de delimitação (Quadrantes) 
A determinação do "Local Ideal" é realizada com base na freqüência de ocorrência da "temperatura ideal" dentro de cada quadrante ou região. O critério para se verificar se a temperatura ideal representada pela "linha" branca pode pertencer a uma região é baseada em uma "Tabela de Decisão" (Tabelas 13 e 14). Neste critério, caso a "linha" branca estiver dentro do quadrante e esta for maior que um terço do comprimento do quadrante, é atribuído o valor "1". Caso contrário, ela recebe o valor " 0 ". O total de ocorrências comuns às 6 condições térmicas é considerado o "local ideal"

Tabela 13 - Tabela de decisão - Situação: Ocup./Desoc

\begin{tabular}{|c|c|c|c|c|c|c|c|c|c|c|c|}
\hline \multirow{7}{*}{$\begin{array}{c}\text { Ocupado / } \\
\text { Desocupado }\end{array}$} & $\mathrm{SP}\left[{ }^{0} \mathbf{c}\right]$ & 1 & 2 & 3 & 4 & 5 & 6 & 7 & 8 & 9 & $\begin{array}{c}\text { OCORRÊNCIA } \\
\text { NOS } \\
\text { QUADRANTES }\end{array}$ \\
\hline & 21 & & & & 1 & 1 & 1 & & & & $4 ; 5 ; 6$ \\
\hline & 22 & & & & 1 & 1 & 1 & & & 1 & $4 ; 5 ; 6 ; 9$ \\
\hline & 23 & & & & 1 & 1 & 1 & & & 1 & $4 ; 5 ; 6 ; 9$ \\
\hline & 24 & & & & 1 & 1 & 1 & & & 1 & $4 ; 5 ; 6 ; 9$ \\
\hline & 25 & & & 1 & 1 & 1 & 1 & & & 1 & $3 ; 4 ; 5 ; 6 ; 9$ \\
\hline & 26 & & & & & & & 1 & 1 & & $7 ; 8$ \\
\hline & $\begin{array}{c}\text { Total } \\
\text { Ocorrências }\end{array}$ & 0 & 0 & 1 & 5 & 5 & 5 & 1 & 1 & 4 & \\
\hline & $\begin{array}{c}\text { Maior } \\
\text { Ocorrência }\end{array}$ & \multicolumn{9}{|c|}{5} & \\
\hline
\end{tabular}

Tabela 14 - Tabela de decisão - Situação: "Desocupado"

\begin{tabular}{|c|c|c|c|c|c|c|c|c|c|c|c|}
\hline \multirow{7}{*}{ Desocupado } & $\mathrm{SP}\left[{ }^{0} \mathbf{c}\right]$ & 1 & 2 & 3 & 4 & 5 & 6 & 7 & 8 & 9 & $\begin{array}{c}\text { OCORRÊNCIA } \\
\text { NOS } \\
\text { QUADRANTES }\end{array}$ \\
\hline & 21 & & & & 1 & 1 & 1 & & & 1 & $4 ; 5 ; 6 ; 9$ \\
\hline & 22 & & & 1 & 1 & 1 & 1 & & & 1 & $3 ; 4 ; 5 ; 6 ; 9$ \\
\hline & 23 & & & & 1 & 1 & & 1 & & 1 & $4 ; 5 ; 7 ; 9$ \\
\hline & 24 & & & & 1 & 1 & 1 & & & 1 & $4 ; 5 ; 6 ; 9$ \\
\hline & 25 & & & & 1 & 1 & 1 & & & 1 & $4 ; 5 ; 6 ; 9$ \\
\hline & 26 & & & & 1 & 1 & & & 1 & & $4 ; 5 ; 8$ \\
\hline & $\begin{array}{c}\text { Total } \\
\text { Ocorrências }\end{array}$ & 0 & 0 & 1 & 6 & 6 & 4 & 1 & 1 & 5 & \\
\hline & $\begin{array}{c}\text { Maior } \\
\text { Ocorrência }\end{array}$ & \multicolumn{9}{|c|}{6} & \\
\hline
\end{tabular}


A. Resultados das Condições Térmicas do "Local Ideal" na altura h2=0,60 m

Condições Térmicas do "Local Ideal"

(Situação: Ocup./Desoc. - Vista Aérea do nível h2=0,60 m)

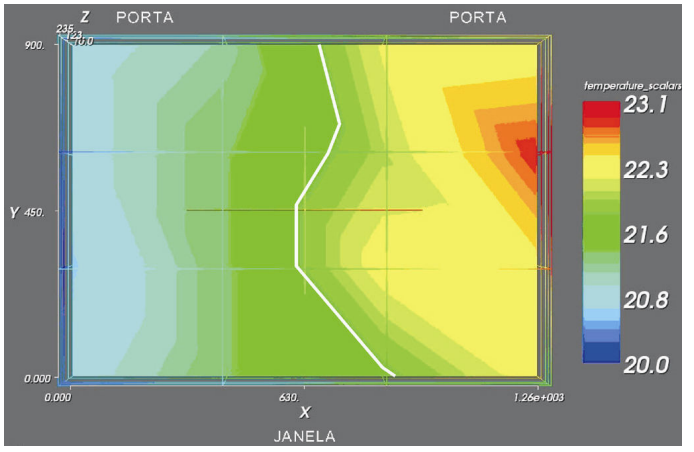

Figura 45 - Ocup./Desoc. -SP21

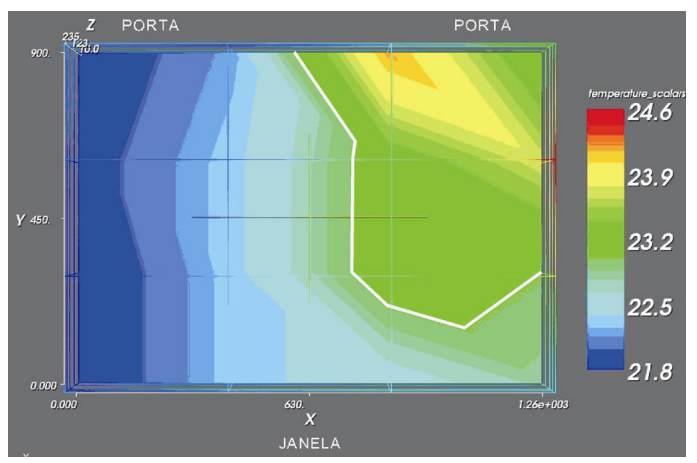

Figura 47 - Ocup./Desoc. -SP23

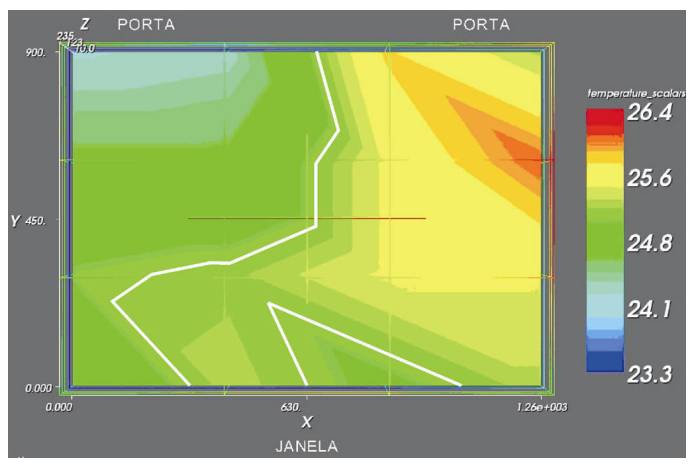

Figura 49 - Ocup./Desoc. -SP25

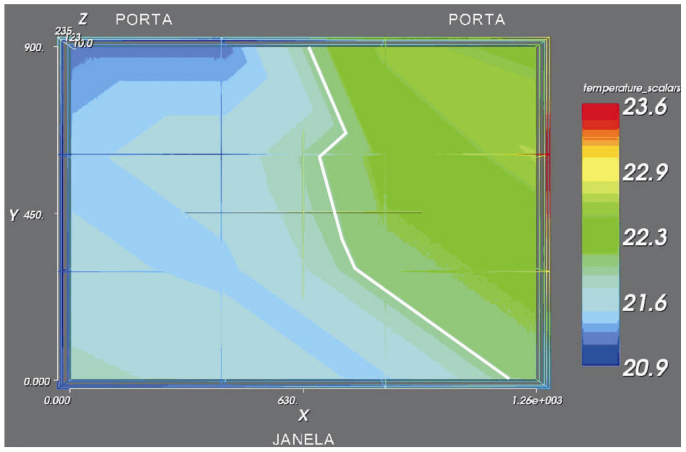

Figura 46 - Ocup./Desoc. -SP22

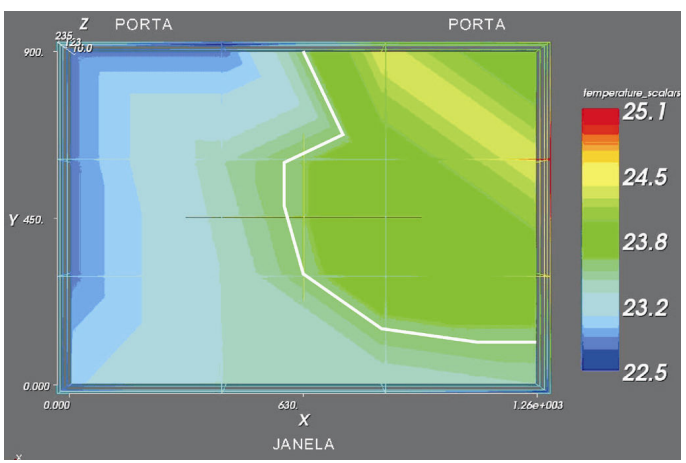

Figura 48 - Ocup./Desoc. -SP24

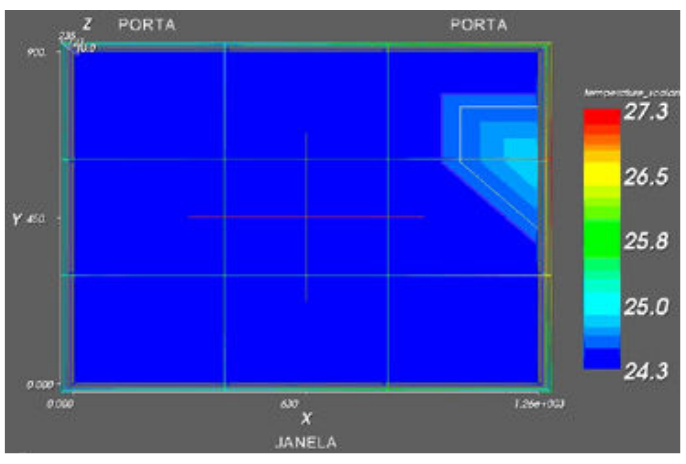

Figura 50 - Ocup./Desoc. -SP26 
Condições Térmicas do "Local Ideal"

(Situação: "Desocupado" - Vista Aérea do nível h2=0,60 m)

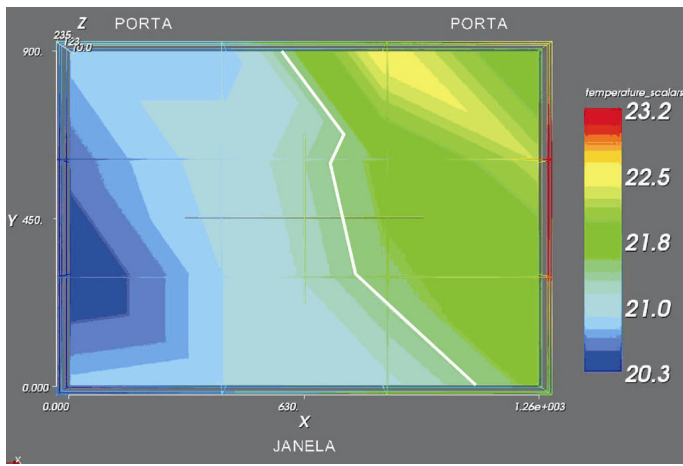

Figura 51 - Desocupado - SP21

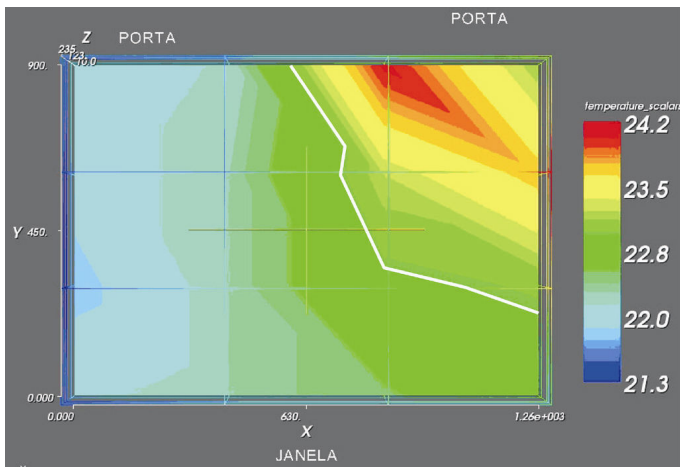

Figura 53 - Desocupado. -SP23

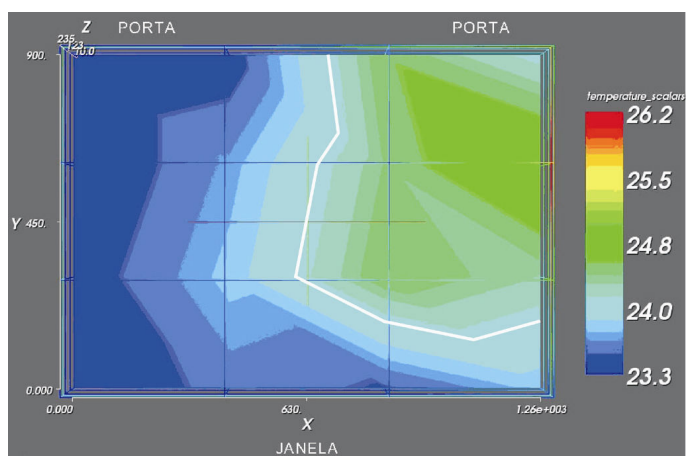

Figura 55 - Desocupado. -SP25

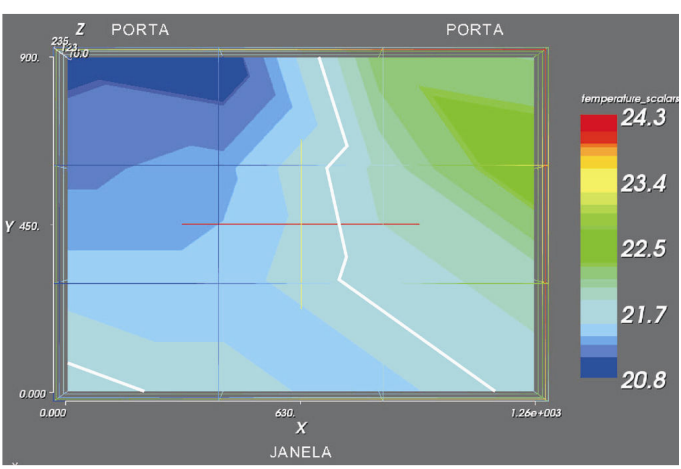

Figura 52 - Desocupado. -SP22

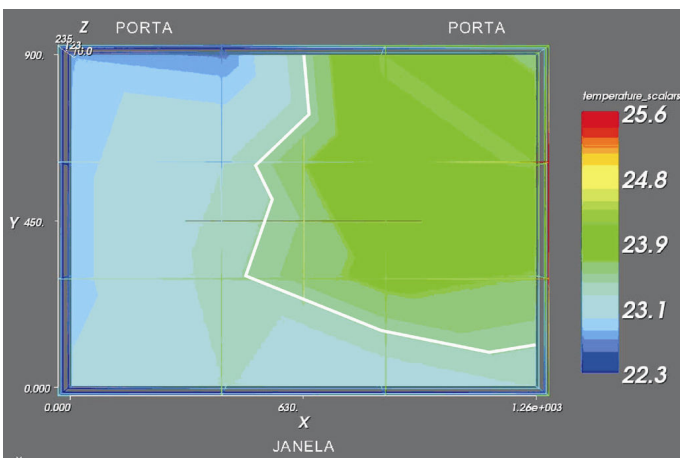

Figura 54 - Desocupado. -SP24

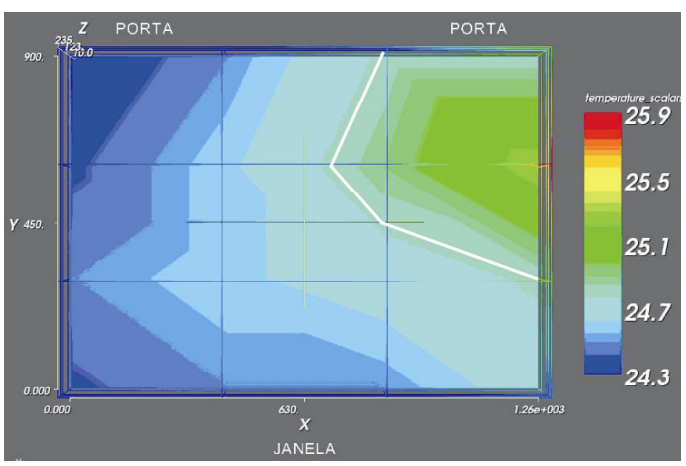

Figura 56 - Desocupado. - SP26 
B. Análise dos "Locais Ideais" na altura $h 2=0,60 \mathrm{~m}$

Por meio das Fig. 45 a 56, onde são apresentadas as condições térmicas do "Local ideal" podem ser feitas as seguintes análises:

Na situação: Ocupado./Desocupado, observou-se que entre os setpoints $21^{\circ} \mathrm{C}$ e $25^{\circ} \mathrm{C}$, o "local ideal" ficou próximo a região central da sala, principalmente nos quadrantes 4, 5 e 6 . A exceção foi o SP26, onde o "local ideal" ficou nos quadrantes 7 e 8. De forma semelhante, na situação: "Desocupado"a maior freqüência de ocorrência da "temperatura ideal" foi na região central da sala em todos os setpoints de temperatura, notadamente nos quadrantes 4 e 5 .

Portanto, a partir destes resultados conclui-se que um local ou região com grandes possibilidades de apresentarem esta "temperatura ideal" são os quadrantes 4 e 5 . Estes quadrantes representam os locais, onde seria interessante posicionar o sensor ou os sensores de temperatura, e com os quais seria possível coletar, com melhor veracidade em relação ao sensor fixo, a informação da temperatura mais representativa do ambiente na altura de conforto. 


\section{CONCLUSÕES E CONSIDERAÇÕES FINAIS}

Os resultados desta pesquisa estão divididos basicamente em três partes, representadas pelos objetivos específicos $N^{0} 1,2$ e 3. O primeiro objetivo específico foi tratado na atividade 5, no qual se buscava determinar os índices de ajuste em 6 diferentes condições de temperatura. O segundo e terceiro objetivo específico, que representam estudos adicionais a esta pesquisa, foram desenvolvidos na atividade 6. Nesta atividade, foram tratados os estudos de caracterização do ambiente térmico através da análise do perfil de estratificação do ar e por meio de uma ferramenta de representação gráfica, onde foi determinado o local ou região, na altura de conforto, onde a temperatura é a mais representativa do ambiente.

Com relação ao objetivo específico $\mathrm{N}^{\circ} 1$, os dados de temperatura do ar através dos sensores fixos e móveis foram coletados, tratados e seus resultados mostrados e analisados nos diferentes capítulos que compõem esta pesquisa. Foram determinados a partir destes dados os índices de ajuste para cada setpoint de temperatura, notadamente na altura de conforto, e seu comportamento foi explicado através de causas e efeitos, que ainda merecem novas pesquisas para complementar e elucidar certas hipóteses levantadas.

Durante o período de medição, foram consideradas duas situações de análise com referência ao período considerado de medição. Uma situação envolvia o período de medição na qual o ambiente estava desocupado e em outro, considerava-se o período de medição total, considerando tanto situação de medição com o ambiente ocupado quanto com ele desocupado. As medições com a sala desocupada foram realizadas no mesmo dia em que houve a medição com "ocupação".

Foi observado que para cada condição térmica foi determinado um índice de ajuste correspondente que não foi exatamente o mesmo nas seis condições de temperatura. Portanto, não foi determinado um único valor de índice de ajuste comum a todos os setpoints e situações de medição, mas sim vários índices individuais para cada setpoint. A obtenção da melhor estimativa dos índices de ajuste demandaria muitas outras medições nas mesmas condições de contorno e um processo mais ágil de tratamento de dados. Como sugestão, estes valores 
deveriam ser gerados de forma automática, onde os dados de medição dos sensores móveis fossem totalmente interligados com o sistema de automação do laboratório gerando automaticamente padrões de comportamento destes índices e possivelmente um valor ou função matemática mais plausível.

Portanto, embora não tenha sido possível obter um único índice de ajuste em todas as situações de medições, foi possível encontrar uma boa estimativa de seu comportamento e um valor aproximado, comprovando-se a eficácia e aplicabilidade do método de trabalho.

Os resultados desta pesquisa estão apresentados na Tabela 15.

Tabela 15 - "Tabela Resumo e 6 setpoints de temperatura

\begin{tabular}{|c|c|c|c|c|c|c|}
\hline \multirow[b]{2}{*}{$\begin{array}{c}\text { Setpoint } \\
{\left[{ }^{\circ} \mathrm{C}\right]}\end{array}$} & \multicolumn{2}{|c|}{$\begin{array}{l}\text { "TEMPERATURAS } \\
\text { IDEAIS" [0] }\end{array}$} & \multicolumn{2}{|c|}{$\begin{array}{c}\text { INDICES DE AJUSTE } \\
{\left[{ }^{\circ}\right]}\end{array}$} & \multicolumn{2}{|c|}{ "LOCAIS IDEAL" } \\
\hline & $\begin{array}{c}\text { Desoc / } \\
\text { Ocup }\end{array}$ & Desocupado & $\begin{array}{c}\text { Desoc / } \\
\text { Ocup }\end{array}$ & Desocupado & $\begin{array}{l}\text { Desoc / } \\
\text { Ocup }\end{array}$ & Desocupado \\
\hline 21 & 21.3 & 21.3 & -0.2 & -0.1 & $4 ; 5 ; 6$ & $4 ; 5 ; 6 ; 9$ \\
\hline 22 & 21.8 & 21.8 & -0.2 & -0.2 & $4 ; 5 ; 6 ; 9$ & $3 ; 4 ; 5 ; 6 ; 9$ \\
\hline 23 & 22.8 & 22.8 & 0.2 & 0.2 & $4 ; 5 ; 6 ; 9$ & $4 ; 5 ; 7 ; 9$ \\
\hline 24 & 23.7 & 23.3 & 0.1 & -0.1 & $4 ; 5 ; 6 ; 9$ & $4 ; 5 ; 6 ; 9$ \\
\hline 25 & 24.7 & 23.9 & 0.2 & 0 & $\begin{array}{c}3 ; 4 ; 5 ; 6 \\
9\end{array}$ & $4 ; 5 ; 6 ; 9$ \\
\hline \multirow[t]{5}{*}{26} & 25.3 & 24.7 & 0.4 & 0.7 & $7 ; 8$ & $4 ; 5 ; 8$ \\
\hline & & & 0.1 & 0.1 & $4 ; 5 ; 6$ & $4 ; 5$ \\
\hline & & & \multicolumn{2}{|c|}{ MEDIA } & \multicolumn{2}{|c|}{ MAIOR FREQUÊNCIA } \\
\hline & & & 0.2 & 0.3 & \multicolumn{2}{|c|}{$4 ; 5$} \\
\hline & & & \multicolumn{2}{|c|}{ DESVIO PADRÃO } & \multicolumn{2}{|c|}{ "REGIÕES IDEAIS" } \\
\hline
\end{tabular}

Com relação a aplicabilidade do índice de ajuste, verifica-se que os índices não apresentaram uma mudança substancial em cada uma das situações de medição, de forma que na média, os índices foram iguais a $0,1^{\circ} \mathrm{C}$. Com base nestes valores, pode-se observar que os índices a serem inseridos no algoritmo do sistema de controle, específicos para o ambiente experimental com sistema de teto frio, não fazem muita diferença em termos de melhora na eficiência do sistema de controle do teto frio, pois estes valores, em módulo, são muito baixos (menores que $1^{\circ} \mathrm{C}$ ). Além disso, verificou-se que praticamente não houve estratificação do ar nas 6 alturas de 
medição, indicando que o sistema de condicionamento de ar e o sistema de automação e controle estão bem regulados. Dessa forma, o(s) sensor(es) de temperatura poderia estar posicionado em qualquer local da sala medindo,com razoável precisão, a temperatura do ar. Por este motivo, pode-se concluir que os quatro sensores fixos existentes na sala, instalados na parede a 2,0 m de altura, medem adequadamente a temperatura do ar.

Tendo-se por base o sistema de condicionamento de ar existente no ambiente experimental com controle das condições ambientais feitos por sensores de temperatura, pode-se concluir que uma melhora desta medição poderia ser alcançada por meio do posicionamento dos sensores de temperatura no chamado "local ideal". O resultado do tratamento dos dados possibilitou verificar que para a maioria dos casos, a "temperatura ideal" foi encontrada nos quadrantes ou regiões 4 e 5. Diante desta constatação, é possível considerar que a melhor região para se colocar um sensor de temperatura para a determinação da temperatura mais representativa do ambiente na altura de conforto $(\mathrm{h} 2=0,60 \mathrm{~m})$ seria nestes dois quadrantes. A Fig. 57 ilustra onde os sensores poderiam ser posicionados. Neste caso, esta figura representa a condição térmica para a situação de medição Ocupado/Desocupado, setpoint $23^{\circ} \mathrm{C}$.

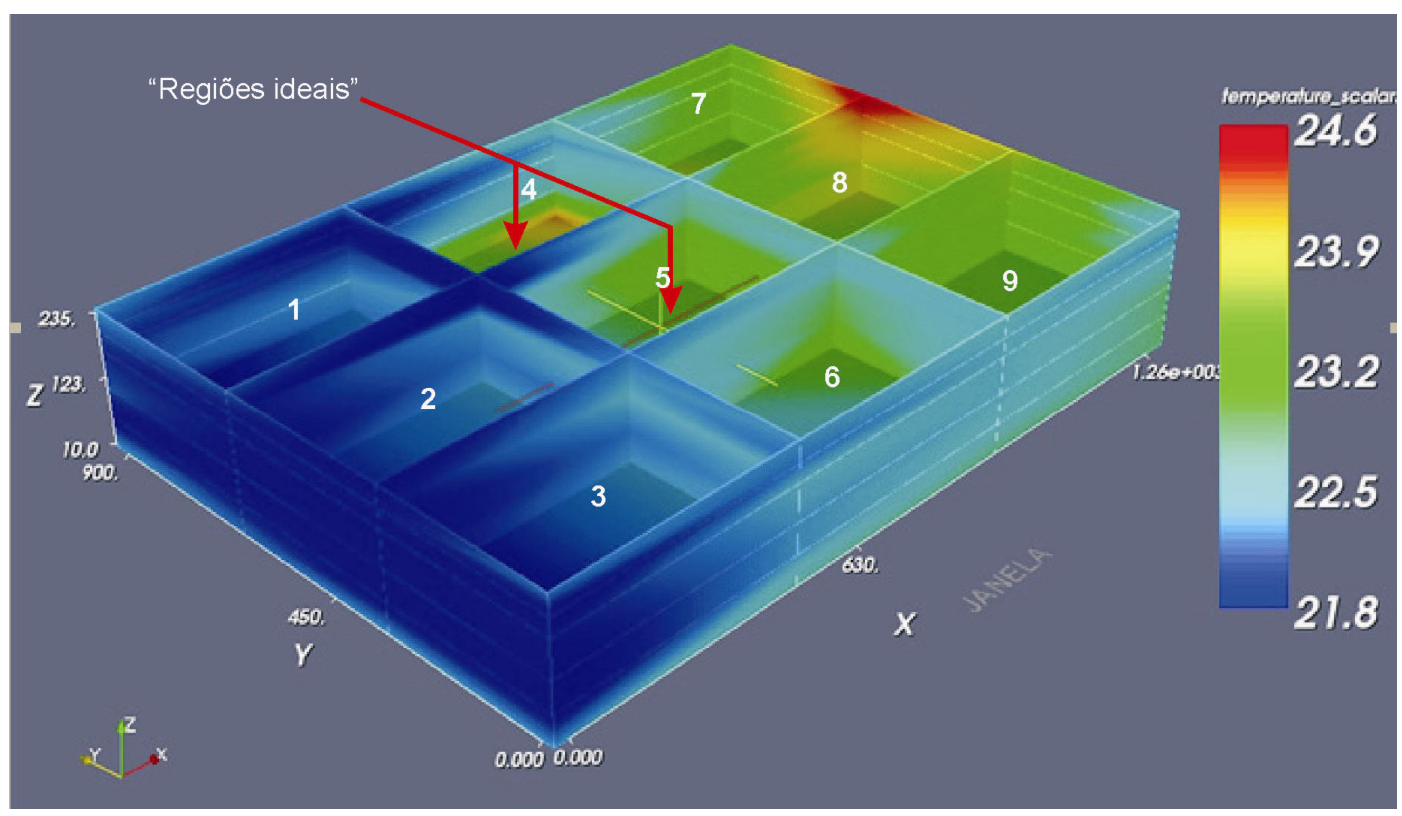

Figura 57 - Regiões Ideais 
Outra sugestão como complementação desta pesquisa é a criação de uma interface no sistema de supervisão predial na qual seja possível a inserção de um campo com a "temperatura desejada" na altura de conforto. Como existe uma diferença desta "temperatura desejada" com o setpoint de temperatura da sala e com o valor medido pelo sensor fixo de temperatura, deveria existir uma tabela correlacionando estes dois valores. Assim, para cada "temperatura desejada" escrita neste campo estaria sendo destinada ao sistema de condicionamento de ar outra temperatura relacionada, que incorporaria o índice de ajuste no valor de temperatura do sensor fixo e um fator de correção entre o valor do sensor fixo e o setpoint de temperatura.

Para isso, seria necessário medir as condições térmicas durante vários dias e em várias condições externas, considerando-se as mesmas condições internas de contorno. Somente através de um cruzamento destas informações baseados em uma grande amostragem seria possível se determinar com mais precisão os índices de ajuste e os fatores de correção para altura de conforto térmico.

Com relação aos objetivos específicos $\mathrm{N}^{0} 2$ e 3 , explicadas na atividade 6 , todas as análises propostas inicialmente foram atendidas com sucesso. Foram realizadas várias análises sobre as condições térmicas tais como a caracterização do ambiente quanto ao perfil de estratificação do ar e o grau de homogeneização do ambiente. Adicionalmente, foram determinados os "locais ideais", e foi feito um mapeamento das condições térmicas para as diferentes condições térmicas impostas pelas condições de contorno. Isso permitiu a visualização da distribuição da temperatura no ambiente experimental, facilitando bastante a compreensão do funcionamento do sistema de condicionamento de ar.

Com relação aos equipamentos e instrumentos utilizados na pesquisa, estes serviram a seu propósito de forma satisfatória. Por exemplo, embora em grande quantidade, o uso de hastes com sensores móveis de temperatura para coleta simultânea de dados se mostrou uma solução bem coerente e discreta, haja vista que os dados numéricos medidos em regime transiente sofrem variações constantes.

A maior dificuldade encontrada foi a medição com a sala ocupada, pois havia uma grande preocupação com a segurança dos equipamentos e a garantia da confiabilidade das medições, pois os equipamentos ficavam expostos às pessoas e sempre havia o risco de alguém se esbarrar em algum sensor ou influenciar nas 
medições através da movimentação em sua proximidade. Entretanto, quanto a esta última situação, comprovou-se que este evento não influenciou substancialmente nas medições. Excluindo-se estas dificuldades, o propósito das medições com a sala ocupada foi importante para se verificar o atendimento do sistema de condicionamento de ar para combater a carga de calor latente e sensível, com máxima fidelidade às condições reais de uso. 


\section{REFERÊNCIAS}

AMERICAN SOCIETY OF HEATING, REFRIGERATING AND AIR-CONDITIONING ENGINEERS. Thermal environmental conditions for human occupancy. Atlanta, GA, c1995. 4 p. ANSI/ASHRAE 55-2004.

BEHNE, M. Indoor air quality in rooms with cooled ceilings: mixing ventilation or rather displacement ventilation? Energy and Buildings, Lausanne, v. 30, n. 2, p. 155-166, jun. 1999.

BRUNK, M.F. Cooling ceilings: an opportunity to reduce energy costs by way of radiant cooling. ASHRAE Transactions, Atlanta, v. 99, n. 2, p. 479-487, 1993.

FANGER, P. O. Thermal comfort, analysis and application in environmental engineering. New York: McGraw-Hill, 1972. 245p.

IMANARI, T.; OMORI, T.; BOGOKI, K. Thermal comfort and energy consumption of the radiant ceiling panel system: comparison with the conventional all-air system. Energy and Buildings, Lausanne, v. 30, n. 2, p. 167-175, jun.1999.

INTERNATIONAL ORGANIZATION FOR STANDARDIZATION. ISO 7726: thermal environments - instrument and method for measuring physical quantities. Geneva, 1998. 39 p.

INTERNATIONAL ORGANIZATION FOR STANDARDIZATION. ISO 7730: moderate thermal environments - determination of the PMV and PPD indexes and specification of the conditions of thermal comfort. Geneva, 1994. $19 \mathrm{p}$.

LEITE, B. C. C. Sistema de ar condicionado com insuflamento pelo piso em ambientes de escritórios: avaliação do conforto térmico e condições de operação. 2003. 235p. Tese (Doutorado) - Escola Politécnica, Universidade de São Paulo, São Paulo, 2003.

LOVEDAY, D. L. et al. Displacement ventilation environments with chilled ceilings: thermal comfort design within the context of the BS EN ISO7730 versus Adaptive debate. Energy and Buildings, Lausanne, v. 34, n.6, p. 573-579, julho. 2002. 
LOVEDAY, D. L. et al. Designing for thermal comfort in combined chilled ceiling/displacement ventilation environments. ASHRAE Transactions, Atlanta, v. 104, n. 1B, p. 901-911, 1998.

MAGALHÃES, M. N.; LIMA, A. C. P. Noções de probabilidade e estatística. 6. ed. São Paulo: EDUSP, 2005. 382 p.

MATSUKI, N. et al. Performance of radiant cooling system integrated with ice storage. Energy and Buildings, Lausanne, v. 30, n. 2, p. 177-183, jun. 1999.

MEDRONHO, R. A. Epidemiologia. São Paulo: Atheneu, 2002. 600 p.

MILONE, G. Estatística geral e aplicada. São Paulo: Thomson Pioneira, 2004. $498 p$.

MIRIEL, J.; SERRES, L.; TROMBE, A. Radiant ceiling panel heating-cooling systems: experimental and simulated study of the performances, thermal comfort and energy consumptions. Applied Thermal Engineering, Oxford, v. 22, n. 16, p. 18611873, nov. 2002.

MONTGOMERY, D. C.; RUNGER, G. C. Estatística aplicada e probabilidade para engenheiros. 2 ed. Rio de Janeiro: Livros Técnicos e Científicos, 2003. 461 p.

MUMMA, S. A. Chilled ceiling in parallel with dedicated with outdoor air systems: Addressing the concerns of condensation, capacity, and cost. ASHRAE Transactions, Atlanta, v. 108, n. 2, p. 220-231, 2002.

NIU, J.; KOOI, J. D.; RHEE, H. V. D. Energy saving possibilities with cooled-ceiling systems. Energy and Buildings, Lausanne, v. 23, n. 2, p. 147-158, dezembro. 1995.

NIU, J.; KOOI, J. V. D.; REE, H. V. D. Cooling load dynamics of rooms with cooled ceilings. Building Services and Engineering and Research Technology, London, v. 18, n. 4 , p. $201-207,1997$.

$\mathrm{NIU}, \mathrm{J}$; $\mathrm{KOOI}, \mathrm{J}$. V. Indoor climate in rooms with cooled ceiling systems. Building and Environment, Oxford, v. 29, n. 3, p. 283-290, julho. 1994. 
NOVOSELAC, A.; SREBRIC, J. A critical review on the performance and design of combined cooled ceiling and displacement ventilation systems. Energy and Buildings, Lausanne, v. 34, n. 5, p. 497-509, jun. 2002.

PAGANO, M.; GAUVREAU, K. Princípios de bioestatística. São Paulo: Thomson Pioneira, 2004. $506 \mathrm{p}$.

SODEC, F. Economic viability of cooling ceiling systems. Energy and Buildings, Lausanne, v. 30, n. 2, p. 195-201, jun. 1999.

STETIU, C. Energy and peak power savings potential of radiant cooling system in US commercial buildings. Energy and Buildings, Lausanne, v. 30, n. 2, p. 127-138, jun. 1999.

STETIU, C. Radiant cooling in US office buildings: towards eliminating the perception of climate-imposed barriers. 1997. 306 p. Thesis (Ph. D. in Energy and Resources) - University of California, Berkeley, 1997. 


\section{REFERÊNCIAS COMPLEMENTARES}

ALAMDARI, F. Displacement ventilation and cooled ceilings. In: ROOMVENT' 98 INTERNATIONAL CONFERENCE ON AIR DISTRIBUTION IN ROOMS, 6., Stockholm, Sweden. Proceedings... Stockholm, Sweden: KTH, Building Services Engineering, 1998. v. 1, p. 197-204.

ALAMDARI, F.; EAGLES, N. Displacement ventilation and chilled ceilings. Bracknell, Berkshire: Building Services Research and Information Association, 1996. 32 p. (BSRIA technical note TN, 2/96).

AMERICAN SOCIETY OF HEATING, REFRIGERATING AND AIR-CONDITIONING ENGINEERS. 2005 ASHRAE handbook: fundamentals. Atlanta, 2005. 1 v.

ANTONOPOULOS, K. A.; VRACHOPOULOS, M.; TZIVANIDIS, C. Experimental evaluation of energy savings in air-conditioning using metal ceiling panels. Applied Thermal Engineering, Oxford, v. 18, n. 11, p. 1129-1138, Nov. 1998.

ASSOCIAÇÃO BRASILEIRA DE NORMAS TÉCNICAS. NBR 6401: instalações centrais de ar condicionado para conforto - parâmetros básicos de projeto. Rio de Janeiro, 1980. $17 \mathrm{p}$.

BEHNE, M. Is there a risk of draft in rooms with cooled ceilings?: measurement of air velocities and turbulences. ASHRAE Transactions, Atlanta, v. 101, n. 2, p. 744752, 1995.

BEHNE, M. The influence of the arrangement of cooling ceilings on thermal comfort. In: INDOOR AIR '93 - INTERNATIONAL CONFERENCE ON INDOOR AIR QUALITY AND CLIMATE, 6., 1993, Espoo. Proceedings... Espoo: Laboratory of Heating, Ventilating and Air Conditioning, Helsinki University of Technology, 1993. v. 5, p. 413-418.

BEJAN, A. Transferência de calor. Traduzido por Euryclides de Jesus Zerbini; Ricardo Santilli Ekman Simoes. São Paulo: Edgard Blucher, 1996. 540 p.

BROHUS, $\mathrm{H}$. Influence of a cooled ceiling on indoor air quality in a displacement ventilated room examined by means of CFD. In: ROOMVENT' 98 - INTERNATIONAL CONFERENCE ON AIR DISTRIBUTION IN ROOMS, 6., Stockholm, Sweden. Proceedings... Stockholm, Sweden: KTH, Building Services Engineering, 1998. v. 1, p. 53-60. 
CHEN, Q.; GLICKSMAN, L. R.; SREBRIC, J. Simplified methodology to factor room air movement and the impact on thermal comfort into design of radiative, convective and hybrid heating and cooling systems. Atlanta, Ga.: ASHRAE, 1999. 184 p. ASHRAE RP-927. Sponsored by ASHRAE TC 6.4, In-Space Convection Heating and TC4.10, Indoor Environmental Modeling. Final report submitted to ASHRAE.

CHEONG, K. W. Ventilation and air quality in an office building. Building services engineering research \& technology, London, v. 17, n. 4, p. 167-176, 1996.

CONROY, C. L.; MUMMA, S. A. Ceiling radiant cooling panels as a viable distributed parallel sensible cooling technology integrated with dedicated outdoor air systems. ASHRAE Transactions, Atlanta, v. 107, n. 1, paper AT-01-7-5, 2001.

CREDER, H. Instalações de ar condicionado. 6 ed. Rio de Janeiro: Livros Técnicos e Científicos, 2004. 318 p.

CRESPO, A. A. Estatística Fácil. 18 ed. São Paulo: Saraiva, 2002. 224 p.

FANGER, P. O. Thermal Comfort: Analysis and Applications in Environmental Engineering. McGraw-Hill Book Company, New York., 1972. 244 p.

FEUSTEL, E. H.; STETIU, C. Hydronic radiant cooling - preliminary assessment. Energy and Buildings, Lausanne, v. 22, p. 193-205, 1995.

FITZNER, K. Displacement ventilation and cooled ceilings, results of laboratory tests and practical installations. In: INDOOR AIR'96 - INTERNATIONAL CONFERENCE ON INDOOR AIR QUALITY AND CLIMATE, 7., Tokyo, Japan. Proceedings... Tokyo, Japan, 1996. v.1, p. 41-50.

FROTA, A. B.; SCHIFFER S. R. Manual de conforto térmico. 2 ed. São Paulo: Nobel, 1995. 243 p.

GAN, G. Towards a better indoor thermal environment-A CFD analysis of the performance of chilled ceiling system. In: INTERNATIONAL SYMPOSIUM ON VENTILATION FOR CONTAMINANT CONTROL, 4., 1994, Stockholm. Proceedings... Solna, Sverige: Arbetsmiljo Institutet \& Forfattarna, 1994. p. 551556. 
HODDER, S. G. et al. Thermal comfort in chilled ceiling and displacement ventilation environments: vertical radiant temperature asymmetry effects. Energy and Buildings, Lausanne, v. 27, p. 167-173, 1998.

HOLMAN, J. P. Transferência de calor. São Paulo: McGraw-Hill do Brasil, 1983. $639 \mathrm{p}$.

HU, S.; CHEN, Q.; GLICKSMAN, L. R. Comparison of energy consumption between displacement and mixing ventilation for different US building and climates. ASHRAE Transactions, Atlanta, v. 105, p. 453-464, 1999.

HUGHES, W. F. Dinâmica dos fluídos. Colaboração de John A Brighton. São Paulo: McGraw-Hill do Brasil, 1979. 358 p.

INCROPERA, F.P. Fundamentos de transferência de calor e de massa. Colaboração de David P Dewitt. 4. ed. Rio de Janeiro: Livros Técnicos e Científicos, 1998. 494 p.

INTERNATIONAL ORGANIZATION FOR STANDARDIZATION. ISO 7243: estimation of the heat stress on working man, based on the WBGT-index (wet bulb globe temperature). Geneva, 1989. 9 p.

INTERNATIONAL ORGANIZATION FOR STANDARDIZATION. ISO 7933: analytical determination and interpretation of thermal stress using calculation of required sweet rate. Geneva, 1989. 20 p.

JIANG, Z.; CHEN, Q.; MOSER, A. Indoor airflow with cooling panel and radiative /convective heat source. ASHRAE Transactions, Atlanta, v. 98, n. 1, p. 33-42, 1992.

KRUHNE, $\mathrm{H}$. Effect of cooled ceilings in rooms with displacement ventilation on the air quality. INDOOR AIR '93 - INTERNATIONAL CONFERENCE ON INDOOR AIR QUALITY AND CLIMATE, 6., 1993, Espoo. Proceedings... Espoo: Laboratory of Heating, Ventilating and Air Conditioning, Helsinki University of Technology, 1993. v. 5, p. 395-400.

KULPMANN, R. W. Thermal comfort and air quality in rooms with cooled ceilings results of scientific investigations. ASHRAE Transactions, Atlanta, v. 99, n. 2, p. 488-502, 1993.

NIU, J.; BURNETT, J. Integrating radiant/operative temperature controls into building energy simulation. ASHRAE Transactions, Atlanta, v. 104, n. 2, p. 210-217,1998. 
NIU, J.; KOOI, J.V.D. Numerical investigations of thermal comfort and indoor contaminant distribution in a room with cooled ceiling system. In: INDOOR AIR '93 INTERNATIONAL CONFERENCE ON INDOOR AIR QUALITY AND CLIMATE, 6., 1993, Espoo. Proceedings... Espoo: Laboratory of Heating, Ventilating and Air Conditioning, Helsinki University of Technology, 1993. v. 5, p. 331-336.

OZISIK, M. N. Transferência de calor: um texto básico. Rio de Janeiro: Guanabara, 1990. $661 \mathrm{p}$.

PROCHASKA, V.; KEGEL, B.; KOFOED, P. Control aspects of displacement ventilation with cooled ceiling. In: ROOMVENT '92: INTERNATIONAL CONFERENCE OF THE AIR DISTRIBUTION IN ROOMS, 3., 1992, Aalborg, Denmark. Proceedings... Lnygby, Denmark: The Association, 1992. v. 3, p. 53-68.

REA, L. M.; PARKER, R. A. Designing and conducting survey research: a comprehensive guide. 2. ed. San Francisco: Jossey-Bass Publishers, 1997. 254 p.

ROHSENOW, W. M. et al. Fenômenos de transporte. Colaboração de Donald R Pitts. Traduzido por Adir Moyses Luiz. Rio de Janeiro: Guanabara Dois, 1979. 765 p.

RUAS, C. A. Avaliação de conforto térmico: contribuição à aplicação prática das normas internacionais. 2001. 77 p. Dissertação (Mestrado) - Faculdade de Engenharia Civil, Universidade Estadual de Campinas, Campinas, 2001.

SONNTAG, R.E. Fundamentos de termodinâmica. Colaboração de Gordon John Van Wylen; Claus Borgnakke.Traduzido por Euryclides de Jesus Zerbini. São Paulo: Edgard Blucher, 1998. 537 p.

STOECKER, W. F.; JONES, J. W. Refrigeração e ar condicionado. 2 ed. São Paulo: McGraw-Hill, 1985. 482 p.

TAN, H. et al. Cooled ceilings / Displacement ventilation hybrid air conditioning system - Design criteria. In: ROOMVENT' 98 - INTERNATIONAL CONFERENCE ON AIR DISTRIBUTION IN ROOMS, 6., Stockholm, Sweden. Proceedings... Stockholm, Sweden: KTH, Building Services Engineering, 1998. v. 1, p. 77-84.

TROX. Sistema de techos frios. São Paulo: Trox Technik, 2000. Texto técnico.

VAN WYLEN, G. J.; SONNTAG, R. E.; BORGNAKKE, C. Fundamentos da termodinâmica clássica. São Paulo: Edgard Blücher, 1990. 589 p. 
WATERS, J. R.; SIMONS, M. W., GRAZEBOOK, J. Air distribution and air quality in a large open space. Building Services Engineer Research \& Technology, London, v. 20 , n. 4 , p. $195-200,1999$.

YUAN, X.; CHEN, Q.; GLICKSMAN, L.R. A critical review of displacement ventilation. ASHRAE Transactions, Atlanta, v. 104, n. 1A, p. 78-90, 1998.

ZMRHAL,V.; HENSEN, J.; FRANTIŠEK, D. Modelling and simulation of a room with a radiant cooling ceiling. In: INTERNATIONAL IBPSA CONFERENCE, 8., 2003, Eindhoven. Proceedings... Eindhoven, 2003. p. 1491-1496. 
APÊNDICE A - Tabelas e gráficos de dados da variável temperatura do ar por setpoint (SP) e altura (h) - Situação: Ocup./Desoc. - Setpoint $21^{\circ} \mathrm{C}$; h1=0,10 m 
SETPOINT de Temperatura $=21^{\circ} \mathrm{C}$

Tabelas

Gráficos

F $\mathrm{Qu}$

i $a d r$

g 0

$\mathrm{u}$

r

a

Tabela 16 - Situação OCUP. I DESOC. $-\mathrm{SP}=21^{\circ} \mathrm{C}$; h1 $=0,10 \mathrm{~m}$; Medição a

Tabela 17 - Situação OCUP. I DESOC. $-\mathrm{SP}=21^{\circ} \mathrm{C}$; $\mathrm{h} 1=0,10 \mathrm{~m}$; Medição $\mathrm{b}$

Tabela 18 - Situação OCUP. I DESOC. $-\mathrm{SP}=21^{\circ} \mathrm{C}$;

Gráfico 11- Situação OCUP. / DESOC. $\mathrm{SP}=21^{\circ} \mathrm{C} ; \mathrm{h} 1=0,10 \mathrm{~m}$; Medição a

Gráfico 12- Situação OCUP. / DESOC. $\mathrm{SP}=21^{\circ} \mathrm{C} ; \mathrm{h} 1=0,10 \mathrm{~m}$; Medição $\mathrm{b}$

Gráfico 13- Situação OCUP. / DESOC. $\mathrm{SP}=21^{\circ} \mathrm{C} ; \mathrm{h} 1=0,10 \mathrm{~m}$; Medição $\mathrm{C}$ h1 $=0,10 \mathrm{~m}$; Medição c 
Tabela 19 - Situação OCUP. I DESOC. $-\mathrm{SP}=21^{\circ} \mathrm{C}$; h1 $=0,10 \mathrm{~m}$; Medição d

Tabela 20 - Situação OCUP. I DESOC. $-\mathrm{SP}=21^{\circ} \mathrm{C}$; h1 $=0,10 \mathrm{~m}$; Medição e

Tabela 21 - Situação OCUP. I

DESOC. $-\mathrm{SP}=21^{\circ} \mathrm{C}$; h1 $=0,10 \mathrm{~m}$; Resumo das Medições
Gráfico 14- Situação OCUP. / DESOC. $\mathrm{SP}=21^{\circ} \mathrm{C} ; \mathrm{h} 1=0,10 \mathrm{~m}$; Medição d

Gráfico 15- Situação OCUP. / DESOC. $\mathrm{SP}=21^{\circ} \mathrm{C} ; \mathrm{h} 1=0,10 \mathrm{~m}$; Medição e

Gráfico 16- Situação OCUP. / DESOC. $\mathrm{SP}=21^{\circ} \mathrm{C} ; \mathrm{h} 1=0,10 \mathrm{~m}$; Resumo das Medições 
Tabela 22 - Situação OCUP. I DESOC. $-\mathrm{SP}=21^{\circ} \mathrm{C}$; h2 $=0,60 \mathrm{~m}$; Medição a

Tabela 23 - Situação OCUP. I DESOC. $-\mathrm{SP}=21^{\circ} \mathrm{C}$; h2 $=0,60 \mathrm{~m}$; Medição $\mathrm{b}$

Tabela 24 - Situação OCUP. I DESOC. $-\mathrm{SP}=21^{\circ} \mathrm{C}$; h2 $=0,60 \mathrm{~m}$; Medição C
Gráfico 17- Situação OCUP. / DESOC. $\mathrm{SP}=21^{\circ} \mathrm{C} ; \mathrm{h} 2=0,60 \mathrm{~m}$; Medição a

Gráfico 18- Situação OCUP. / DESOC. $\mathrm{SP}=21^{\circ} \mathrm{C} ; \mathrm{h} 2=0,60 \mathrm{~m}$; Medição a

Gráfico 19- Situação OCUP. / DESOC. $\mathrm{SP}=21^{\circ} \mathrm{C} ; \mathrm{h} 2=0,60 \mathrm{~m}$; Medição a 
Tabela 25 - Situação OCUP. I DESOC. $-\mathrm{SP}=21^{\circ} \mathrm{C}$; h2 $=0,60 \mathrm{~m}$; Medição d

Tabela 26 - Situação OCUP. I DESOC. $-\mathrm{SP}=21^{\circ} \mathrm{C}$; h2=0,60m; Medição e

Tabela 27 - Situação OCUP. I DESOC. $-\mathrm{SP}=21^{\circ} \mathrm{C}$; h2 $=0,60 \mathrm{~m}$; Resumo das Medições
Gráfico 20- Situação OCUP. / DESOC. $\mathrm{SP}=21^{\circ} \mathrm{C} ; \mathrm{h} 2=0,60 \mathrm{~m}$; Medição d

Gráfico 21- Situação OCUP. / DESOC. $\mathrm{SP}=21^{\circ} \mathrm{C}$; h2=0,60m; Medição e

Gráfico 22- Situação OCUP. / DESOC. $\mathrm{SP}=21^{\circ} \mathrm{C} ; \mathrm{h} 2=0,60 \mathrm{~m} ;$ Resumo das Medições 
Tabela 28 - Situação OCUP. I DESOC. $-\mathrm{SP}=21^{\circ} \mathrm{C}$; h3=1,10m; Medição a

Tabela 29 - Situação OCUP. I DESOC. $-\mathrm{SP}=21^{\circ} \mathrm{C}$; h3=1,10m; Medição b

Tabela 30 - Situação OCUP. I DESOC. $-\mathrm{SP}=21^{\circ} \mathrm{C}$; h3=1,10m; Medição c
Gráfico 23- Situação OCUP. / DESOC. $\mathrm{SP}=21^{\circ} \mathrm{C} ; \mathrm{h} 3=1,10 \mathrm{~m}$; Medição a

Gráfico 24- Situação OCUP. / DESOC. $\mathrm{SP}=21^{\circ} \mathrm{C} ; \mathrm{h} 3=1,10 \mathrm{~m}$; Medição $\mathrm{b}$

Gráfico 25- Situação OCUP. / DESOC. $\mathrm{SP}=21^{\circ} \mathrm{C} ; \mathrm{h} 3=1,10 \mathrm{~m}$; Medição $\mathrm{C}$ 


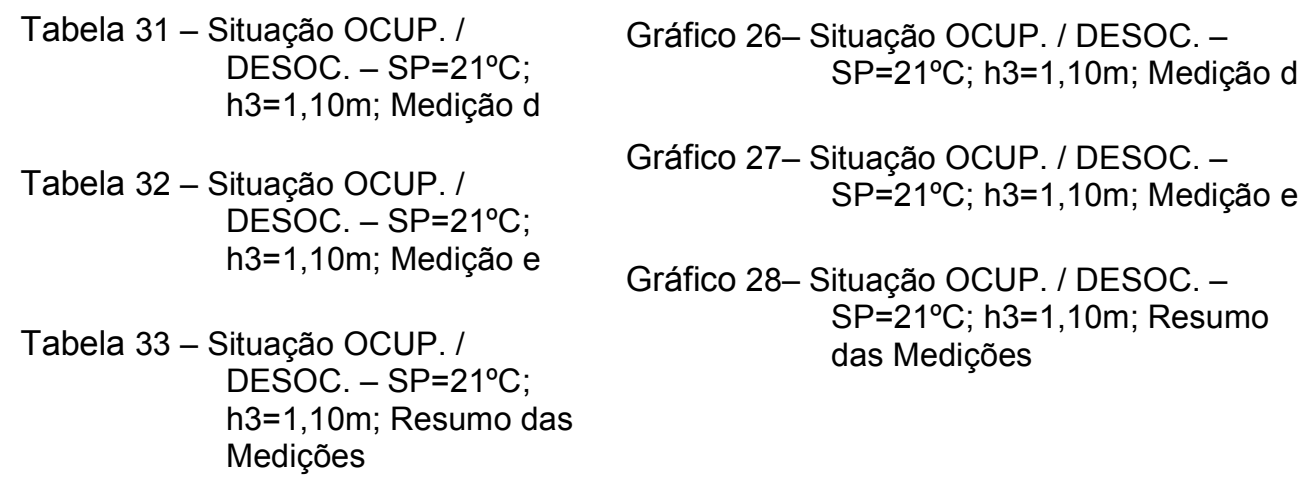


Tabela 34 - Situação OCUP. I DESOC. $-\mathrm{SP}=21^{\circ} \mathrm{C}$; h4=1,70m; Medição a

Tabela 35 - Situação OCUP. I DESOC. $-\mathrm{SP}=21^{\circ} \mathrm{C}$; h4=1,70m; Medição b

Tabela 36 - Situação OCUP. I DESOC. $-\mathrm{SP}=21^{\circ} \mathrm{C}$; h4=1,70m; Medição c
Gráfico 29- Situação OCUP. / DESOC. $\mathrm{SP}=21^{\circ} \mathrm{C} ; \mathrm{h} 4=1,70 \mathrm{~m}$; Medição a

Gráfico 30- Situação OCUP. / DESOC. $\mathrm{SP}=21^{\circ} \mathrm{C}$; $\mathrm{h} 4=1,70 \mathrm{~m}$; Medição b

Gráfico 31- Situação OCUP. / DESOC. $\mathrm{SP}=21^{\circ} \mathrm{C} ; \mathrm{h} 4=1,70 \mathrm{~m}$; Medição $\mathrm{C}$ 
Tabela 37 - Situação OCUP. I DESOC. $-\mathrm{SP}=21^{\circ} \mathrm{C}$; h4=1,70m; Medição d

Tabela 38 - Situação OCUP. I DESOC. $-\mathrm{SP}=21^{\circ} \mathrm{C}$; h4=1,70m; Medição e

Tabela 39 - Situação OCUP. I DESOC. $-\mathrm{SP}=21^{\circ} \mathrm{C}$; $\mathrm{h} 4=1,70 \mathrm{~m}$; Resumo das Medições
Gráfico 32- Situação OCUP. / DESOC. $\mathrm{SP}=21^{\circ} \mathrm{C} ; \mathrm{h} 4=1,70 \mathrm{~m}$; Medição d

Gráfico 33- Situação OCUP. / DESOC. $\mathrm{SP}=21^{\circ} \mathrm{C} ; \mathrm{h} 4=1,70 \mathrm{~m}$; Medição e

Gráfico 34- Situação OCUP. / DESOC. $\mathrm{SP}=21^{\circ} \mathrm{C}$; $\mathrm{h} 4=1,70 \mathrm{~m}$; Resumo das Medições 
Tabela 40 - Situação OCUP. I DESOC. $-\mathrm{SP}=21^{\circ} \mathrm{C}$; h5=2,00m; Medição a

Tabela 41 - Situação OCUP. I DESOC. $-\mathrm{SP}=21^{\circ} \mathrm{C}$; h5=2,00m; Medição b

Tabela 42 - Situação OCUP. I DESOC. $-\mathrm{SP}=21^{\circ} \mathrm{C}$; h5=2,00m; Medição c
Gráfico 35- Situação OCUP. / DESOC. $\mathrm{SP}=21^{\circ} \mathrm{C}$; h5=2,00m; Medição a

Gráfico 36- Situação OCUP. / DESOC. $\mathrm{SP}=21^{\circ} \mathrm{C} ; \mathrm{h} 5=2,00 \mathrm{~m}$; Medição b

Gráfico 37- Situação OCUP. / DESOC. $\mathrm{SP}=21^{\circ} \mathrm{C} ; \mathrm{h} 5=2,00 \mathrm{~m}$; Medição $\mathrm{C}$ 


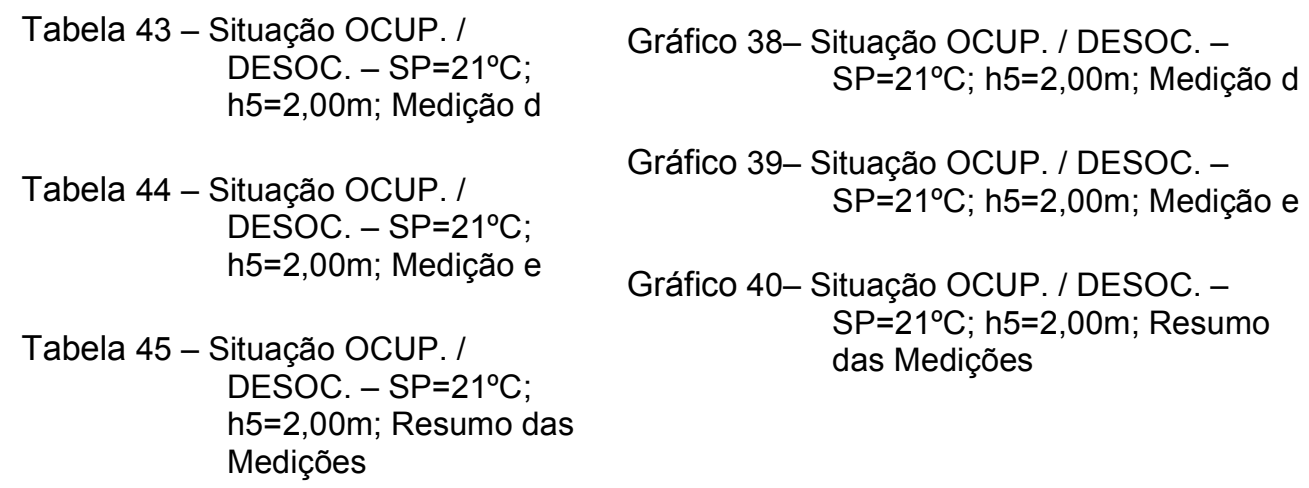


Tabela 46 - Situação OCUP. I DESOC. $-\mathrm{SP}=21^{\circ} \mathrm{C}$; h6=2,35m; Medição a

Tabela 47 - Situação OCUP. I DESOC. $-\mathrm{SP}=21^{\circ} \mathrm{C}$; h6 $=2,35 \mathrm{~m}$; Medição $b$

Tabela 48 - Situação OCUP. I DESOC. $-\mathrm{SP}=21^{\circ} \mathrm{C}$; h6 $=2,35 \mathrm{~m}$; Medição $\mathrm{c}$
Gráfico 41- Situação OCUP. / DESOC. $\mathrm{SP}=21^{\circ} \mathrm{C} ; \mathrm{h} 6=2,35 \mathrm{~m}$; Medição a

Gráfico 42- Situação OCUP. / DESOC. $\mathrm{SP}=21^{\circ} \mathrm{C}$; h6=2,35m; Medição $\mathrm{b}$

Gráfico 43- Situação OCUP. / DESOC. $\mathrm{SP}=21^{\circ} \mathrm{C} ; \mathrm{h} 6=2,35 \mathrm{~m}$; Medição $\mathrm{C}$ 
Tabela 49 - Situação OCUP. I DESOC. $-\mathrm{SP}=21^{\circ} \mathrm{C}$; h6=2,35m; Medição d

Tabela 50 - Situação OCUP. I DESOC. $-\mathrm{SP}=21^{\circ} \mathrm{C}$; h6=2,35m; Medição e
Gráfico 44- Situação OCUP. / DESOC. $\mathrm{SP}=21^{\circ} \mathrm{C} ; \mathrm{h} 6=2,35 \mathrm{~m}$; Medição $\mathrm{d}$

Gráfico 45- Situação OCUP. / DESOC. $\mathrm{SP}=21^{\circ} \mathrm{C} ; \mathrm{h} 6=2,35 \mathrm{~m}$; Medição e

Gráfico 46- Situação OCUP. / DESOC. -

Tabela 51 - Situação OCUP. / SP=21 ${ }^{\circ} \mathrm{C} ; \mathrm{h} 6=2,35 \mathrm{~m}$; Resumo das Medições DESOC. - $\mathrm{SP}=21^{\circ} \mathrm{C} ; \quad \mathrm{h} 6=2,35 \mathrm{~m}$;

Resumo das Medições 
APÊNDICE B - Tabelas e gráficos dos índices de ajuste sob 6 condições térmicas (setpoints); Situação de medição Ocupado/Desocupado e Desocupado 
Tabelas dos índices de Ajuste nos 6 setpoints de temperatura - OCUP./DESOC.

Tabela 52 - Índices de Ajuste- Ocup./Desoc. - SP21

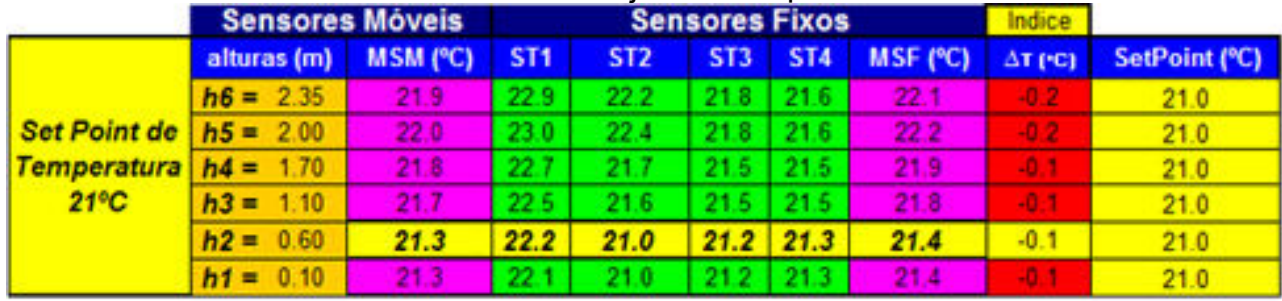

Tabela 53 - Índices de Ajuste - Ocup./Desoc. - SP22

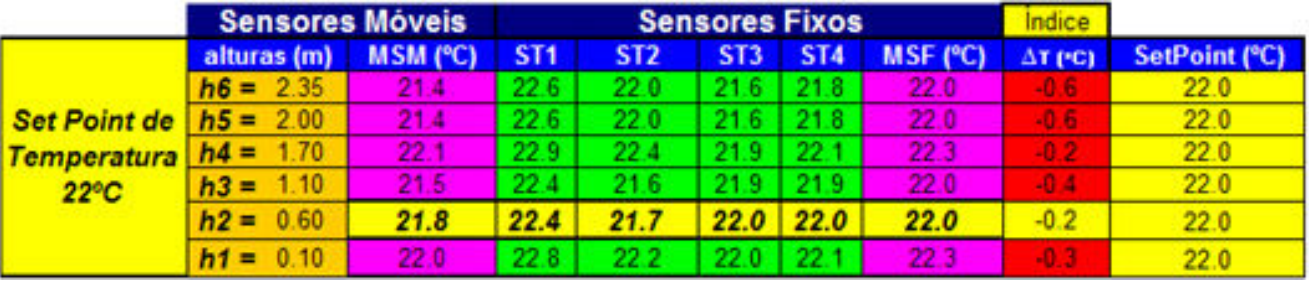

Tabela 54 - Índices de Ajuste - Ocup./Desoc. - SP23

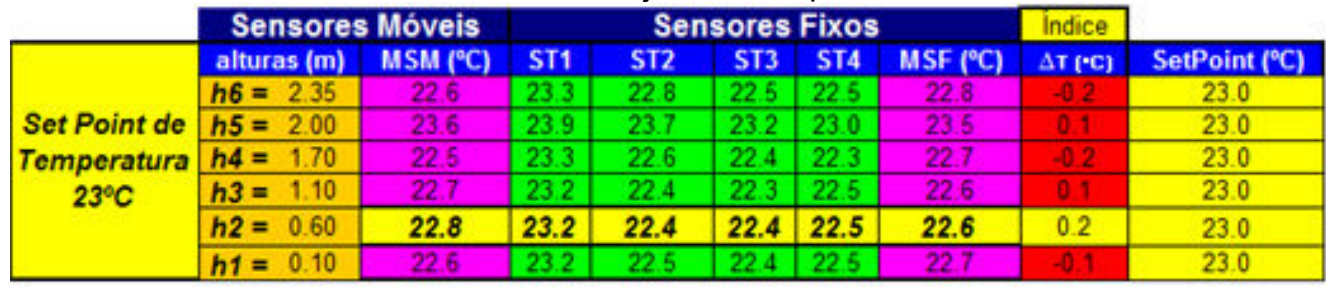

Tabela 55 - Índices de Ajuste - Ocup./Desoc. - SP24

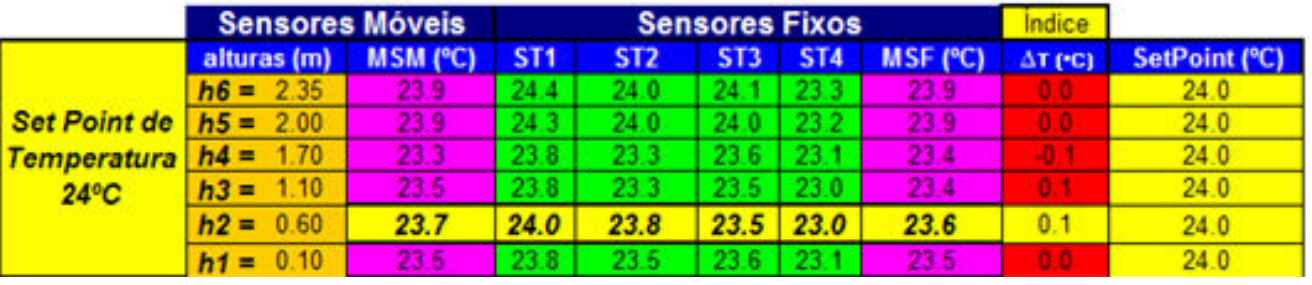

Tabela 56 - Índices de Ajuste - Ocup./Desoc. - SP25

\begin{tabular}{|l|l|l|}
\hline Sensores Móveis & Sensores Fixos & indice \\
\hline
\end{tabular}

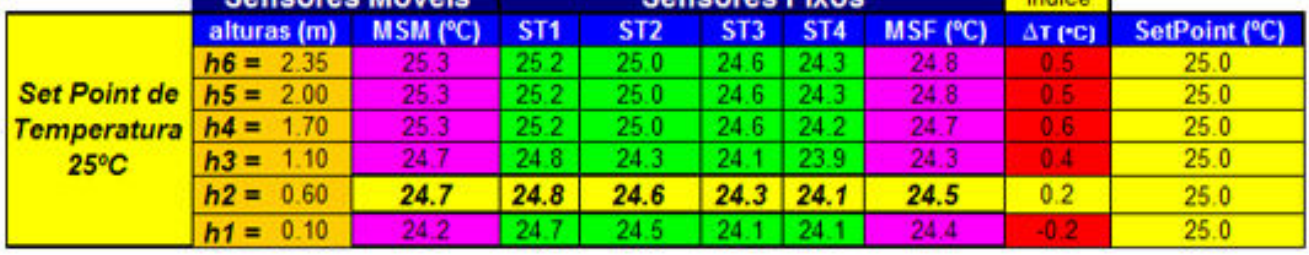

Tabela 57 - Índices de Ajuste - Ocup./Desoc. - SP26

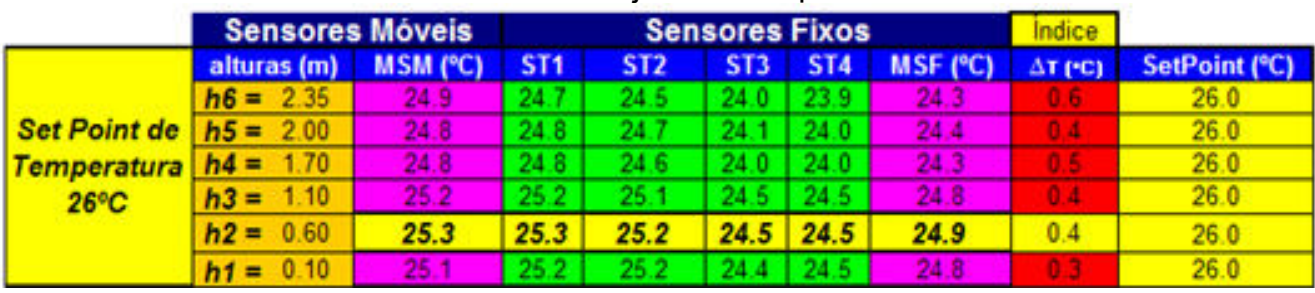


Gráfico 47 - MSM e MSF nas 6 alturas de medição; Ocup./Desoc. - SP21

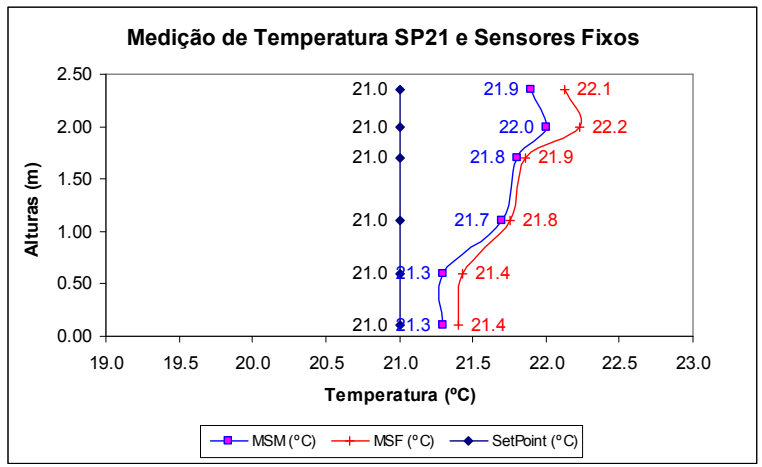

Gráfico 49 - MSM e MSF nas 6 alturas de medição; Ocup./Desoc. - SP23

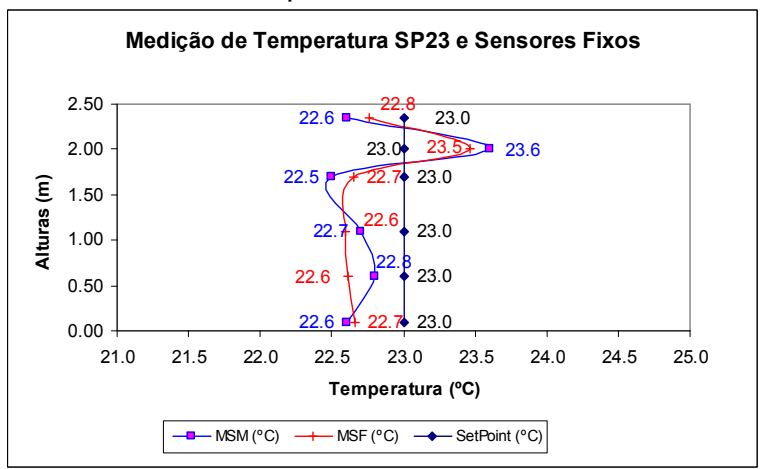

Gráfico 51 - MSM e MSF nas 6 alturas de medição; Ocup./Desoc. - SP25

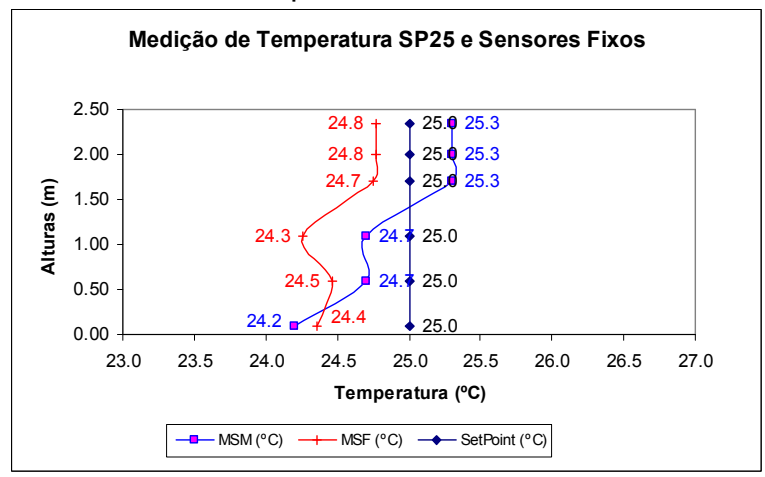

Gráfico 48 - MSM e MSF nas 6 alturas de medição ; Ocup./Desoc. - SP22

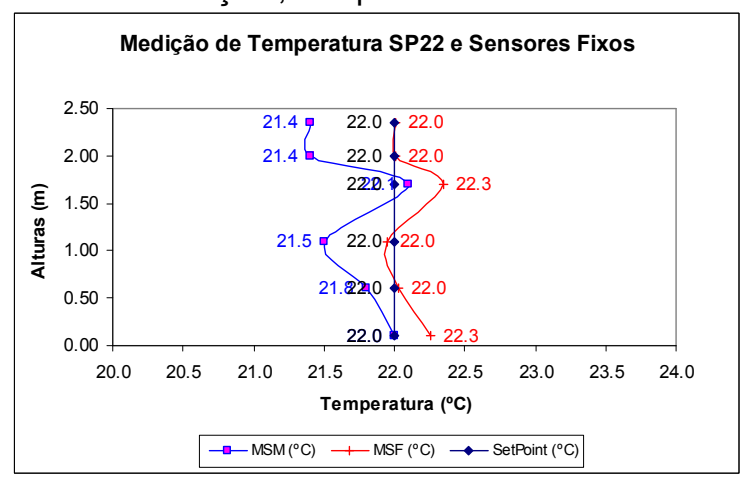

Gráfico 50 - MSM e MSF nas 6 alturas de medição; Ocup./Desoc. - SP24

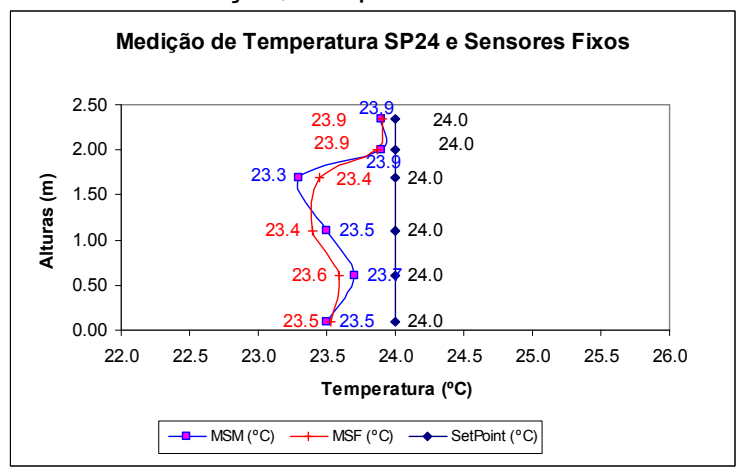

Gráfico 52 - MSM e MSF nas 6 alturas de medição; Ocup./Desoc. - SP26

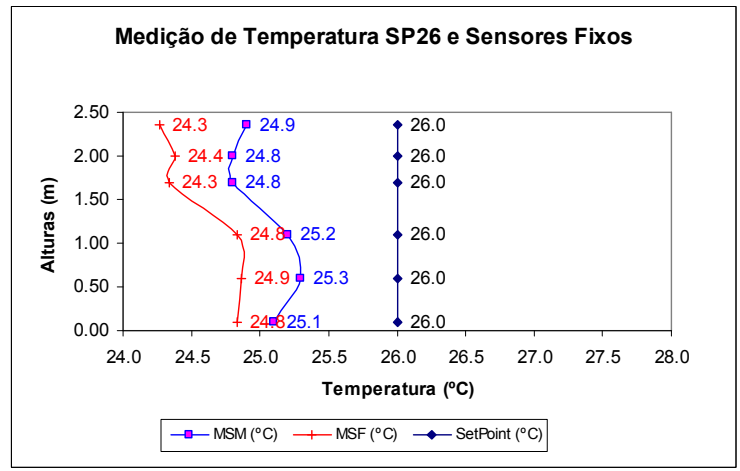


Tabelas dos índices de Ajuste nos 6 setpoints de temperatura - DESOCUPADO

Tabela 58 - Índices de Ajuste- Desocupado - SP21

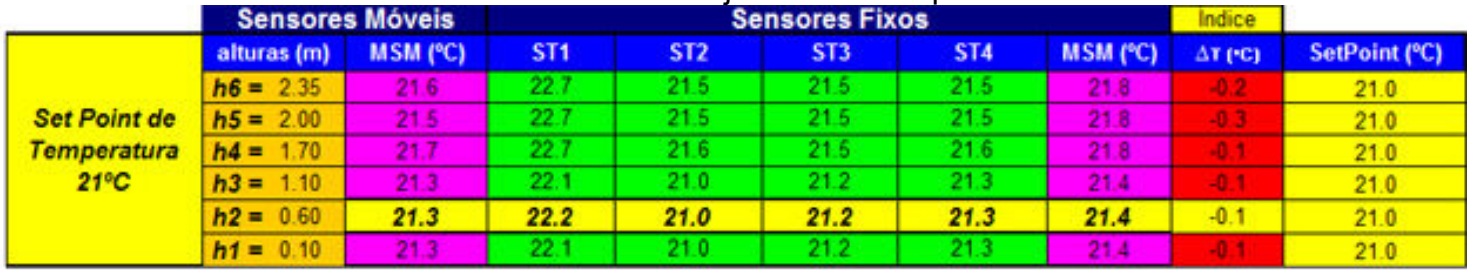

Tabela 59 - Índices de Ajuste - Desocupado. - SP22

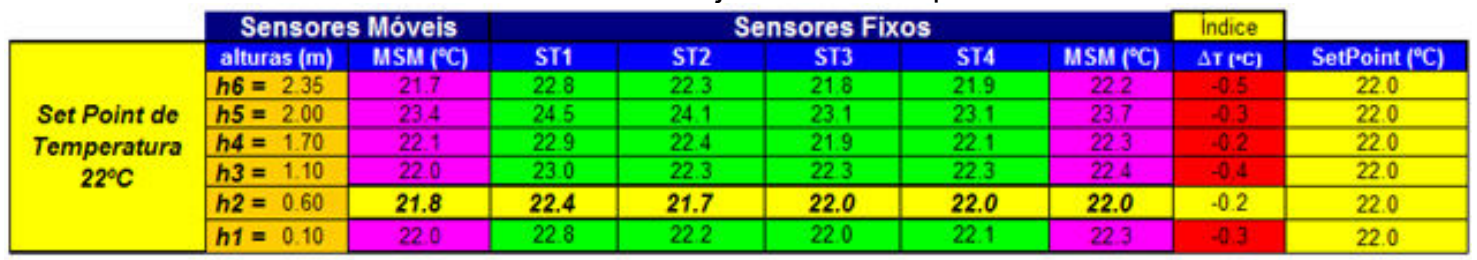

Tabela 60 - Índices de Ajuste - Desocupado - SP23

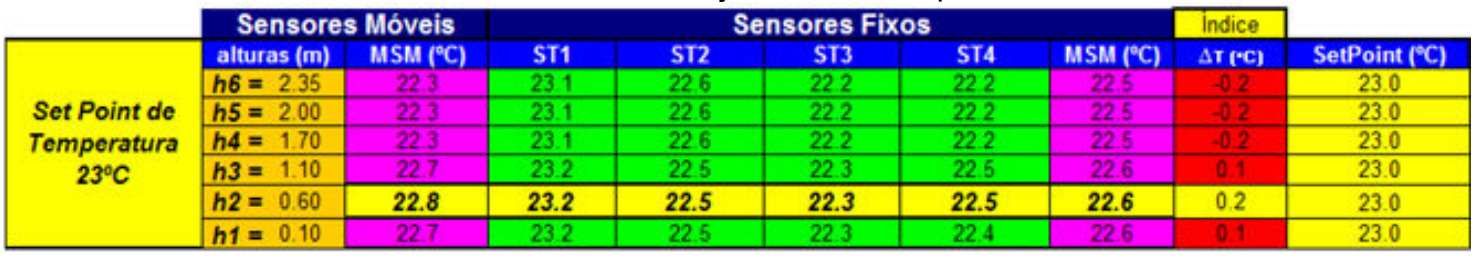

Tabela 61 - Índices de Ajuste - Desocupado. - SP24

\begin{tabular}{|c|c|c|c|c|c|c|c|c|c|}
\hline & \multicolumn{2}{|c|}{ Sensores Móveis } & \multicolumn{5}{|c|}{ Sensores Fixos } & \multicolumn{2}{|l|}{ Indice } \\
\hline \multirow{5}{*}{$\begin{array}{l}\text { Set Point de } \\
\text { Temperatura } \\
24^{\circ} \mathrm{C}\end{array}$} & alturas $(\mathrm{m})$ & $\operatorname{MSM}\left({ }^{\circ} \mathrm{C}\right)$ & ST1 & ST2 & ST3 & ST4 & $\operatorname{MSM}\left({ }^{\circ} \mathrm{C}\right)$ & $\Delta \mathbf{T}(* C)$ & SetPoint $\left({ }^{\circ} \mathrm{C}\right)$ \\
\hline & $h 5=2.00$ & 23.3 & 236 & 23.0 & 23.3 & 22.8 & 23.2 & 0.1 & 240 \\
\hline & $h 3=1.10$ & 23.1 & 23.6 & 22.9 & 23.2 & 22.9 & 23.2 & 0.0 & 24.0 \\
\hline & $h 2=0.60$ & 23.3 & 23.7 & 23.3 & 23.6 & 23.1 & 23.4 & -0.1 & 24.0 \\
\hline & $h 1=0.10$ & 23.3 & 23.7 & 23.3 & 23.6 & 23.1 & 23.4 & -0.1 & 24.0 \\
\hline
\end{tabular}

Tabela 62 - Índices de Ajuste - Desocupado - SP25

\begin{tabular}{|c|c|c|c|c|c|c|c|c|c|}
\hline & \multicolumn{7}{|c|}{ Sensores Fixos } & \multicolumn{2}{|l|}{ Indice } \\
\hline \multirow{7}{*}{$\begin{array}{l}\text { Set Point de } \\
\text { Temperatura } \\
25^{\circ} \mathrm{C}\end{array}$} & alturas $(\mathrm{m})$ & $\operatorname{MSM}\left({ }^{\circ} \mathrm{C}\right)$ & ST1 & ST2 & $\mathrm{ST3}$ & ST4 & $\operatorname{MSM}\left({ }^{\circ} \mathrm{C}\right)$ & $\Delta \mathrm{T}\left({ }^{*} \mathrm{C}\right)$ & SetPoint $\left({ }^{\circ} \mathrm{C}\right)$ \\
\hline & $h 6=2.35$ & 23.8 & 24.1 & 23.2 & 23.3 & 23.3 & 23.5 & 0.3 & 25.0 \\
\hline & $h 5=2.00$ & 24.6 & 24.9 & 243 & 24.1 & 24.2 & 24.4 & 0.2 & 25.0 \\
\hline & $h 4=1.70$ & 23.8 & 24.2 & 23.4 & 23.5 & 23.5 & 23.6 & 02 & 25.0 \\
\hline & $h 3=1.10$ & 23.8 & 24.1 & 23.2 & 23.3 & 23.4 & 23.5 & 0.3 & 25.0 \\
\hline & $h 2=0.60$ & 23.9 & 24.3 & 23.8 & 23.7 & 23.7 & 23.9 & 0.0 & 25.0 \\
\hline & $h 1=0.10$ & 23.8 & 24.3 & 23.7 & 23.7 & 23.7 & 23.9 & -0.1 & 25.0 \\
\hline
\end{tabular}

Tabela 63 - Índices de Ajuste - Desocupado - SP26

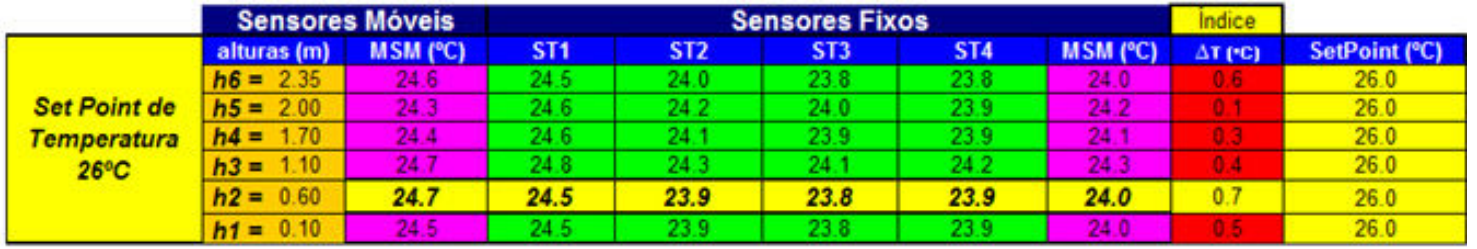


Gráfico 53 - MSM e MSF nas 6 alturas de medição; Desocupado - SP21

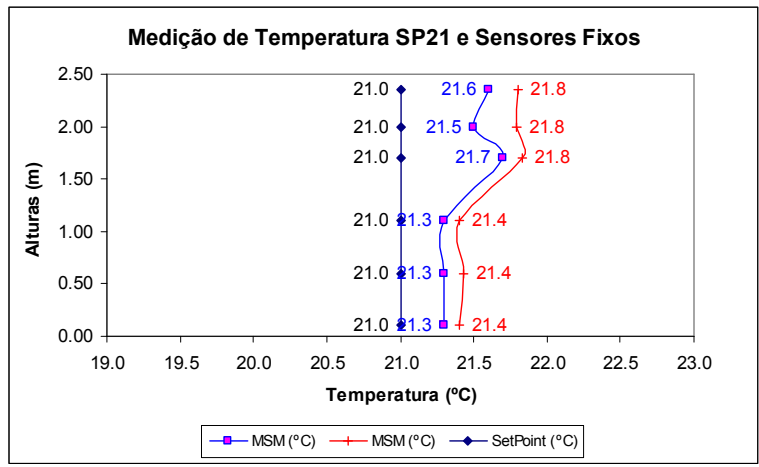

Gráfico 55 - MSM e MSF nas 6 alturas de medição; Desocupado. - SP23

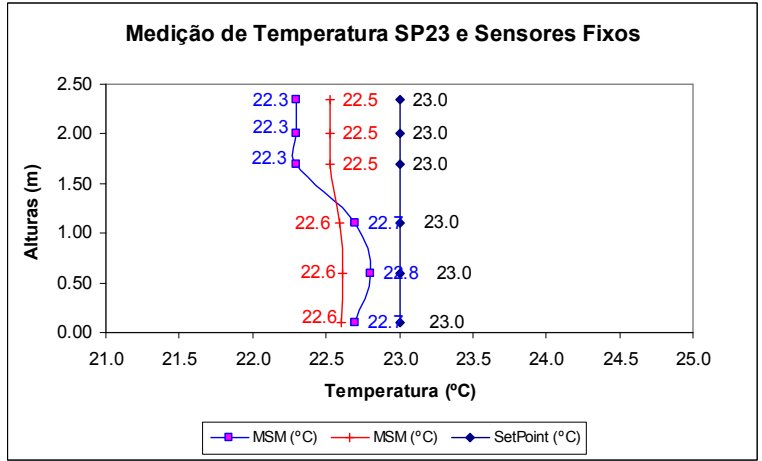

Gráfico 57 - MSM e MSF nas 6 alturas de medição; Desocupado - SP25

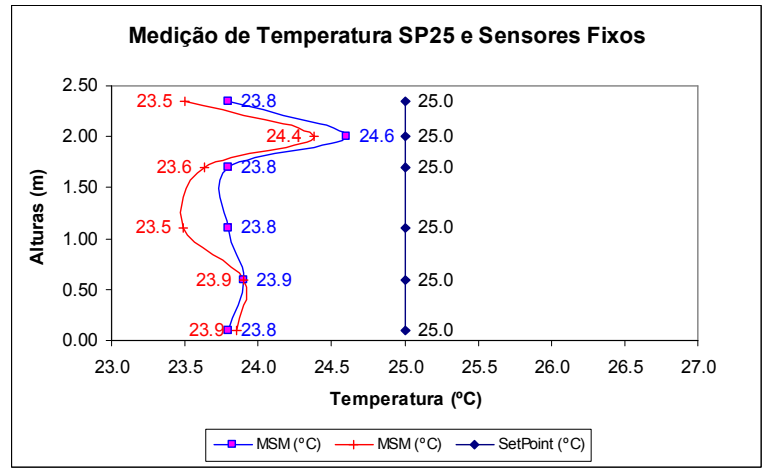

Gráfico 54 - MSM e MSF nas 6 alturas de medição; Desocupado - SP22

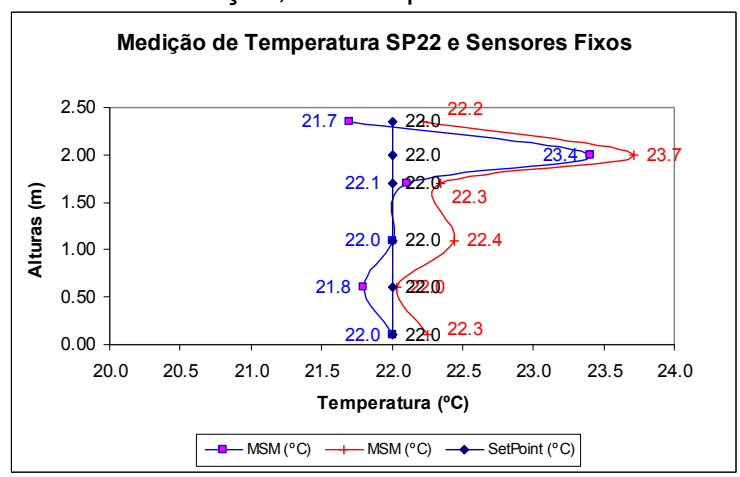

Gráfico 56 - MSM e MSF nas 6 alturas de medição; Desocupado. - SP24

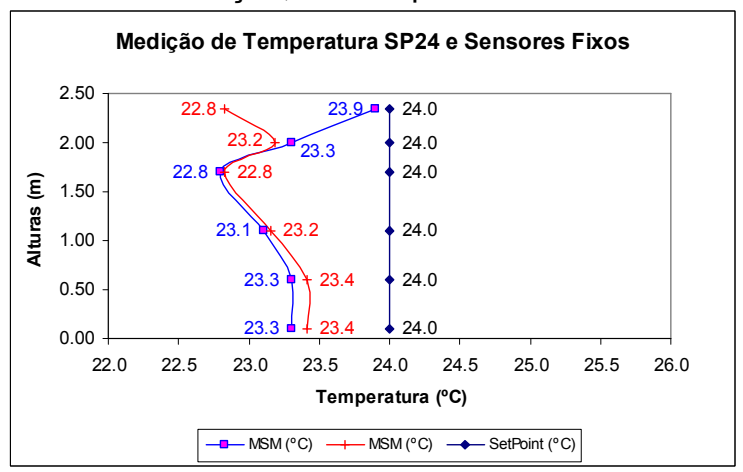

Gráfico 58 - MSM e MSF nas 6 alturas de medição; Desocupado - SP26

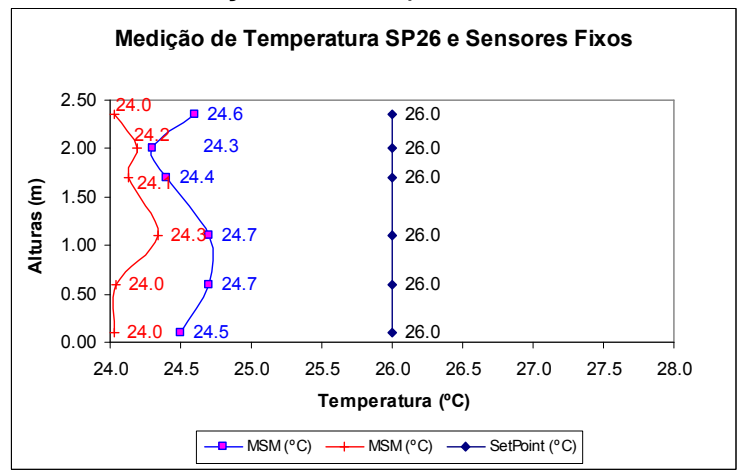


APÊNDICE C - Tabelas e gráficos dos dados da variável temperatura do ar nos 16 pontos de medição em relação às 6 altura (h)) 
Tabela 64 - Dados de MSM e MSF nas 16 posições e 6 alturas -SP21 - Ocup./Desoc.

\begin{tabular}{|c|c|c|c|c|c|c|c|c|c|c|c|c|c|}
\hline \multicolumn{1}{|c|}{ MSM } & \multicolumn{1}{|c|}{ MSF } \\
\hline Alturas & 0,10 & 0,60 & 1,10 & 1,70 & 2,00 & 2,35 & Alturas & 0,10 & 0,60 & 1,10 & 1,70 & 2,00 & 2,35 \\
\hline P1 & 20,8 & 20,8 & 21,1 & 20,9 & 21,0 & 21,4 & P1 & 21,4 & 21,4 & 21,8 & 21,9 & 22,2 & 22,1 \\
\hline P2 & 20,4 & 20,6 & 20,7 & 20,8 & 21,0 & 20,9 & P2 & 21,4 & 21,4 & 21,8 & 21,9 & 22,2 & 22,1 \\
\hline P3 & 20,8 & 20,3 & 20,8 & 20,5 & 21,1 & 21,1 & P3 & 21,4 & 21,4 & 21,8 & 21,9 & 22,2 & 22,1 \\
\hline P4 & 20,8 & 20,8 & 20,8 & 21,0 & 21,3 & 21,2 & P4 & 21,4 & 21,4 & 21,8 & 21,9 & 22,2 & 22,1 \\
\hline P5 & 20,8 & 20,8 & 21,1 & 21,2 & 21,3 & 21,2 & P5 & 21,4 & 21,4 & 21,8 & 21,9 & 22,2 & 22,1 \\
\hline P6 & 20,8 & 21,0 & 21,7 & 21,3 & 21,3 & 21,1 & P6 & 21,4 & 21,4 & 21,8 & 21,9 & 22,2 & 22,1 \\
\hline P7 & 20,8 & 20,9 & 21,3 & 21,1 & 21,7 & 21,3 & P7 & 21,4 & 21,4 & 21,8 & 21,9 & 22,2 & 22,1 \\
\hline P8 & 21,2 & 20,9 & 21,2 & 21,0 & 21,8 & 21,3 & P8 & 21,4 & 21,4 & 21,8 & 21,9 & 22,2 & 22,1 \\
\hline P9 & 21,3 & 22,5 & 22,1 & 22,0 & 21,8 & 22,1 & P9 & 21,4 & 21,4 & 21,8 & 21,9 & 22,2 & 22,1 \\
\hline P10 & 21,3 & 21,6 & 22,4 & 22,3 & 22,4 & 21,8 & P10 & 21,4 & 21,4 & 21,8 & 21,9 & 22,2 & 22,1 \\
\hline P11 & 21,3 & 21,5 & 21,9 & 22,2 & 22,8 & 22,2 & P11 & 21,4 & 21,4 & 21,8 & 21,9 & 22,2 & 22,1 \\
\hline P12 & 21,2 & 21,1 & 21,5 & 21,6 & 22,4 & 22,0 & P12 & 21,4 & 21,4 & 21,8 & 21,9 & 22,2 & 22,1 \\
\hline P13 & 21,7 & 21,6 & 22,2 & 22,3 & 22,7 & 22,5 & P13 & 21,4 & 21,4 & 21,8 & 21,9 & 22,2 & 22,1 \\
\hline P14 & 22,2 & 22,2 & 22,6 & 23,1 & 23,2 & 23,2 & P14 & 21,4 & 21,4 & 21,8 & 21,9 & 22,2 & 22,1 \\
\hline P15 & 21,9 & 21,7 & 22,3 & 22,9 & 23,3 & 23,2 & P15 & 21,4 & 21,4 & 21,8 & 21,9 & 22,2 & 22,1 \\
\hline P16 & 21,4 & 21,6 & 21,9 & 21,9 & 22,1 & 22,2 & P16 & 21,4 & 21,4 & 21,8 & 21,9 & 22,2 & 22,1 \\
\hline SP21 & 21,0 & 21,0 & 21,0 & 21,0 & 21,0 & 21,0 & SP21 & 21,0 & 21,0 & 21,0 & 21,0 & 21,0 & 21,0 \\
\hline
\end{tabular}

Gráfico 59 - MSM nos 16 pontos de medição - SP21 - Ocup./Desoc.

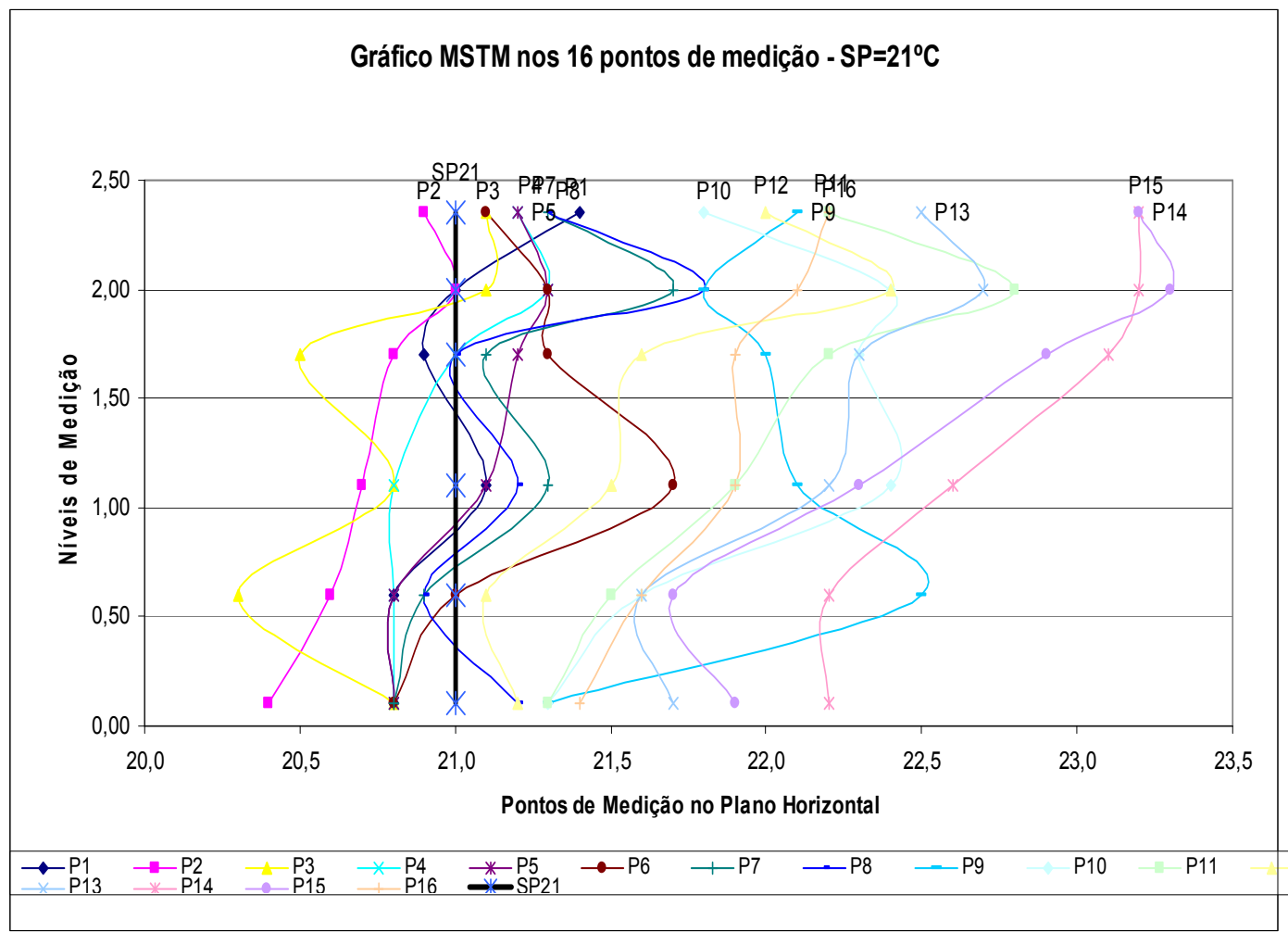


Tabela 65 - Dados de MSM e MSF nas 16 posições e 6 alturas - SP22 - Ocup./Desoc.

\begin{tabular}{|c|c|c|c|c|c|c|c|c|c|c|c|c|c|}
\hline \multicolumn{1}{|c|}{ MSM } & \multicolumn{1}{c|}{ MSF } \\
\hline Alturas & 0,10 & 0,60 & 1,10 & 1,70 & 2,00 & 2,35 & Alturas & 0,10 & 0,60 & 1,10 & 1,70 & 2,00 & 2,35 \\
\hline P1 & 21,6 & 21,0 & 21,0 & 21,6 & 20,9 & 20,9 & P1 & 22,3 & 22,0 & 22,0 & 22,3 & 22,0 & 22,0 \\
\hline P2 & 21,3 & 21,2 & 21,0 & 21,2 & 20,6 & 20,6 & P2 & 22,3 & 22,0 & 22,0 & 22,3 & 22,0 & 22,0 \\
\hline P3 & 21,6 & 21,4 & 21,2 & 20,8 & 20,7 & 20,7 & P3 & 22,3 & 22,0 & 22,0 & 22,3 & 22,0 & 22,0 \\
\hline P4 & 21,6 & 21,8 & 21,4 & 21,3 & 20,8 & 20,8 & P4 & 22,3 & 22,0 & 22,0 & 22,3 & 22,0 & 22,0 \\
\hline P5 & 21,5 & 20,9 & 20,9 & 21,5 & 21,0 & 21,0 & P5 & 22,3 & 22,0 & 22,0 & 22,3 & 22,0 & 22,0 \\
\hline P6 & 21,3 & 21,3 & 21,2 & 21,1 & 20,7 & 20,7 & P6 & 22,3 & 22,0 & 22,0 & 22,3 & 22,0 & 22,0 \\
\hline P7 & 21,3 & 21,4 & 21,0 & 21,6 & 20,9 & 20,9 & P7 & 22,3 & 22,0 & 22,0 & 22,3 & 22,0 & 22,0 \\
\hline P8 & 21,8 & 21,6 & 21,4 & 21,2 & 20,9 & 20,9 & P8 & 22,3 & 22,0 & 22,0 & 22,3 & 22,0 & 22,0 \\
\hline P9 & 21,9 & 22,2 & 21,5 & 22,5 & 21,3 & 21,3 & P9 & 22,3 & 22,0 & 22,0 & 22,3 & 22,0 & 22,0 \\
\hline P10 & 22,3 & 21,9 & 22,0 & 22,4 & 21,6 & 21,6 & P10 & 22,3 & 22,0 & 22,0 & 22,3 & 22,0 & 22,0 \\
\hline P11 & 22,1 & 21,8 & 21,6 & 22,1 & 21,4 & 21,4 & P11 & 22,3 & 22,0 & 22,0 & 22,3 & 22,0 & 22,0 \\
\hline P12 & 21,9 & 21,4 & 21,4 & 21,9 & 21,3 & 21,3 & P12 & 22,3 & 22,0 & 22,0 & 22,3 & 22,0 & 22,0 \\
\hline P13 & 22,2 & 22,1 & 22,0 & 22,8 & 22,1 & 22,1 & P13 & 22,3 & 22,0 & 22,0 & 22,3 & 22,0 & 22,0 \\
\hline P14 & 23,2 & 22,5 & 22,6 & 23,4 & 23,1 & 23,1 & P14 & 22,3 & 22,0 & 22,0 & 22,3 & 22,0 & 22,0 \\
\hline P15 & 22,7 & 21,9 & 21,9 & 23,2 & 22,4 & 22,4 & P15 & 22,3 & 22,0 & 22,0 & 22,3 & 22,0 & 22,0 \\
\hline P16 & 22,1 & 21,8 & 21,7 & 22,2 & 21,1 & 21,1 & P16 & 22,3 & 22,0 & 22,0 & 22,3 & 22,0 & 22,0 \\
\hline SP22 & 22,0 & 22,0 & 22,0 & 22,0 & 22,0 & 22,0 & SP22 & 22,0 & 22,0 & 22,0 & 22,0 & 22,0 & 22,0 \\
\hline
\end{tabular}

Gráfico 60 - MSM nos 16 pontos de medição - SP22 - Ocup./Desoc.

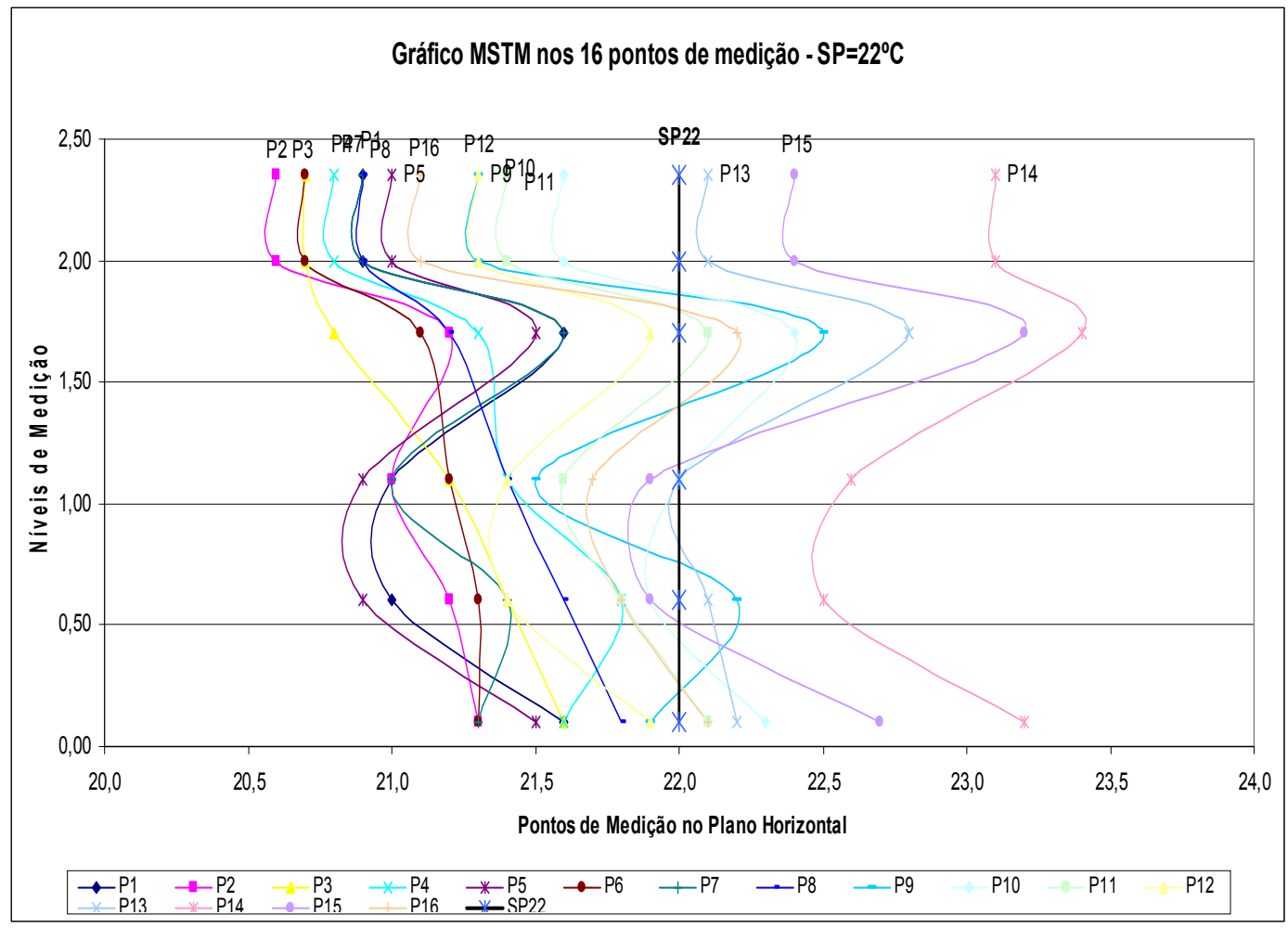


Tabela 66 - Dados de MSM e MSF nas 16 posições e 6 alturas - SP23 - Ocup./Desoc.

\begin{tabular}{|c|c|c|c|c|c|c|c|c|c|c|c|c|c|}
\hline \multicolumn{10}{|c|}{ MSM } & \multicolumn{1}{c|}{ MSF } \\
\hline Alturas & 0,10 & 0,60 & 1,10 & 1,70 & 2,00 & 2,35 & Alturas & 0,10 & 0,60 & 1,10 & 1,70 & 2,00 & 2,35 \\
\hline P1 & 22,0 & 21,9 & 22,2 & 21,5 & 23,1 & 22,2 & P1 & 22,7 & 22,6 & 22,6 & 22,7 & 23,5 & 22,8 \\
\hline P2 & 22,1 & 21,9 & 21,8 & 21,6 & 23,0 & 21,8 & P2 & 22,7 & 22,6 & 22,6 & 22,7 & 23,5 & 22,8 \\
\hline P3 & 22,2 & 21,8 & 21,8 & 21,5 & 23,4 & 21,8 & P3 & 22,7 & 22,6 & 22,6 & 22,7 & 23,5 & 22,8 \\
\hline P4 & 22,3 & 22,0 & 21,8 & 21,5 & 23,1 & 21,7 & P4 & 22,7 & 22,6 & 22,6 & 22,7 & 23,5 & 22,8 \\
\hline P5 & 22,0 & 22,1 & 22,3 & 21,8 & 22,2 & 21,8 & P5 & 22,7 & 22,6 & 22,6 & 22,7 & 23,5 & 22,8 \\
\hline P6 & 22,1 & 22,3 & 22,3 & 21,8 & 23,0 & 21,6 & P6 & 22,7 & 22,6 & 22,6 & 22,7 & 23,5 & 22,8 \\
\hline P7 & 22,2 & 22,3 & 22,2 & 22,0 & 23,4 & 22,0 & P7 & 22,7 & 22,6 & 22,6 & 22,7 & 23,5 & 22,8 \\
\hline P8 & 22,5 & 22,2 & 22,3 & 22,1 & 23,3 & 22,2 & P8 & 22,7 & 22,6 & 22,6 & 22,7 & 23,5 & 22,8 \\
\hline P9 & 22,3 & 24,0 & 22,7 & 22,4 & 22,5 & 22,5 & P9 & 22,7 & 22,6 & 22,6 & 22,7 & 23,5 & 22,8 \\
\hline P10 & 22,9 & 23,2 & 23,4 & 22,7 & 23,6 & 22,2 & P10 & 22,7 & 22,6 & 22,6 & 22,7 & 23,5 & 22,8 \\
\hline P11 & 22,9 & 23,0 & 22,9 & 22,5 & 23,7 & 22,5 & P11 & 22,7 & 22,6 & 22,6 & 22,7 & 23,5 & 22,8 \\
\hline P12 & 22,6 & 22,4 & 22,4 & 22,3 & 23,7 & 22,4 & P12 & 22,7 & 22,6 & 22,6 & 22,7 & 23,5 & 22,8 \\
\hline P13 & 23,0 & 23,1 & 23,1 & 23,1 & 23,5 & 23,3 & P13 & 22,7 & 22,6 & 22,6 & 22,7 & 23,5 & 22,8 \\
\hline P14 & 23,7 & 23,7 & 23,7 & 23,9 & 24,8 & 24,4 & P14 & 22,7 & 22,6 & 22,6 & 22,7 & 23,5 & 22,8 \\
\hline P15 & 23,1 & 23,0 & 23,1 & 23,6 & 24,8 & 23,8 & P15 & 22,7 & 22,6 & 22,6 & 22,7 & 23,5 & 22,8 \\
\hline P16 & 22,7 & 22,8 & 22,7 & 22,7 & 23,6 & 22,7 & P16 & 22,7 & 22,6 & 22,6 & 22,7 & 23,5 & 22,8 \\
\hline SP23 & 23,0 & 23,0 & 23,0 & 23,0 & 23,0 & 23,0 & SP23 & 23,0 & 23,0 & 23,0 & 23,0 & 23,0 & 23,0 \\
\hline
\end{tabular}

Gráfico 61 - MSM nos 16 pontos de medição - SP23 - Ocup./Desoc.

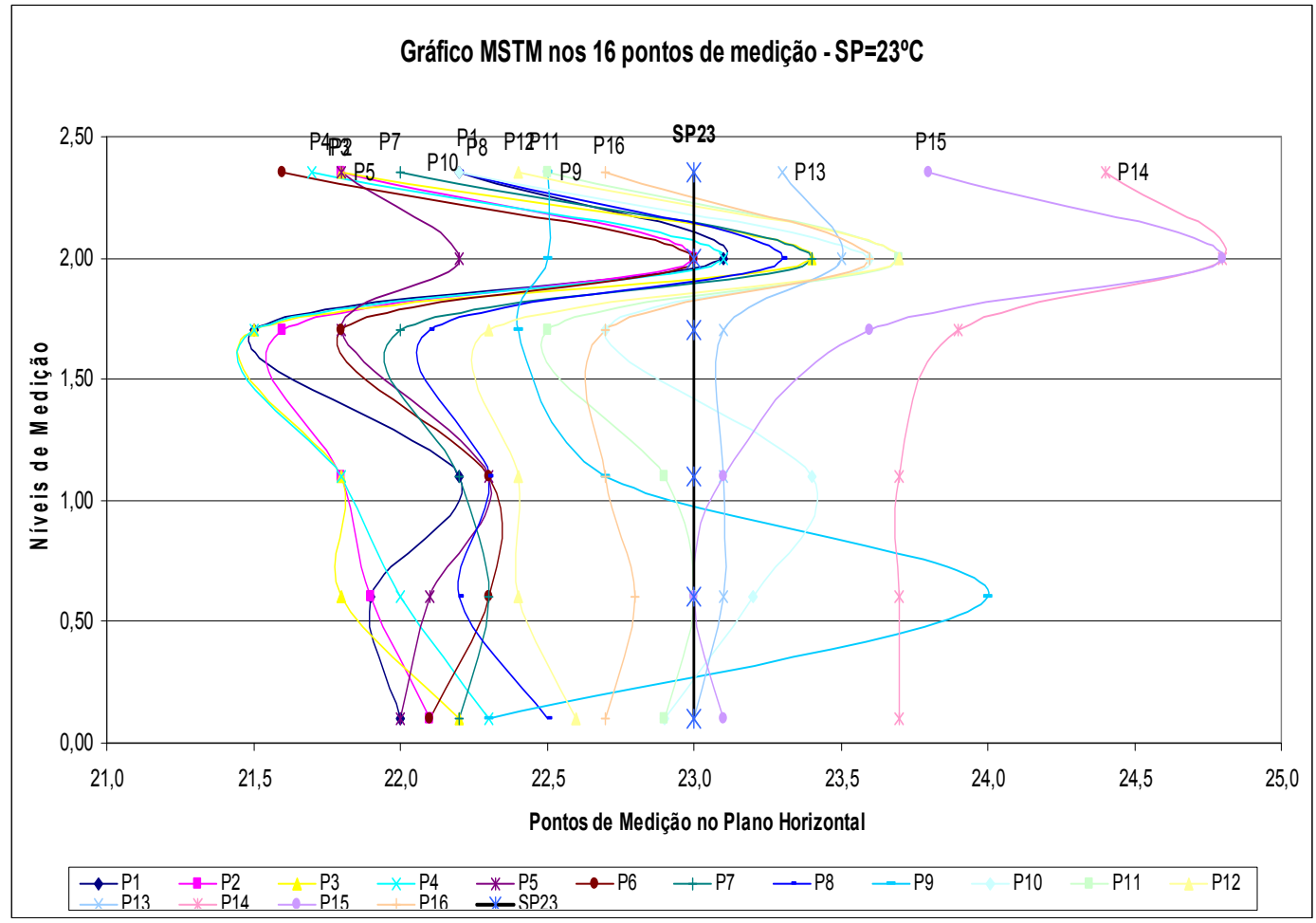


Tabela 67 - Dados de MSM e MSF nas 16 posições e 6 alturas - SP24 - Ocup./Desoc.

\begin{tabular}{|c|c|c|c|c|c|c|c|c|c|c|c|c|c|}
\hline \multicolumn{1}{|c|}{ MSM } & \multicolumn{7}{|c|}{ MSF } \\
\hline Alturas & 0,10 & 0,60 & 1,10 & 1,70 & 2,00 & 2,35 & Alturas & 0,10 & 0,60 & 1,10 & 1,70 & 2,00 & 2,35 \\
\hline P1 & 23,0 & 23,1 & 22,6 & 23,0 & 22,9 & 23,2 & P1 & 23,5 & 23,6 & 23,4 & 23,4 & 23,9 & 23,9 \\
\hline P2 & 23,1 & 23,2 & 22,9 & 22,9 & 23,0 & 23,3 & P2 & 23,5 & 23,6 & 23,4 & 23,4 & 23,9 & 23,9 \\
\hline P3 & 23,2 & 23,4 & 23,2 & 22,9 & 23,5 & 23,4 & P3 & 23,5 & 23,6 & 23,4 & 23,4 & 23,9 & 23,9 \\
\hline P4 & 23,4 & 23,4 & 22,7 & 22,8 & 23,4 & 23,2 & P4 & 23,5 & 23,6 & 23,4 & 23,4 & 23,9 & 23,9 \\
\hline P5 & 22,7 & 23,1 & 22,7 & 22,7 & 22,6 & 22,7 & P5 & 23,5 & 23,6 & 23,4 & 23,4 & 23,9 & 23,9 \\
\hline P6 & 23,0 & 23,6 & 23,0 & 23,1 & 23,2 & 22,7 & P6 & 23,5 & 23,6 & 23,4 & 23,4 & 23,9 & 23,9 \\
\hline P7 & 23,3 & 23,7 & 23,2 & 23,3 & 23,8 & 23,8 & P7 & 23,5 & 23,6 & 23,4 & 23,4 & 23,9 & 23,9 \\
\hline P8 & 23,8 & 23,9 & 23,5 & 23,3 & 23,9 & 23,9 & P8 & 23,5 & 23,6 & 23,4 & 23,4 & 23,9 & 23,9 \\
\hline P9 & 23,1 & 24,6 & 23,7 & 23,7 & 23,6 & 23,8 & P9 & 23,5 & 23,6 & 23,4 & 23,4 & 23,9 & 23,9 \\
\hline P10 & 23,6 & 24,2 & 24,2 & 23,8 & 23,9 & 23,7 & P10 & 23,5 & 23,6 & 23,4 & 23,4 & 23,9 & 23,9 \\
\hline P11 & 24,0 & 24,1 & 23,8 & 23,4 & 24,4 & 24,4 & P11 & 23,5 & 23,6 & 23,4 & 23,4 & 23,9 & 23,9 \\
\hline P12 & 23,6 & 23,6 & 23,3 & 23,2 & 24,3 & 24,1 & P12 & 23,5 & 23,6 & 23,4 & 23,4 & 23,9 & 23,9 \\
\hline P13 & 23,8 & 23,9 & 23,9 & 23,7 & 24,3 & 24,1 & P13 & 23,5 & 23,6 & 23,4 & 23,4 & 23,9 & 23,9 \\
\hline P14 & 24,4 & 24,6 & 24,4 & 24,6 & 25,3 & 25,6 & P14 & 23,5 & 23,6 & 23,4 & 23,4 & 23,9 & 23,9 \\
\hline P15 & 24,0 & 23,9 & 24,1 & 24,4 & 25,0 & 25,3 & P15 & 23,5 & 23,6 & 23,4 & 23,4 & 23,9 & 23,9 \\
\hline P16 & 23,6 & 23,8 & 23,5 & 23,3 & 23,8 & 24,1 & P16 & 23,5 & 23,6 & 23,4 & 23,4 & 23,9 & 23,9 \\
\hline SP24 & 24,0 & 24,0 & 24,0 & 24,0 & 24,0 & 24,0 & SP24 & 24,0 & 24,0 & 24,0 & 24,0 & 24,0 & 24,0 \\
\hline
\end{tabular}

Gráfico 62 - MSM nos 16 pontos de medição - SP24 - Ocup./Desoc.

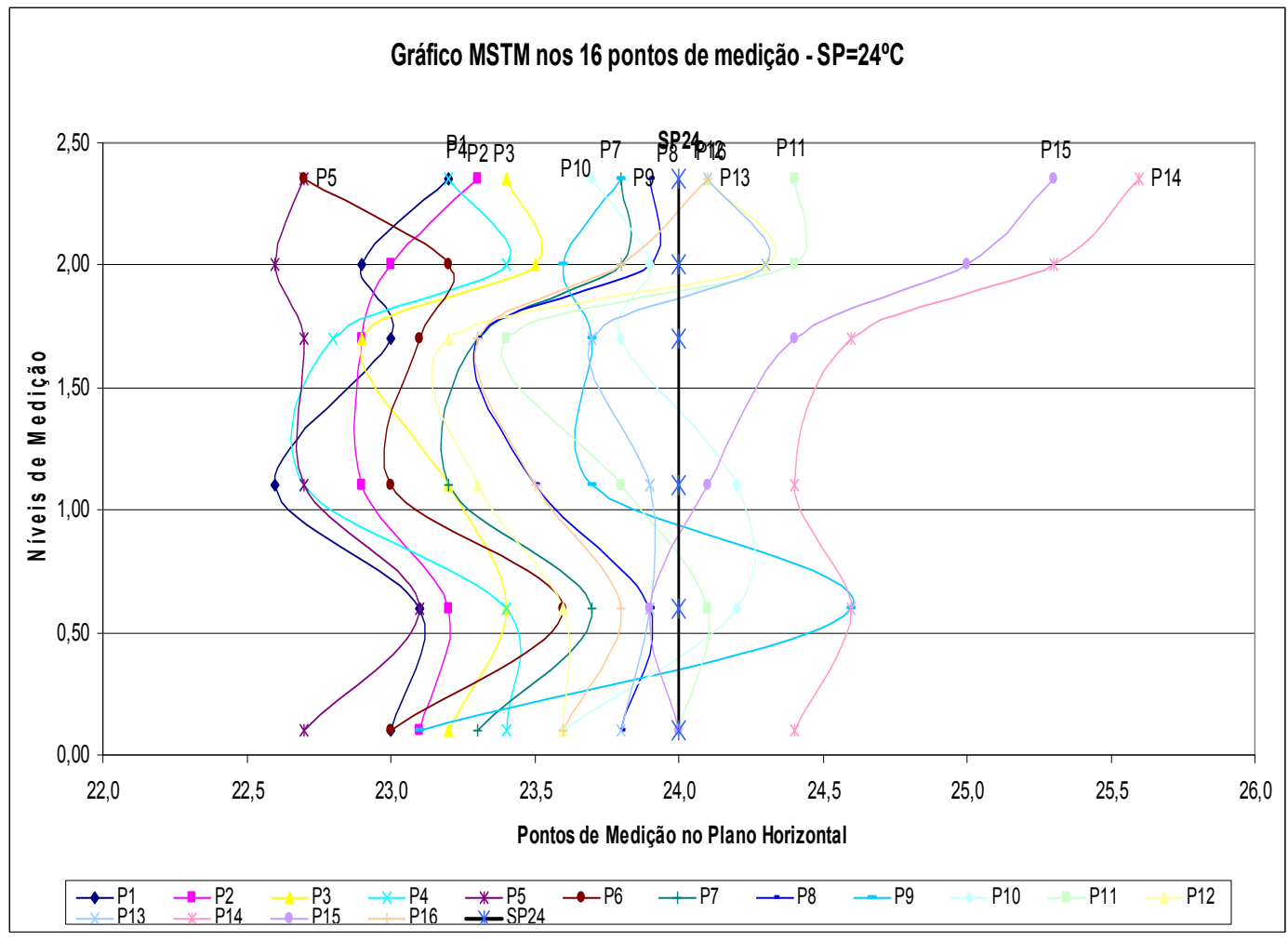


Tabela 68 - Dados de MSM e MSF nas 16 posições e 6 alturas - SP25 -:Ocup./Desoc.

\begin{tabular}{|c|c|c|c|c|c|c|c|c|c|c|c|c|c|}
\hline \multicolumn{1}{|c|}{ MSM } \\
\hline Alturas & 0,10 & 0,60 & 1,10 & 1,70 & 2,00 & 2,35 & Alturas & 0,10 & 0,60 & 1,10 & 1,70 & 2,00 & 2,35 \\
\hline P1 & 23,8 & 23,8 & 23,9 & 24,4 & 24,8 & 24,9 & P1 & 24,4 & 24,5 & 24,3 & 24,7 & 24,8 & 24,8 \\
\hline P2 & 24,2 & 24,2 & 24,2 & 24,8 & 24,9 & 25,0 & P2 & 24,4 & 24,5 & 24,3 & 24,7 & 24,8 & 24,8 \\
\hline P3 & 24,0 & 24,5 & 24,5 & 24,8 & 24,9 & 24,8 & P3 & 24,4 & 24,5 & 24,3 & 24,7 & 24,8 & 24,8 \\
\hline P4 & 24,2 & 24,1 & 24,2 & 24,8 & 24,8 & 24,8 & P4 & 24,4 & 24,5 & 24,3 & 24,7 & 24,8 & 24,8 \\
\hline P5 & 24,5 & 24,0 & 24,9 & 24,3 & 24,3 & 24,4 & P5 & 24,4 & 24,5 & 24,3 & 24,7 & 24,8 & 24,8 \\
\hline P6 & 23,8 & 24,3 & 24,3 & 24,7 & 25,1 & 25,2 & P6 & 24,4 & 24,5 & 24,3 & 24,7 & 24,8 & 24,8 \\
\hline P7 & 24,1 & 24,5 & 24,6 & 25,5 & 25,6 & 25,6 & P7 & 24,4 & 24,5 & 24,3 & 24,7 & 24,8 & 24,8 \\
\hline P8 & 24,6 & 24,6 & 24,5 & 25,4 & 25,3 & 25,3 & P8 & 24,4 & 24,5 & 24,3 & 24,7 & 24,8 & 24,8 \\
\hline P9 & 24,9 & 25,3 & 24,6 & 25,0 & 25,1 & 25,2 & P9 & 24,4 & 24,5 & 24,3 & 24,7 & 24,8 & 24,8 \\
\hline P10 & 24,1 & 25,1 & 25,1 & 25,3 & 25,3 & 24,9 & P10 & 24,4 & 24,5 & 24,3 & 24,7 & 24,8 & 24,8 \\
\hline P11 & 24,6 & 25,0 & 24,8 & 25,3 & 25,0 & 24,9 & P11 & 24,4 & 24,5 & 24,3 & 24,7 & 24,8 & 24,8 \\
\hline P12 & 24,4 & 24,4 & 24,5 & 25,2 & 25,4 & 25,6 & P12 & 24,4 & 24,5 & 24,3 & 24,7 & 24,8 & 24,8 \\
\hline P13 & 24,4 & 24,8 & 25,0 & 25,7 & 25,6 & 25,7 & P13 & 24,4 & 24,5 & 24,3 & 24,7 & 24,8 & 24,8 \\
\hline P14 & 25,3 & 25,5 & 25,6 & 26,3 & 26,6 & 27,0 & P14 & 24,4 & 24,5 & 24,3 & 24,7 & 24,8 & 24,8 \\
\hline P15 & 24,8 & 24,9 & 25,1 & 25,9 & 26,0 & 26,1 & P15 & 24,4 & 24,5 & 24,3 & 24,7 & 24,8 & 24,8 \\
\hline P16 & 24,3 & 24,6 & 24,7 & 25,3 & 25,0 & 25,4 & P16 & 24,4 & 24,5 & 24,3 & 24,7 & 24,8 & 24,8 \\
\hline SP25 & 25,0 & 25,0 & 25,0 & 25,0 & 25,0 & 25,0 & SP25 & 25,0 & 25,0 & 25,0 & 25,0 & 25,0 & 25,0 \\
\hline
\end{tabular}

Gráfico 63 - MSM nos 16 pontos de medição - SP25 - Ocup./Desoc.

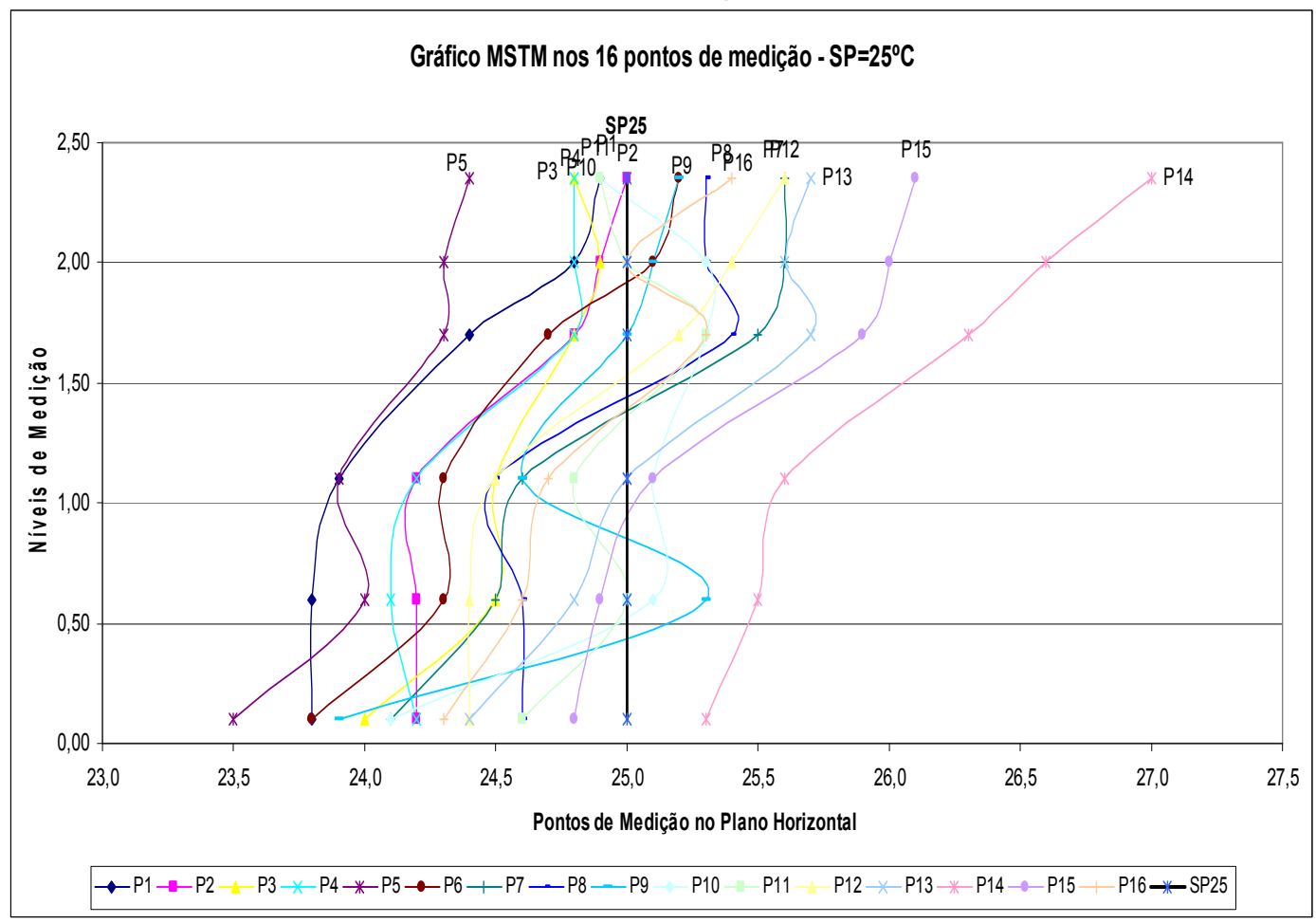


Tabela 69 - Dados de MSM e MSF nas 16 posições e 6 alturas - SP26 - Ocup./Desoc.

\begin{tabular}{|c|c|c|c|c|c|c|c|c|c|c|c|c|c|}
\hline \multicolumn{1}{|c|}{ MSM } & \multicolumn{1}{|c|}{ MSF } \\
\hline Alturas & 0,10 & 0,60 & 1,10 & 1,70 & 2,00 & 2,35 & Alturas & 0,10 & 0,60 & 1,10 & 1,70 & 2,00 & 2,35 \\
\hline P1 & 24,6 & 24,5 & 24,5 & 24,3 & 24,5 & 24,5 & P1 & 24,8 & 24,9 & 24,8 & 24,3 & 24,4 & 24,3 \\
\hline P2 & 24,8 & 24,7 & 24,6 & 24,5 & 24,5 & 24,5 & P2 & 24,8 & 24,9 & 24,8 & 24,3 & 24,4 & 24,3 \\
\hline P3 & 24,9 & 24,9 & 24,7 & 24,3 & 24,6 & 24,5 & P3 & 24,8 & 24,9 & 24,8 & 24,3 & 24,4 & 24,3 \\
\hline P4 & 24,8 & 24,7 & 24,6 & 24,3 & 24,3 & 24,4 & P4 & 24,8 & 24,9 & 24,8 & 24,3 & 24,4 & 24,3 \\
\hline P5 & 24,4 & 24,8 & 24,6 & 24,3 & 24,3 & 24,3 & P5 & 24,8 & 24,9 & 24,8 & 24,3 & 24,4 & 24,3 \\
\hline P6 & 24,8 & 25,1 & 24,8 & 24,5 & 24,5 & 24,5 & P6 & 24,8 & 24,9 & 24,8 & 24,3 & 24,4 & 24,3 \\
\hline P7 & 25,0 & 25,3 & 25,1 & 24,7 & 24,7 & 24,5 & P7 & 24,8 & 24,9 & 24,8 & 24,3 & 24,4 & 24,3 \\
\hline P8 & 25,3 & 25,1 & 25,0 & 24,5 & 24,6 & 24,5 & P8 & 24,8 & 24,9 & 24,8 & 24,3 & 24,4 & 24,3 \\
\hline P9 & 25,1 & 26,3 & 25,1 & 24,6 & 24,6 & 24,8 & P9 & 24,8 & 24,9 & 24,8 & 24,3 & 24,4 & 24,3 \\
\hline P10 & 25,1 & 25,8 & 25,6 & 24,7 & 25,0 & 24,7 & P10 & 24,8 & 24,9 & 24,8 & 24,3 & 24,4 & 24,3 \\
\hline P11 & 25,5 & 25,7 & 25,7 & 24,8 & 24,9 & 24,8 & P11 & 24,8 & 24,9 & 24,8 & 24,3 & 24,4 & 24,3 \\
\hline P12 & 25,3 & 25,2 & 25,2 & 24,7 & 24,8 & 24,7 & P12 & 24,8 & 24,9 & 24,8 & 24,3 & 24,4 & 24,3 \\
\hline P13 & 25,4 & 25,4 & 25,6 & 25,0 & 25,2 & 25,3 & P13 & 24,8 & 24,9 & 24,8 & 24,3 & 24,4 & 24,3 \\
\hline P14 & 26,2 & 26,2 & 26,2 & 25,8 & 26,0 & 26,2 & P14 & 24,8 & 24,9 & 24,8 & 24,3 & 24,4 & 24,3 \\
\hline P15 & 25,6 & 25,7 & 25,8 & 25,5 & 25,5 & 25,7 & P15 & 24,8 & 24,9 & 24,8 & 24,3 & 24,4 & 24,3 \\
\hline P16 & 25,1 & 25,3 & 25,3 & 24,7 & 24,8 & 24,8 & P16 & 24,8 & 24,9 & 24,8 & 24,3 & 24,4 & 24,3 \\
\hline SP26 & 26,0 & 26,0 & 26,0 & 26,0 & 26,0 & 26,0 & SP26 & 26,0 & 26,0 & 26,0 & 26,0 & 26,0 & 26,0 \\
\hline
\end{tabular}

Gráfico 64 - MSM nos 16 pontos de medição - SP26 -“Ocup./Desoc.”

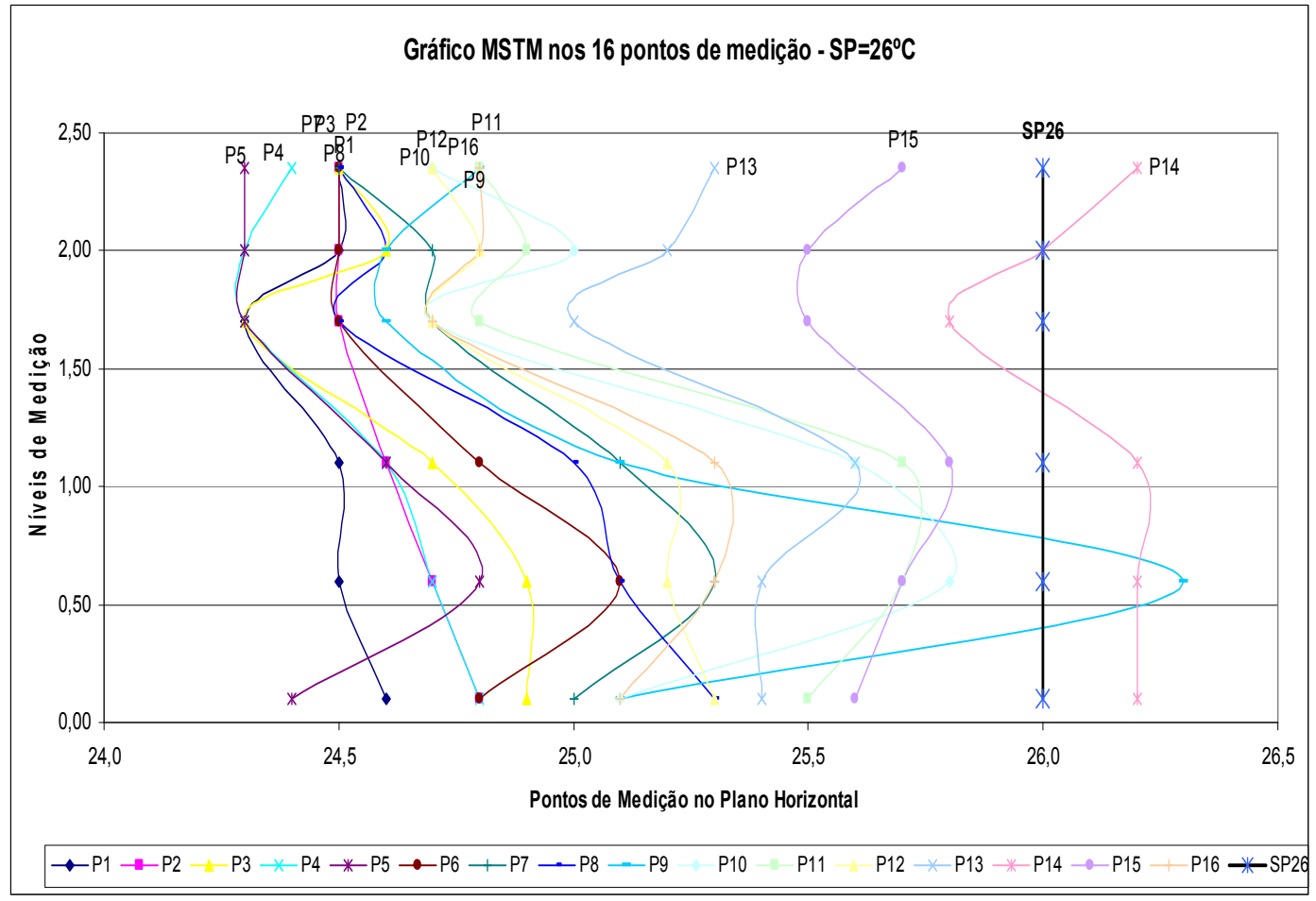


Tabela 70 - Dados de MSM e MSF nas 16 posições e 6 alturas - SP21 -: Desocupado.

\begin{tabular}{|c|c|c|c|c|c|c|c|c|c|c|c|c|c|}
\hline \multicolumn{1}{|c|}{ MSM } & \multicolumn{1}{c|}{ MSF } \\
\hline Alturas & 0,10 & 0,60 & 1,10 & 1,70 & 2,00 & 2,35 & Alturas & 0,10 & 0,60 & 1,10 & 1,70 & 2,00 & 2,35 \\
\hline P1 & 20,8 & 20,8 & 20,8 & 20,8 & 20,8 & 21,1 & P1 & 21,4 & 21,4 & 21,4 & 21,8 & 21,8 & 21,8 \\
\hline P2 & 20,4 & 20,6 & 20,3 & 20,6 & 20,3 & 20,4 & P2 & 21,4 & 21,4 & 21,4 & 21,8 & 21,8 & 21,8 \\
\hline P3 & 20,8 & 20,3 & 20,3 & 20,3 & 20,4 & 20,6 & P3 & 21,4 & 21,4 & 21,4 & 21,8 & 21,8 & 21,8 \\
\hline P4 & 20,8 & 20,8 & 20,3 & 20,8 & 20,4 & 20,7 & P4 & 21,4 & 21,4 & 21,4 & 21,8 & 21,8 & 21,8 \\
\hline P5 & 20,8 & 20,8 & 20,8 & 21,2 & 21,3 & 21,2 & P5 & 21,4 & 21,4 & 21,4 & 21,8 & 21,8 & 21,8 \\
\hline P6 & 20,8 & 21,0 & 21,6 & 21,2 & 21,0 & 20,8 & P6 & 21,4 & 21,4 & 21,4 & 21,8 & 21,8 & 21,8 \\
\hline P7 & 20,8 & 20,9 & 20,9 & 21,0 & 21,0 & 20,8 & P7 & 21,4 & 21,4 & 21,4 & 21,8 & 21,8 & 21,8 \\
\hline P8 & 21,2 & 20,9 & 20,8 & 20,8 & 20,8 & 20,8 & P8 & 21,4 & 21,4 & 21,4 & 21,8 & 21,8 & 21,8 \\
\hline P9 & 21,3 & 22,5 & 21,6 & 21,8 & 21,8 & 22,0 & P9 & 21,4 & 21,4 & 21,4 & 21,8 & 21,8 & 21,8 \\
\hline P10 & 21,3 & 21,6 & 21,8 & 22,2 & 22,0 & 21,4 & P10 & 21,4 & 21,4 & 21,4 & 21,8 & 21,8 & 21,8 \\
\hline P11 & 21,3 & 21,5 & 21,4 & 22,1 & 21,8 & 22,1 & P11 & 21,4 & 21,4 & 21,4 & 21,8 & 21,8 & 21,8 \\
\hline P12 & 21,2 & 21,1 & 20,9 & 21,4 & 21,8 & 21,5 & P12 & 21,4 & 21,4 & 21,4 & 21,8 & 21,8 & 21,8 \\
\hline P13 & 21,7 & 21,6 & 21,6 & 22,2 & 22,5 & 22,4 & P13 & 21,4 & 21,4 & 21,4 & 21,8 & 21,8 & 21,8 \\
\hline P14 & 22,2 & 22,2 & 22,2 & 23,0 & 23,2 & 23,1 & P14 & 21,4 & 21,4 & 21,4 & 21,8 & 21,8 & 21,8 \\
\hline P15 & 21,9 & 21,7 & 21,9 & 22,8 & 22,9 & 22,9 & P15 & 21,4 & 21,4 & 21,4 & 21,8 & 21,8 & 21,8 \\
\hline P16 & 21,4 & 21,6 & 21,4 & 21,8 & 21,4 & 21,8 & P16 & 21,4 & 21,4 & 21,4 & 21,8 & 21,8 & 21,8 \\
\hline Media & 21,2 & 21,2 & 21,2 & 21,5 & 21,5 & 21,5 & SP21 & 21,0 & 21,0 & 21,0 & 21,0 & 21,0 & 21,0 \\
\hline
\end{tabular}

Gráfico 65 - MSM nos 16 pontos de medição - SP21 -"Desocupado"

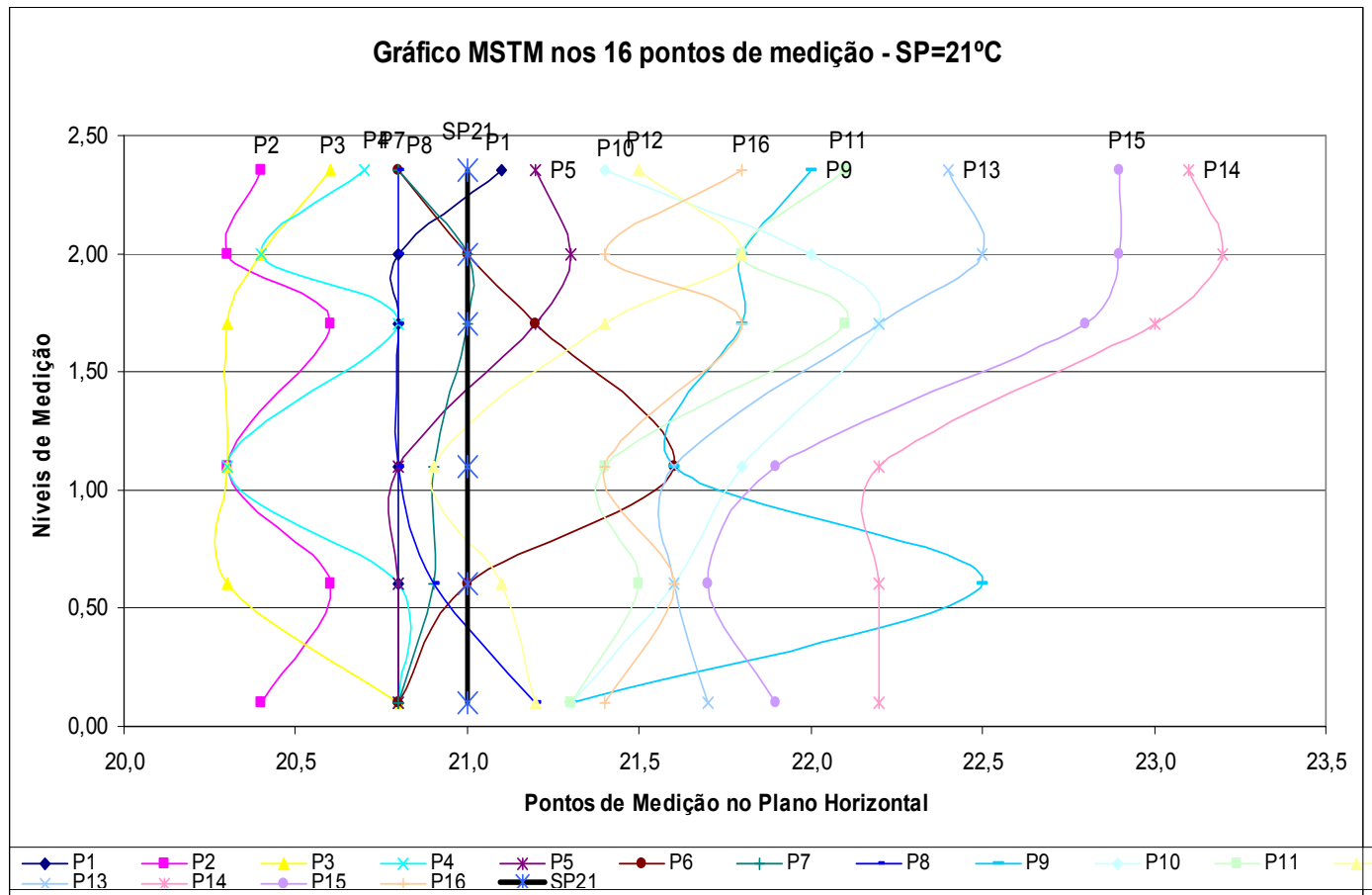


Tabela 71 - Dados de MSM e MSF nas 16 posições e 6 alturas - SP22 - Desocupado.

\begin{tabular}{|c|c|c|c|c|c|c|c|c|c|c|c|c|c|}
\hline \multicolumn{1}{|c|}{ MSM } & \multicolumn{1}{c|}{ MSF } \\
\hline Alturas & 0,10 & 0,60 & 1,10 & 1,70 & 2,00 & 2,35 & Alturas & 0,10 & 0,60 & 1,10 & 1,70 & 2,00 & 2,35 \\
\hline P1 & 21,6 & 21,0 & 21,6 & 21,6 & 23,0 & 21,2 & P1 & 22,3 & 22,0 & 22,4 & 22,3 & 23,7 & 22,2 \\
\hline P2 & 21,3 & 21,2 & 21,5 & 21,2 & 22,6 & 20,8 & P2 & 22,3 & 22,0 & 22,4 & 22,3 & 23,7 & 22,2 \\
\hline P3 & 21,6 & 21,4 & 21,7 & 20,8 & 22,5 & 20,8 & P3 & 22,3 & 22,0 & 22,4 & 22,3 & 23,7 & 22,2 \\
\hline P4 & 21,6 & 21,8 & 21,8 & 21,3 & 22,6 & 20,9 & P4 & 22,3 & 22,0 & 22,4 & 22,3 & 23,7 & 22,2 \\
\hline P5 & 21,5 & 20,9 & 21,6 & 21,5 & 23,3 & 21,3 & P5 & 22,3 & 22,0 & 22,4 & 22,3 & 23,7 & 22,2 \\
\hline P6 & 21,3 & 21,3 & 21,9 & 21,1 & 22,8 & 20,8 & P6 & 22,3 & 22,0 & 22,4 & 22,3 & 23,7 & 22,2 \\
\hline P7 & 21,3 & 21,4 & 21,7 & 21,6 & 23,3 & 21,1 & P7 & 22,3 & 22,0 & 22,4 & 22,3 & 23,7 & 22,2 \\
\hline P8 & 21,8 & 21,6 & 22,1 & 21,2 & 23,1 & 21,3 & P8 & 22,3 & 22,0 & 22,4 & 22,3 & 23,7 & 22,2 \\
\hline P9 & 22,0 & 22,2 & 22,1 & 22,5 & 23,9 & 21,6 & P9 & 22,3 & 22,0 & 22,4 & 22,3 & 23,7 & 22,2 \\
\hline P10 & 22,2 & 21,9 & 22,6 & 22,4 & 24,0 & 21,7 & P10 & 22,3 & 22,0 & 22,4 & 22,3 & 23,7 & 22,2 \\
\hline P11 & 22,1 & 21,8 & 22,1 & 22,1 & 23,7 & 21,7 & P11 & 22,3 & 22,0 & 22,4 & 22,3 & 23,7 & 22,2 \\
\hline P12 & 21,7 & 21,4 & 21,4 & 21,9 & 23,4 & 21,5 & P12 & 22,3 & 22,0 & 22,4 & 22,3 & 23,7 & 22,2 \\
\hline P13 & 22,3 & 22,1 & 22,7 & 22,8 & 24,2 & 22,2 & P13 & 22,3 & 22,0 & 22,4 & 22,3 & 23,7 & 22,2 \\
\hline P14 & 23,2 & 22,5 & 23,0 & 23,4 & 24,3 & 23,6 & P14 & 22,3 & 22,0 & 22,4 & 22,3 & 23,7 & 22,2 \\
\hline P15 & 22,7 & 21,9 & 22,3 & 23,2 & 24,2 & 23,0 & P15 & 22,3 & 22,0 & 22,4 & 22,3 & 23,7 & 22,2 \\
\hline P16 & 22,1 & 21,8 & 22,2 & 22,2 & 23,5 & 21,8 & P16 & 22,3 & 22,0 & 22,4 & 22,3 & 23,7 & 22,2 \\
\hline Media & 21,9 & 21,6 & 22,0 & 21,9 & 23,4 & 21,6 & SP22 & 22,0 & 22,0 & 22,0 & 22,0 & 22,0 & 22,0 \\
\hline
\end{tabular}

Gráfico 66 - MSM nos 16 pontos de medição - SP22 -"Desocupado."

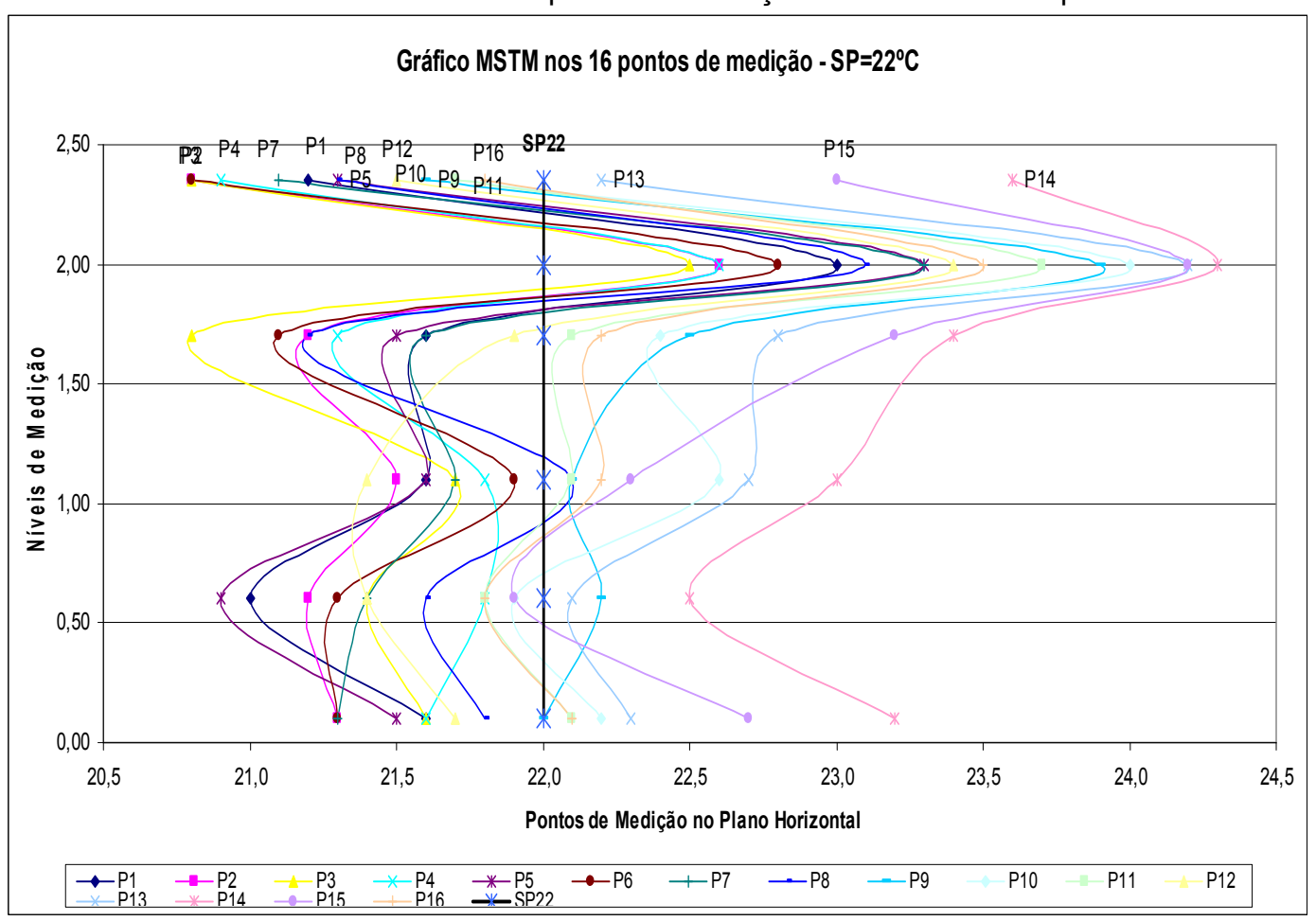


Tabela 72 - Dados de MSM e MSF nas 16 posições e 6 alturas - SP23 - Desocupado

\begin{tabular}{|c|c|c|c|c|c|c|c|c|c|c|c|c|c|}
\hline \multicolumn{10}{|c|}{ MSM } & \multicolumn{1}{|c|}{ MSF } \\
\hline Alturas & 0,10 & 0,60 & 1,10 & 1,70 & 2,00 & 2,35 & Alturas & 0,10 & 0,60 & 1,10 & 1,70 & 2,00 & 2,35 \\
\hline P1 & 22,2 & 22,0 & 22,2 & 21,5 & 21,6 & 21,7 & P1 & 22,6 & 22,6 & 22,6 & 22,5 & 22,5 & 22,5 \\
\hline P2 & 22,1 & 22,0 & 21,8 & 21,4 & 21,4 & 21,5 & P2 & 22,6 & 22,6 & 22,6 & 22,5 & 22,5 & 22,5 \\
\hline P3 & 22,2 & 21,8 & 21,8 & 21,3 & 21,4 & 21,4 & P3 & 22,6 & 22,6 & 22,6 & 22,5 & 22,5 & 22,5 \\
\hline P4 & 22,3 & 22,1 & 21,8 & 21,5 & 21,5 & 21,5 & P4 & 22,6 & 22,6 & 22,6 & 22,5 & 22,5 & 22,5 \\
\hline P5 & 22,2 & 22,2 & 22,3 & 21,8 & 21,8 & 21,7 & P5 & 22,6 & 22,6 & 22,6 & 22,5 & 22,5 & 22,5 \\
\hline P6 & 22,2 & 22,3 & 22,3 & 21,7 & 21,6 & 21,5 & P6 & 22,6 & 22,6 & 22,6 & 22,5 & 22,5 & 22,5 \\
\hline P7 & 22,2 & 22,3 & 22,2 & 21,8 & 22,0 & 21,8 & P7 & 22,6 & 22,6 & 22,6 & 22,5 & 22,5 & 22,5 \\
\hline P8 & 22,6 & 22,3 & 22,3 & 21,8 & 22,0 & 22,0 & P8 & 22,6 & 22,6 & 22,6 & 22,5 & 22,5 & 22,5 \\
\hline P9 & 22,4 & 24,1 & 22,7 & 22,2 & 22,3 & 22,5 & P9 & 22,6 & 22,6 & 22,6 & 22,5 & 22,5 & 22,5 \\
\hline P10 & 23,0 & 23,2 & 23,4 & 22,6 & 22,5 & 22,1 & P10 & 22,6 & 22,6 & 22,6 & 22,5 & 22,5 & 22,5 \\
\hline P11 & 22,9 & 22,9 & 22,9 & 22,5 & 22,4 & 22,4 & P11 & 22,6 & 22,6 & 22,6 & 22,5 & 22,5 & 22,5 \\
\hline P12 & 22,7 & 22,5 & 22,4 & 22,3 & 22,3 & 22,4 & P12 & 22,6 & 22,6 & 22,6 & 22,5 & 22,5 & 22,5 \\
\hline P13 & 23,1 & 23,1 & 23,1 & 23,0 & 23,1 & 23,1 & P13 & 22,6 & 22,6 & 22,6 & 22,5 & 22,5 & 22,5 \\
\hline P14 & 23,7 & 23,7 & 23,7 & 23,7 & 23,9 & 24,2 & P14 & 22,6 & 22,6 & 22,6 & 22,5 & 22,5 & 22,5 \\
\hline P15 & 23,1 & 23,0 & 23,1 & 23,3 & 23,3 & 23,6 & P15 & 22,6 & 22,6 & 22,6 & 22,5 & 22,5 & 22,5 \\
\hline P16 & 22,8 & 22,8 & 22,7 & 22,5 & 22,0 & 22,5 & P16 & 22,6 & 22,6 & 22,6 & 22,5 & 22,5 & 22,5 \\
\hline Media & 22,6 & 22,6 & 22,5 & 22,2 & 22,2 & 22,2 & SP23 & 23,0 & 23,0 & 23,0 & 23,0 & 23,0 & 23,0 \\
\hline
\end{tabular}

Gráfico 67 - MSM nos 16 pontos de medição - SP23 -“Desocupado.”

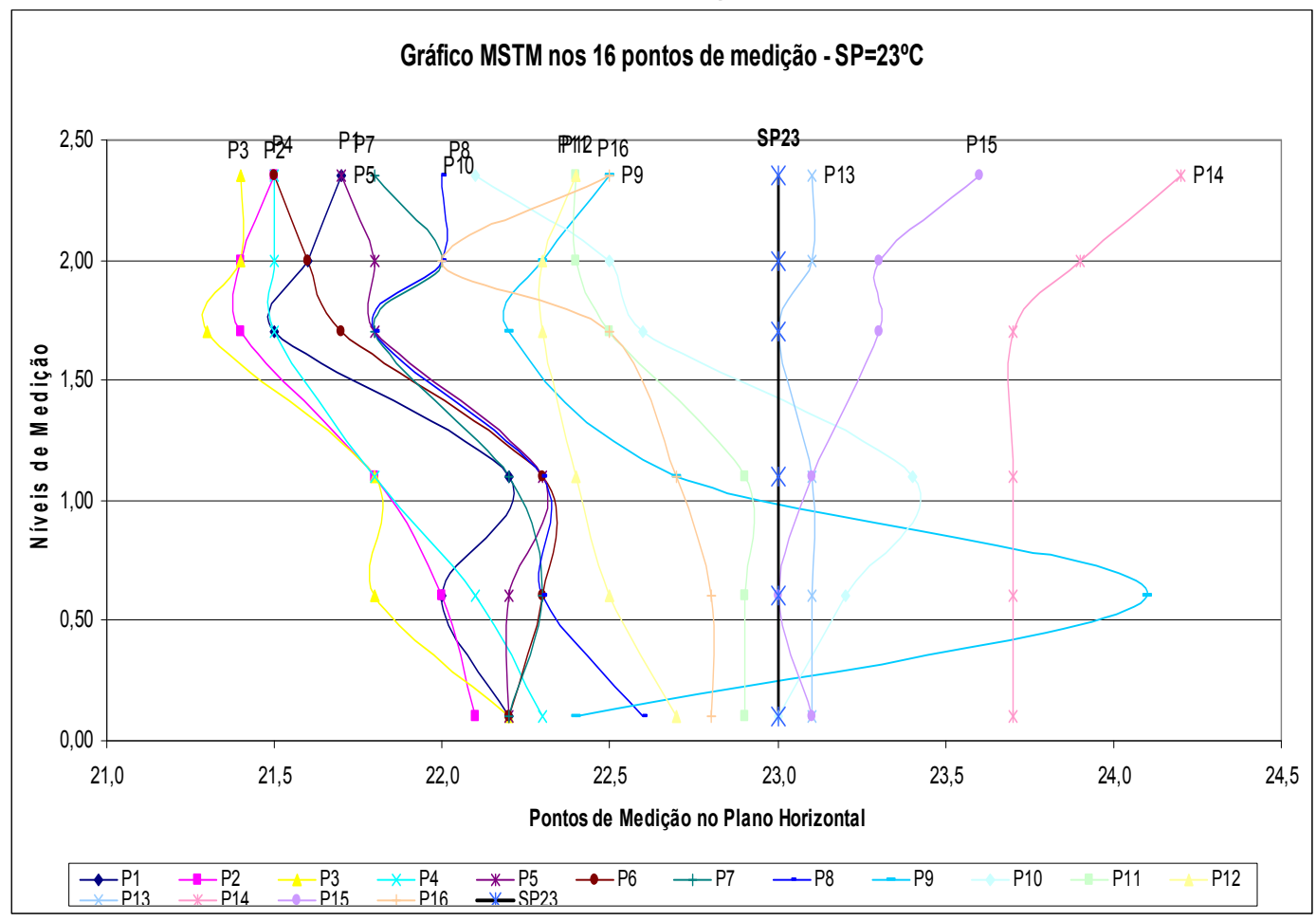


Tabela 73 - Dados de MSM e MSF nas 16 posições e 6 alturas - SP24 - Desocupado.

\begin{tabular}{|c|c|c|c|c|c|c|c|c|c|c|c|c|c|}
\hline \multicolumn{7}{|c|}{ MSM } & \multicolumn{7}{|c|}{ MSF } \\
\hline Alturas & 0,10 & 0,60 & 1,10 & 1,70 & 2,00 & 2,35 & Alturas & 0,10 & 0,60 & 1,10 & 1,70 & 2,00 & 2,35 \\
\hline P1 & 22,8 & 22,8 & 22,3 & 22,3 & 22,7 & 23,2 & P1 & 23,4 & 23,4 & 23,2 & 22,8 & 23,2 & 22,8 \\
\hline P2 & 23,0 & 22,9 & 22,4 & 22,3 & 22,7 & 23,3 & P2 & 23,4 & 23,4 & 23,2 & 22,8 & 23,2 & 22,8 \\
\hline P3 & 23,0 & 22,9 & 22,6 & 22,3 & 22,8 & 23,4 & P3 & 23,4 & 23,4 & 23,2 & 22,8 & 23,2 & 22,8 \\
\hline P4 & 23,2 & 23,0 & 22,3 & 22,3 & 22,8 & 23,2 & P4 & 23,4 & 23,4 & 23,2 & 22,8 & 23,2 & 22,8 \\
\hline P5 & 22,6 & 22,7 & 22,7 & 22,3 & 22,5 & 22,7 & P5 & 23,4 & 23,4 & 23,2 & 22,8 & 23,2 & 22,8 \\
\hline P6 & 22,8 & 23,3 & 22,7 & 22,3 & 22,6 & 22,7 & P6 & 23,4 & 23,4 & 23,2 & 22,8 & 23,2 & 22,8 \\
\hline P7 & 23,1 & 23,4 & 22,8 & 22,3 & 22,9 & 23,8 & P7 & 23,4 & 23,4 & 23,2 & 22,8 & 23,2 & 22,8 \\
\hline P8 & 23,6 & 23,3 & 22,9 & 22,3 & 22,9 & 23,9 & P8 & 23,4 & 23,4 & 23,2 & 22,8 & 23,2 & 22,8 \\
\hline P9 & 23,1 & 24,2 & 23,1 & 22,7 & 23,3 & 23,8 & P9 & 23,4 & 23,4 & 23,2 & 22,8 & 23,2 & 22,8 \\
\hline P10 & 23,5 & 24,1 & 23,6 & 22,8 & 23,2 & 23,7 & P10 & 23,4 & 23,4 & 23,2 & 22,8 & 23,2 & 22,8 \\
\hline P11 & 23,8 & 23,8 & 23,3 & 22,8 & 23,2 & 24,4 & P11 & 23,4 & 23,4 & 23,2 & 22,8 & 23,2 & 22,8 \\
\hline P12 & 23,4 & 23,1 & 22,9 & 22,4 & 23,0 & 24,1 & P12 & 23,4 & 23,4 & 23,2 & 22,8 & 23,2 & 22,8 \\
\hline P13 & 23,7 & 23,6 & 23,6 & 23,1 & 23,7 & 24,1 & P13 & 23,4 & 23,4 & 23,2 & 22,8 & 23,2 & 22,8 \\
\hline P14 & 24,2 & 24,2 & 24,2 & 24,1 & 24,6 & 25,6 & P14 & 23,4 & 23,4 & 23,2 & 22,8 & 23,2 & 22,8 \\
\hline P15 & 23,9 & 23,7 & 23,5 & 23,5 & 24,0 & 25,3 & P15 & 23,4 & 23,4 & 23,2 & 22,8 & 23,2 & 22,8 \\
\hline P16 & 23,4 & 23,3 & 23,0 & 22,5 & 22,9 & 24,1 & P16 & 23,4 & 23,4 & 23,2 & 22,8 & 23,2 & 22,8 \\
\hline Media & 23,3 & 23,4 & 23,0 & 22,6 & 23,1 & 23,8 & SP24 & 24,0 & 24,0 & 24,0 & 24,0 & 24,0 & 24,0 \\
\hline
\end{tabular}

Gráfico 68 - MSM nos 16 pontos de medição - SP24 - Desocupado.

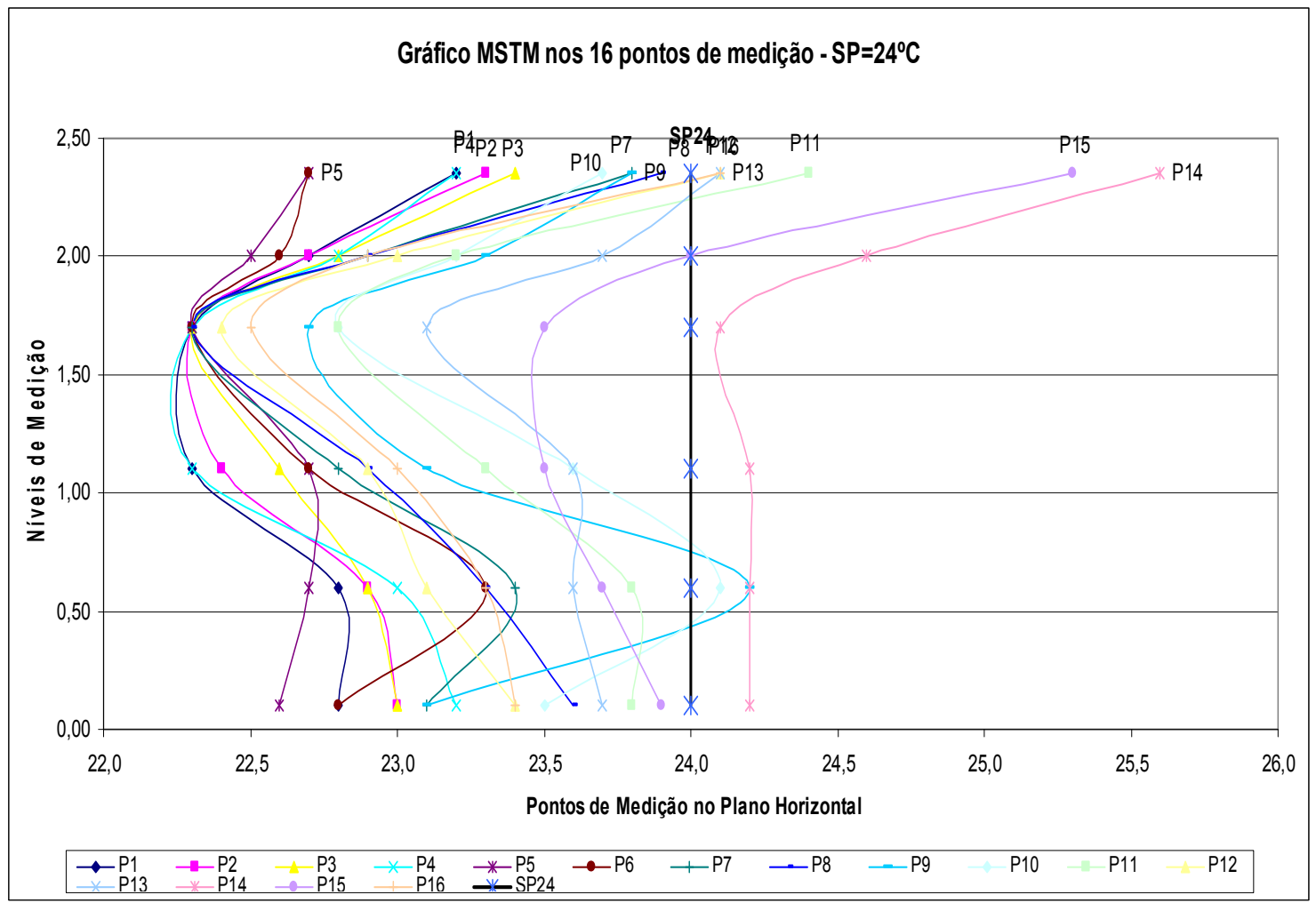


Tabela 74 - Dados de MSM e MSF nas 16 posições e 6 alturas - SP25 - Desocupado.

\begin{tabular}{|c|c|c|c|c|c|c|c|c|c|c|c|c|c|}
\hline \multicolumn{1}{|c|}{ MSM } & \multicolumn{1}{c|}{ MSF } \\
\hline Alturas & 0,10 & 0,60 & 1,10 & 1,70 & 2,00 & 2,35 & Alturas & 0,10 & 0,60 & 1,10 & 1,70 & 2,00 & 2,35 \\
\hline P1 & 23,4 & 23,3 & 23,3 & 23,3 & 24,5 & 23,4 & P1 & 23,9 & 23,9 & 23,5 & 23,6 & 24,4 & 23,5 \\
\hline P2 & 23,6 & 23,3 & 23,3 & 23,3 & 24,1 & 23,3 & P2 & 23,9 & 23,9 & 23,5 & 23,6 & 24,4 & 23,5 \\
\hline P3 & 23,4 & 23,4 & 23,3 & 23,3 & 24,4 & 23,3 & P3 & 23,9 & 23,9 & 23,5 & 23,6 & 24,4 & 23,5 \\
\hline P4 & 23,6 & 23,3 & 23,3 & 23,3 & 24,1 & 23,3 & P4 & 23,9 & 23,9 & 23,5 & 23,6 & 24,4 & 23,5 \\
\hline P5 & 23,3 & 23,4 & 23,3 & 23,3 & 24,1 & 23,3 & P5 & 23,9 & 23,9 & 23,5 & 23,6 & 24,4 & 23,5 \\
\hline P6 & 23,3 & 23,7 & 23,7 & 23,4 & 24,3 & 23,3 & P6 & 23,9 & 23,9 & 23,5 & 23,6 & 24,4 & 23,5 \\
\hline P7 & 23,7 & 23,8 & 23,4 & 23,4 & 24,4 & 23,3 & P7 & 23,9 & 23,9 & 23,5 & 23,6 & 24,4 & 23,5 \\
\hline P8 & 23,9 & 23,6 & 23,3 & 23,3 & 24,2 & 23,3 & P8 & 23,9 & 23,9 & 23,5 & 23,6 & 24,4 & 23,5 \\
\hline P9 & 23,5 & 24,5 & 23,7 & 23,8 & 24,8 & 23,7 & P9 & 23,9 & 23,9 & 23,5 & 23,6 & 24,4 & 23,5 \\
\hline P10 & 23,8 & 24,4 & 24,3 & 23,9 & 25,0 & 23,4 & P10 & 23,9 & 23,9 & 23,5 & 23,6 & 24,4 & 23,5 \\
\hline P11 & 24,2 & 24,5 & 23,9 & 23,9 & 24,7 & 23,7 & P11 & 23,9 & 23,9 & 23,5 & 23,6 & 24,4 & 23,5 \\
\hline P12 & 23,8 & 23,5 & 23,4 & 23,4 & 24,2 & 23,4 & P12 & 23,9 & 23,9 & 23,5 & 23,6 & 24,4 & 23,5 \\
\hline P13 & 24,1 & 24,1 & 24,1 & 24,1 & 25,3 & 24,5 & P13 & 23,9 & 23,9 & 23,5 & 23,6 & 24,4 & 23,5 \\
\hline P14 & 24,8 & 24,9 & 24,7 & 25,1 & 26,2 & 25,6 & P14 & 23,9 & 23,9 & 23,5 & 23,6 & 24,4 & 23,5 \\
\hline P15 & 24,4 & 24,3 & 24,3 & 24,6 & 25,3 & 24,6 & P15 & 23,9 & 23,9 & 23,5 & 23,6 & 24,4 & 23,5 \\
\hline P16 & 23,9 & 23,8 & 23,8 & 23,5 & 24,3 & 23,5 & P16 & 23,9 & 23,9 & 23,5 & 23,6 & 24,4 & 23,5 \\
\hline Media & 23,8 & 23,9 & 23,7 & 23,7 & 24,6 & 23,7 & SP25 & 25,0 & 25,0 & 25,0 & 25,0 & 25,0 & 25,0 \\
\hline
\end{tabular}

Gráfico 69 - MSM nos 16 pontos de medição - SP25 - "Desocupado"

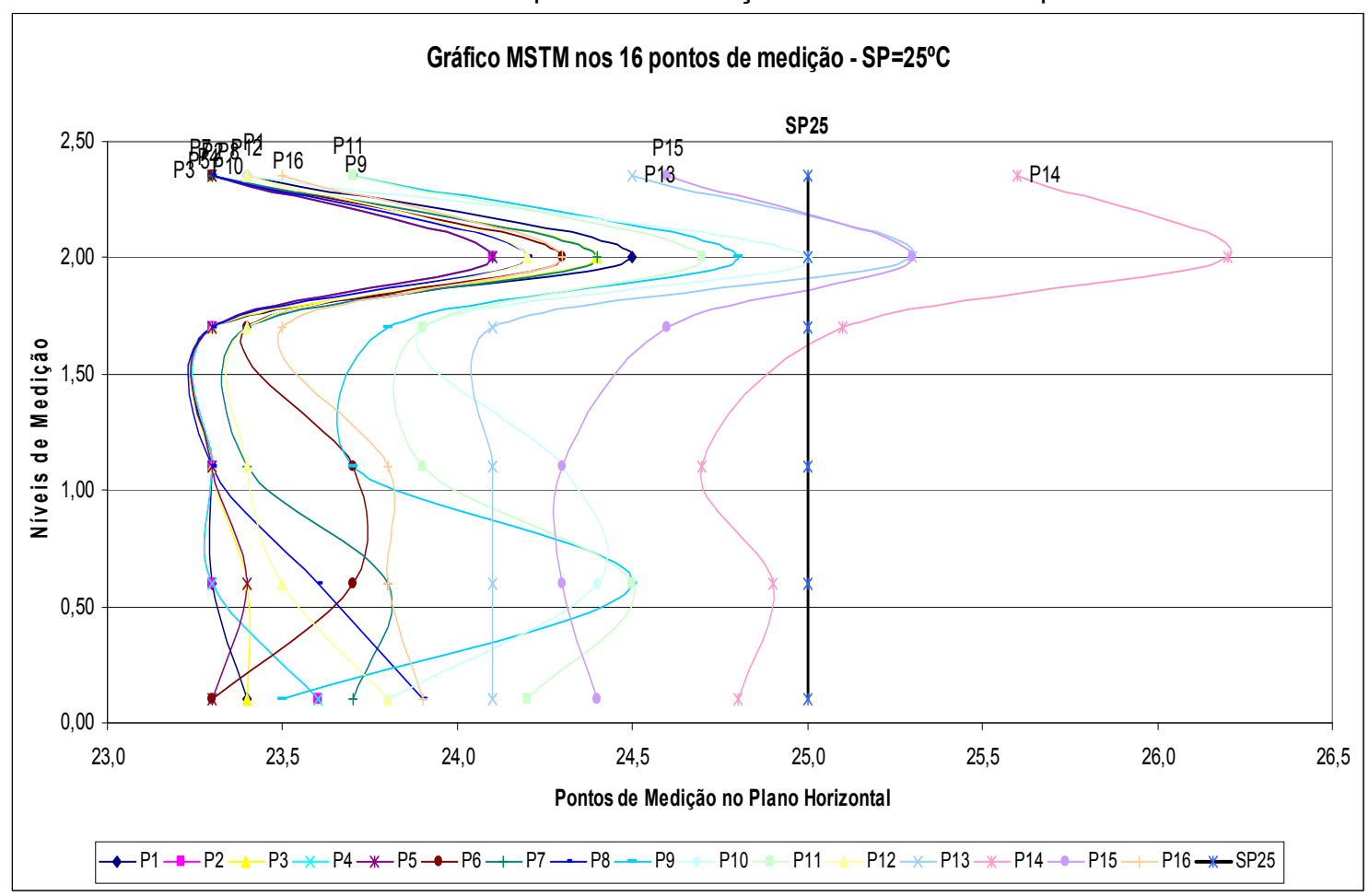


Tabela 75 - Dados de MSM e MSF nas 16 posições e 6 alturas - SP26 - Desocupado.

\begin{tabular}{|c|c|c|c|c|c|c|c|c|c|c|c|c|c|}
\hline \multicolumn{1}{|c|}{ MSM } \\
\hline Alturas & 0,10 & 0,60 & 1,10 & 1,70 & 2,00 & 2,35 & Alturas & 0,10 & 0,60 & 1,10 & 1,70 & 2,00 & 2,35 \\
\hline P1 & 24,4 & 24,3 & 24,3 & 24,3 & 24,3 & 24,3 & P1 & 24,0 & 24,0 & 24,3 & 24,1 & 24,2 & 24,0 \\
\hline P2 & 24,4 & 24,4 & 24,3 & 24,3 & 24,3 & 24,3 & P2 & 24,0 & 24,0 & 24,3 & 24,1 & 24,2 & 24,0 \\
\hline P3 & 24,5 & 24,5 & 24,3 & 24,3 & 24,3 & 24,3 & P3 & 24,0 & 24,0 & 24,3 & 24,1 & 24,2 & 24,0 \\
\hline P4 & 24,4 & 24,4 & 24,3 & 24,3 & 24,3 & 24,3 & P4 & 24,0 & 24,0 & 24,3 & 24,1 & 24,2 & 24,0 \\
\hline P5 & 24,3 & 24,5 & 24,3 & 24,3 & 24,3 & 24,3 & P5 & 24,0 & 24,0 & 24,3 & 24,1 & 24,2 & 24,0 \\
\hline P6 & 24,3 & 24,6 & 24,4 & 24,3 & 24,3 & 24,3 & P6 & 24,0 & 24,0 & 24,3 & 24,1 & 24,2 & 24,0 \\
\hline P7 & 24,3 & 24,6 & 24,4 & 24,3 & 24,3 & 24,3 & P7 & 24,0 & 24,0 & 24,3 & 24,1 & 24,2 & 24,0 \\
\hline P8 & 24,4 & 24,5 & 24,4 & 24,3 & 24,3 & 24,3 & P8 & 24,0 & 24,0 & 24,3 & 24,1 & 24,2 & 24,0 \\
\hline P9 & 24,5 & 24,8 & 24,7 & 24,3 & 24,3 & 24,5 & P9 & 24,0 & 24,0 & 24,3 & 24,1 & 24,2 & 24,0 \\
\hline P10 & 24,4 & 24,9 & 25,1 & 24,3 & 24,3 & 24,3 & P10 & 24,0 & 24,0 & 24,3 & 24,1 & 24,2 & 24,0 \\
\hline P11 & 24,6 & 24,7 & 24,8 & 24,3 & 24,3 & 24,4 & P11 & 24,0 & 24,0 & 24,3 & 24,1 & 24,2 & 24,0 \\
\hline P12 & 24,6 & 24,5 & 24,4 & 24,3 & 24,3 & 24,3 & P12 & 24,0 & 24,0 & 24,3 & 24,1 & 24,2 & 24,0 \\
\hline P13 & 24,5 & 24,8 & 25,2 & 24,7 & 25,1 & 25,1 & P13 & 24,0 & 24,0 & 24,3 & 24,1 & 24,2 & 24,0 \\
\hline P14 & 24,9 & 25,3 & 25,5 & 25,5 & 25,6 & 25,9 & P14 & 24,0 & 24,0 & 24,3 & 24,1 & 24,2 & 24,0 \\
\hline P15 & 24,7 & 24,8 & 25,1 & 25,0 & 25,0 & 25,1 & P15 & 24,0 & 24,0 & 24,3 & 24,1 & 24,2 & 24,0 \\
\hline P16 & 24,5 & 24,7 & 24,6 & 24,4 & 24,4 & 24,4 & P16 & 24,0 & 24,0 & 24,3 & 24,1 & 24,2 & 24,0 \\
\hline Media & 24,5 & 24,6 & 24,6 & 24,5 & 24,5 & 24,5 & SP26 & 26,0 & 26,0 & 26,0 & 26,0 & 26,0 & 26,0 \\
\hline
\end{tabular}

Gráfico 70 - MSM nos 16 pontos de medição - SP26 - "Desocupado”.

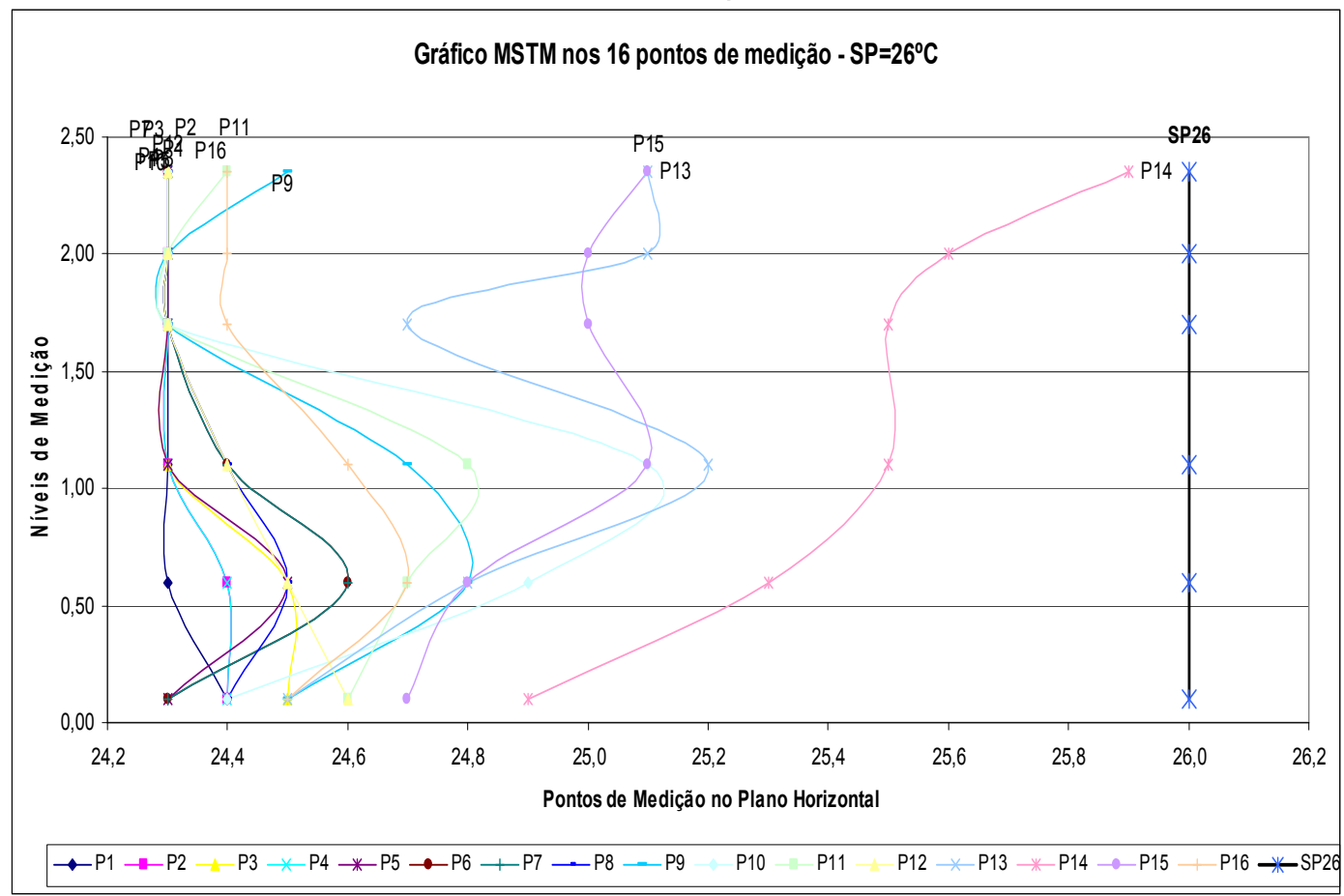


APÊNDICE D - Resumo dos dados de temperatura do ar na situação de medição com Ambientes "Ocupado /

Desocupado" 
Tabela 76 - Resumo dos dados de temperatura do ar - Ocup./Desoc.

\begin{tabular}{|c|c|c|c|c|c|}
\hline & Alturas & Temperatura Média do Ar dos 16 Pontos $\left({ }^{\circ} \mathrm{C}\right)$ & $\begin{array}{l}\text { Desvio Padrão } \\
\text { (DV) }\end{array}$ & DV/Media \% & $\begin{array}{l}\text { Desvio Padrão } \\
\text { das } 6 \text { alturas }\end{array}$ \\
\hline \multirow{6}{*}{$\frac{\bar{N}}{\sim}$} & $\mathrm{H} 6=2,35 \mathrm{~m}$ & 21,79 & 0,73 & 3,36 & \multirow{6}{*}{0,31} \\
\hline & $\mathrm{H} 5=2,00 \mathrm{~m}$ & 21,95 & 0,77 & 3,53 & \\
\hline & $\mathrm{H} 4=1,70 \mathrm{~m}$ & 21,63 & 0,78 & 3,60 & \\
\hline & $\mathrm{H} 3=1,10 \mathrm{~m}$ & 21,60 & 0,62 & 2,87 & \\
\hline & $\mathrm{h} 2=0,60 \mathrm{~m}$ & 21,24 & 0,60 & 2,81 & \\
\hline & $\mathrm{H} 1=0,10 \mathrm{~m}$ & 21,17 & 0,48 & 2,25 & \\
\hline \multirow{6}{*}{$\frac{N}{\curvearrowright}$} & $\mathrm{H} 6=2,35 \mathrm{~m}$ & 21,30 & 0,70 & 3,27 & \multirow{6}{*}{0,28} \\
\hline & $\mathrm{H} 5=2,00 \mathrm{~m}$ & 21,30 & 0,70 & 3,27 & \\
\hline & $\mathrm{H} 4=1,70 \mathrm{~m}$ & 21,93 & 0,78 & 3,53 & \\
\hline & $\mathrm{H} 3=1,10 \mathrm{~m}$ & 21,49 & 0,46 & 2,16 & \\
\hline & $\mathrm{h} 2=0,60 \mathrm{~m}$ & 21,64 & 0,44 & 2,04 & \\
\hline & $\mathrm{H} 1=0,10 \mathrm{~m}$ & 21,90 & 0,53 & 2,41 & \\
\hline \multirow{6}{*}{$\frac{\infty}{\infty}$} & $\mathrm{H} 6=2,35 \mathrm{~m}$ & 22,43 & 0,79 & 3,52 & \multirow{6}{*}{0,39} \\
\hline & $\mathrm{H} 5=2,00 \mathrm{~m}$ & 23,42 & 0,68 & 2,91 & \\
\hline & $\mathrm{H} 4=1,70 \mathrm{~m}$ & 22,31 & 0,74 & 3,33 & \\
\hline & $\mathrm{H} 3=1,10 \mathrm{~m}$ & 22,54 & 0,57 & 2,55 & \\
\hline & $\mathrm{h} 2=0,60 \mathrm{~m}$ & 22,61 & 0,67 & 2,97 & \\
\hline & $\mathrm{H} 1=0,10 \mathrm{~m}$ & 22,54 & 0,48 & 2,14 & \\
\hline \multirow{6}{*}{ 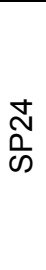 } & $\mathrm{H} 6=2,35 \mathrm{~m}$ & 23,83 & 0,80 & 3,37 & \multirow{6}{*}{0,21} \\
\hline & $\mathrm{H} 5=2,00 \mathrm{~m}$ & 23,81 & 0,74 & 3,09 & \\
\hline & $\mathrm{H} 4=1,70 \mathrm{~m}$ & 23,38 & 0,54 & 2,33 & \\
\hline & $\mathrm{H} 3=1,10 \mathrm{~m}$ & 23,42 & 0,56 & 2,41 & \\
\hline & $\mathrm{h} 2=0,60 \mathrm{~m}$ & 23,76 & 0,47 & 1,97 & \\
\hline & $\mathrm{H} 1=0,10 \mathrm{~m}$ & 23,48 & 0,46 & 1,94 & \\
\hline \multirow{6}{*}{$\frac{\stackrel{\sim}{N}}{\sim}$} & $\mathrm{H} 6=2,35 \mathrm{~m}$ & 25,30 & 0,62 & 2,45 & \multirow{6}{*}{0,43} \\
\hline & $\mathrm{H} 5=2,00 \mathrm{~m}$ & 25,23 & 0,54 & 2,14 & \\
\hline & $\mathrm{H} 4=1,70 \mathrm{~m}$ & 25,17 & 0,54 & 2,13 & \\
\hline & $\mathrm{H} 3=1,10 \mathrm{~m}$ & 24,59 & 0,46 & 1,86 & \\
\hline & $\mathrm{h} 2=0,60 \mathrm{~m}$ & 24,60 & 0,48 & 1,94 & \\
\hline & $\mathrm{H} 1=0,10 \mathrm{~m}$ & 24,25 & 0,44 & 1,81 & \\
\hline \multirow{6}{*}{$\begin{array}{l}\stackrel{\infty}{N} \\
\stackrel{0}{\omega}\end{array}$} & $\mathrm{H} 6=2,35 \mathrm{~m}$ & 24,79 & 0,52 & 2,08 & \multirow{6}{*}{0,24} \\
\hline & $\mathrm{H} 5=2,00 \mathrm{~m}$ & 24,80 & 0,45 & 1,82 & \\
\hline & $\mathrm{H} 4=1,70 \mathrm{~m}$ & 24,70 & 0,43 & 1,72 & \\
\hline & $\mathrm{H} 3=1,10 \mathrm{~m}$ & 25,15 & 0,51 & 2,04 & \\
\hline & $\mathrm{h} 2=0,60 \mathrm{~m}$ & 25,29 & 0,53 & 2,10 & \\
\hline & $\mathrm{H} 1=0,10 \mathrm{~m}$ & 25,12 & 0,44 & 1,73 & \\
\hline
\end{tabular}


Tabela 77 - Temperaturas do ar nas alturas de conforto - Ocup./Desoc.

\begin{tabular}{|c|c|c|c|c|c|c|}
\hline & & & & $\begin{array}{c}\text { Temperatura } \\
\text { Média }\end{array}$ & DV \% & $\begin{array}{c}\text { DV/Media } \\
\%\end{array}$ \\
\hline \multirow{12}{*}{$\frac{\check{N}}{\sigma}$} & \multirow{3}{*}{ AMBIENTE } & \multirow{3}{*}{16 Pontos } & $\mathrm{h} 2=0,60 \mathrm{~m}$ & 21,2 & 0,60 & 2,8 \\
\hline & & & $\mathrm{H} 1=0,10 \mathrm{~m}$ & 21,2 & 0,5 & 2,2 \\
\hline & & & Relação & 21,2 & 0,05 & 0,25 \\
\hline & \multirow{3}{*}{$\begin{array}{c}\text { Zona de } \\
\text { Ocupação }\end{array}$} & \multirow{3}{*}{$\begin{array}{l}\text { P2, P3, P6, } \\
\text { P7, P10, P11, } \\
\text { P14 e P15 }\end{array}$} & $\mathrm{h} 2=0,60 \mathrm{~m}$ & 21,2 & 0,63 & 2,98 \\
\hline & & & $\mathrm{H} 1=0,10 \mathrm{~m}$ & 21,2 & 0,61 & 2,89 \\
\hline & & & Relação & 21,2 & 0,03 & 0,13 \\
\hline & \multirow{3}{*}{ Zona Periférica } & \multirow{3}{*}{$\begin{array}{c}\mathrm{P} 4, \mathrm{P} 8, \mathrm{P} 12 \mathrm{e} \\
\text { P16 }\end{array}$} & $\mathrm{h} 2=0,60 \mathrm{~m}$ & 21,1 & 0,7 & 3,42 \\
\hline & & & $\mathrm{H} 1=0,10 \mathrm{~m}$ & 21,2 & 0,4 & 1,76 \\
\hline & & & Relação & 21,1 & 0,04 & 0,17 \\
\hline & \multirow{3}{*}{$\begin{array}{c}\text { Zona de } \\
\text { Circulação }\end{array}$} & \multirow{3}{*}{$\begin{array}{c}\mathrm{P} 1, \mathrm{P} 5, \mathrm{P} 9 \mathrm{e} \\
\mathrm{P} 13\end{array}$} & $\mathrm{~h} 2=0,60 \mathrm{~m}$ & 21,4 & 0,7 & 3,27 \\
\hline & & & $\mathrm{H} 1=0,10 \mathrm{~m}$ & 21,2 & 0,8 & 3,67 \\
\hline & & & Relação & 21,3 & 0,19 & 0,91 \\
\hline \multirow{12}{*}{$\begin{array}{l}\text { N } \\
\text { ふ }\end{array}$} & \multirow{3}{*}{ AMBIENTE } & \multirow{3}{*}{16 Pontos } & $\mathrm{h} 2=0,60 \mathrm{~m}$ & 21,6 & 0,44 & 2,0 \\
\hline & & & $\mathrm{H} 1=0,10 \mathrm{~m}$ & 21,9 & 0,5 & 2,4 \\
\hline & & & Relação & 21,8 & 0,19 & 0,85 \\
\hline & \multirow{3}{*}{$\begin{array}{c}\text { Zona de } \\
\text { Ocupação }\end{array}$} & \multirow{3}{*}{$\begin{array}{l}\text { P2, P3, P6, } \\
\text { P7, P10, P11, } \\
\text { P14 e P15 }\end{array}$} & $\mathrm{h} 2=0,60 \mathrm{~m}$ & 21,7 & 0,43 & 2,00 \\
\hline & & & $\mathrm{H} 1=0,10 \mathrm{~m}$ & 22,0 & 0,72 & 3,29 \\
\hline & & & Relação & 21,8 & 0,21 & 0,97 \\
\hline & \multirow{3}{*}{ Zona Periférica } & \multirow{3}{*}{$\begin{array}{c}\mathrm{P} 4, \mathrm{P} 8, \mathrm{P} 12 \text { e } \\
\text { P16 }\end{array}$} & $\mathrm{h} 2=0,60 \mathrm{~m}$ & 21,7 & 0,6 & 2,74 \\
\hline & & & $\mathrm{H} 1=0,10 \mathrm{~m}$ & 21,9 & 0,3 & 1,31 \\
\hline & & & Relação & 21,8 & 0,14 & 0,65 \\
\hline & \multirow{3}{*}{$\begin{array}{c}\text { Zona de } \\
\text { Circulação }\end{array}$} & \multirow{3}{*}{$\begin{array}{c}\mathrm{P} 1, \mathrm{P} 5, \mathrm{P} 9 \mathrm{e} \\
\mathrm{P} 13\end{array}$} & $\mathrm{~h} 2=0,60 \mathrm{~m}$ & 21,6 & 0,6 & 2,79 \\
\hline & & & $\mathrm{H} 1=0,10 \mathrm{~m}$ & 21,8 & 0,9 & 4,19 \\
\hline & & & Relação & 21,7 & 0,18 & 0,82 \\
\hline \multirow{12}{*}{$\frac{n}{n}$} & \multirow{3}{*}{ AMBIENTE } & \multirow{3}{*}{16 Pontos } & $\mathrm{h} 2=0,60 \mathrm{~m}$ & 22,6 & 0,67 & 3,0 \\
\hline & & & $\mathrm{H} 1=0,10 \mathrm{~m}$ & 22,5 & 0,5 & 2,1 \\
\hline & & & Relação & 22,6 & 0,05 & 0,22 \\
\hline & \multirow{3}{*}{$\begin{array}{c}\text { Zona de } \\
\text { Ocupação }\end{array}$} & \multirow{3}{*}{$\begin{array}{c}\text { P2, P3, P6, } \\
\text { P7, P10, P11, } \\
\text { P14 e P15 }\end{array}$} & $\mathrm{h} 2=0,60 \mathrm{~m}$ & 22,7 & 0,67 & 2,98 \\
\hline & & & $\mathrm{H} 1=0,10 \mathrm{~m}$ & 22,7 & 0,59 & 2,61 \\
\hline & & & Relação & 22,7 & 0,00 & 0,00 \\
\hline & \multirow{3}{*}{ Zona Periférica } & \multirow{3}{*}{$\begin{array}{c}\mathrm{P} 4, \mathrm{P} 8, \mathrm{P} 12 \mathrm{e} \\
\mathrm{P} 16\end{array}$} & $\mathrm{~h} 2=0,60 \mathrm{~m}$ & 22,4 & 0,8 & 3,62 \\
\hline & & & $\mathrm{H} 1=0,10 \mathrm{~m}$ & 22,5 & 0,4 & 1,87 \\
\hline & & & Relação & 22,4 & 0,12 & 0,55 \\
\hline & \multirow{3}{*}{$\begin{array}{c}\text { Zona de } \\
\text { Circulação }\end{array}$} & \multirow{3}{*}{$\begin{array}{c}\mathrm{P} 1, \mathrm{P} 5, \mathrm{P} 9 \mathrm{e} \\
\mathrm{P} 13\end{array}$} & $\mathrm{~h} 2=0,60 \mathrm{~m}$ & 22,8 & 0,8 & 3,61 \\
\hline & & & $\mathrm{H} 1=0,10 \mathrm{~m}$ & 22,3 & 0,8 & 3,43 \\
\hline & & & Relação & 22,6 & 0,32 & 1,41 \\
\hline
\end{tabular}


Continuação da tabela 71 .

\begin{tabular}{|c|c|c|c|c|c|c|}
\hline \multirow{12}{*}{$\frac{\searrow}{\sim}$} & \multirow{3}{*}{ AMBIENTE } & \multirow{3}{*}{16 Pontos } & $\mathrm{h} 2=0,60 \mathrm{~m}$ & 23,8 & 0,47 & 2,0 \\
\hline & & & $\mathrm{H} 1=0,10 \mathrm{~m}$ & 23,5 & 0,5 & 1,9 \\
\hline & & & Relação & 23,6 & 0,20 & 0,84 \\
\hline & \multirow{3}{*}{$\begin{array}{c}\text { Zona de } \\
\text { Ocupação }\end{array}$} & \multirow{3}{*}{$\begin{array}{l}\text { P2, P3, P6, } \\
\text { P7, P10, P11, } \\
\text { P14 e P15 }\end{array}$} & $\mathrm{h} 2=0,60 \mathrm{~m}$ & 23,8 & 0,46 & 1,92 \\
\hline & & & $\mathrm{H} 1=0,10 \mathrm{~m}$ & 23,6 & 0,51 & 2,16 \\
\hline & & & Relação & 23,7 & 0,19 & 0,78 \\
\hline & \multirow{3}{*}{ Zona Periférica } & \multirow{3}{*}{$\begin{array}{c}\mathrm{P} 4, \mathrm{P} 8, \mathrm{P} 12 \mathrm{e} \\
\text { P16 }\end{array}$} & $\mathrm{h} 2=0,60 \mathrm{~m}$ & 23,7 & 0,6 & 2,60 \\
\hline & & & $\mathrm{H} 1=0,10 \mathrm{~m}$ & 23,6 & 0,5 & 2,01 \\
\hline & & & Relação & 23,6 & 0,05 & 0,22 \\
\hline & \multirow{3}{*}{$\begin{array}{c}\text { Zona de } \\
\text { Circulação }\end{array}$} & \multirow{3}{*}{$\begin{array}{c}\text { P1, P5, P9 e } \\
\text { P13 }\end{array}$} & $\mathrm{h} 2=0,60 \mathrm{~m}$ & 23,7 & 0,6 & 2,63 \\
\hline & & & $\mathrm{H} 1=0,10 \mathrm{~m}$ & 23,2 & 0,6 & 2,76 \\
\hline & & & Relação & 23,4 & 0,37 & 1,59 \\
\hline \multirow{12}{*}{$\frac{n}{n}$} & \multirow{3}{*}{ AMBIENTE } & \multirow{3}{*}{16 Pontos } & $\mathrm{h} 2=0,60 \mathrm{~m}$ & 24,6 & 0,48 & 1,9 \\
\hline & & & $\mathrm{H} 1=0,10 \mathrm{~m}$ & 24,3 & 0,4 & 1,8 \\
\hline & & & Relação & 24,4 & 0,25 & 1,01 \\
\hline & \multirow{3}{*}{$\begin{array}{c}\text { Zona de } \\
\text { Ocupação }\end{array}$} & \multirow{3}{*}{$\begin{array}{c}\text { P2, P3, P6, } \\
\text { P7, P10, P11, } \\
\text { P14 e P15 }\end{array}$} & $\mathrm{h} 2=0,60 \mathrm{~m}$ & 24,8 & 0,45 & 1,81 \\
\hline & & & $\mathrm{H} 1=0,10 \mathrm{~m}$ & 24,4 & 0,50 & 2,05 \\
\hline & & & Relação & 24,6 & 0,27 & 1,12 \\
\hline & \multirow{3}{*}{ Zona Periférica } & \multirow{3}{*}{$\begin{array}{c}\mathrm{P} 4, \mathrm{P} 8, \mathrm{P} 12 \mathrm{e} \\
\text { P16 }\end{array}$} & $\mathrm{h} 2=0,60 \mathrm{~m}$ & 24,4 & 0,5 & 2,20 \\
\hline & & & $\mathrm{H} 1=0,10 \mathrm{~m}$ & 24,4 & 0,4 & 1,64 \\
\hline & & & Relação & 24,4 & 0,04 & 0,14 \\
\hline & \multirow{3}{*}{$\begin{array}{c}\text { Zona de } \\
\text { Circulação }\end{array}$} & \multirow{3}{*}{$\begin{array}{c}\mathrm{P} 1, \mathrm{P} 5, \mathrm{P} 9 \mathrm{e} \\
\mathrm{P} 13\end{array}$} & $\mathrm{~h} 2=0,60 \mathrm{~m}$ & 24,5 & 0,6 & 2,57 \\
\hline & & & $\mathrm{H} 1=0,10 \mathrm{~m}$ & 23,9 & 0,7 & 2,74 \\
\hline & & & Relação & 24,2 & 0,41 & 1,68 \\
\hline \multirow{12}{*}{$\stackrel{\stackrel{\oplus}{N}}{\stackrel{n}{\omega}}$} & \multirow{3}{*}{ AMBIENTE } & \multirow{3}{*}{16 Pontos } & $\mathrm{h} 2=0,60 \mathrm{~m}$ & 25,3 & 0,53 & 2,1 \\
\hline & & & $\mathrm{H} 1=0,10 \mathrm{~m}$ & 25,1 & 0,4 & 1,7 \\
\hline & & & Relação & 25,2 & 0,12 & 0,49 \\
\hline & \multirow{3}{*}{$\begin{array}{c}\text { Zona de } \\
\text { Ocupação }\end{array}$} & \multirow{3}{*}{$\begin{array}{l}\text { P2, P3, P6, } \\
\text { P7, P10, P11, } \\
\text { P14 e P15 }\end{array}$} & $\mathrm{h} 2=0,60 \mathrm{~m}$ & 25,4 & 0,51 & 2,00 \\
\hline & & & $\mathrm{H} 1=0,10 \mathrm{~m}$ & 25,2 & 0,49 & 1,95 \\
\hline & & & Relação & 25,3 & 0,13 & 0,52 \\
\hline & \multirow{3}{*}{ Zona Periférica } & \multirow{3}{*}{$\begin{array}{c}\mathrm{P} 4, \mathrm{P} 8, \mathrm{P} 12 \mathrm{e} \\
\mathrm{P} 16\end{array}$} & $\mathrm{~h} 2=0,60 \mathrm{~m}$ & 25,1 & 0,6 & 2,49 \\
\hline & & & $\mathrm{H} 1=0,10 \mathrm{~m}$ & 25,1 & 0,4 & 1,69 \\
\hline & & & Relação & 25,1 & 0,04 & 0,14 \\
\hline & \multirow{3}{*}{$\begin{array}{c}\text { Zona de } \\
\text { Circulação }\end{array}$} & \multirow{3}{*}{$\begin{array}{c}\mathrm{P} 1, \mathrm{P} 5, \mathrm{P} 9 \mathrm{e} \\
\mathrm{P} 13\end{array}$} & $\mathrm{~h} 2=0,60 \mathrm{~m}$ & 25,3 & 0,7 & 2,68 \\
\hline & & & $\mathrm{H} 1=0,10 \mathrm{~m}$ & 24,9 & 0,7 & 2,67 \\
\hline & & & Relação & 25,1 & 0,27 & 1,06 \\
\hline
\end{tabular}


Tabela 78 - Resumo dos dados de temperatura do ar - Desocupação

\begin{tabular}{|c|c|c|c|c|c|}
\hline & Alturas & Temperatura Média do Ar dos 16 Pontos $\left({ }^{\circ} \mathrm{C}\right)$ & $\begin{array}{l}\text { Desvio Padrão das } 16 \\
\text { posições (DV) }\end{array}$ & DV/Media \% & $\begin{array}{l}\text { Desvio Padrão } \\
\text { das } 6 \text { alturas }\end{array}$ \\
\hline \multirow{6}{*}{$\begin{array}{l}\bar{\sim} \\
\text { ஸे }\end{array}$} & $\mathrm{H} 6=2,35 \mathrm{~m}$ & 21,48 & 0,83 & 3,88 & \multirow{6}{*}{0,16} \\
\hline & $\mathrm{H} 5=2,00 \mathrm{~m}$ & 21,46 & 0,88 & 4,12 & \\
\hline & $\mathrm{H} 4=1,70 \mathrm{~m}$ & 21,50 & 0,80 & 3,72 & \\
\hline & $\mathrm{H} 3=1,10 \mathrm{~m}$ & 21,16 & 0,60 & 2,86 & \\
\hline & $\mathrm{h} 2=0,60 \mathrm{~m}$ & 21,24 & 0,60 & 2,81 & \\
\hline & $\mathrm{H} 1=0,10 \mathrm{~m}$ & 21,17 & 0,48 & 2,25 & \\
\hline \multirow{6}{*}{$\begin{array}{l}\text { N } \\
\text { ஸ }\end{array}$} & $\mathrm{H} 6=2,35 \mathrm{~m}$ & 21,58 & 0,79 & 3,67 & \multirow{6}{*}{0,67} \\
\hline & $\mathrm{H} 5=2,00 \mathrm{~m}$ & 23,40 & 0,61 & 2,59 & \\
\hline & $\mathrm{H} 4=1,70 \mathrm{~m}$ & 21,93 & 0,78 & 3,53 & \\
\hline & $\mathrm{H} 3=1,10 \mathrm{~m}$ & 22,02 & 0,46 & 2,09 & \\
\hline & $\mathrm{h} 2=0,60 \mathrm{~m}$ & 21,64 & 0,44 & 2,04 & \\
\hline & $\mathrm{H} 1=0,10 \mathrm{~m}$ & 21,89 & 0,53 & 2,43 & \\
\hline \multirow{6}{*}{$\begin{array}{c}\stackrel{2}{N} \\
\text { ஸे }\end{array}$} & $\mathrm{H} 6=2,35 \mathrm{~m}$ & 22,24 & 0,81 & 3,64 & \multirow{6}{*}{0,22} \\
\hline & $\mathrm{H} 5=2,00 \mathrm{~m}$ & 22,19 & 0,72 & 3,26 & \\
\hline & $\mathrm{H} 4=1,70 \mathrm{~m}$ & 22,18 & 0,71 & 3,21 & \\
\hline & $\mathrm{H} 3=1,10 \mathrm{~m}$ & 22,54 & 0,57 & 2,55 & \\
\hline & $\mathrm{h} 2=0,60 \mathrm{~m}$ & 22,64 & 0,65 & 2,88 & \\
\hline & $\mathrm{H} 1=0,10 \mathrm{~m}$ & 22,61 & 0,46 & 2,04 & \\
\hline \multirow{6}{*}{$\begin{array}{l}\stackrel{ \pm}{\sim} \\
\text { 心 }\end{array}$} & $\mathrm{H} 6=2,35 \mathrm{~m}$ & 23,83 & 0,80 & 3,37 & \multirow{6}{*}{0,40} \\
\hline & $\mathrm{H} 5=2,00 \mathrm{~m}$ & 23,11 & 0,56 & 2,43 & \\
\hline & $\mathrm{H} 4=1,70 \mathrm{~m}$ & 22,64 & 0,53 & 2,32 & \\
\hline & $\mathrm{H} 3=1,10 \mathrm{~m}$ & 22,99 & 0,53 & 2,31 & \\
\hline & $\mathrm{h} 2=0,60 \mathrm{~m}$ & 23,39 & 0,50 & 2,12 & \\
\hline & $\mathrm{H} 1=0,10 \mathrm{~m}$ & 23,3 & 0,45 & 1,91 & \\
\hline \multirow{6}{*}{$\begin{array}{l}\stackrel{\sim}{N} \\
\frac{n}{\omega}\end{array}$} & $\mathrm{H} 6=2,35 \mathrm{~m}$ & 23,68 & 0,66 & 2,78 & \multirow{6}{*}{0,37} \\
\hline & $\mathrm{H} 5=2,00 \mathrm{~m}$ & 24,62 & 0,58 & 2,36 & \\
\hline & $\mathrm{H} 4=1,70 \mathrm{~m}$ & 23,68 & 0,53 & 2,26 & \\
\hline & $\mathrm{H} 3=1,10 \mathrm{~m}$ & 23,69 & 0,45 & 1,91 & \\
\hline & $\mathrm{h} 2=0,60 \mathrm{~m}$ & 23,86 & 0,52 & 2,17 & \\
\hline & $\mathrm{H} 1=0,10 \mathrm{~m}$ & 23,79 & 0,42 & 1,76 & \\
\hline \multirow{6}{*}{$\begin{array}{l}0 \\
\stackrel{N}{\alpha} \\
\text { क }\end{array}$} & $\mathrm{H} 6=2,35 \mathrm{~m}$ & 24,53 & 0,45 & 1,85 & \multirow{6}{*}{0,08} \\
\hline & $\mathrm{H} 5=2,00 \mathrm{~m}$ & 24,48 & 0,39 & 1,60 & \\
\hline & $\mathrm{H} 4=1,70 \mathrm{~m}$ & 24,45 & 0,34 & 1,39 & \\
\hline & $\mathrm{H} 3=1,10 \mathrm{~m}$ & 24,63 & 0,39 & 1,59 & \\
\hline & $\mathrm{h} 2=0,60 \mathrm{~m}$ & 24,64 & 0,24 & 0,99 & \\
\hline & $\mathrm{H} 1=0,10 \mathrm{~m}$ & 24,48 & 0,16 & 0,65 & \\
\hline
\end{tabular}


Tabela 79 - Temperaturas do ar nas alturas de conforto - Desocupado

\begin{tabular}{|c|c|c|c|c|c|c|}
\hline & & & & $\begin{array}{c}\text { Temperatura } \\
\text { Média }\end{array}$ & DV \% & $\begin{array}{c}\text { DV/Media } \\
\%\end{array}$ \\
\hline \multirow{12}{*}{$\stackrel{\nwarrow}{\nwarrow}$} & \multirow{3}{*}{ AMBIENTE } & \multirow{3}{*}{16 Pontos } & $\mathrm{h} 2=0,60 \mathrm{~m}$ & 21,2 & 0,60 & 2,8 \\
\hline & & & $\mathrm{H} 1=0,10 \mathrm{~m}$ & 21,2 & 0,5 & 2,2 \\
\hline & & & Relação & 21,2 & 0,05 & 0,25 \\
\hline & \multirow{3}{*}{$\begin{array}{c}\text { Zona de } \\
\text { Ocupação }\end{array}$} & \multirow{3}{*}{$\begin{array}{l}\text { P2, P3, P6, } \\
\text { P7, P10, P11, } \\
\text { P14 e P15 }\end{array}$} & $\mathrm{h} 2=0,60 \mathrm{~m}$ & 21,2 & 0,63 & 2,98 \\
\hline & & & $\mathrm{H} 1=0,10 \mathrm{~m}$ & 21,2 & 0,61 & 2,89 \\
\hline & & & Relação & 21,2 & 0,03 & 0,13 \\
\hline & \multirow{3}{*}{ Zona Periférica } & \multirow{3}{*}{$\begin{array}{c}\mathrm{P} 4, \mathrm{P} 8, \mathrm{P} 12 \mathrm{e} \\
\text { P16 }\end{array}$} & $\mathrm{h} 2=0,60 \mathrm{~m}$ & 21,1 & 0,7 & 3,42 \\
\hline & & & $\mathrm{H} 1=0,10 \mathrm{~m}$ & 21,2 & 0,4 & 1,76 \\
\hline & & & Relação & 21,1 & 0,04 & 0,17 \\
\hline & \multirow{3}{*}{$\begin{array}{c}\text { Zona de } \\
\text { Circulação }\end{array}$} & \multirow{3}{*}{$\begin{array}{c}\text { P1, P5, P9 e } \\
\text { P13 }\end{array}$} & $\mathrm{h} 2=0,60 \mathrm{~m}$ & 21,4 & 0,7 & 3,27 \\
\hline & & & $\mathrm{H} 1=0,10 \mathrm{~m}$ & 21,2 & 0,8 & 3,67 \\
\hline & & & Relação & 21,3 & 0,19 & 0,91 \\
\hline \multirow{12}{*}{$\begin{array}{l}\text { ָे } \\
\text { ஸ }\end{array}$} & \multirow{3}{*}{ AMBIENTE } & \multirow{3}{*}{16 Pontos } & $\mathrm{h} 2=0,60 \mathrm{~m}$ & 21,6 & 0,44 & 2,0 \\
\hline & & & $\mathrm{H} 1=0,10 \mathrm{~m}$ & 21,9 & 0,5 & 2,4 \\
\hline & & & Relação & 21,8 & 0,18 & 0,83 \\
\hline & \multirow{6}{*}{$\begin{array}{c}\text { Zona de } \\
\text { Ocupação }\end{array}$} & \multirow{3}{*}{$\begin{array}{c}\text { P2, P3, P6, } \\
\text { P7, P10, P11, } \\
\text { P14 e P15 }\end{array}$} & $\mathrm{h} 2=0,60 \mathrm{~m}$ & 21,7 & 0,43 & 2,00 \\
\hline & & & $\mathrm{H} 1=0,10 \mathrm{~m}$ & 22,0 & 0,72 & 3,26 \\
\hline & & & Relação & 21,8 & 0,20 & 0,93 \\
\hline & & \multirow{3}{*}{$\begin{array}{c}\mathrm{P} 4, \mathrm{P} 8, \mathrm{P} 12 \mathrm{e} \\
\text { P16 }\end{array}$} & $\mathrm{h} 2=0,60 \mathrm{~m}$ & 21,7 & 0,6 & 2,74 \\
\hline & & & $\mathrm{H} 1=0,10 \mathrm{~m}$ & 21,8 & 0,3 & 1,52 \\
\hline & & & Relação & 21,7 & 0,11 & 0,49 \\
\hline & \multirow{3}{*}{$\begin{array}{c}\text { Zona de } \\
\text { Circulação }\end{array}$} & \multirow{3}{*}{$\begin{array}{c}\mathrm{P} 1, \mathrm{P} 5, \mathrm{P} 9 \mathrm{e} \\
\mathrm{P} 13\end{array}$} & $\mathrm{~h} 2=0,60 \mathrm{~m}$ & 21,6 & 0,6 & 2,79 \\
\hline & & & $\mathrm{H} 1=0,10 \mathrm{~m}$ & 21,9 & 0,9 & 4,14 \\
\hline & & & Relação & 21,7 & 0,21 & 0,98 \\
\hline \multirow{12}{*}{$\stackrel{\stackrel{m}{N}}{\infty}$} & \multirow{3}{*}{ AMBIENTE } & \multirow{3}{*}{16 Pontos } & $\mathrm{h} 2=0,60 \mathrm{~m}$ & 22,6 & 0,65 & 2,9 \\
\hline & & & $\mathrm{H} 1=0,10 \mathrm{~m}$ & 22,6 & 0,5 & 2,0 \\
\hline & & & Relação & 22,6 & 0,03 & 0,12 \\
\hline & & P2, P3, P6, & $\mathrm{h} 2=0,60 \mathrm{~m}$ & 22,7 & 0,65 & 2,88 \\
\hline & $\begin{array}{l}\text { Zona de } \\
\text { Ocupação }\end{array}$ & P7, P10, P11, & $\mathrm{H} 1=0,10 \mathrm{~m}$ & 22,7 & 0,58 & 2,58 \\
\hline & & & Relação & 22,7 & 0,02 & 0,08 \\
\hline & & & $\mathrm{h} 2=0,60 \mathrm{~m}$ & 22,4 & 0,8 & 3,63 \\
\hline & Zona Periférica & $\begin{array}{c}P 4, P 8, P 12 \mathrm{e} \\
\text { P16 }\end{array}$ & $\mathrm{H} 1=0,10 \mathrm{~m}$ & 22,6 & 0,4 & 1,71 \\
\hline & & & Relação & 22,5 & 0,12 & 0,55 \\
\hline & & & $\mathrm{h} 2=0,60 \mathrm{~m}$ & 22,9 & 0,8 & 3,45 \\
\hline & $\begin{array}{l}\text { Zona de } \\
\text { Circulação }\end{array}$ & $\begin{array}{c}\text { P1, P5, P9 e } \\
\text { P13 }\end{array}$ & $\mathrm{H} 1=0,10 \mathrm{~m}$ & 22,5 & 0,8 & 3,34 \\
\hline & & & Relação & 22,7 & 0,27 & 1,17 \\
\hline
\end{tabular}


Continuação da tabela 73.

\begin{tabular}{|c|c|c|c|c|c|c|}
\hline \multirow{12}{*}{$\begin{array}{l}\stackrel{+}{N} \\
\text { c }\end{array}$} & \multirow{3}{*}{ AMBIENTE } & \multirow{3}{*}{16 Pontos } & $\mathrm{h} 2=0,60 \mathrm{~m}$ & 23,4 & 0,50 & 2,1 \\
\hline & & & $\mathrm{H} 1=0,10 \mathrm{~m}$ & 23,3 & 0,4 & 1,9 \\
\hline & & & Relação & 23,4 & 0,05 & 0,23 \\
\hline & \multirow{3}{*}{$\begin{array}{l}\text { Zona de } \\
\text { Ocupação }\end{array}$} & \multirow{3}{*}{$\begin{array}{l}\text { P2, P3, P6, } \\
\text { P7, P10, P11, } \\
\text { P14 e P15 }\end{array}$} & $\mathrm{h} 2=0,60 \mathrm{~m}$ & 23,5 & 0,50 & 2,12 \\
\hline & & & $\mathrm{H} 1=0,10 \mathrm{~m}$ & 23,4 & 0,51 & 2,18 \\
\hline & & & Relação & 23,5 & 0,09 & 0,38 \\
\hline & \multirow{3}{*}{ Zona Periférica } & \multirow{3}{*}{$\begin{array}{l}\text { P4, P8, P12 e } \\
\text { P16 }\end{array}$} & $\mathrm{h} 2=0,60 \mathrm{~m}$ & 23,2 & 0,6 & 2,67 \\
\hline & & & $\mathrm{H} 1=0,10 \mathrm{~m}$ & 23,4 & 0,5 & 1,96 \\
\hline & & & Relação & 23,3 & 0,16 & 0,68 \\
\hline & \multirow{3}{*}{$\begin{array}{c}\text { Zona de } \\
\text { Circulação }\end{array}$} & \multirow{3}{*}{$\begin{array}{l}\text { P1, P5, P9 e } \\
\text { P13 }\end{array}$} & $\mathrm{h} 2=0,60 \mathrm{~m}$ & 23,3 & 0,6 & 2,70 \\
\hline & & & $\mathrm{H} 1=0,10 \mathrm{~m}$ & 23,1 & 0,6 & 2,71 \\
\hline & & & Relação & 23,2 & 0,19 & 0,84 \\
\hline \multirow{12}{*}{$\begin{array}{c}\stackrel{2}{N} \\
\text { n }\end{array}$} & \multirow{3}{*}{ AMBIENTE } & \multirow{3}{*}{16 Pontos } & $\mathrm{h} 2=0,60 \mathrm{~m}$ & 23,9 & 0,52 & 2,2 \\
\hline & & & $\mathrm{H} 1=0,10 \mathrm{~m}$ & 23,8 & 0,4 & 1,8 \\
\hline & & & Relação & 23,8 & 0,05 & 0,20 \\
\hline & \multirow{3}{*}{$\begin{array}{l}\text { Zona de } \\
\text { Ocupação }\end{array}$} & \multirow{3}{*}{$\begin{array}{l}\text { P2, P3, P6, } \\
\text { P7, P10, P11, } \\
\text { P14 e P15 }\end{array}$} & $\mathrm{h} 2=0,60 \mathrm{~m}$ & 24,0 & 0,57 & 2,37 \\
\hline & & & $\mathrm{H} 1=0,10 \mathrm{~m}$ & 23,9 & 0,52 & 2,18 \\
\hline & & & Relação & 24,0 & 0,10 & 0,41 \\
\hline & \multirow{3}{*}{ Zona Periférica } & \multirow{3}{*}{$\begin{array}{c}\text { P4, P8, P12 e } \\
\text { P16 }\end{array}$} & $\mathrm{h} 2=0,60 \mathrm{~m}$ & 23,6 & 0,5 & 1,95 \\
\hline & & & $\mathrm{H} 1=0,10 \mathrm{~m}$ & 23,8 & 0,3 & 1,47 \\
\hline & & & Relação & 23,7 & 0,18 & 0,75 \\
\hline & \multirow{3}{*}{$\begin{array}{c}\text { Zona de } \\
\text { Circulação }\end{array}$} & \multirow{3}{*}{$\begin{array}{l}\text { P1, P5, P9 e } \\
\text { P13 }\end{array}$} & $\mathrm{h} 2=0,60 \mathrm{~m}$ & 23,8 & 0,7 & 3,00 \\
\hline & & & $\mathrm{H} 1=0,10 \mathrm{~m}$ & 23,6 & 0,6 & 2,76 \\
\hline & & & Relação & 23,7 & 0,18 & 0,75 \\
\hline \multirow{12}{*}{$\begin{array}{l}\stackrel{\oplus}{N} \\
\text { cे }\end{array}$} & \multirow{3}{*}{ AMBIENTE } & \multirow{3}{*}{16 Pontos } & $\mathrm{h} 2=0,60 \mathrm{~m}$ & 24,6 & 0,24 & 1,0 \\
\hline & & & $\mathrm{H} 1=0,10 \mathrm{~m}$ & 24,5 & 0,2 & 0,7 \\
\hline & & & Relação & 24,6 & 0,11 & 0,47 \\
\hline & \multirow{3}{*}{$\begin{array}{l}\text { Zona de } \\
\text { Ocupação }\end{array}$} & \multirow{3}{*}{$\begin{array}{l}\text { P2, P3, P6, } \\
\text { P7, P10, P11, } \\
\text { P14 e P15 }\end{array}$} & $\mathrm{h} 2=0,60 \mathrm{~m}$ & 24,7 & 0,28 & 1,14 \\
\hline & & & $\mathrm{H} 1=0,10 \mathrm{~m}$ & 24,5 & 0,21 & 0,86 \\
\hline & & & Relação & 24,6 & 0,15 & 0,61 \\
\hline & \multirow{3}{*}{ Zona Periférica } & \multirow{3}{*}{$\begin{array}{l}\text { P4, P8, P12 e } \\
\text { P16 }\end{array}$} & $\mathrm{h} 2=0,60 \mathrm{~m}$ & 24,5 & 0,1 & 0,59 \\
\hline & & & $\mathrm{H} 1=0,10 \mathrm{~m}$ & 24,5 & 0,1 & 0,40 \\
\hline & & & Relação & 24,5 & 0,04 & 0,14 \\
\hline & \multirow{3}{*}{$\begin{array}{c}\text { Zona de } \\
\text { Circulação }\end{array}$} & \multirow{3}{*}{$\begin{array}{l}\text { P1, P5, P9 e } \\
\text { P13 }\end{array}$} & $\mathrm{h} 2=0,60 \mathrm{~m}$ & 24,6 & 0,4 & 1,59 \\
\hline & & & $\mathrm{H} 1=0,10 \mathrm{~m}$ & 24,4 & 0,3 & 1,11 \\
\hline & & & Relação & 24,5 & 0,12 & 0,50 \\
\hline
\end{tabular}


APÊNDICE E - Gráficos das condições térmicas do ambiente experimental da situação de medição Ocup./Desoc 
Situação: “Ocupado/Desocupado”

Vista Aérea dos Planos Horizontais nas 6 alturas - SETPOINT SP $=21^{\circ} \mathrm{C}$

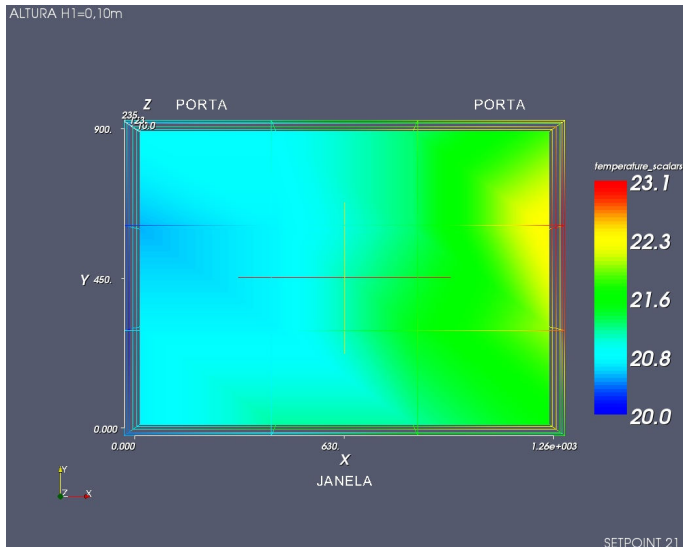

Figura 58 - Ocup./Desoc. SP21 -h1=0,10 m

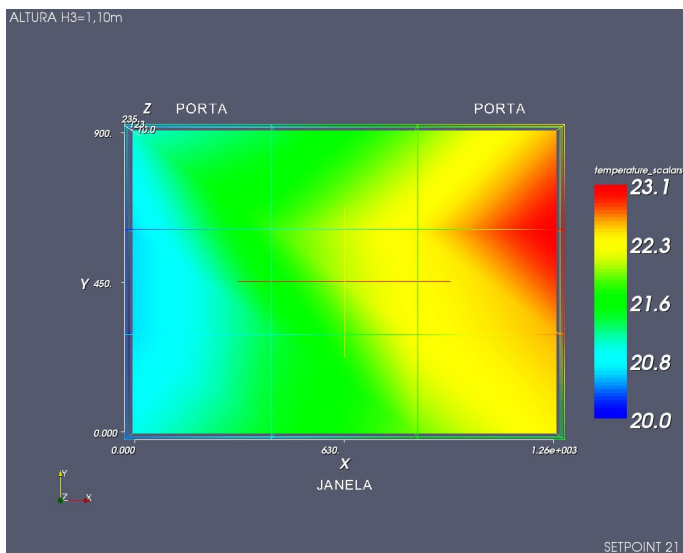

Figura 60 - Ocup./Desoc.- SP21 -h3=1,10 m

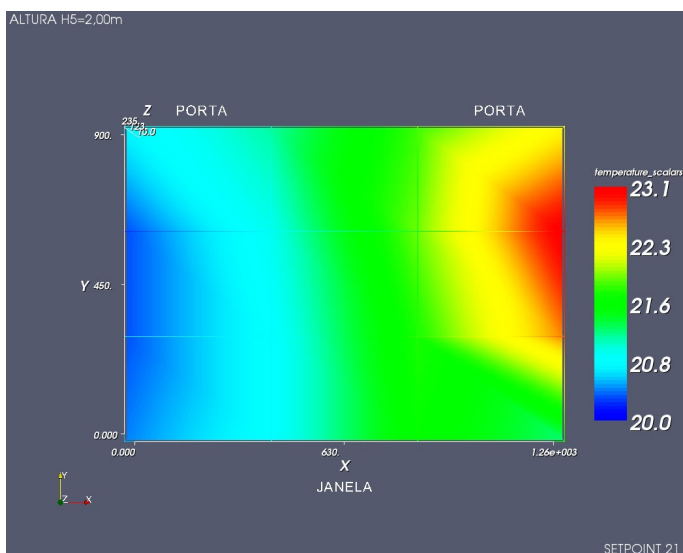

Figura 62 - Ocup./Desoc.- SP21 -h5=2,00 m

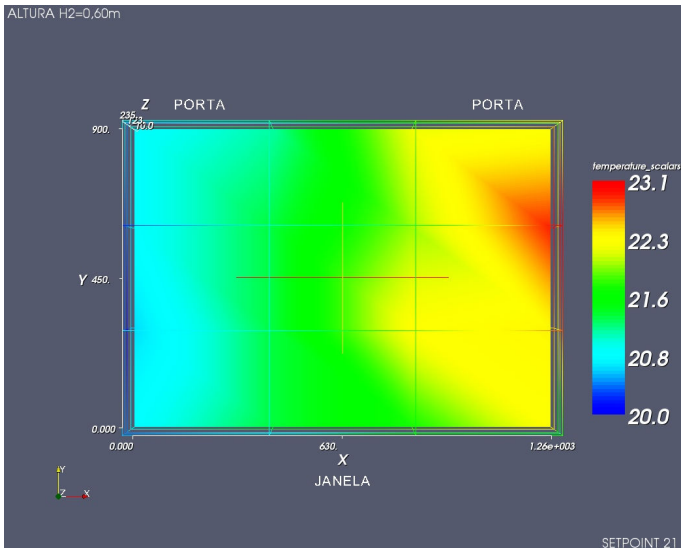

Figura 59 - Ocup./Desoc. - SP21 -h2=0,60 m

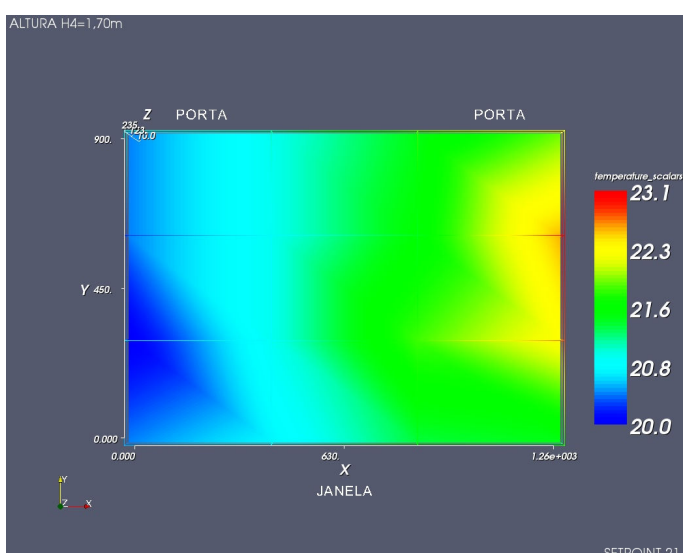

Figura 61 - Ocup./Desoc.- SP21 -h4=1,70 m

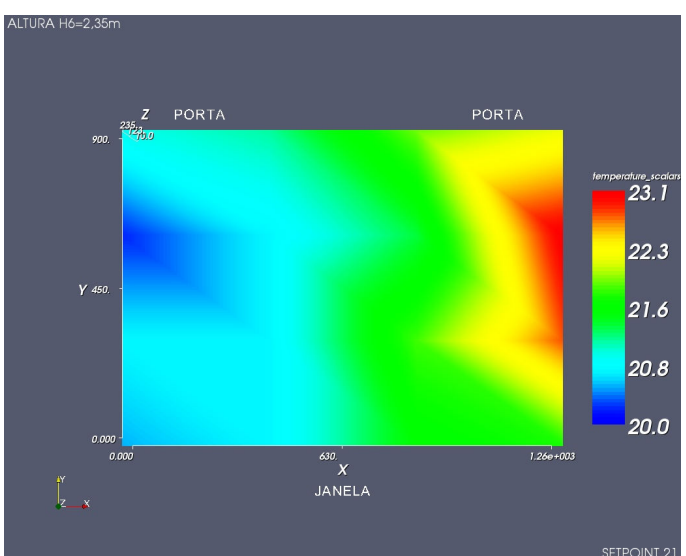

Figura 63 - Ocup./Desoc. $-\mathrm{SP} 21-\mathrm{h} 6=2,35 \mathrm{~m}$ 
Vista Aérea dos Planos Horizontais nas 6 alturas - SETPOINT SP $=22^{\circ} \mathrm{C}$

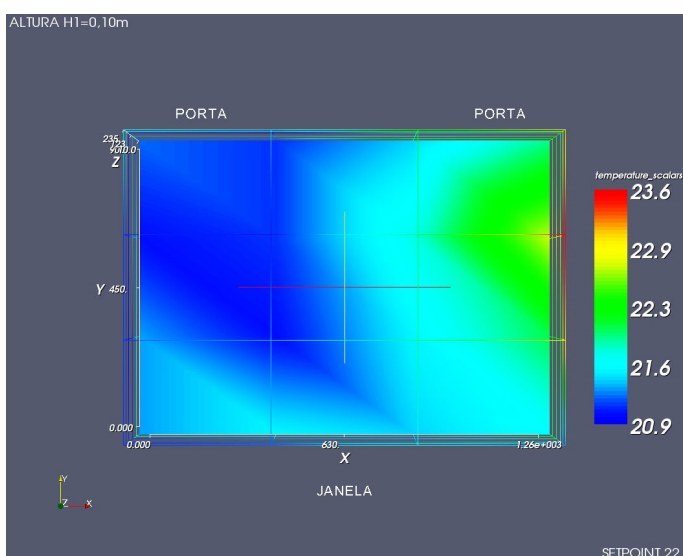

Figura 64 - Ocup./Desoc. $-\mathrm{SP} 22$-h1 $=0,10 \mathrm{~m}$

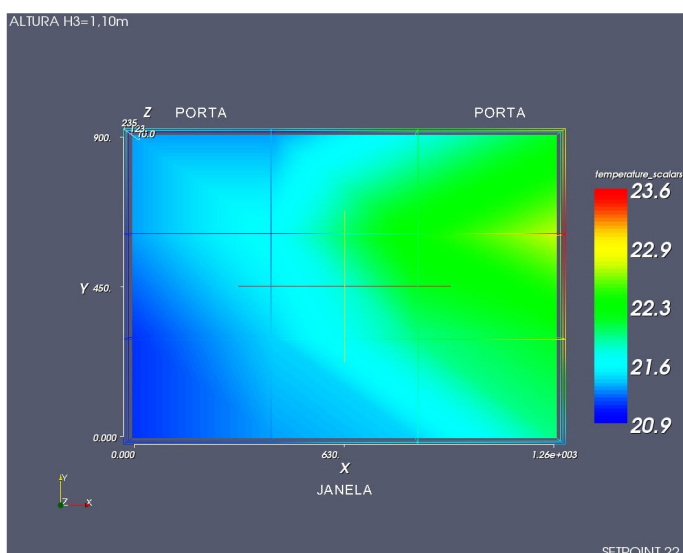

Figura 66 - Ocup./Desoc.- SP22 -h3=1,10 m

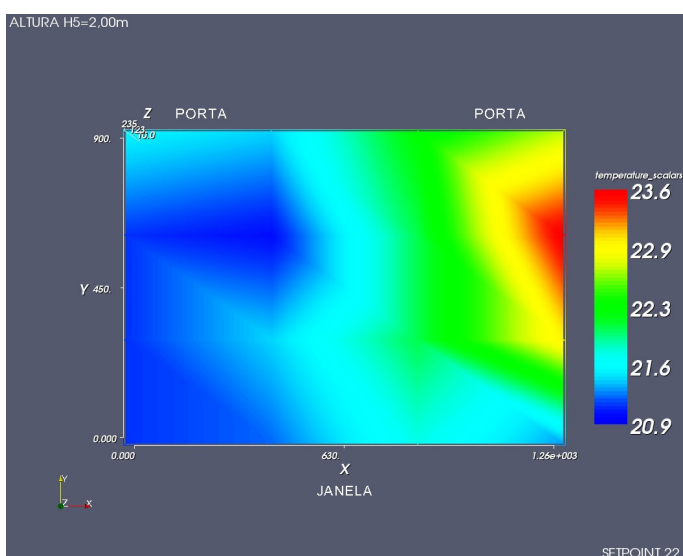

Figura 68 - Ocup./Desoc.- SP22 -h5=2,00 m

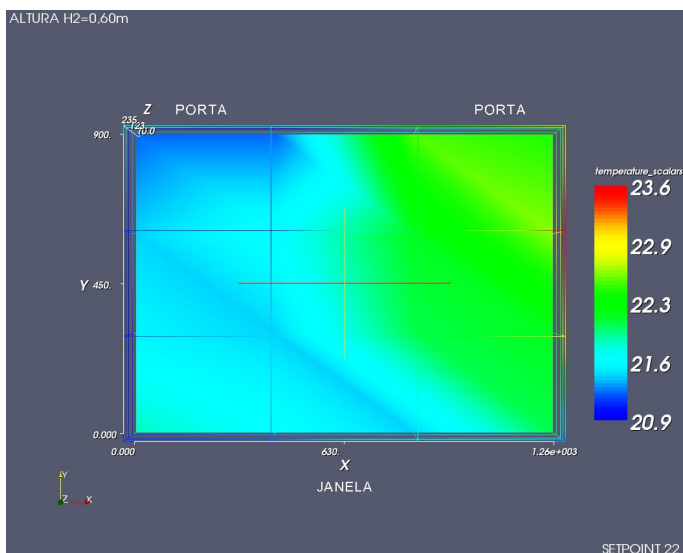

Figura 65 - Ocup./Desoc. $-\mathrm{SP} 22$-h2=0,60 m

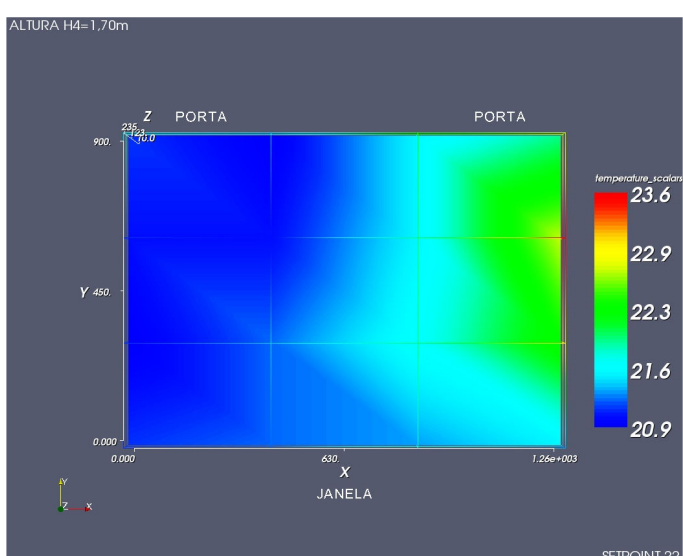

Figura 67 - Ocup./Desoc.- SP22 -h4=1,70 m

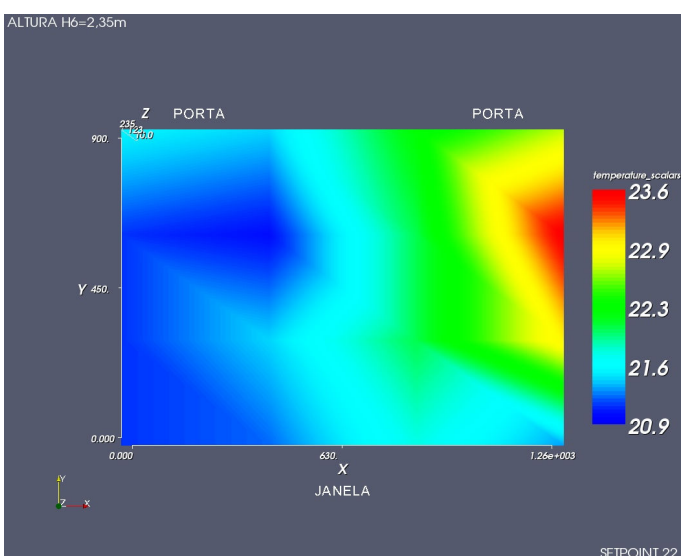

Figura 69 - Ocup./Desoc. - SP22 -h6=2,35 m 
Vista Aérea dos Planos Horizontais nas 6 alturas - SETPOINT SP $=23^{\circ} \mathrm{C}$

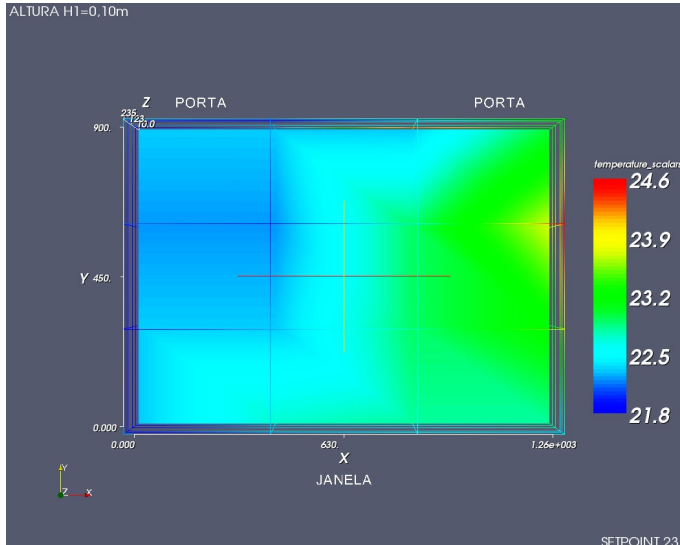

Figura 70 - Ocup./Desoc.- SP23 -h1=0,10 m

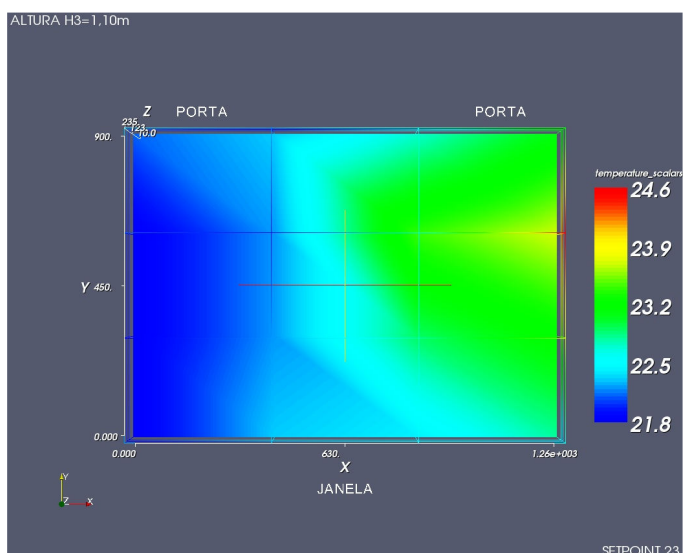

Figura 72 - Ocup./Desoc.- SP23 -h3=1,10 m

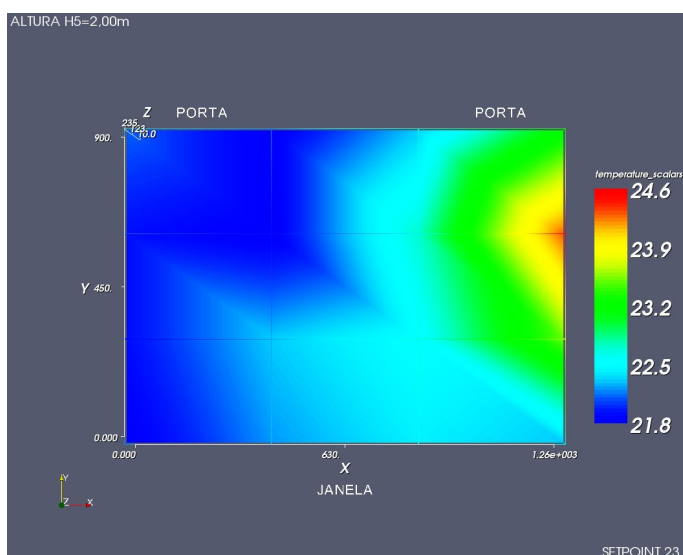

Figura 74 - Ocup./Desoc.- SP23 -h5=2,00 m

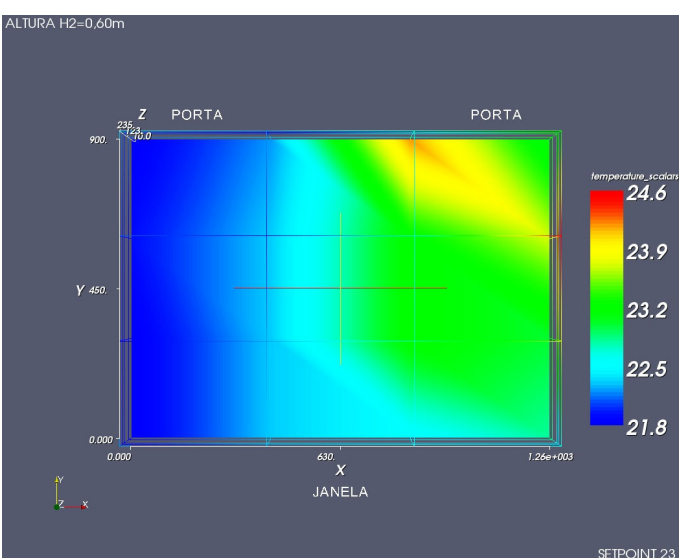

Figura 71 - Ocup./Desoc. - SP23 -h2=0,60 m

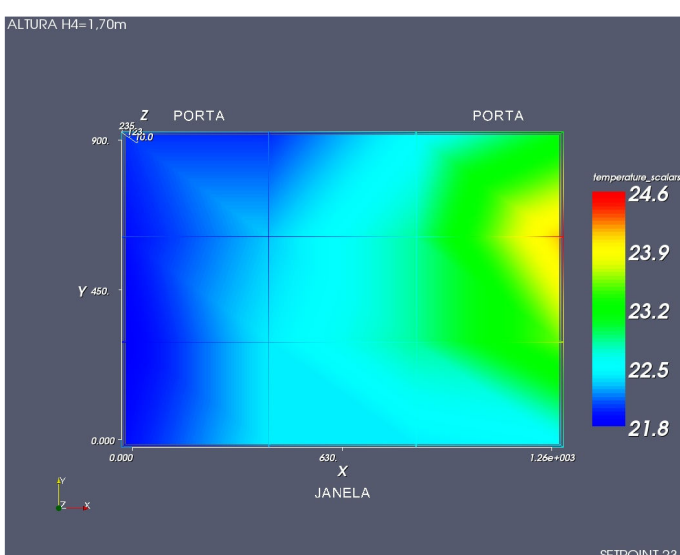

Figura 73 - Ocup./Desoc.- SP23 -h4=1,70 m

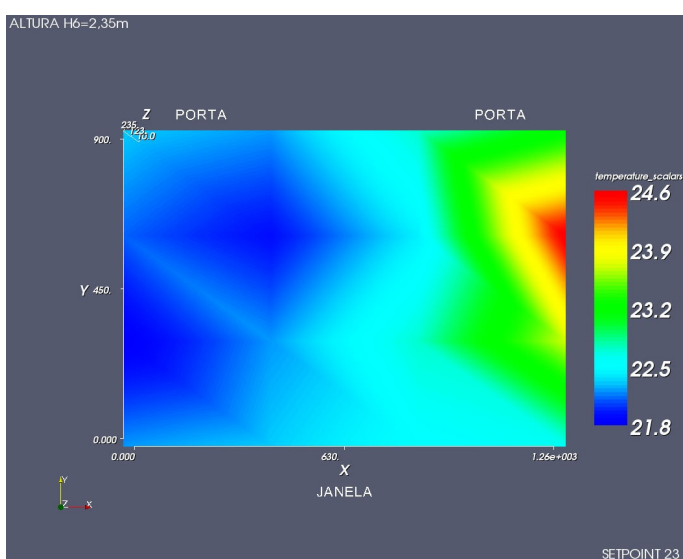

Figura 75 - Ocup./Desoc. - SP23 -h6=2,35 m 
Vista Aérea dos Planos Horizontais nas 6 alturas - SETPOINT SP $=24{ }^{\circ} \mathrm{C}$

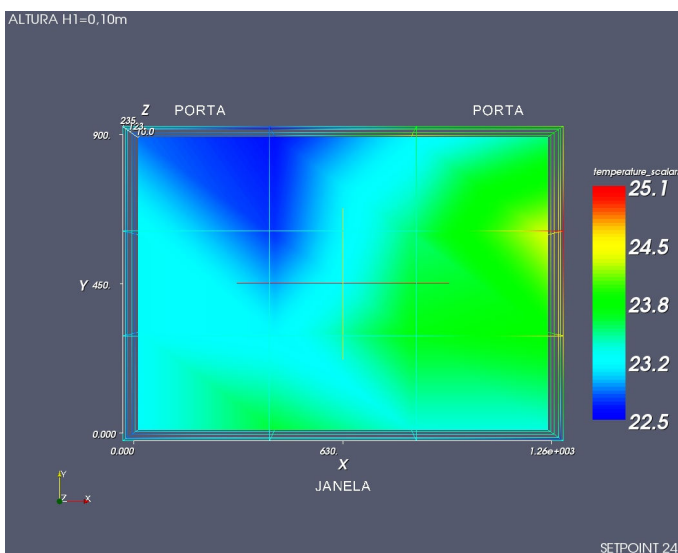

Figura 76 - Ocup./Desoc.- SP24 -h1=0,10 m

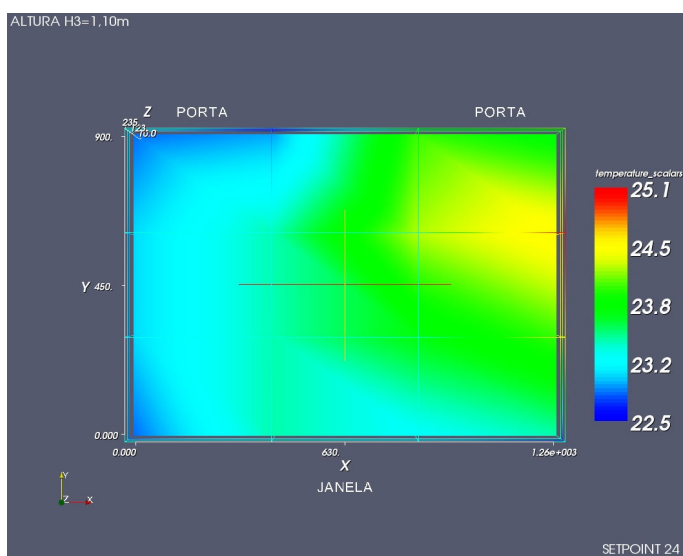

Figura 78 - Ocup./Desoc.- SP24 -h3=1,10 m

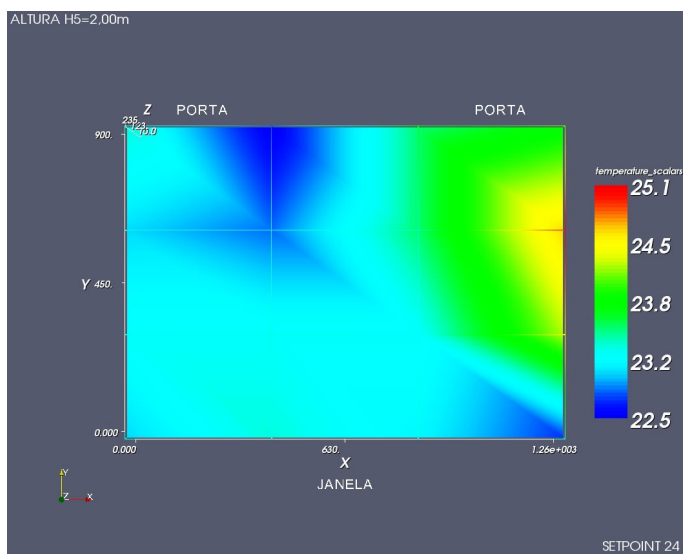

Figura 80 - Ocup./Desoc.- SP24 -h5=2,00 m

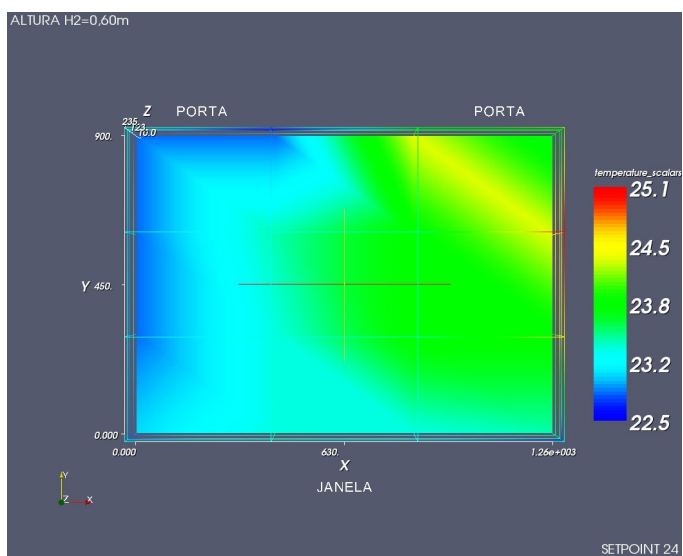

Figura 77 - Ocup./Desoc.- SP24 -h2=0,60 m

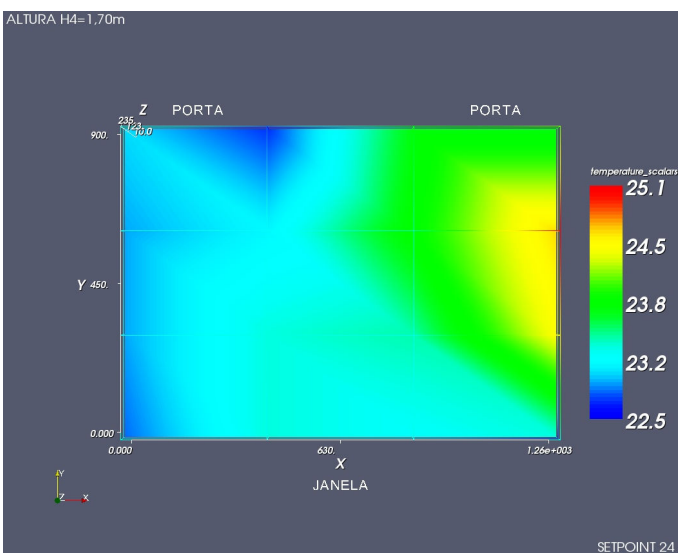

Figura 79 - Ocup./Desoc.- SP24 -h4=1,70 m

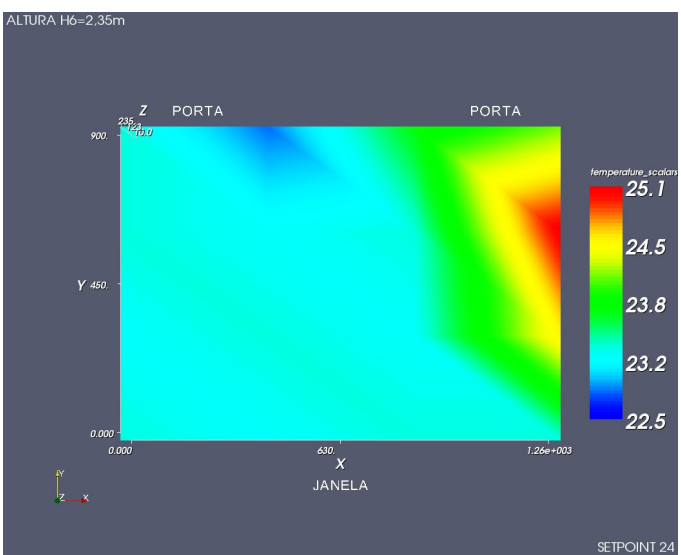

Figura 81 - Ocup./Desoc. - SP24 -h6=2,35 m 
Vista Aérea dos Planos Horizontais nas 6 alturas - SETPOINT SP $=25^{\circ} \mathrm{C}$

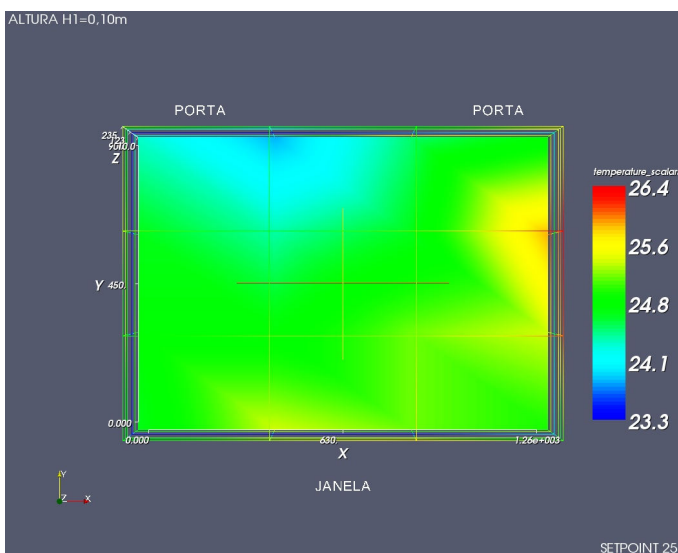

Figura 82 - Ocup./Desoc.- SP25 -h1=0,10 m

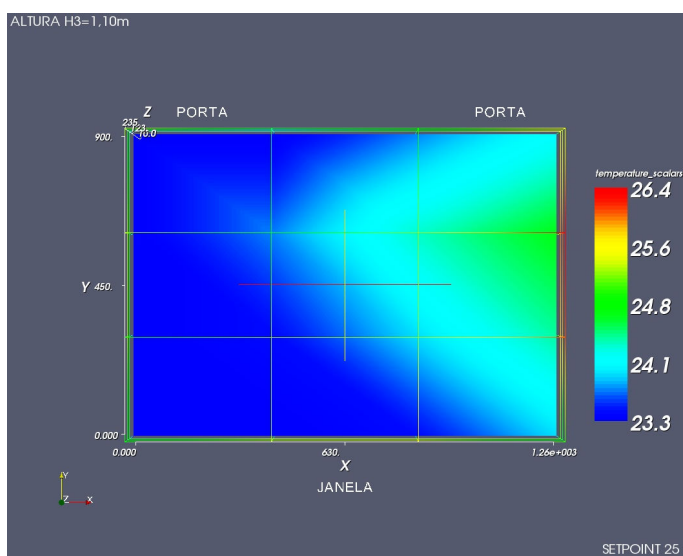

Figura 84 - Ocup./Desoc.- SP25 -h3=1,10 m

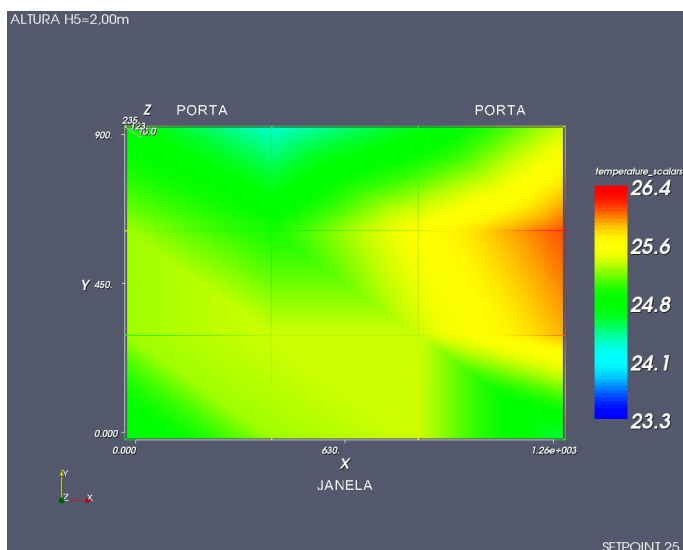

Figura 86 - Ocup./Desoc.- SP25 -h5=2,00 m

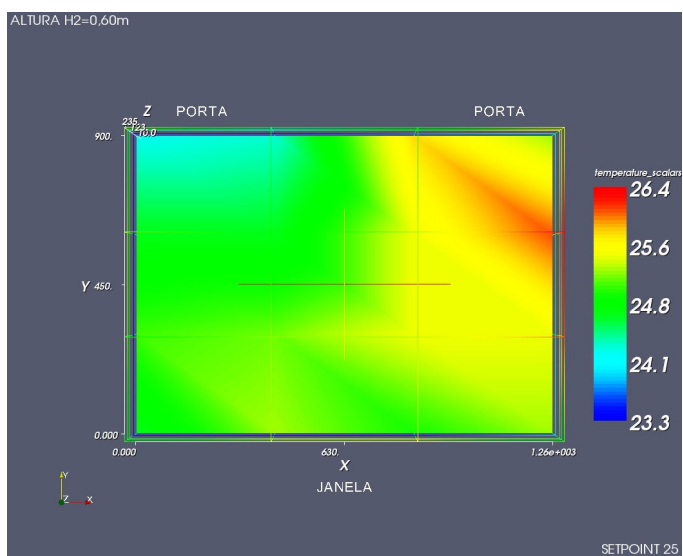

Figura 83 - Ocup./Desoc.- SP25 -h2=0,60 m

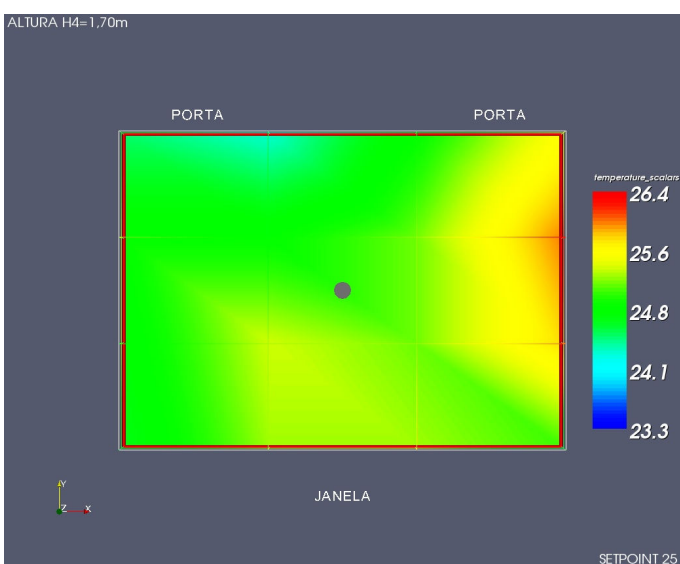

Figura 85 - Ocup./Desoc.- SP25 -h4=1,70 m

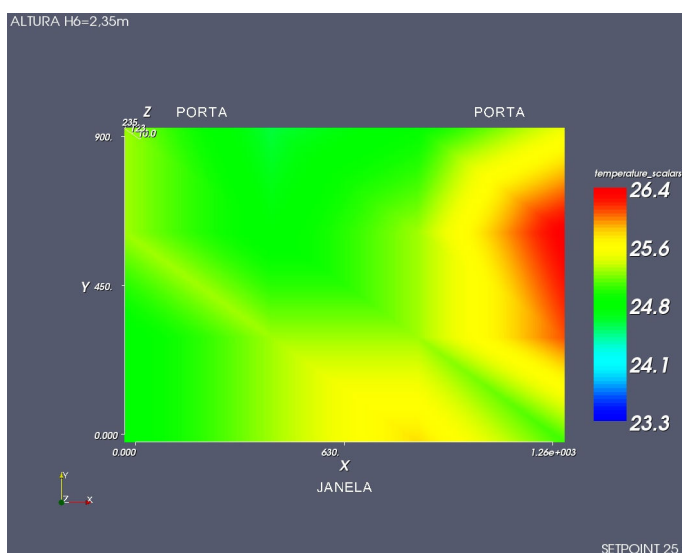

Figura 87 - Ocup./Desoc.- SP25 -h6=2,35 m 
Vistas Aérea dos Planos Horizontais nas 6 alturas - SETPOINT SP $=26{ }^{\circ} \mathrm{C}$

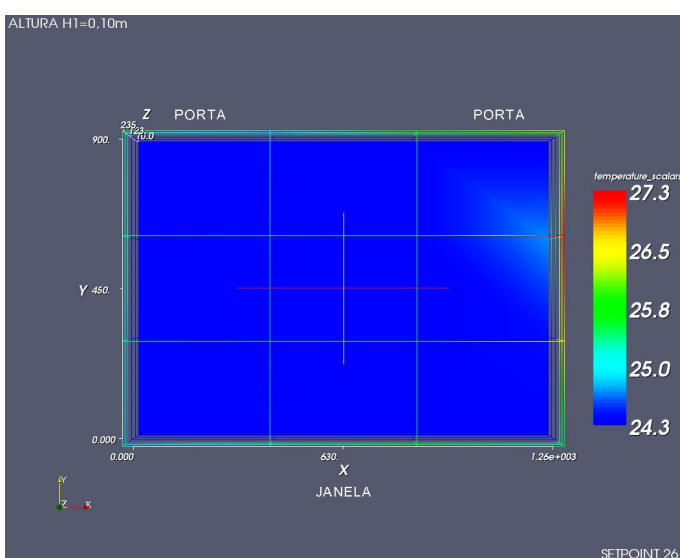

Figura 88 - Ocup./Desoc.- SP26 -h1=0,10 m

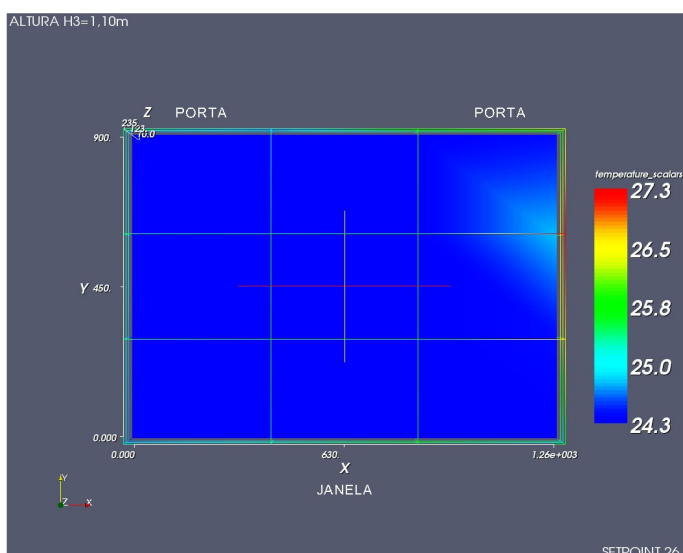

Figura 90 - Ocup./Desoc.- SP26 -h3=1,10 m

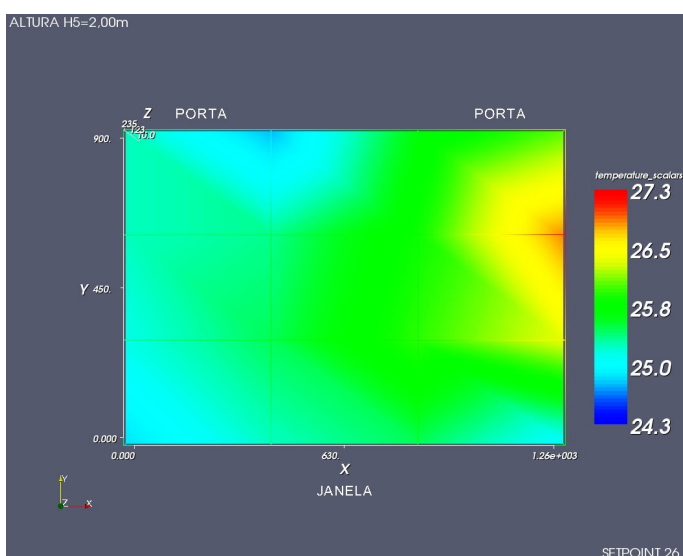

Figura 92 - Ocup./Desoc.- SP26 -h5=2,00 m

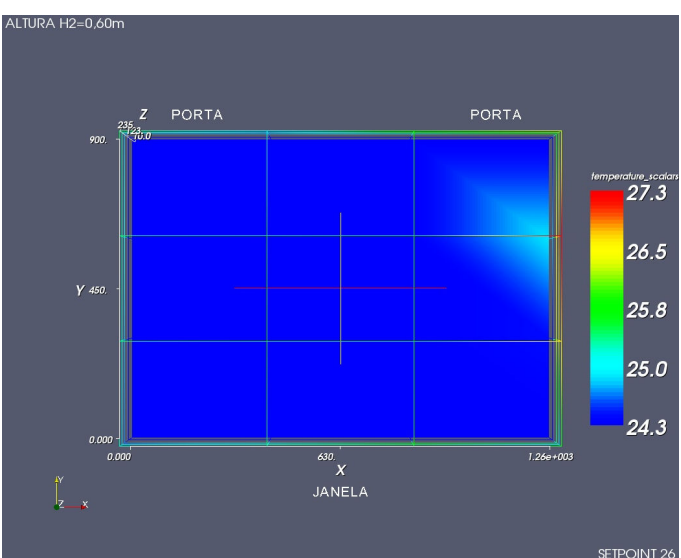

Figura 89 - Ocup./Desoc. - SP26 -h2=0,60 m

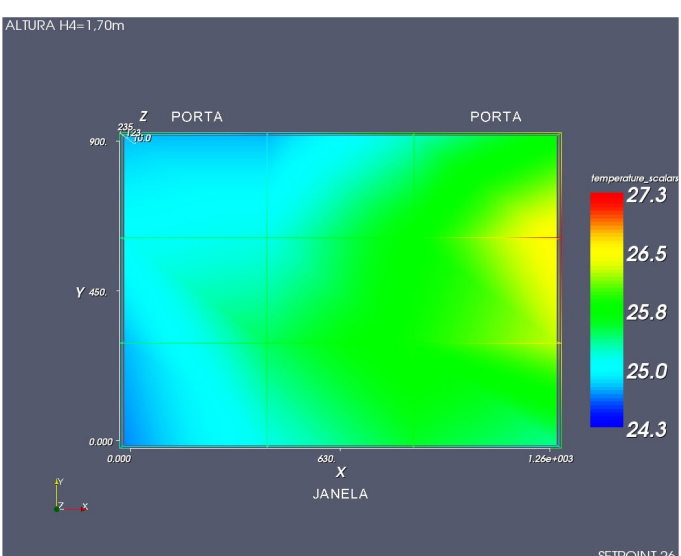

Figura 91 - Ocup./Desoc.- SP26 -h4=1,70 m

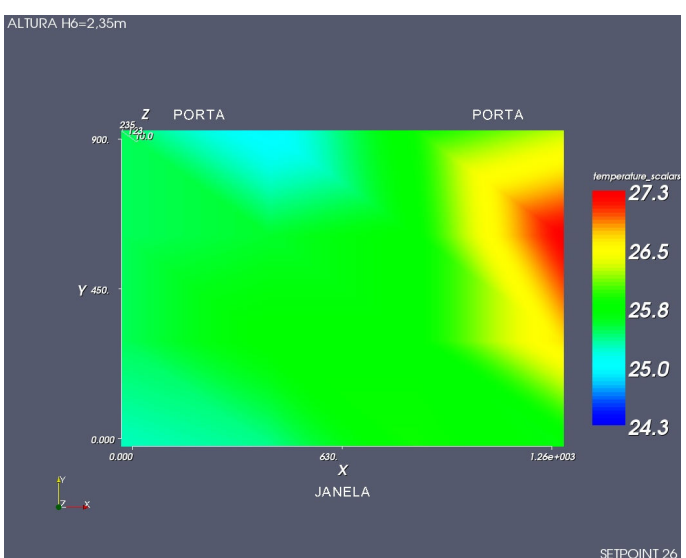

Figura 93 - Ocup./Desoc.- SP26 -h6=2,35 m 
Vistas em cortes das condições térmicas - Situação de medição: Ocup./Desoc.

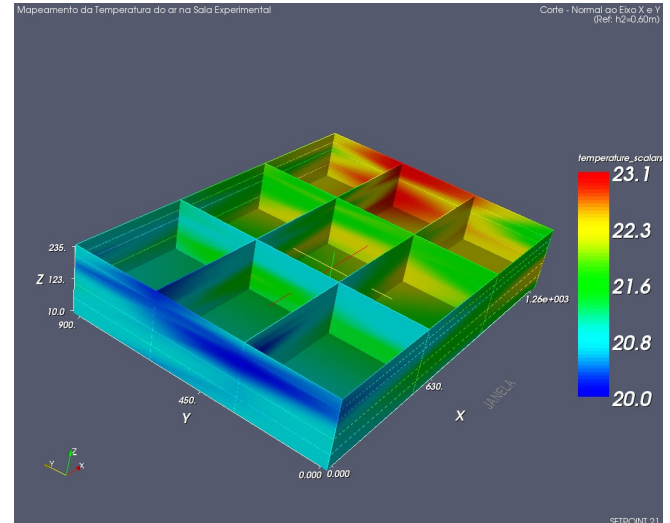

Figura 94 - Ocup./Desoc.- SP21

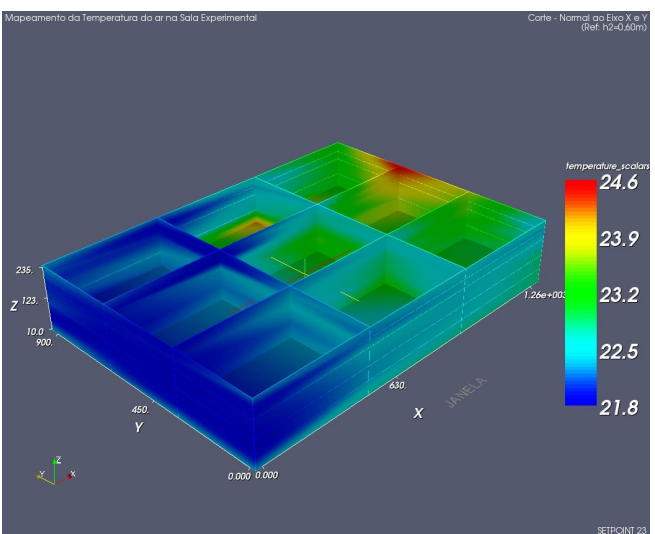

Figura 96 - Ocup./Desoc.- SP23

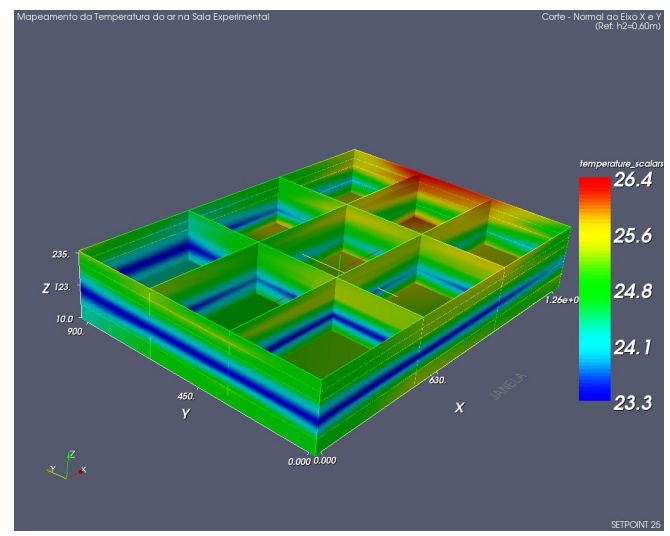

Figura 98 - Ocup./Desoc.- SP25

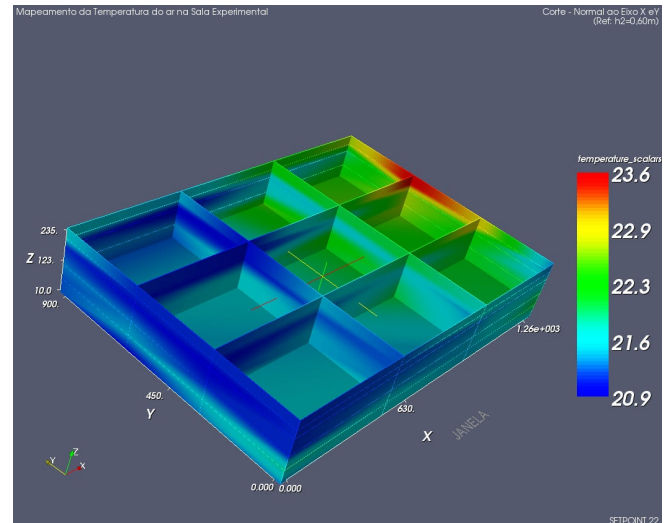

Figura 95 - Ocup./Desoc.- SP22

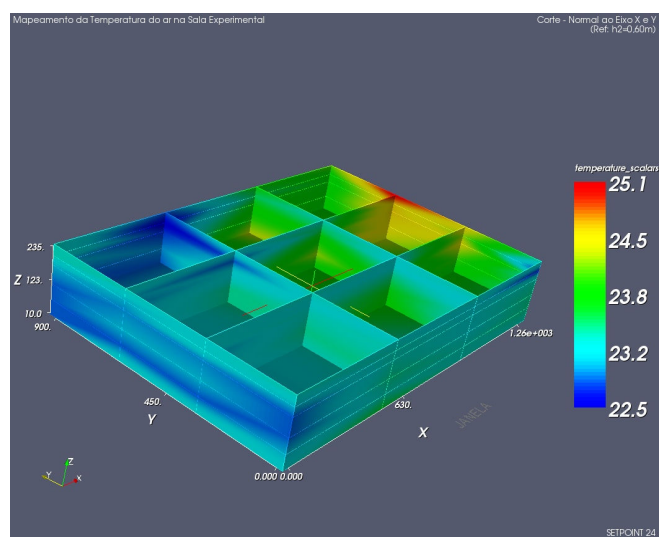

Figura 97 - Ocup./Desoc.- SP24

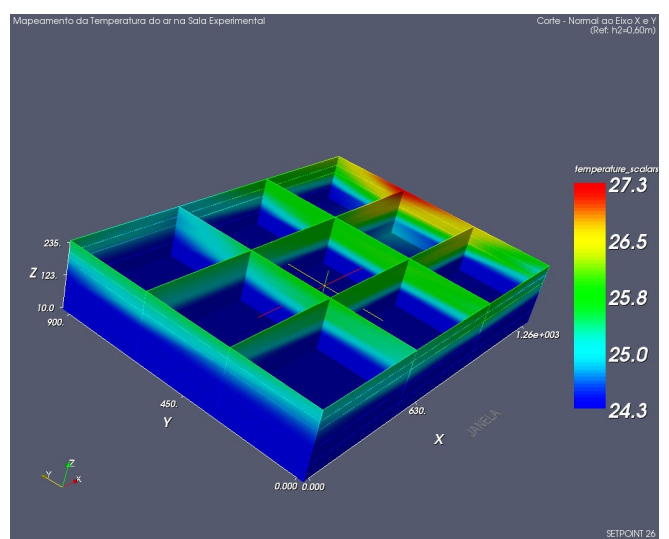

Figura 99 - Ocup./Desoc.- SP26 
ANEXO A - Explicação sobre Modos de controle

Proporcional $(P)$, Integral (I) e Derivativo (D) e suas combinações 
Para a explicação dos diferentes modos de controle será utilizado o exemplo do controle de abertura e fechamento das válvulas de água gelada dos painéis radiantes, que é feito pelo atuador, através de comandos originados do controlador. Para o exemplo, será considerado que a variável "abertura da válvula" (y) é função da variável controlada "temperatura" da placa $(x)$.

Proporcional: No modo de controle proporcional, a abertura da válvula (y) é proporcional à temperatura desejada da placa $(\mathrm{x})$ a qual deve ser o mais próximo possível do setpoint de temperatura do ar no ambiente. Neste modo, a ação é segura e rápida, mas, a exatidão não é muito boa. Quando existe um desvio da temperatura deseja da placa $(\Delta \mathrm{x})$ em relação ao setpoint, a ação de abrir ou fechar a válvula é automática, rápida e não resulta em oscilações da temperatura e nem em desvios consideráveis. Entretanto, este método não é capaz de assegurar que a temperatura desejada seja igual ao setpoint de temperatura do ar. No máximo, a abertura ou fechamento das válvulas permitirá que a temperatura desejada fique "aproximadamente" próxima ao setpoint de temperatura do ar.

Matematicamente, a ação de controle proporcional, ilustrada na Fig. 100 pode ser representada pela eq. (21):

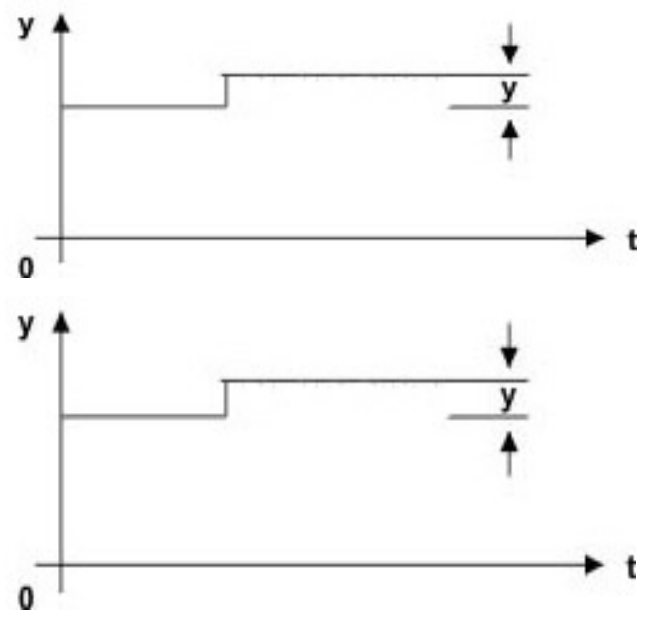

Figura 100 - Comportamento proporcional

Expressão matemática:

$$
y=f(x)
$$


Integral: No modo integral de controle, a velocidade de ação é proporcional ao desvio, isto é, o atuador irá acionar a válvula, sem nunca alcançar estabilidade por ter a zona de regulagem também um comportamento integral. O comportamento da ação integral demora bastante para restituir a temperatura desejada $(x)$ ao setpoint de temperatura do ar, embora quase sempre a temperatura desejada se igualará ao setpoint de temperatura do ar. O maior inconveniente é que este método resulta em uma instabilidade absoluta porque, devido à sua atividade contínua, diversas vezes a temperatura desejada oscila fortemente. Seu único recurso contra este inconveniente é acionar a válvula lentamente, mas, na medida em que a manobra é lentamente executada, aumenta-se o tempo de regulagem da temperatura desejada ao setpoint de temperatura do ar.

Em termos matemáticos pode-se dizer que para um desvio $(\Delta x)$ do valor regulado (desvio da temperatura desejada em relação ao setpoint de temperatura), a ação integral é uma manobra do órgão de controle (atuador), visualizada na Fig. 101, que pode ser representado pela eq. (22):

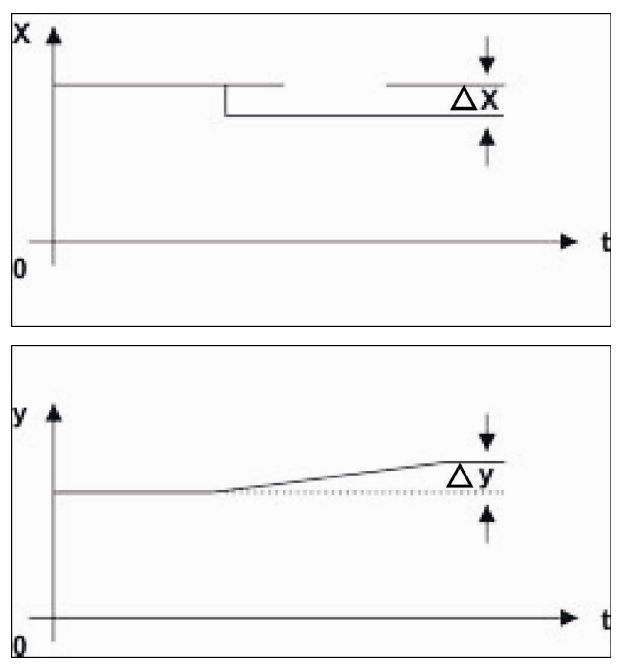

Figura 101 - Comportamento Integral

Expressão matemática:

$$
y=\int f(x) d t
$$


Diferencial: O modo de controle diferencial tem como característica uma ação rápida e enérgica, de forma que a válvula abre ou feche abruptamente causando fortes variações de pressão na rede hidráulica. Este comportamento não permite a regulagem da temperatura desejada $(\mathrm{x}$ ) ao setpoint de temperatura do ar (Fig. 102). Normalmente, este tipo de controle diferencial é utilizado em conjunto com o controle proporcional e integral para se atingir o valor do setpoint de maneira mais rápida.

Matematicamente, a ação diferencial tem um valor que é diretamente proporcional ao grau do desvio e inversamente proporcional à duração, sendo representado pela eq. (23):

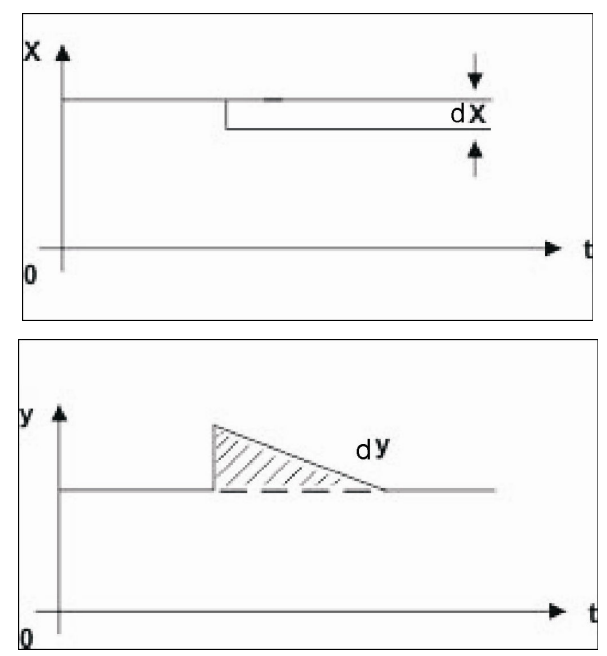

Figura 102 - Comportamento Diferencial

Expressão matemática:

$$
y=\frac{d f(x)}{d t}
$$

A ação PROPORCIONA-DIFERENCIAL-INTEGRAL (PID) é a combinação destes três modos de controle que foram descritos anteriormente. Esta combinação determina uma ação corretiva sobre o ponto de controle, fazendo com que este se aproxime mais rapidamente ao valor do "setpoint", de tal forma que não haja desvios. Resumidamente, ele apresenta as seguintes características (Fig. 103):

- compensação imediata da perturbação;

- exagero necessário para combater a inércia de mudança de nível;

- volta exata ao valor prescrito 
$\mathrm{Na}$ prática, constitui uma combinação de modos de controle pouco utilizada devido ao risco de oscilações se mal configurado. Usualmente, o modo de controle mais utilizado é o que apresenta os modos de controle Proporcional-Integral (PI).

Matematicamente, representa a soma das três funções anteriormente citadas, conforme a eq. (24):
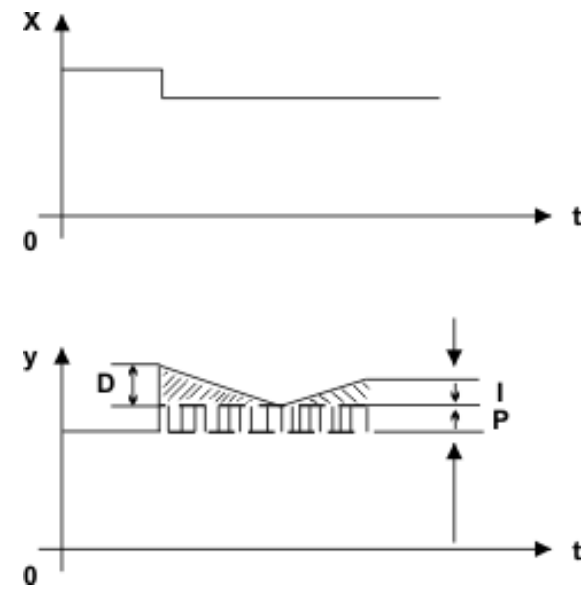

Figura 103 - Comportamento PID

Expressão matemática:

$$
y=f(x)+\int f(x) d t+\frac{d f(x)}{d t}
$$

